\title{
Essays on economics of education and school choice
}

Citation for published version (APA):

Parra Cely, S. A. (2018). Essays on economics of education and school choice. [Doctoral Thesis, Maastricht University]. Datawyse / Universitaire Pers Maastricht. https://doi.org/10.26481/dis.20181009sp

Document status and date:

Published: 01/01/2018

DOI:

10.26481/dis.20181009sp

Document Version:

Publisher's PDF, also known as Version of record

\section{Please check the document version of this publication:}

- A submitted manuscript is the version of the article upon submission and before peer-review. There can be important differences between the submitted version and the official published version of record.

People interested in the research are advised to contact the author for the final version of the publication, or visit the DOI to the publisher's website.

- The final author version and the galley proof are versions of the publication after peer review.

- The final published version features the final layout of the paper including the volume, issue and page numbers.

Link to publication

\footnotetext{
General rights rights.

- You may freely distribute the URL identifying the publication in the public portal. please follow below link for the End User Agreement:

www.umlib.nl/taverne-license

Take down policy

If you believe that this document breaches copyright please contact us at:

repository@maastrichtuniversity.nl

providing details and we will investigate your claim.
}

Copyright and moral rights for the publications made accessible in the public portal are retained by the authors and/or other copyright owners and it is a condition of accessing publications that users recognise and abide by the legal requirements associated with these

- Users may download and print one copy of any publication from the public portal for the purpose of private study or research.

- You may not further distribute the material or use it for any profit-making activity or commercial gain

If the publication is distributed under the terms of Article $25 \mathrm{fa}$ of the Dutch Copyright Act, indicated by the "Taverne" license above, 
Essays on Economics of Education

\section{and School Choice}

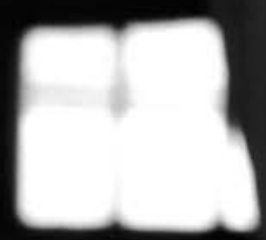


(C) Sergio Parra-Cely, Maastricht 2018

All rights reserved. No part of this publication may be reproduced, stored in a retrieval system, or transmitted in any form, or by any means, electronic, mechanical, photocopying, recording or otherwise, without the prior permission in writing, from the author.

Published by Datawyse / Universitaire Pers Maastricht

Florijnruwe 111-06 6218 CA

Maastricht, Netherlands

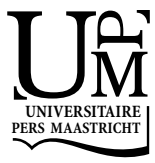

ISBN 978-94-6380-024-2

Cover picture: Doisneau, Robert. "L’information scolaire, Paris". 1956

(c) 2018 Atelier Robert Doisneau. All rights reserved. www.robert-doisneau.com 


\title{
Essays on Economics of Education and School Choice
}

\author{
DISSERTATION \\ to obtain the degree of Doctor at Maastricht University, \\ on the authority of the Rector Magnificus, \\ Prof. dr. Rianne M. Letschert, \\ in accordance with the decision of the Board of Deans, \\ to be defended in public on Day, October 9, 2018, at 16:00 hours
}

by

Sergio Armando Parra Cely 


\section{Supervisor}

Prof. Dr. Lex Borghans

\section{Co-Supervisor}

Dr. Bart H.H. Golsteyn

\section{Assessment Committee}

Prof. Dr. Olivier Marie (Chair)

Dr. Steffen Künn

Prof. Dr. Dinnand Webbink, Erasmus School of Economics

Dr. Sunčica Vujić, University of Antwerp 
'A man's work is nothing but this slow trek to rediscover, through the detours of art, those two or three great and simple images in whose presence his heart first opened'

—Albert Camus, "Entre oui et non" in L'Envers et l'endroit (1937) 



\section{Acknowledgments}

This thesis is the result of an interesting personal journey that, in principle, had the purpose of delay my insertion into the labor market at all costs. Naive as I was, I end up working more than I ever imagined. Pursuing a Doctorate in Economics is probably one of the most fulfilling and revealing life experiences I ever had. And sometimes a journey is more enjoyable when we travel with company. In Maastricht, I had the privilege to share my student life with a wonderful selection of supervisors, professors, colleagues, friends, family, and significant others. This is the time to thank you all.

I am deeply grateful to my supervisors, Prof. Dr. Lex Borghans and Dr. Bart H.H. Golsteyn. Lex, I want to thank you for let me be part of your research group, and for providing the conditions to make my Ph.D. experience a very rewarding one. I particularly value our insightful discussions, and the degree of discretion and freedom that you, as my main supervisor, granted me to pursue the research agenda that I was interested to follow. Bart, I want to thank you for your excellent supervision, as well as for all your friendship and support in crucial stages of this project. I sincerely wish that we can continue working as coauthors in many interesting research questions that might arise in the future.

This thesis have significantly improved with the comments of the assessment committee: Prof. Dr. Olivier Marie, Dr. Steffen Künn, Prof. Dr. Dinand Webbink, and Dr. Sunčica Vujić. I want to thank you all for your thoughtful suggestions to improve each chapter separately, as for the opportunity to discuss my work in different settings. I believe that all your feedback combined, seriously contributed to the quality of this dissertation and the peer-reviewed publications that (hopefully) will come out of it.

I was fortunate to count with many friends and acquaintances to hang around in this beautiful city that is Maastricht. I want to thank all my friends from the Economics of Education research group, ROA, UNU-MERIT, FASOS, Ph.D. Academy, and many others that will not be named but have a place in my heart. Thank you for the parties, dinners, hikes, trips, gifts, and cherished moments we shared. A special acknowledgment goes to the one and only, secret "booze" party committee. Thank you everyone for the great drinking sessions, where the political incorrectness and nasty, dark humor we enjoyed was at the order of the day. I certainly miss them now.

I want to thank my mother, Maria del Carmen, and my brother, Diego, for their constant support and unquestionable faith in me succeeding on this project. You are right about the fact that thinking positively in moments of doubt or adversity is nothing but a dominant strategy that we need to follow every day. 
Finally, I want to express my gratitude to you, Clotilde. Thank you for your love, friendship, support, and unbounded patience that, all combined, bring me joy and comfort until this day.

Maastricht, June 2018 


\section{Summary}

Numerous econometric techniques and identification strategies have been recently developed to recovering causal effects in social sciences. Given the recent availability of administrative datasets of public use, policymakers have increased their demand for evidence-based educational interventions. Motivated by this trend, this dissertation explores several aspects of the economics of human capital acquisition, such as the role of heterogeneous parental preferences for education and their influence on final schooling choices, the impact of internal displacement inflows on educational outcomes at hosting communities, and the effects of grade retention on academic performance at the end of secondary school. Together, these Essays on Economics of Education and School Choice, refine existing thinking on the effect of intended and unintended interventions, at the individual and group levels, that determine educational outcomes with significant economic consequences.

In Chapter 1, a demand model for academic tracks at secondary school is implemented to assess whether parents from opposite socio-economic backgrounds value education differently. Using data from a regional secondary school system in the Netherlands, we obtain evidence of educational sorting that explains the existing "enrollment gap" between students with different upbringings but comparable prior academic performance. In Chapter 2, by using numerous administrative datasets on political competition, civil conflict outcomes, and test scores from Colombia, we implement a regression-discontinuity design to document the negative effect of internally displaced inflows on educational outcomes of students in hosting areas. Finally, Chapter 3 exploits a natural experiment on retention in the Colombian education system, to assess the effects of increased grade retention on academic achievement, in the form of high-school exit exam scores.

The findings of this thesis contribute to both the academic and policy debates by suggesting that: i) inequalities in the access to educational opportunities can undermine social and intergenerational mobility, even in those school systems that pose no barriers of entry or significant transactions costs, ii) educational policies implemented in the shadow of an internal displacement crisis can be ineffective as internal displacement effects are severe and persistent, and iii) the policy recommendation of retaining more students at the national level can be counterproductive as the net-benefits of retaining more students are non-linear, marginally decreasing, and largely heterogeneous among academic subjects, schools and students. 



\section{Contents}

Acknowledgments $\quad$ vii

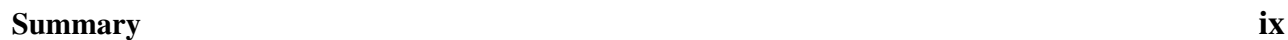

1. Introduction 1

2. Heterogeneous Preferences for Academic Tracks at Secondary School 5

2.1 Introduction . . . . . . . . . . . . . . . . . . . . 6

2.2 The Dutch Education System: An Overview ～. . . . . . . . . . . . . . . . 10

2.3 Empirical Strategy . . . . . . . . . . . . . . . . . . . . 11

2.3.1 A Model of School-Track Choice . . . . . . . . . . . . . . . . . . . . . . 12

2.3 .2 Estimation . . . . . . . . . . . . . . . . . . . . 14

2.3.3 The BLP Algorithm . . . . . . . . . . . . . . . . . . . 15

2.3 .4 Identification Strategy ～. . . . . . . . . . . . . . . . 17

2.3.5 Recovering Willingness to Travel (WTT) Estimates . . . . . . . . . . . . . . 18

2.4 Data Description . . . . . . . . . . . . . . . . . . . . . . . . . 18

2.4 .1 Data Overview . . . . . . . . . . . . . . . . . 18

2.4 .2 Markets . . . . . . . . . . . . . . . . . . . 19

2.4 .3 Students . . . . . . . . . . . . . . . . . 20

2.4 .4 Alternatives . . . . . . . . . . . . . . . . . 20

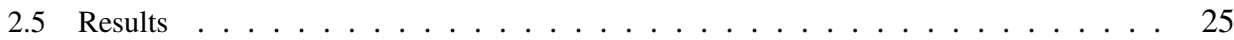

2.5.1 Recovering Mean Utility Values _ . . . . . . . . . . . . . . . . . 25

2.5.2 Instrumental Variable Selection And Discussion of Potential Violations . . . . 26

2.5.3 Parental Willingness to Travel for School-Track Attributes . . . . . . . . . . . 31

2.5.4 Heterogeneous Preferences for Track Placement . . . . . . . . . . . . . . . . 33

2.5.5 Welfare Considerations . . . . . . . . . . . . . . . 35

2.6 Concluding Remarks . . . . . . . . . . . . . . . . . . . . . . . . . . 38

2.7 Appendix: Tables and Figures . . . . . . . . . . . . . . . . . 40

3. Is Internally Forced Migration Affecting Educational Achievements in Hosting Communities?

3.1 Introduction . . . . . . . . . . . . . . . . . . . . . . . 44

3.2 Background Information . . . . . . . . . . . . . . . . . . . . . 48

3.2.1 Internal Refugees in the Colombian Civil Conflict . . . . . . . . . . . . . . . 48

3.2.2 The Political System in Colombia _. . . . . . . . . . . . . . 52 
3.3 A Model of Political Loyalty and Internal Displacement . . . . . . . . . . . . . . 52

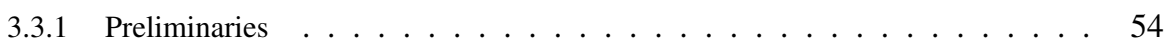

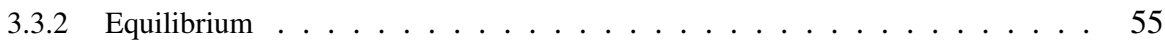

3.3.2.1 The Terrorist's Optimal Intimidation Rule . . . . . . . . . . . 55

3.3.2.2 The Citizen's Optimal Decision Rule . . . . . . . . . . . . . . . . 56

3.3.2.3 Equilibrium Definition . . . . . . . . . . . . . . . 58

3.3.3 Explaining Differences in Internally Displaced Flows . . . . . . . . . . . . 59

3.4 Data Overview . . . . . . . . . . . . . . . . . . . . . . . 61

3.4.1 Municipal Elections . . . . . . . . . . . . . . . . . . 61

3.4.2 Data on Internally Forced Migration and Civil Conflict _ . . . . . . . . . . . 62

3.4 .3 Other Covariates . . . . . . . . . . . . . . . . . . . 63

3.4 .4 Merging Electoral Outcomes with Test Scores . . . . . . . . . . . . . . . . 63

3.5 Empirical Strategy . . . . . . . . . . . . . . . . . . . . . . . 64

3.5.1 Econometric Methodology . . . . . . . . . . . . . . . . . . . 64

3.5.2 Identifying the Effect of Internally Forced Migration on Test Scores . . . . . . 65

3.6 Results . . . . . . . . . . . . . . . . . . . . . 66

3.6 .1 Summary Statistics . . . . . . . . . . . . . . . . . . . . 66

3.6 .2 On The Validity of the RD Design . . . . . . . . . . . . . . . . 67

3.6.3 The Effects of Political Loyalty on Internally Forced Migration ～. . . . . . . 72

3.6.3.1 Mechanisms . . . . . . . . . . . . . . . . 74

3.6.4 The Effects of IDP Reception on Educational Outcomes . . . . . . . . . . . . 79

3.6.4.1 Effects on Average Test Scores . . . . . . . . . . . . . . . . 79

3.6.4.2 Effects Across the Test Scores' Distribution . . . . . . . . . . . 80

3.6.4.3 Effects by Daily Working Schedules . . . . . . . . . . . . . . 84

3.6.4.4 Effects by Gender Composition at School . . . . . . . . . . . . . . 85

3.7 Concluding Remarks ． . . . . . . . . . . . . . . . . . . . . . . . 88

3.8 Appendix: Mathematical Proofs . . . . . . . . . . . . . . . . . . . . . . . . 89

3.9 Appendix: Tables and Figures ～. . . . . . . . . . . . . . . . . . . . . . . . . . . 92

4. The Effect of Grade Retention on Secondary School Performance: Evidence from a Natural Experiment 99

4.1 Introduction . . . . . . . . . . . . . . . . . . . . 100

4.2 Institutional Background . . . . . . . . . . . . . . . . . . . . . . . . . 104

4.2.1 The Colombian Educational System _ . . . . . . . . . . . . . . . . . . 104

4.2.2 The Automatic Promotion Policy Rule (AUP) . . . . . . . . . . . . . . . . . 105

4.3 Empirical Strategy . . . . . . . . . . . . . . . . . . . . 105

4.4 Data Overview . . . . . . . . . . . . . . . . . . . . . . . . . . . . . . . . . 109

4.4.1 Sources of Information and Sample Selection . . . . . . . . . . . . . 110

4.4 .2 Common Trends . . . . . . . . . . . . . . . . . . . . . 111

4.4 .3 Summary Statistics . . . . . . . . . . . . . . . . . . . 111

4.5 Results . . . . . . . . . . . . . . . . . . . 116

4.5.1 The Effect of the FRP Regime on Schools' Test Scores _ . . . . . . . . . . 116 
4.5.2 Defining Retained and Non-Retained Students ～. . . . . . . . . . . . 118

4.5.3 On the Non-Linear Effects of Grade Retention . . . . . . . . . . . . . . 121

4.5.4 Effects along the Test Scores' Distribution . . . . . . . . . . . . . . . . 122

4.5.5 Testing the Common Trend Assumption . . . . . . . . . . . . . . . . . . . . 126

4.5.6 Additional Robustness Checks . . . . . . . . . . . . . . . . . . . . 128

4.5.7 Potential Mechanisms ． . . . . . . . . . . . . . . . . . . . . . . . . 129

4.6 Concluding Remarks . . . . . . . . . . . . . . . . . . . . 133

4.7 Appendix: Tables and Figures . . . . . . . . . . . . . . . . . . . . . 134

$\begin{array}{ll}\text { Bibliography } & 143\end{array}$

$\begin{array}{ll}\text { Addendum on Valorization } & 153\end{array}$

$\begin{array}{ll}\text { About the Author } & 157\end{array}$ 



\section{List of Tables}

2.1 Summary Statistics - Options per Academic Market . . . . . . . . . . . . . . 21

2.2 Summary Statistics - Pupils Characteristics . . . . . . . . . . . . . . . . 22

2.3 Summary Statistics - School's Attributes by Academic Track . . . . . . . . . . . . . 23

2.4 Summary Statistics - School-Track Attributes by Parental Educational Background . . . . . 24

2.5 Conditional Logit Estimations . . . . . . . . . . . . . . . . . . . . . 27

2.6 High Track's Enrollment Probabilities - Differences by Students' Attributes . . . . . . . . . 28

2.7 Instrument Selection - First Stage Regressions . . . . . . . . . . . . . . . . . 30

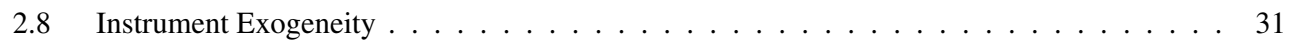

2.9 Mean Utility Regressions ． . . . . . . . . . . . . . . . . . . . . . . . . 32

2.10 Willingness to Travel for School-Track Features . . . . . . . . . . . . . . . . . 33

2.11 WTT for Pre-University Tracks by Parental Educational Background . . . . . . . . . . . 34

2.12 Differences in WTT for Pre-University Tracks by Students' Features . . . . . . . . . . . 37

2.13 Individual Compensated Valuation for the Absence of one Academic Track . . . . . . . . 38

A.1.1 Aggregated Market Shares . . . . . . . . . . . . . . . . . . 40

A.1.2 Summary Statistics -School-Track Attributes per Student Features . . . . . . . . . . . . . . 41

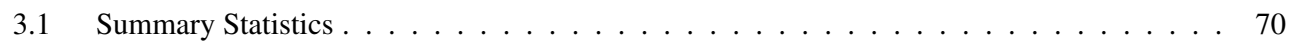

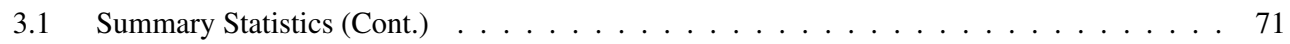

3.2 Effect of Political Loyalty on Internally Forced Migration into Hosting Municipalities - RD

Estimates . . . . . . . . . . . . . . . . . . . . . . . . . . 73

3.3 Mechanisms: Election Characteristics . . . . . . . . . . . . . . . . . 75

3.4 Mechanisms: Civil Conflict Related Variables . . . . . . . . . . . . . . . . . . . 77

3.5 Mechanisms: Public Finance Related Variables . . . . . . . . . . . . . . . . . . . . 78

3.6 Effects of Internally Forced Migration Inflows on Average Test Scores _ . . . . . . . . 80

3.7 Effect of Internally Forced Migration Inflows on Math Test Scores' Distribution _ . . . . . 82

3.8 Effects of Internally Forced Migration Inflows on Language Test Scores' Distribution $\ldots . \quad 83$

3.9 Effects of Internally Forced Migration on Test Scores by School's Working Schedule (IV-

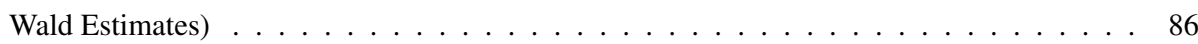

3.10 Effects of Internally Forced Migration on Test Scores by Females' Proportion at School (IV-Wald Estimates) $\ldots \ldots \ldots$. . . . . . . . . . . . . . . . . . . 87

A.3.1 Discontinuity of Baseline Covariates - RD Estimates . . . . . . . . . . . . . . . . . 94

A.3.1 Discontinuity of Baseline Covariates - RD Estimates (Cont.) ～. . . . . . . . . . . . . 95

A.3.2 Effect of Political Loyalty on Internally Forced Migration from Origin Municipalities - RD

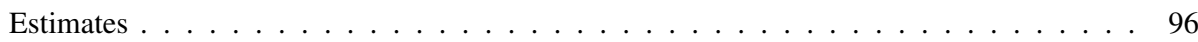

4.1 Summary Statistics: Schools' Characteristics during AUP Regime . . . . . . . . . . . 115 
4.2 Selection Into Treatment Status - OLS Regressions ～. . . . . . . . . . . . . . . . 117

4.3 Effect of the FRP Regime on Average Test Scores . . . . . . . . . . . . . . . . . . 119

4.4 Effects of the FRP Regime on SABER11 Test Scores by Plausible Retention Status . . . . 120

4.5 Effects of the FRP Regime on SABER11 Test Scores: Results by Multiple Treatment Cat-

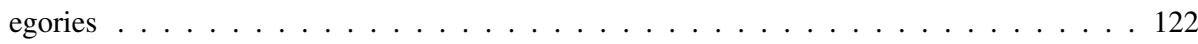

4.6 Effect of the FRP Regime on SABER11 Test Scores' Distribution by Multiple Treatment

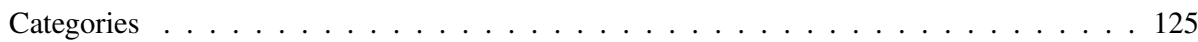

4.7 Common Trends Assumption Test . . . . . . . . . . . . . . . . . . . . . . 127

4.8 Placebo Tests: FRP Regime Started Before Original Date . . . . . . . . . . . . . . 128

4.9 Effect of the FRP Regimen on SABER11 Test Scores: Mechanisms . . . . . . . . . . . . . 131

A.4.1 Selection Into Treatment Status - Ordered Probit Models ～. . . . . . . . . . . . . . 136

A.4.2 Common Trend Assumption Test by Multiple Treatment Categories . . . . . . . . . . . . . 137

A.4.3 Placebo Test Using Multiple Treatment Groups: FRP Regime Started Before 2010 . . . . 138

A.4.4 Effect of the FRP Regime on Test Scores: Balanced Panel Estimations . . . . . . . . . . . 139

A.4.5 Effect of the FRP Regime on Test Scores: Excluding Anticipatory Effects . . . . . . . . . 140 


\section{List of Figures}

2.1 Observed Vs. Predicted Market Shares - All Specifications _ . . . . . . . . . . . . . 29

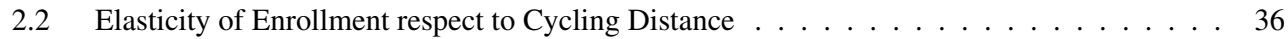

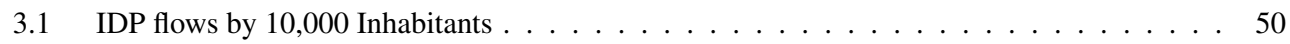

3.2 Internal Refugees Flows in Colombia $(1993-2012) \ldots \ldots \ldots \ldots \ldots$

3.3 Effect of Political Loyalty on IDP reception - RD Figures . . . . . . . . . . . . . . 68

3.4 Effects of Political Loyalty on SABER11 Test Scores - RD Figures ～. . . . . . . . . . . 69

A.3.1 Effect of Political Loyalty on IDP Expulsion - RD Figures . . . . . . . . . . . . . . . 92

A.3.2 Margin of Political Loyalty: Discontinuity Tests . . . . . . . . . . . . . . . . . . . . 93

4.1 Retention Rates per Multiple Treatment Status ～. . . . . . . . . . . . . . . . 107

4.2 Test Scores by Treatment Status . . . . . . . . . . . . . . . . . . . . . . . . . . . 113

4.3 Test Scores by Treatment Status - Multiple Treatment Groups ～. . . . . . . . . . . . . . 114

4.4 Effect of the FRP Regime on SABER11 Test Scores' Distribution . . . . . . . . . . . . . . 124

4.5 Mechanisms: Variation in Teachers' Composition . . . . . . . . . . . . . . . . 132

A.4.1 Test Scores Residuals by Treatment Status ～. . . . . . . . . . . . . . . . . . . . . 134

A.4.2 Test Scores Residuals by Treatment Status - Multiple Treatment Groups . . . . . . . . . . . 135 



\section{Introduction}

There is an increasing demand for evidence-based policy in education. The unobserved idiosyncrasy of students, parents, schools and academic markets, poses a great empirical challenge with regards to the identification of relevant factors that causally affect future economic outcomes through human capital acquisition. Problems of reverse causality, omitted variable bias, self-selection and measurement error, question researchers' attempts to recover reliable treatment effects by using traditional, less demanding econometric methods. Fortunately, while new identification strategies that distinguish correlation from causality are continuously gaining popularity, large administrative, highly representative microlevel datasets are widely available to use. Innovative research agendas on the economics of education have been established in the spirit of unveiling causal relationships and transmission mechanisms that, with the former state of the art in economics, would have been impossible to quantify consistently.

This dissertation provides three examples of how a combination of administrative data and econometric tools designed to make causal inference improves our understanding on the influence of (un)intended policy interventions in education. In particular, these essays focus on schooling choices and academic performance of students at secondary school. Each chapter addresses a specific question behind an important policy debate:

1. Do children select academic programs that do not match their abilities because of their parents' preferences for education? (Chapter 2)

2. Does internally forced migration negatively affect the educational achievements of students in hosting communities? (Chapter 3)

3. What are the effects of grade retention on school performance at the end of secondary school? (Chapter 4)

The three essays in this dissertation combined support the notion that the design of educational policies is a complex task because two reasons. (i) Academic markets are plagued with the same inefficiencies that are evident in regular markets, reducing the effectiveness of educational interventions in influencing future economic outcomes. (ii) Even if some academic markets are close to what can be considered "competitive", heterogeneous preferences for academic attributes and further informational barriers impair participants to select the programs that reflect their abilities the best. 


\section{The Economics of School Choice Under Early Tracking}

In Chapter 2, we assess the impact of heterogeneous parental preferences for education on students' choices in a context of early tracking. School choice has been proven to be one of the most difficult topics to study in the economics of education literature. As academic markets can be characterized as a twosided matching relationship, households' preferences for schools and schools' preferences for students determine observed final choices simultaneously. Many contributions in this strand of the literature use quasi-experiments to exploit random variation on the choice sets of parents and students. Thus, a natural question to address is whether the predictions from this research remain robust if, instead, we consider an educational system that does not impose any restrictions on choice, but at the same time offers a large variety of academic options.

In this essay, we use a unique dataset from the Netherlands, to estimate the parental demand for academic programs in a (plausible) free-choice secondary school system. Our specification, a multinomial discrete model in combination with an instrumental variables approach, controls for the endogeneity of commuting costs, schools' attributes, and the characteristics of pupils attending education. We recover consistent willingness to travel estimates, to find that parents with higher socio-economic background let their children commute 0.8 kilometers more to attend school (equivalent to a 0.3 standard deviation effect), and that their children enroll more often into schools with academic tracks that grant direct admission to university. These academic tracks are socially valuable, explaining an average welfare loss of 1 Euro (2.8 kilometers commuted) per day at school for those children without the opportunity to attend these programs. These results support the idea that less educated parents sort into academic tracks with lower economic prospects, despite their children's prior academic performance suggests otherwise, and even in school systems where restrictions to choice are negligible.

\section{Forced Migration and Educational Achievements}

The impact of migration flows on educational outcomes in hosting communities is an understudied but increasingly popular research agenda, which has yielded mixed results with a special focus on economic migration. One of the key challenges in this field is to address the potential endogeneity of migration decisions, as migrants choose to locate in areas where the perceived economic prospects are the largest. Consequently, some recent contributions have exploited random variation in migration flows due to external civil conflict or natural catastrophes, as a trick to recover the effect of migration flows on educational achievements of native students. However, many contributions have pointed to the significant barriers in language and culture that may explain differences in outcomes that, with a more homogeneous population, would be absent.

In Chapter 3, we focus on the impact of internal displacement flows to overcome the limitations of prior research. Specifically, we make use of random shifts in political support at local elections that, in 
the context of the Colombian civil conflict, triggered massive flows of internally displaced people into politically loyal municipalities. By using a fuzzy regression-discontinuity design, we identify the causal effect of internal displacement on high-school exit exams. Results from this study suggest a sizable negative effect of about 0.4 standard deviations on schools' math and language scores during the first two years of incumbency. Students at the upper end of the test performance distribution obtained lower scores for both subjects, relative to comparable students in disloyal municipalities. We also observe that schools with a balanced gender distribution of students and schools implementing a full working day spell are the least affected by the internally displaced influx. The key implication of these results is that the effectiveness of short-run policy interventions addressed to foster educational attainments might be reduced in the shadow of a migration crisis.

\section{The Effects of Grade Retention on Secondary School Performance}

Grade retention is one of the most controversial interventions in education, as its consequences are theoretically and empirically unclear. Firstly, it is expected that students at the lower end of the ability distribution will benefit more from grade retention, since they will have more time and resources to master the concepts required to be promoted into the next grade. Secondly, better students can benefit from increased retention as the peer composition in the classroom improves. However, grade retention also exhibits negative effects since it may harm students' motivation, as well as other desirable personality traits that are positively correlated with better educational outcomes. In addition, many studies identify these effects for students at the margin, without highlighting the extent to which these effects differ across all types of students and schools. As individual ability is not observable by the econometrician, it is expected that any study devoted to consistently estimate the impacts of increased retention will deal with the classic omitted variable bias problem in causal inference.

In Chapter 4, we assess the effects of retention on performance in secondary school, exploiting a change in retention legislation in Colombia. In 2010, the rule that forced schools to retain up to a maximum of five percent of students was abolished. We observe that retention rates increased dramatically due to the law change, with large heterogeneity among schools. Using this variation in a difference-in-differences model, we show that retaining more students increased performance on language tests but not on math tests. Retained students benefited from increased retention. Marginally non retained students who belong to the lower end of the distribution performed worse as retention increased. Distinguishing between low, middle and highly treated schools reveals the non-linearity of the effect of retention: in middle treated schools the improvement for retained students was more pronounced than in highly treated schools. We also suggest the increasing participation of young, inexperienced teachers in the school's workforce as the major transmission mechanism. The main implication of our analysis therefore is that the effectiveness of increased retention depends not only on the position of the school in the retention distribution, but also on the proportion of experienced teachers in the classroom. 



\section{Heterogeneous Preferences for Academic Tracks at Secondary School*}

*I am indebted to Lex Borghans and Bart Golsteyn for their guidance, as well as to Roxanne Korthals, Stan Vermeulen, Omar Rodriguez, Clotilde Mahe, Karen van der Wiel, and participants at the DUHR Seminar at Maastricht University, the Lisbon 4th Workshop on Economics and Econometrics of Education, and the ESPE 2017 conference at Glasgow for their valuable comments and suggestions. I am also grateful to Tyas Prevoo for his help clarifying some aspects of the database. 


\subsection{Introduction}

Identifying the degree to which vulnerable groups engage in suboptimal schooling decisions is crucial to evaluate the effectiveness of education as a vehicle to promote human development and intergenerational mobility (Manski, 1992; Burgess and Briggs, 2010). Large costs of attendance, administrative restrictions, congestion, and other market frictions, are arguments provided by a large body of literature on school choice to explain how children, with the same academic ability and motivation, end up with unequal educational outcomes (Hoxby, 2003). Furthermore, confounding factors influencing parental valuations for academic features make it difficult to isolate a "desire for education" effect. Thus, traditional hedonic regressions and multinomial discrete choice models used in the school-choice literature, while easily tractable, fail to recover decision makers' differences in tastes induced by variation on school's features (Nevo, 2000; Bayer and McMillan, 2005). An alternative to circumvent these problems is to implement econometric methods designed to identify endogenous preferences for schooling, as well as studying specific educational markets with a large variety in the alternatives offered but no restrictions to choice in place.

In this chapter we propose a framework to recover households' preferences for academic programs in the presence of educational sorting. By considering parents' revealed decisions in an unconstrained school system with early tracking and large product differentiation, the objective of this study is twofold. First, we aim to provide a consistent estimation of the existing enrollment gap into the higher academic tracks at secondary education. This enrollment gap privileges the schooling outcomes of students from higher socio-economic family backgrounds, relative to pupils with less fortunate upbringings but comparable academic performance in primary education. Hence, quantifying the extent to which non-academic household's attributes affect the likelihood of human capital investments is of paramount importance for the design of educational policies that account for such differences. Second, this study seeks to recover the heterogeneous preferences for schooling options that parents with diverse educational attainments might exhibit, as an attempt to identify the elements that determine the enrollment gap.

The secondary school system in the Netherlands has a large tradition encouraging participants to choose educational options freely. While regulated by the Inspectorate of Education, publicly and privately managed schools are characterized by being equally funded with central government's revenues, implying that almost no tuition fees are charged. Moreover, the small variation in geographic conditions and the easy anticipation of changes in climate privilege cycling as the main mode of transportation (Van Goeverden and De Boer, 2013). Without catchment areas, or other sophisticated mechanisms to deal with congested markets, the Dutch case provides a good opportunity to identify educational sorting incentives that are not determined by restrictions to choice, which is a novelty with respect to the previous literature on the economics of education. ${ }^{1}$

\footnotetext{
${ }^{1}$ Some restrictions might exist in big cities such as Amsterdam, where due to capacity constraints other mechanisms such as waiting lists, random lotteries, and clearinghouses have been recently implemented. However, as we will elaborate later, the education system considered here is free from such interventions.
} 
Students' performance at primary school plays a key role in determining future enrollment outcomes. The secondary education system in the Netherlands is characterized as an early tracking system where pupils, after finishing primary school, are required to attend one among three academic options to continue their education: A higher track that, after completion, grants direct admission to university programs, a lower track which gives admission to community college education, and a vocational track that accounts for rather technical, on-the-job training needs. Since the right to pursue tertiary education at the university level depends on whether the high track is selected, suboptimal schooling decisions occur when children are enrolled in lower tracks but prior academic performance would suggest they are suited to attend the higher track.

This study starts by estimating a model of demand for differentiated products, applied to the education market (Berry et al. 1995, 2004; hereafter BLP). After classifying pupils by their municipality of residence and parental educational attainments, we exploit variation in both students characteristics and their choice sets, within and across markets, to recover unobserved mean valuations for all school-tracks observed. The specification considered here decomposes the utility of choosing an academic program into the satisfaction level that is common to all students in a market where that option is selected, and deviations from mean preferences which are determined by students' specific characteristics. In order to obtain these valuations, we implement the contraction mapping algorithm suggested in the literature of demand estimation to ensure that, for a given set of pupils' attributes, mean preferences equalize the observed market shares -understood as the fraction of children at each market who select a particular option- with the ones the empirical model predicts (Berry et al., 1995).

By estimating individual enrollment probabilities with the BLP model, we find that students with highly educated parents (i.e. at least one parent obtained a post-secondary degree) are $24 \%$ more likely to be in the high track, relative to equally capable pupils with low-educated parents (i.e. parents whose maximum educational attainment is high-school or below). We compare individual enrollment probabilities with estimates based on more simple, conditional logit demand models. Results from this exercise suggest that traditional models either underestimate or neglect the enrollment rate gap among pupils from different socio-economic background. The BLP approach is then more appropriate to estimate these relationships as traditional models do not account for substitution patterns in the demand for academic programs that depend on students' characteristics, inducing different schooling decisions for a given choice set.

The analysis continues by decomposing mean utility levels obtained from the BLP model on the different academic features per school-track combination to recover parental preferences for academic programs, school denomination, and observed quality, among other characteristics. In our model, we expect unobserved features to be correlated with the average distance students commute to attend secondary education, in the same way as the price of an item can be correlated with its unobserved quality. We deal with this endogeneity problem by exploiting the plausibly exogenous variation of rival options outside each school's "geographical area of influence" as an instrumental variable to provide consistent mean willingness to travel (WTT) estimates for a particular bundle of educational features. 
Specifically, we construct different concentric rings (distance buffers) to calculate the number of rival schools located between say, $a$ and $b$ kilometers away from each school, in order to account for the fact that competition is spatially concentrated but uncorrelated with latent school-track covariates. Since both residential and school locations are not exogenous, in order for our identification strategy to work we need to assume that schools' locations in the arbitrarily-built areas outside the influential zone of each institution are not correlated with unobserved elements that influence the educational choices observed in the data. Moreover, we expect the larger the number of rival schools located around each option, the lower the final average distance traveled per school-track. We also include the cycling distance of each educative institution to the closest city hall as an additional instrument to account for each school-track's degree of accessibility from urban and rural areas (Noailly et al., 2012). Hence, we expect the closer the distance between the school and the city-hall is, the higher its accessibility and the lower the average cycling distance pupils will travel to receive education.

Finally, we conduct differences-in-means tests by parental educational attainments on WTT estimates to assess whether parents self-select their children into higher tracks. Results from this (second) estimation stage show that, considering the pure vocational track as a baseline option, parents value all remaining tracks positively. However, in high-educated families parents are willing to let their children commute 0.8 kilometers ( 0.3 standard deviations) more (less) to attend the higher (lower) track. This asymmetry in preferences is almost fifty percent smaller than the one obtained using traditional hedonic travel models, suggesting that the IV estimator accounts for the potential overestimation of parental WTT for education. All results combined provide a clear evidence of educational sorting based on parental socio-economic status, even after controlling for pupils' previous academic performance.

We also conduct extensions of the model to evaluate how variation of preferences for academic tracks depends on prior academic performance, as well as on primary school's peers. In particular, lower preferences for the high track are more likely to develop when the pupil's performance at the primary school exit test does not belong to the group of top $10 \%$ performers. Surprisingly, neither receiving positive recommendations to attend the high track, nor having more primary school peers choosing the same alternative, modify preferences of low educated parents. We claim that these results can partially be attributed to the fact that pupils from highly educated parents have better opportunities to build academic profiles that make them more attractive for secondary schools.

Our model also allows us to conduct a policy simulation in order to assess the value of the different academic tracks offered after primary school is finished. The policy counterfactual exercise implemented here is to calculate the utility loss decision makers would face as all alternatives pertaining to a particular track are removed from the original choice set, forcing them either to commute longer distances to attend the desired track, or choosing a lower track available at reach. Using a compensated variation approach we find that, in absence of the higher track, commuting costs for the average student increase by 2.8 kilometers, implying a welfare loss of 1 Euro per day attended at school. We observe qualitatively similar (but quantitatively lower) results for the lower track, suggesting that the high track is the academic option 
that socially is the most valuable. To our knowledge, these are the first of such kind of estimates for the Dutch education system.

This chapter contributes to the literature on parental preferences for schools. From a demand perspective, many papers address the extent to which education systems with barriers to free selection have a detrimental effect on both students' and schools' educational outcomes (Hoxby, 2003). Because school choice is an endogenous phenomenon, many of these studies try to exploit random variation in school competition by the use of natural experiments on admission procedures (Rincke, 2006; Cullen et al., 2006), introduction of vouchers (Hsieh and Urquiola, 2006; Figlio and Hart, 2014; Chumacero et al., 2011), variations on housing prices along school district boundaries (Black, 1999; McMillan, 2005), and availability of information about school quality (Hastings and Weinstein, 2008; Hastings et al., 2009), in order to consistently measure preferences for academic attributes. This study brings additional evidence about the presence of incentives to self-select into suboptimal academic options, in a context where the role of latent cofactors that determine final schooling decisions is negligible because of the absence of transaction costs, market frictions, and administrative restrictions that will impair parents and/or children to reveal their true preferences.

Moreover, this chapter also intends to provide updated estimates on the heterogeneity of parental preferences for education in the Dutch secondary school system. Koning and Van der Wiel (2013) study the effect of school-quality information on school choice using individual and school level information of first year students at secondary schools. Despite the fact that schools' quality scores have a positive relation with the number of new students enrolled in the first year, the authors recognize that no causal inference can be extracted from individual choice data. Their paper presents commuting distance to each school as the leading determinant of choice, with pupils willing to travel 220 meters on average to attend an institution with higher quality. In a related article, Cabus and Cornelisz (2014) use kernel estimation techniques to match students in different education markets, in order to assess the effect of market competition on both academic sorting and students' performance. After controlling for pupil and household level information, these authors find that schools use supply-driven product differentiation in order to attract high-achieving students. Nonetheless, higher ability schools converge, in terms of performance, to lower ability schools by accepting "students at the margin" in order to complete their enrollment requirements. Using administrative data from the city of Amsterdam, Ruijs and Oosterbeek (2014) analyze the determinants of secondary school choice. Their results contradict previous findings by suggesting that school quality is an inconsistent predictor of revealed parental choices. Moreover, they find a significant, positive primary school peers' effect on final enrollment decisions. Close to the spirit of this research, Borghans et al. (2015) estimate mixed logit models to recover parental preferences for primary schools. They find that lower educated parents tend to choose underperforming schools, and overall, aspects such as distance, religious affiliation, and the implementation of an alternative teaching philosophy are key determinants of school choice. With the notable exception of Cabus and Cornelisz (2014), the previous papers do not address the potential endogeneity of school choice. Hence, this research seeks to fill this gap by explicitly addressing the potential correlation between traveling costs and unobserved attributes at the school-track level. 
Finally, this chapter aims to discuss the effects of traveling costs on educational choices. Alderman et al. (2001) find a positive effect of reducing commuting distances on enrollment rates in private schools for poor children in Pakistan. Examining the Chilean case, some evidence has been found of the impacts of traveling costs on schooling decisions, showing that students are willing to commute more to avoid paying larger fees (Chumacero et al., 2011). Comparable results have been found for primary education in the Netherlands, where parents are willing to let their child commute 300 meters more to avoid attending education at lower quality schools (Borghans et al., 2015). However, none of these studies addresses the potential correlation between unobserved academic attributes and pupils' commuting costs. The present study is closely related, in spirit and methodology, with the research developed by Carneiro et al. (2016). After instrumenting commuting distances with the distance from each household to other relevant facilities (Hospitals), they find that students not only prefer to attend education at closer options, but also are willing to pay at least three quarters of the average annual fees at private schools to reduce their commuting distance by 500 meters. The WTT estimates we obtain are also higher than the ones suggested by previous research. We claim related papers underestimate parental WTT because of i) the downward bias in such coefficients when the correlation between the student's commuting distance and other latent cofactors at the school-track level is not addressed, and ii) the heterogeneity in transportation modes that reduces the parental sensitivity to changes in the distance their children travel to attend school.

This chapter proceeds by first offering a brief overview of the Dutch education system. Section 3 describes the empirical strategy implemented, emphasizing on the different roles of both individual and school-track information. Section 4 presents the data overview. In Section 5 we discuss the parameter estimates, as well as results on WTT calculations. Finally, Section 6 concludes.

\subsection{The Dutch Education System: An Overview}

Since 1917, the Dutch government has guaranteed freedom of education consisting in (1) giving citizens the right to establish schools that embrace their own educational, religious, and social beliefs; and (2) allowing parents to freely decide, at any academic level, to which educational institutions their children should register. Education is publicly funded. Hence, both privately and publicly managed schools receive the same resources, but they are subject to quality monitoring from the Inspectorate of Education. Schools that fail to comply the Inspectorate's quality standards will not receive funding, but this occurs seldomly. In practice, this implies that education is almost free, with no administrative restrictions placed in order to influence school choices. Moreover, the fairly accurate weather forecasts, and the little variation in geography, induce parents to select schools that are close to their residence, with very low incentives to change their home location in order to live close to preferred schools (Koning and Van der Wiel, 2013).

Education is mandatory at the primary and secondary education levels until age sixteen. From age 4 to 12 , students attend primary school, where they receive a unified curriculum of courses and prepara- 
tory activities. In their last year of elementary education, pupils are required to present a nationwide, standardized exam (in Dutch: CITO), that serves to build an objective performance measure for pupils and schools. In addition, each student receives a (subjective) recommendation from the primary school teacher about the academic track they are most suited to follow afterwards. From age 12 to age 14, most students attend general secondary education. By the end of the second year, schools will consider current performance and previous performance indicators from elementary school, to suggest students a placement in one among the three different academic tracks the system offers. The pre-university track, or high track (in Dutch: VWO), is designed to prepare students interested in post-secondary education at the university level. The higher vocational education, or lower track (in Dutch: HAVO) provides sufficient instruction to attend higher professional education at the community college level. Finally, the system offers a pure lower vocational track (in Dutch: VMBO) which trains pupils to receive further non-academic, technical training after finishing high school. Mobility between tracks is possible but costly. For instance, upper mobility from the low track implies taking one or two additional years of instruction, relative to the time will take to complete the high track from the beginning. This implies that parents concerned to facilitate their children with opportunities to attend university will be better off by choosing the pre-university track.

Starting the third year of secondary education, the school proposes a tracking allocation to the parents, incorporating information about the pupil's previous academic performance indicated by both the CITO tests scores and the advice given by the primary school. While secondary schools have enough discretion to abide the tracking recommendation from the pupil's primary school, parents can indirectly influence the final tracking result as well. They can exert pressure to elementary school's teachers seeking to obtain a better recommendation for their child, or bargain with the secondary school to guarantee enrollment in the academic track that fits their preferences the best (Korthals, 2015). In practice, this implies that parents can decide whether to comply or not with the final tracking outcome by approaching many secondary schools until the child is accepted in the desired track. ${ }^{2}$ At the end of secondary education, students present a national standardized exam that accounts for fifty percent of final grades. The remainder percentage is determined by school-specific exams that are held between the last two or three years of secondary education (Ruijs and Oosterbeek, 2014). In order to assess the quality at the secondary education level, the Inspectorate of Education monitors results at the national standardized exam, as well as the percentage of pupils that failed to graduate in time. This accountability policy gives schools enough incentives to refine their tracking placements, either through being more selective, or by assessing information from primary schools more carefully.

\subsection{Empirical Strategy}

In this section we present an adaptation of the methodology proposed by Berry et al. (2004) to recover taste parameters from a model of choice with customer heterogeneity and product differentiation. The

\footnotetext{
${ }^{2}$ To our knowledge, there is no legal restriction that impairs parents to implement such strategy.
} 
key aspect of this estimation strategy is to incorporate micro-level and market level information, in contrast with previous contributions that use market level aggregated data (Berry et al., 1995; Nevo, 2000) or individual data alone (McFadden, 1974). We model the decisions to choose a particular schooltrack at the end of the second year of secondary education. In this sense, as most of the tracking decisions are made at the school level, this model is coherent with the parental decision to comply or not with this final track allocation.

\subsubsection{A Model of School-Track Choice}

Consider a secondary education system where $T$ different academic markets are observed, with $t=$ $1, \ldots, T$ and $i=1, \ldots, N_{t}$ indexing each market, and the number of pupils per market, respectively. ${ }^{3}$ By using this classification we are accounting for geographic and socio-demographic variation that might affect both, the composition of students in each selected option, and the set of alternatives that all pupils from a particular market can choose from. Hence, a choice set is composed by $1+J_{t}$ alternatives, where $j=0$ represents an outside option common to all markets, and $j=1, \ldots, J_{t}$ indexes the remaining available alternatives at market $t$.

We define an alternative as a school-track pair. The main purpose of this demand model is to account for the selection process made by parents on the academic track their child should follow. These academic tracks, after completion, grant the student the right to attend post-secondary education at the university level. Thus, we model school-track choices between a "High Track", that allows the pupil to enroll in a scientific university program, and a "Low Track", which leads the student to register at a mixed vocational-academic program offered by a university of applied sciences ${ }^{4}$. We set the outside option as all school-track combinations leading to a pure vocational high-school track degree. Hence, this outside option has a non-zero market share across all markets, and market heterogeneity is largely explained by the availability of remaining alternatives. ${ }^{5}$

We suggest the following specification of the indirect utility obtained by student $i$ from attending schooltrack $j$ at market $t$ :

$$
u_{i j t}=\gamma x_{j t}+\xi_{j t}-\beta_{i} \overline{d_{j t}}+\varepsilon_{i j t},
$$

where $x_{j t}=\left\{x_{j t 1}, \ldots, x_{j t k}\right\}$ is a vector of $k$ observed attributes of school-track $j$, e.g. school-denomination, type of track, and quality aspects such as average standardized test scores and percentage of pupils who

\footnotetext{
${ }^{3}$ We recognize that schooling decisions are strongly influenced by parents' preferences. In this approach we are modeling the final choice made as a result of a bargaining process between all members of the household. Hence, we will use "Parents', "Pupils", "Students", "Households", and related terms interchangeably.

${ }^{4}$ Universities of applied sciences (hogeschool) offer education at the level of community colleges in the US education system

${ }^{5}$ This definition of the outside option is possible since education in the Netherlands is mandatory until the age sixteen. Hence, all pupils should attend education at one of the educational tracks offered by the Dutch educational system.
} 
fail to graduate in time. $\xi_{j t}$ denotes all attributes of school-track $j$ at market $t$ that are unobserved by the econometrician, but observed by the decision makers. With respect to the cost of attending classes at a particular school-track, let $\overline{d_{j t}}$ denote the average cycling distance a student from market $t$ has to travel in order to attend education at option $j .{ }^{6}$ Finally, $\varepsilon_{i j t}$ is an individual mean-zero stochastic term with a type-I extreme value distribution.

The utility specification in (2.1) implies that the heterogeneity of preferences for academic tracks and other school attributes is driven only by how much parents value the average commuting costs their children face to attend school-track $j$. We denote this valuation by $\beta_{i}$. We assume that the heterogeneity in such valuation is explained by a set of observed individual covariates $D_{i}$, which include demographic attributes and all relevant academic information that influences the final school-track outcome. ${ }^{7}$ In order to maintain simplicity, we adopt a linear relationship in parameters:

$$
\beta_{i}=\beta^{m}+\beta^{o} D_{i}
$$

where $\beta^{o}$ indicates the weights of observed individual characteristics on preferences for cycling. It is important to point out that, because it is possible to add an individual specific constant without changing the preference order over all alternatives, we can normalize utility levels by fixing the indirect utility value of the outside option to zero. This implies that $u_{i 0 t}=0 \forall i \in n_{t}, \forall t \in T$. Therefore, utility levels now should be interpreted as the differences in utility among all options, relative to the utility level perceived by attending a vocational track.

Substituting equation (2.2) into (2.1), the student-level choice model is obtained:

$$
\begin{aligned}
u_{i j t} & =\delta_{j t}-\beta^{o} \overline{d_{j t}} D_{i}+\varepsilon_{i j t} \\
\delta_{j t} & =\gamma x_{j t}-\beta^{m} \overline{d_{j t}}+\xi_{j t},
\end{aligned}
$$

\footnotetext{
${ }^{6} \mathrm{We}$ focus on this particular notion of distance as a way to capture preferences for commuting that do not depend on pupils' residence location alone. For instance, we can consider the hypothetical case where all pupils in a market face the same distance for each option and their covariates determine the propensity to travel to a certain destination. An alternative approach would be to work with individual commuting distances, but this is an individual characteristic rather than a school-track attribute to control for. Namely, working with average distance per alternative implies that commuting costs have a direct role on determining demand for the different options available in a market.

${ }^{7}$ To understand how variation on households' characteristics imply different preferences for academic programs consider the following example: Assume that there are only two families that share the same choice set. As these families differ in many dimensions, their preferences for commuting to the same alternative will vary as well. In specification (2.1) the main implicit assumption we impose is that there are no heterogeneity in preferences for academic tracks that is explained by any other reason than differences in average commuting costs' valuations that, in an hedonic model perspective, will imply different willingness to travel estimates. By restricting our model to account for this transmission mechanism alone we make sure that heterogeneous preferences for academic tracks are revealed by the cycling distance pupils commute.
} 
where $\delta_{j t}$ captures mean-valuations of school-tracks characteristics that are invariant across students. Equations (2.3) and (2.4) also show that is possible to decompose the indirect utility in a linear component (i.e. the mean utility level), plus a non-linear term that measures deviations from mean preferences that depend on the student's covariates.

Regarding individual's heterogeneity, we define a pupil as a duple $\left(D_{i}, \varepsilon_{i t}\right)$ with $\varepsilon_{i t}=\left(\varepsilon_{i 0 t}, \ldots, \varepsilon_{i J_{t} t}\right)$. Then, the set of students at market $t$ that choose to attend school-track $j$ is defined as the group whose attributes lead them to select such option against all other available alternatives:

$$
A_{j t}\left(x_{j t}, \overline{d_{j t}}, D_{i} ; \beta^{o}\right)=\left\{\left(D_{i}, \varepsilon_{i t}\right) \mid u_{i j t} \geq u_{i l t}, \forall l=0,1, \ldots, J_{t}\right\} .
$$

Let us denote $\delta_{t}=\left\{\delta_{1 t}, \ldots, \delta_{J_{t}}\right\}, x_{t}=\left\{x_{1 t}, \ldots, x_{J_{t}}\right\}$, and $\overline{d_{t}}=\left\{\overline{d_{1 t}}, \ldots, \overline{d_{J_{t}}}\right\}$. Including the assumption that ties do not occur, and recalling that $\varepsilon_{i t}$ follows a type-I extreme value distribution, the probability that a pupil from market $t$ with characteristics $D_{i}$ prefers alternative $j$ takes the logit form:

$$
\hat{P}_{i j t}\left(x_{t}, \delta_{t}, \overline{d_{t}}, D_{i} ; \beta^{o}\right)=\frac{\exp \left(\delta_{j t}-\beta^{o} \overline{d_{j t}} D_{i}\right)}{1+\sum_{l=1}^{J_{t}} \exp \left(\delta_{l t}-\beta \overline{d_{j t}} D_{i}\right)}
$$

where $P($.$) denotes population distribution functions. Since all pupils from a particular market select$ their preferred alternatives from the same choice set, aggregate (predicted) market shares are recovered by calculating the average of all individual probabilities of selecting alternative $j$ at market $t$.

$$
\hat{P}_{j t}\left(x_{t}, \delta_{t}, d_{t} ; \beta^{o}\right)=N_{t}^{-1} \sum_{i=1}^{N_{t}} \hat{P}_{i j t}\left(x_{t}, \delta_{t}, \overline{d_{t}}, D_{i} ; \beta^{o}\right) .
$$

\subsubsection{Estimation}

In our framework we follow the demand estimation problem using both market-level and individual-level data (Berry et al., 2004). Equation (2.5) implies that the model could be estimated using a conditional logit with alternative-specific fixed effects $\delta_{j t}$. This model would yield consistent estimators of $\left(\delta_{t}, \beta^{o}\right)$ without resorting to additional restrictions on $\xi_{j t}$. Indeed, estimating equation (2.3) using a conditional logit specification is enough to recover individual choice probabilities, as well as market share predictions $\hat{P}_{j t}$.

However, in the above setting it is not possible to identify parameters $\left(\gamma, \beta^{m}\right)$. Since $\delta_{j t}$ is a function of school-track $j^{\prime} s$ characteristics, decomposing $\delta_{j t}$ in observed attributes is not enough to capture consistent estimators of $\gamma$ and $\beta^{m}$, unless there is no correlation between those attributes and $\xi_{j t}$. Namely, while estimating $\gamma$ and $\beta^{m}$ we face the classic endogeneity problem in econometrics. This issue is especially challenging when we consider the potential relationship between $\xi_{j t}$ and $\overline{d_{j t}}$. Unobserved school-track quality, strategic school location, and residential sorting, among other factors, may influence the average 
distance pupils need to travel, $\left(\overline{d_{j t}}\right)$. As a consequence, any estimation of these structural parameters, as well as individual elasticities and WTT, will be inconsistent.

In order to identify all coefficients from the original model, we need to resort to market level data. By recovering mean utility values alone we can use aggregated information on school-track's attributes to consistently estimate $\gamma$ and $\beta^{m}$. To perform this estimation process, we rely on an influential result from the empirical industrial organization literature, which states that there exists a contraction mapping between the observed market shares, and the market shares implied by the model, on $\delta_{j t}$ (Berry et al., 1995). Namely, given a set of parameters $\beta^{o}$, there is a unique vector of mean valuations per alternative $\delta=\left(\delta_{1}, \ldots, \delta_{T}\right)$ such that the observed market shares and the ones the model predicts are (asymptotically) equivalent. Once parameters $\left(\delta, \beta^{o}\right)$ are identified, it is possible to estimate $\left(\gamma, \beta^{m}\right)$ as a function of school-track observed attributes by any econometric method that corrects the potential endogeneity problem stated above. The particularities of this estimation process are explained in the next subsection.

\subsubsection{The BLP Algorithm}

In this setting, we need two different databases. On the one hand, we construct a market-level database, which includes all relevant market information, market shares per alternative, and observable characteristics of all options available within each market. In this database the unit of observation is a marketschool-track combination. On the other hand, we build an individual-level database, with information about choice sets, school-track alternatives, demographics, and academic attributes per pupil. In this database the unit of observation is a student-school-track combination.

Using these sources of information, the estimation algorithm can be implemented by following the next steps: ${ }^{8}$

Step I: Given some initial values for $\delta$, labeled $\delta_{0}$, we use the individual-level dataset to estimate a conditional logit by maximum likelihood to recover $\beta^{o}$ parameters, as well as individual choice probabilities denoted by $\hat{P}_{i j t}$.

Step II: Using results from Step I, recover $\delta_{t}$ by solving for each market an implicit system of equations:

$$
\hat{P}_{j t}\left(\delta_{t}, \beta^{o}\right)=s_{j t}, \quad j=1, . ., J_{t}
$$

\footnotetext{
${ }^{8}$ See Train (2009) for a detailed exposition of the BLP algorithm.
} 
where $s_{j t}$ is the observed market share for alternative $j$ at market $t$ in the data. Using the contraction mapping suggested by Berry et al. (1995), the system of equations for all markets has a unique solution characterized by the following equation:

$$
\delta^{h+1}=\delta^{h}+\ln (S)-\ln \left(\widehat{P}\left(\delta^{h} ; \beta^{o}\right)\right)
$$

Step III: We repeat Step I and II until the distance between mean utility vectors at the last two iterations is lower enough. That is, when $\left\|\delta^{H}-\delta^{H-1}\right\|<\varepsilon$, with $\varepsilon$ denoting the convergence criterion implemented, and $H$ being the minimum number of iterations to reach convergence. After recovering mean utility values, it is possible to invert the system of equations to express the vector $\delta$ as a function of observed market shares:

$$
\delta^{*}\left(S, \beta^{o *}\right)=\widehat{P}^{-1}\left(S, \beta^{o *}\right)
$$

where $(*)$ denotes the parameters when they have been identified.

Step IV: We use results from Step III to define the structural error term as $\xi_{j t}\left(\delta_{j t}^{*}, \gamma, \beta^{m}\right) \equiv \delta_{j t}^{*}\left(s_{j t}, \beta^{o *}\right)-$ $\left[\gamma x_{j t}-\beta^{m} \overline{d_{j t}}\right]$. Then for a set of $M+k+1$ instruments (where $M$ is the number of excluded instruments) $Z=\left\{x, d, z_{1}, \ldots, z_{M}\right\}$, we compute $\left(\gamma, \beta^{m}\right)$ by using an estimator that will fit the set of moments:

$$
E\left[Z^{\prime} \xi\left(\delta^{*}, \gamma^{*}, \beta^{m *}\right)\right]=0
$$

This can be done either by using a minimum distance estimator, such as Generalized Method of Moments (GMM), or by using the instrumental variables estimator (IV). In summary, the whole estimation algorithm can be described in two simple steps: i) Using individual level data to recover unobserved mean utility levels, and ii) using mean utility levels as a dependent variable in a regression on school-track's features to recover mean preferences for the different academic programs available.

Since we are concerned to recover mean valuations of non-vocational academic tracks, we modify equation (2.4) as follows:

$$
\delta_{j t}=\gamma_{h} \operatorname{High}_{j t}+\gamma_{l} \operatorname{Low}_{j t}+\alpha x_{j t}-\beta^{m} \overline{d_{j t}}+\phi_{s}+\psi_{m}+\xi_{j t},
$$

Where parameters $\gamma_{h}$ and $\gamma_{l}$ capture mean preferences for the high track, and the low track, respectively. Parameter $\alpha$ measures average valuations towards other attributes than track denomination. Finally, $\phi_{s}$ $\left(\psi_{m}\right)$ are fixed effects at the school management board (municipal) level. The parameters of interest in this estimation stage are $\left(\gamma_{h}, \gamma_{l}, \beta^{m}\right)$. Since the large majority of schools offer both tracks, it is fair to consider the availability of such tracks as exogenous. This fact implies that the challenge of our 
identification strategy relies mostly on computing consistent estimates of $\beta^{m}$. In the next subsection, we discuss our instruments and identification assumptions.

\subsubsection{Identification Strategy}

The main objective of this estimation process is to recover consistent estimates of mean utility values $\left(\delta_{j t}\right)$ and mean preferences for commuting $\left(\beta^{m}\right)$. Regarding estimation of $\delta_{j t}$, identification is guaranteed since no unobservables at the individual level affect the consistency of parameters which measure deviations from mean preferences. Likewise, our first identification requirement is that individual confounding factors have no role in explaining heterogeneity on preferences for commuting. Under this assumption, mean utilities are identified because of the BLP algorithm implementation. Namely, for a subset of individual interactions, there is a unique vector of mean utilities that equalize the observed market shares with the market shares predicted by the model. As pointed out by Nevo (2000), we only require variation on the choice sets per market, as well as variation of demographic attributes (at least two different individuals) within each market to recover consistent estimates of $\delta_{j t}$.

Identification of $\beta^{m}$ is less straightforward. In an ideal experimental setting, households would have been randomly allocated across different residential locations to later record their school-track choices. Residential sorting motivated by neighborhood composition, and strategic location of school facilities implies that the average distance traveled to each alternative is correlated with unobserved elements that influence school choice. To deal with this issue we implement an instrumental variable approach (IV), using two plausibly exogenous sources of variation. The first instrument is the distance from each school to the closest city hall, as a way to capture its degree of market accessibility(Noailly et al., 2012). We argue that this variable is positively correlated with the average commuting distance to each schooltrack available, but not correlated with unobserved attributes that influence the final schooling decision. Similar instruments have been used in the school choice literature, an example being the distance to the nearest hospital, as a way to control for the endogeneity of traveling costs (Carneiro et al., 2016).

The second set of instruments we implement is motivated by the spatial differentiation of retail markets literature (Davis, 2006; Houde, 2012). We define school-track $j^{\prime} s$ influential area as a concentric circular area with four kilometers radius. Then, we construct concentric rings to count the amount of rival schools located in those rings, just in the same way a dart board is drawn. Hence, we define rivals $(a, b)$ as the number of competing schools located in a concentric ring between $a$ and $b$ kilometers away from schooltrack $j$. Since these concentric areas are arbitrarily generated, school-track locations in such rings are plausibly exogenous. Thus, our identification assumption is that the larger the number of competing schools concentrated outside school-track $j^{\prime} s$ influential area, the lower the average distance commuted to such alternative since pupils living there would prefer to attend education at a nearby school. In that sense, this specific set of instruments are negatively correlated with the average cycling distance to attend education, and not necessarily correlated with other cofounders that influence school choice. 


\subsubsection{Recovering Willingness to Travel (WTT) Estimates}

It is possible to rearrange equation (2.7) to express average distance per alternative as a function of school-track characteristics (we ignore fixed effects to ease the exposition):

$$
\overline{d_{j t}}=\tilde{\gamma}_{h} H i g h_{j t}+\tilde{\gamma}_{l} L o w_{j t}+\tilde{\alpha} x_{j t}+\tilde{\xi_{j t}}-\tilde{\delta_{j t}}
$$

where all parameters with the $(\sim)$ denote that they are divided by the distance coefficient $\beta^{m}$. As Bayer et al. (2007) point out, this equation is nothing more than a corrected hedonic model specification. In such a case, all parameters can be interpreted as the WTT in order to attend (or avoid) any school-track with a particular feature. Thus, from equation (2.7) is it possible to recover such estimates (and their standard errors using the delta method) by calculating the ratio of each parameter associated to each attribute with respect to the distance coefficient. Naive estimations using OLS-hedonic regressions assume that $\tilde{\delta_{j t}}$ is equal to zero, neglecting any endogeneity problem in the identification strategy.

\subsection{Data Description}

In this section we first describe our main sources of information, how these sources were combined to consolidate our final datasets, and the main features of the particular educational system considered for this study. Then, we continue by offering relevant definitions about students, markets, and academic alternatives, as well as summary statistics of our main variables of interest.

\subsubsection{Data Overview}

In this study we use a unique dataset on the educational development of elementary and secondary school children who inhabit a statistically representative province of the Netherlands (South-Limburg). These data are collected in a cooperative project between elementary schools, secondary schools, managerial school boards, local authorities, and Maastricht University, in order to assess school performance and track placement, as well as to promote economic and educational development. This project surveys 7 cohorts of students in their final year of elementary school, for the years 2007 through 2013. Hence, the complete dataset comprises a repeated cross-section of 39,794 pupils, roughly 5,600 per cohort, representing up to $95 \%$ of all primary school coverage in the region.

Since we are concerned to model parental choices at the secondary school level, we use a particular subsample of students (cohort 2009) who were also surveyed in their third year of secondary education. We are able to identify information about household socio-demographic characteristics, prior pupils' 
academic performance at elementary school, and final tracking placements from 4,568 students, covering almost $90 \%$ of all secondary schools in the province where the cooperation project is developed. We decided to discard pupils' information from four municipalities with only one academic track observed (16 students), as well as all students whose main residence is outside the Netherlands (53 students). With respect to pupils' characteristics and previous academic performance, 464 children were dropped from our sample since information about their standardized test scores and primary school advice is missing. In addition, we cannot identify the gender of 136 students neither from the administrative data, nor from the two surveys conducted. This data cleaning process leaves us with 3,988 usable observations to perform estimations at the individual level. ${ }^{9}$

\subsubsection{Markets}

We define a market as a municipality $\times$ household's socio-economic background combination. We measure the latter by recording the highest educational level the parents achieved. A household is labeled as "high-educated" if at least one of the parents reported to have completed post-secondary education (regardless of the track they followed), and is tagged as "low-educated" otherwise. With this information we classify students and the school-tracks they selected in 40 different markets (20 municipalities $\times$ 2 education categories), bringing a maximum of 8 alternatives per market, for a total of 286 different alternatives (excluding the outside option).

By using this market definition, we are accounting for geographic and demographic variation that determines the choice set a student faces when registration at the secondary school is required. While the geographic differences might seem obvious (the larger the population within a municipality, the larger its choice set), we claim that parental educational attainments are also essential to determine the availability of options per market that geographic variation cannot capture alone. Table 2.1 provides evidence about this fact, by reporting the number of alternatives per market. Special attention should be addressed to the variation in the composition of the choice sets. Essentially, markets including students from highly educated families have choice sets with more chances to enroll into the high track. In contrast, we observe that markets where pupils from low-educated families participate offer more alternatives to attend the low track, with few exceptions. In Appendix Table A.1.1 we provide calculations of aggregated market shares per educational track. On average, pupils from high-educated households attend the high track $27 \%$ more than students with low-educated parents. Almost half of the latter attend vocational education, contrasting with only $25 \%$ of the children from high-educated families choosing that option. Overall, students from low-educated families have lower rates of enrollment into pre-university tracks, a fact that is robust for almost all municipalities in our sample.

\footnotetext{
${ }^{9}$ However, it is important to point out that, with exception with students living outside the Netherlands and in those municipalities where all students attended the same track, the remaining students were considered in order to calculate the observed market shares of all school-tracks per market.
} 


\subsubsection{Students}

From our survey data we collected information at the pupil and household levels. In particular, we were able to identify the maximum educational level achieved by the household, the student's gender, as well as measurements of pupil previous performance at elementary school. The first performance measure is the CITO test score, which is measured in a 500-550 range with increments of 1 point. The discreteness of this test allows us to compute 6 groups of percentiles to measure differentials in educational outcomes across students. The second performance measure is the qualitative and, to some extent, subjective advice given by primary schools about the most suitable track the pupil should follow afterwards. We create dummy variables to account for these different recommendations, emphasizing the role of three particular outcomes: receiving a positive advice to attend the high track, receiving an advice to follow the low track, and receiving a mixed (inconclusive) advice, suggesting that the student is suited to attend any of the non-vocational tracks available. Finally, we record each student's gender and identify the number of peers from primary school that attended each alternative, as a way to account for potential spillover effects in final schooling choices.

Table 2.2 reports pupils attributes, making the distinction between the full sample (column (1)), and the groups of students coming from low and high-educated households, respectively (columns (2) and (3)). In column (4) we report the differences in means between both types of pupils. Children from educated parents are on average 7.5 percentage points more likely to obtain results in the upper 10th percentile of the CITO standardized test scores distribution. Moreover, students from low-educated families are 20 percentage points less likely to receive a positive advice for enrolling in the high track. Regarding mixed advices, understood as the inconclusive recommendation from the elementary school suggesting that the pupil can attend both tracks, children from high-educated families received on average 7.6 percentage points more recommendations than pupils from low-educated backgrounds. Not surprisingly, students with low educated parents are 3.5 percentage points more likely to receive an advice to attend the vocational track. Virtually no difference is found in the gender composition among both types of households. On average, students commute 4.4 kilometers to attend secondary education, but students from highly educated families travel slightly longer distances (300 meters).

\subsubsection{Alternatives}

In addition to our individual dataset, we merged student information with data on school-track characteristics using administrative records from the Dutch Inspectorate of Education (in Dutch: DUO). We recorded information on school denomination and whether the school offered an alternative pedagogical method, the type of track offered, the managerial board in charge of each school, and two measures of observed quality. The first measure is the standardized high-school exit test scores that students took at the end of their studies. The second measure is the proportion of pupils that fail to graduate in time per track selected (6 years for the high track, 5 years for the low track). Regarding traveling costs, we use 
information on the location of pupils and schools at the 6-digit postcode level precision and construct cycling distance measurements to each alternative-household combination. ${ }^{10}$ With this information, we compute the average cycling distance per alternative available in each pupil's choice set.

Table 2.1: Summary Statistics - Options per Academic Market

\begin{tabular}{|c|c|c|c|c|c|c|}
\hline \multirow{3}{*}{ Municipality } & \multicolumn{3}{|c|}{ low-educated parents } & \multicolumn{3}{|c|}{ high-educated parents } \\
\hline & Low & High & Total & Low & High & Total \\
\hline & Track & Track & & Track & Track & \\
\hline 1 & 2 & 2 & 4 & 2 & 3 & 5 \\
\hline 2 & 3 & 3 & 6 & 2 & 3 & 5 \\
\hline 3 & 1 & 3 & 4 & 1 & 3 & 4 \\
\hline 4 & 4 & 3 & 7 & 5 & 4 & 9 \\
\hline 5 & 2 & 2 & 4 & 2 & 3 & 5 \\
\hline 6 & 5 & 4 & 9 & 5 & 7 & 12 \\
\hline 7 & 6 & 4 & 10 & 5 & 6 & 11 \\
\hline 8 & 3 & 5 & 8 & 3 & 3 & 6 \\
\hline 9 & 3 & 3 & 6 & 1 & 3 & 4 \\
\hline 10 & 4 & 4 & 8 & 5 & 5 & 10 \\
\hline 11 & 4 & 6 & 10 & 4 & 4 & 8 \\
\hline 12 & 6 & 5 & 11 & 3 & 5 & 8 \\
\hline 13 & 4 & 4 & 8 & 3 & 4 & 7 \\
\hline 14 & 4 & 4 & 8 & 3 & 4 & 7 \\
\hline 15 & 3 & 4 & 7 & 3 & 4 & 7 \\
\hline 16 & 2 & 3 & 5 & 3 & 4 & 7 \\
\hline 17 & 3 & 4 & 7 & 2 & 3 & 5 \\
\hline 18 & 2 & 2 & 4 & 2 & 3 & 5 \\
\hline 19 & 6 & 5 & 11 & 5 & 5 & 10 \\
\hline 20 & 2 & 3 & 5 & 5 & 4 & 9 \\
\hline Observations & 69 & 73 & 142 & 64 & 80 & 144 \\
\hline Mean & 4.04 & 3.96 & 4 & 3.78 & 4.30 & 4.07 \\
\hline Std. Dev. & 1.43 & 1.06 & 1.25 & 1.28 & 1.23 & 1.27 \\
\hline Min & 1 & 2 & 1 & 1 & 3 & 1 \\
\hline Max & 6 & 6 & 6 & 5 & 7 & 7 \\
\hline
\end{tabular}

Notes: Each column reports the number of school-tracks available per market, and the total number of alternatives per municipality. Each market is a municipality-Parental educational attainment combination, for a total of 40 markets.

\footnotetext{
${ }^{10}$ To measure cycling distances, we recover information on postcodes of schools and pupils at the six digit level from our survey dataset. Next, we calculated the distance between these postcodes using the STATA module traveltime 3 , which gathers distance measures and travel time by mode of transport using Google Maps geocoded information (Ozimek and Miles, 2011).
} 
Table 2.2: Summary Statistics - Pupils Characteristics

\begin{tabular}{|c|c|c|c|c|}
\hline & $\begin{array}{c}\text { (1) } \\
\text { All } \\
\text { Students }\end{array}$ & $\begin{array}{c}\text { (2) } \\
\text { Low } \\
\text { Educated }\end{array}$ & $\begin{array}{c}\text { (3) } \\
\text { High } \\
\text { Educated }\end{array}$ & $\begin{array}{c}(4) \\
\text { Difference } \\
(2)-(3)\end{array}$ \\
\hline CITO Score $>P_{90}$ & $\begin{array}{c}0.077 \\
(0.267)\end{array}$ & $\begin{array}{c}0.049 \\
(0.217)\end{array}$ & $\begin{array}{c}0.124 \\
(0.330)\end{array}$ & $\begin{array}{c}-0.075 * * * \\
0.009\end{array}$ \\
\hline CITO Score $\left(P_{75}, P_{90}\right]$ & $\begin{array}{c}0.157 \\
(0.364)\end{array}$ & $\begin{array}{c}0.117 \\
(0.321)\end{array}$ & $\begin{array}{c}0.226 \\
(0.418)\end{array}$ & $\begin{array}{c}-0.109 * * * \\
0.012\end{array}$ \\
\hline CITO Score $\left(P_{50}, P_{75}\right]$ & $\begin{array}{c}0.232 \\
(0.422)\end{array}$ & $\begin{array}{c}0.204 \\
(0.403)\end{array}$ & $\begin{array}{c}0.278 \\
(0.448)\end{array}$ & $\begin{array}{c}-0.075 * * * \\
0.014\end{array}$ \\
\hline CITO Score $\left(P_{25}, P_{50}\right]$ & $\begin{array}{c}0.266 \\
(0.442)\end{array}$ & $\begin{array}{c}0.283 \\
(0.451)\end{array}$ & $\begin{array}{c}0.236 \\
(0.425)\end{array}$ & $\begin{array}{c}0.047 * * * \\
0.014\end{array}$ \\
\hline CITO Score $\left(P_{10}, P_{25}\right]$ & $\begin{array}{c}0.164 \\
(0.371)\end{array}$ & $\begin{array}{c}0.209 \\
(0.406)\end{array}$ & $\begin{array}{c}0.091 \\
(0.288)\end{array}$ & $\begin{array}{c}0.117 * * * \\
0.012\end{array}$ \\
\hline CITO Score $\leq P_{10}$ & $\begin{array}{c}0.103 \\
(0.304)\end{array}$ & $\begin{array}{c}0.139 \\
(0.346)\end{array}$ & $\begin{array}{c}0.044 \\
(0.206)\end{array}$ & $\begin{array}{c}0.095^{* * *} \\
0.010\end{array}$ \\
\hline 1[Advice=High Track $]$ & $\begin{array}{c}0.220 \\
(0.414)\end{array}$ & $\begin{array}{c}0.143 \\
(0.350)\end{array}$ & $\begin{array}{c}0.348 \\
(0.477)\end{array}$ & $\begin{array}{c}-0.205 * * * \\
0.013\end{array}$ \\
\hline 1[Advice=Mixed $]$ & $\begin{array}{c}0.142 \\
(0.349)\end{array}$ & $\begin{array}{c}0.113 \\
(0.317)\end{array}$ & $\begin{array}{c}0.189 \\
(0.392)\end{array}$ & $\begin{array}{c}-0.076 * * * \\
0.011\end{array}$ \\
\hline $1[$ Advice=Low Track $]$ & $\begin{array}{c}0.153 \\
(0.360)\end{array}$ & $\begin{array}{c}0.148 \\
(0.355)\end{array}$ & $\begin{array}{c}0.163 \\
(0.370)\end{array}$ & $\begin{array}{c}-0.016 \\
0.012\end{array}$ \\
\hline 1 [Advice $=$ Vocational Track $]$ & $\begin{array}{c}0.114 \\
(0.318)\end{array}$ & $\begin{array}{c}0.128 \\
(0.334)\end{array}$ & $\begin{array}{c}0.092 \\
(0.290)\end{array}$ & $\begin{array}{l}0.035^{* * *} \\
0.010\end{array}$ \\
\hline 1 [Woman] & $\begin{array}{c}0.514 \\
(0.500)\end{array}$ & $\begin{array}{c}0.519 \\
(0.500)\end{array}$ & $\begin{array}{c}0.505 \\
(0.500)\end{array}$ & $\begin{array}{l}0.013 \\
0.016\end{array}$ \\
\hline \#Peers (Primary School) & $\begin{array}{c}5.968 \\
(6.017)\end{array}$ & $\begin{array}{c}6.965 \\
(6.280)\end{array}$ & $\begin{array}{c}4.304 \\
(5.136)\end{array}$ & $\begin{array}{c}2.661 * * * \\
0.192\end{array}$ \\
\hline $\begin{array}{l}\text { Cycling distance to } \\
\text { selected option (Km.) }\end{array}$ & $\begin{array}{c}4.372 \\
(2.974)\end{array}$ & $\begin{array}{c}4.261 \\
(2.874)\end{array}$ & $\begin{array}{c}4.555 \\
(3.126)\end{array}$ & $\begin{array}{c}-0.294 * * * \\
0.097\end{array}$ \\
\hline Observations & 3988 & 2494 & 1494 & 3988 \\
\hline
\end{tabular}

Table 2.3 shows the distribution of students per school-level attributes and track attended (excluding the outside option). Catholic schools represent 70 percent of total schools' supply. Schools with an alternative teaching methodology account for 15 percent of all schools. While there are virtually no differences in the fail rate among schools offering both tracks (8\% on average), students in the lower track score on average 0.15 standard deviations higher in the central exit exam. Regardless of the track, these exams are graded in the same zero-to-ten scale, suggesting that pupils enrolled in the low track are scoring better. However, since the exam content is not necessarily the same for each track, another much 
more plausible explanation is that students enrolled in the high track might face a more demanding test. Regarding commuting costs, on average students travel seven kilometers to attend non-vocational tracks, while travelling slightly larger distances for to attending the lower track (500 meters).

Table 2.3: Summary Statistics - School's Attributes by Academic Track

\begin{tabular}{lccc}
\hline \hline Variables & Low Track & High Track & Difference \\
& $(1)$ & $(2)$ & $(1)-(2)$ \\
\hline & & & \\
1[Catholic School] & 0.732 & 0.752 & -0.020 \\
& $(0.443)$ & $(0.432)$ & {$[0.018]$} \\
1[Public School] & 0.119 & 0.118 & 0.000 \\
& $(0.324)$ & $(0.323)$ & {$[0.013]$} \\
1[Alternative School] & 0.149 & 0.130 & 0.019 \\
& $(0.356)$ & $(0.337)$ & {$[0.014]$} \\
Fail Rate (10\%) & 0.857 & 0.819 & 0.039 \\
& $(0.401)$ & $(0.766)$ & {$[0.026]$} \\
Central Exam Score & 0.189 & 0.035 & $0.154 * * *$ \\
& $(0.745)$ & $(1.181)$ & {$[0.042]$} \\
Average Distance (Km.) & 7.440 & 6.946 & $0.494 * * *$ \\
& $(2.527)$ & $(1.585)$ & {$[0.086]$} \\
\hline Observations & 1052 & 1276 & 2328
\end{tabular}

Notes: This table reports means and standard deviations of school's characteristics, classified by the type of track the student is enrolled. Column (1) reports results for those pupils enrolled in the Low track (HAVO). Column (2) reports results for those pupils enrolled in the high track (VWO). The outside option is to attend the vocational track (VMBO), therefore students who selected that option are excluded from this table. Column (3) presents differences in means, with standard errors reported in brackets. Standard deviations reported in parenthesis. * p-value $<0.1 * *$ p-value $<0.05 * * *$ p-value $<0.01$.

Table 2.4 reports the distribution of school-track attributes per household educational background. Columns (1) and (2) report means and standard deviations of all characteristics considered, discriminating by families with low and high education level, respectively. Columns (3) and (4) show regressions on observed market shares as a function of school-track characteristics for both groups of pupils. Students from highly educated families are two times more likely to be enrolled in the high track, relative to students from low educated backgrounds. In addition, no difference is found in enrollment rates for the low track between the two groups of students considered. Relative to pupils with low-educated parents, students from a higher economic background fail more often to graduate in time, but also obtain better results in the central standardized test scores after finishing their studies. Furthermore, they travel 6.6 kilometers on average (roughly one kilometer more than pupils from low-educated families) to attend education at secondary schools. Regarding results from columns (3) and (4), a large majority of school-track attributes is negatively correlated with the observed market shares per type of parents. However, the negative correlation is stronger among pupils from low-educated families. Remarkably, $70 \%$ of the variation in market shares can be explained by the entire set of independent variables considered. That is, all attributes considered are powerful enough to explain variation in the market shares per type of household. 
Table 2.4: Summary Statistics - School-Track Attributes by Parental Educational Background

\begin{tabular}{lccccc}
\hline \hline & \multicolumn{2}{c}{ Summary } & & \multicolumn{2}{c}{ Regressions } \\
on Market Shares
\end{tabular}

Appendix Table A.1.2 presents summary statistics of school-track attributes by students' characteristics. Considering CITO test scores, results suggest that there is a positive sorting on track enrollment, where pupils with better (worse) scores are more likely to register into the high (low) track. The same seems to hold for pupils receiving a positive advice to enroll in the high track. Interestingly, a very low proportion of students receiving a mixed advice enrolls in non-catholic schools. Failing rates among female students are 3 percentage points lower than the average for the entire set of pupils in our sample. Considering high-school exit exam scores, larger scores are positively associated with better results in both objective and subjective performance measurements at the primary school level. Finally, considering commuted distances, at least $36 \%$ of students cycle more than four kilometers to reach their preferred schools. Overall, these findings support the idea that individual heterogeneity plays a key role in determining preferences for school-track placements. 


\subsection{Results}

\subsubsection{Recovering Mean Utility Values}

Table 2.5 provides estimates of the full parental choice model in order to compare them with traditional, conditional logit demand specifications. Column (1) reports a conditional logit with no individual heterogeneity. Column (2) displays results of the same model incorporating observed individual heterogeneity. Finally, Column (3) shows results from our suggested specification, while implementing the BLP contraction algorithm to recover fixed effects per alternative that can be interpreted as mean utility levels. Results from our preferred model (3) suggest that the set of attributes considered are positively correlated with the average distance pupils have to cycle in order to attend secondary education. The correlation is stronger in size the better the pupil's performance at primary school is. Thus, students with CITO scores above the mean have significantly higher correlations than pupils with low scores. Regarding primary school tracking recommendations, the less optimistic the advice the higher the correlation with traveling costs. Other attributes, such as the number of peers and gender, are statistically significant, but their correlations are relatively low, suggesting that heterogeneity in traveling preferences are mostly driven by differences in prior academic performance across students.

When we consider all specifications, some inconsistent results emerge. In particular, estimating a conditional logit model without interaction terms implies recovering a negative mean willingness to travel for attributes that commonly are valued positively by parents ( 10 kilometers on average for both tracks). Moreover, this anomaly is not solved by including interaction terms to account for student heterogeneity (Column (2)). Overall, these results point out the empirical problem faced in this setting: While gaining simplicity and tractability, demand estimation by traditional methods will lead to inconsistent estimates of parental preferences for school-track attributes. In contrast, the method we adopt here aggregates all observed and unobserved variation that is constant across individuals, in order to obtain reliable estimates of substitution patterns that depend on students' characteristics.

To better illustrate the advantages of our model, Table 2.6 presents estimations of student enrollment probabilities for the high track. We estimate these probabilities for all specifications considered in Table 2.5. Next, we estimate OLS regressions to account for differences in the mean probability of enrollment that can be explained by changes in students' features. Hence, columns (1)-(3) correspond to the enrollment probabilities derived from a conditional logit without individual heterogeneity. Columns (4)-(6) relax that restriction by incorporing the enrollment probabilities from a model that interacts school-track attributes with pupils' characteristics. Finally, columns (7)-(9) display the results when the dependent variable is the enrollment probability estimated using the BLP algorithm. In these regressions, the coefficient of interest is the one reported in the second row, which accounts for the enrollment gap between pupils from high and low educated households. A positive value indicates that the enrollment gap favours students with high educated parents. 
The findings reported in columns (1)-(6) show that, on average, children have a $20 \%$ chance to be enrolled into the high track. However, after controlling for parental educational background, pupils from higheducated families have a higher likelihood to attend that option. The difference in the size of this effect depends on the specification considered. For traditional conditional logit models the difference is rather small (between 2\% and 3\% after controlling for pupils' covariates). In contrast, the conditional logit model under the BLP contraction algorithm, students with low educated parents are between $20 \%$ and $24 \%$ less likely to attend the high track relative to students from better family backgrounds. This last result is robust either when other students' characteristics are included (columns (7) and (9)).

In general, the key aspect to highlight from these findings is that traditional individual-choice models cannot outperform the BLP approach. The contraction algorithm implemented allows us to recover a unique vector of mean utility values that i) fits the best the distribution of students' attributes per schooltrack selected and ii) equalizes the market shares observed in the data with the aggregated market shares computed using the individual enrollment probabilities the model predicts. Figure 2.1 portrays graphic evidence for this claim, by showing aggregated market shares from all models against the aggregated market shares from the data. Thus, the closer the predicted shares to the 45-degree line, the better the prediction from the model. As argued, traditional specifications predict market shares relatively poorly, especially for larger values. Contrarily, implementing the BLP contraction algorithm provides almost full convergence, as long as a reasonable convergence criterion is set. ${ }^{11}$

\subsubsection{Instrumental Variable Selection And Discussion of Potential Violations}

As we are interested in consistently recovering the structural parameter $\beta^{m}$ to calculate willingness to travel valuations, the instrumental variable that we should implement needs to satisfy two requirements. First, the instrumental variable has to be relevant, in a sense that it is a strong predictor of the average commuting distance to each school-track in the data. Second, the instrumental variable should be exogenous. In particular, we expect the instrument not to be correlated with the academic track supply, as we are concerned to recover preferences over non-vocational denominations.

Relevance: In Table 2.7 we report first stage regressions results using all non-vocational tracks available (286 in total). The dependent variable in each of these estimations is the cycling distance (in kilometers) students, on average, travel to attend a particular school-track. Each regression corresponds to a different instrument and includes all remaining school-track features, plus a set of school board and municipality fixed effects. We use as plausible instruments several combinations of the "concentric rings" rival schools variables to evaluate their relative strength, as well as the distance from each school-track to the closest city hall. Finally, goodness of fit diagnostics and F-statistics used to test the null hypothesis are reported in columns (4) and (5).

\footnotetext{
${ }^{11}$ According to the literature on demand estimation, a reasonable convergence criterion is to set $\varepsilon=10^{-16}$. This was the convergence criterion we selected to implement the BLP contraction algorithm.
} 
Table 2.5: Conditional Logit Estimations

\begin{tabular}{|c|c|c|c|}
\hline & $\begin{array}{c}\text { No } \\
\text { Interactions } \\
(1) \\
\end{array}$ & $\begin{array}{c}\text { With } \\
\text { Interactions } \\
(2)\end{array}$ & $\begin{array}{c}\text { BLP } \\
\text { Algorithm } \\
(3)\end{array}$ \\
\hline \multicolumn{4}{|l|}{ Average Distance $\times$} \\
\hline CITO Score $\left[P_{10}, P_{25}\right)$ & & $\begin{array}{c}0.315^{* * *} \\
(0.065)\end{array}$ & $\begin{array}{c}0.095 * * \\
(0.038)\end{array}$ \\
\hline CITO Score $\left[P_{25}, P_{50}\right)$ & & $\begin{array}{c}0.686 * * * \\
(0.059)\end{array}$ & $\begin{array}{c}0.484 * * * \\
(0.027)\end{array}$ \\
\hline CITO Score $\left[P_{50}, P_{75}\right)$ & & $\begin{array}{c}0.853 * * * \\
(0.059)\end{array}$ & $\begin{array}{c}0.686 * * * \\
(0.025)\end{array}$ \\
\hline CITO Score $\left[P_{75}, P_{90}\right]$ & & $\begin{array}{c}0.992 * * * \\
(0.058)\end{array}$ & $\begin{array}{c}0.864 * * * \\
(0.019)\end{array}$ \\
\hline CITO Score $>P_{90}$ & & $\begin{array}{c}0.999 * * * \\
(0.058)\end{array}$ & $\begin{array}{c}0.839 * * * \\
(0.022)\end{array}$ \\
\hline 1 [advice: mixed] & & $\begin{array}{c}0.169 * * * \\
(0.020)\end{array}$ & $\begin{array}{c}0.198 * * * \\
(0.024)\end{array}$ \\
\hline 1[advice: low track] & & $\begin{array}{c}0.253 * * * \\
(0.021)\end{array}$ & $\begin{array}{c}0.339 * * * \\
(0.027)\end{array}$ \\
\hline 1[advice: vocational track] & & $\begin{array}{c}0.190 * * * \\
(0.036)\end{array}$ & $\begin{array}{c}0.223 * * * \\
(0.039)\end{array}$ \\
\hline \#Peers primary school & & $\begin{array}{c}0.024 * * * \\
(0.001)\end{array}$ & $\begin{array}{c}0.011 * * * \\
(0.001)\end{array}$ \\
\hline $1[$ Female $]$ & & $\begin{array}{c}0.053 * * * \\
(0.014)\end{array}$ & $\begin{array}{c}0.057 * * * \\
(0.017)\end{array}$ \\
\hline $1[$ High Track] & $\begin{array}{c}-1.284 * * * \\
(0.073)\end{array}$ & $\begin{array}{c}0.092 \\
(0.094)\end{array}$ & \\
\hline $1[$ Low Track] & $\begin{array}{c}-1.343 * * * \\
(0.086)\end{array}$ & $\begin{array}{c}0.004 \\
(0.104)\end{array}$ & \\
\hline 1[Public School] & $\begin{array}{c}-0.260 * * * \\
(0.070)\end{array}$ & $\begin{array}{c}-0.233 * * * \\
(0.072)\end{array}$ & \\
\hline 1[Alternative School] & $\begin{array}{c}0.049 \\
(0.066)\end{array}$ & $\begin{array}{l}-0.081 \\
(0.066)\end{array}$ & \\
\hline Fail Rate $(10 \%)$ & $\begin{array}{c}-0.044 \\
(0.057)\end{array}$ & $\begin{array}{c}-0.095 * \\
(0.057)\end{array}$ & \\
\hline Central Exam Score & $\begin{array}{c}0.041 \\
(0.036)\end{array}$ & $\begin{array}{c}0.039 \\
(0.035)\end{array}$ & \\
\hline Average Distance & $\begin{array}{c}-0.127 * * * \\
(0.008)\end{array}$ & $\begin{array}{c}-1.108 * * * \\
(0.060)\end{array}$ & \\
\hline$N$ & 38,373 & 38,373 & 38,373 \\
\hline Log-Likelihood & -7549 & -6688 & -5809 \\
\hline
\end{tabular}

Notes: This table presents coefficients from different conditional logit estimations. The dependent variable in all specifications is a dummy variable that takes value one if a particular school-track was selected and zero for the remaining alternatives. Column (1) reports a conditional logit specification with no individual heterogeneity. Column (2) displays results of the same model incorporing observed individual heterogeneity. Column (3) shows results from our prefered specification, in which we implement the BLP contraction algorithm to recover fixed effects per alternative that can be interpreted as mean utility levels. The outside option consists in attending a vocational track. The categories excluded are the bottom 10th percentile on the CITO exam scores, the primary school advice indicating the student should follow the high track, and whether the academic track is offered by a roman-catholic school. Robust standard errors reported in parentheses. p-value $<0.1 * *$ p-value $<0.05 * * *$ p-value $<0.01$. 


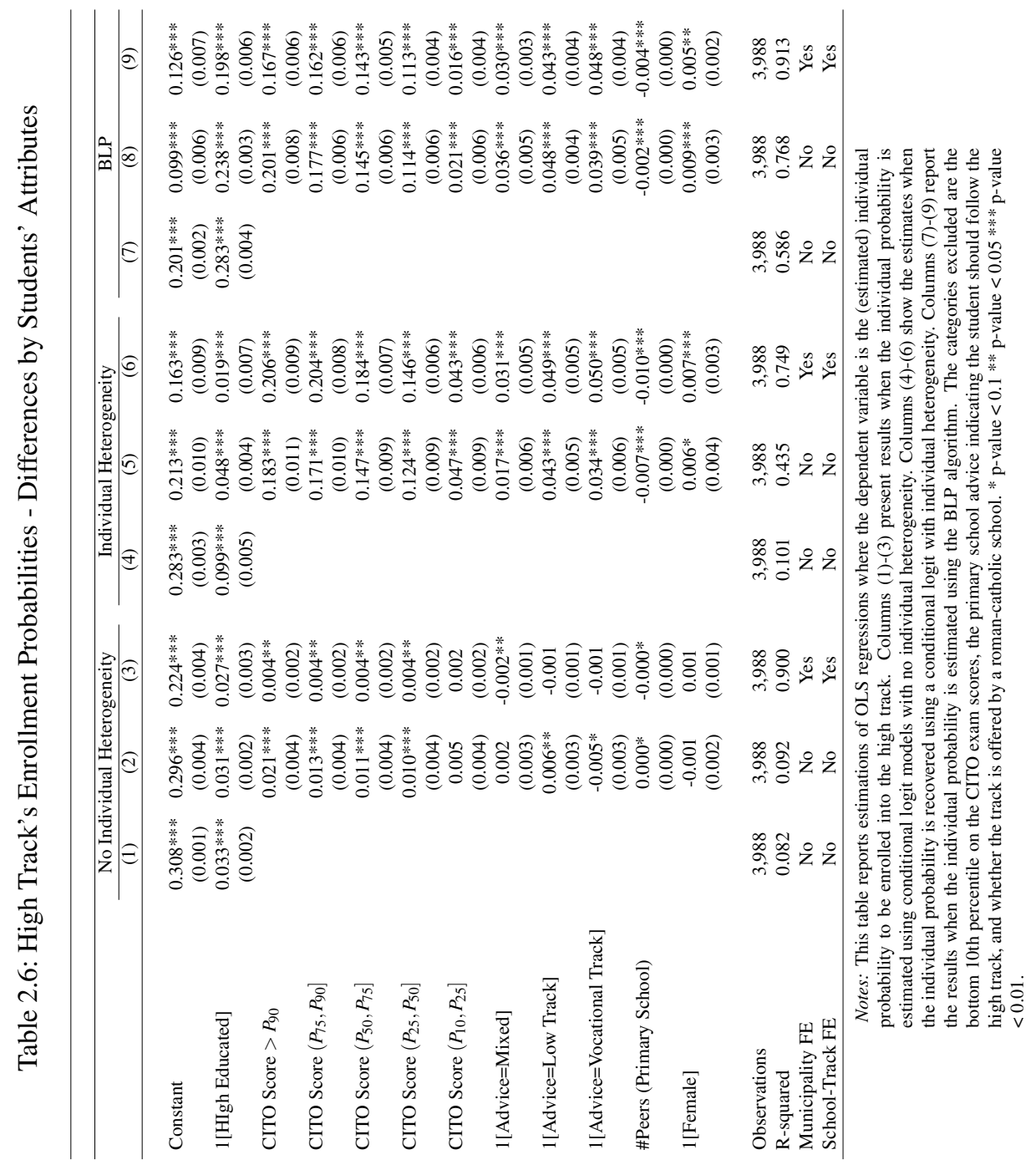


Figure 2.1: Observed Vs. Predicted Market Shares - All Specifications

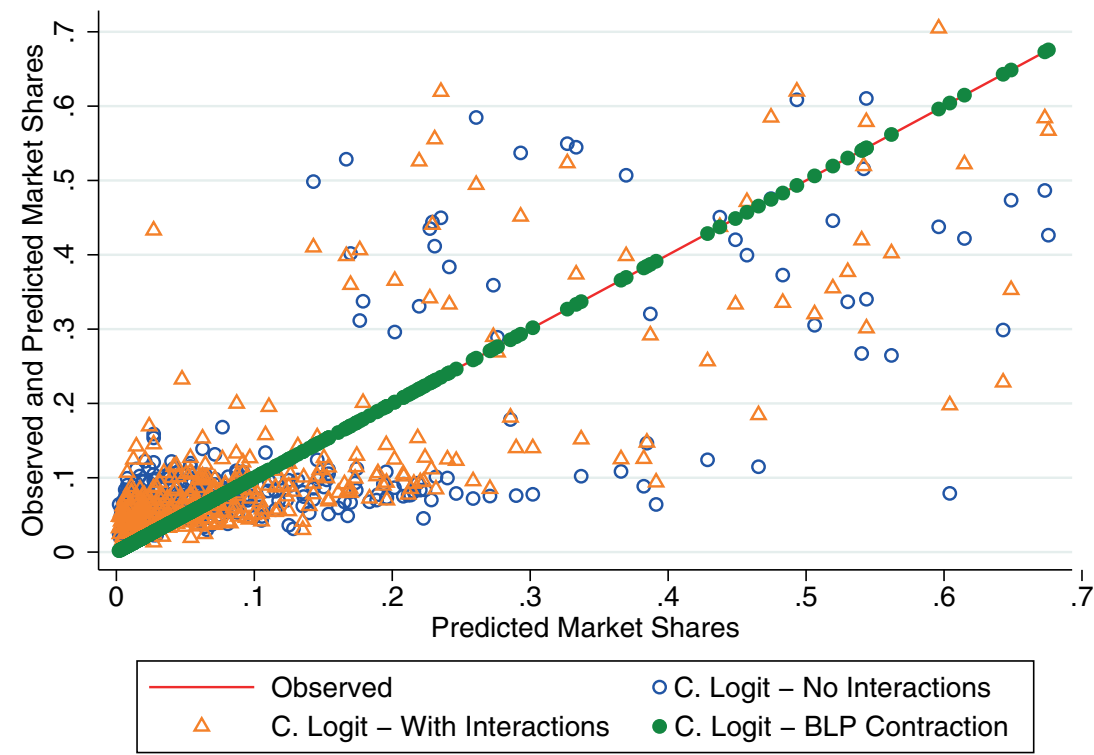

Notes: This figure reports fitted values of aggregated market shares (all tracks) vs. observed market shares. The 45-degree line depicts (sorted) observed values.

Two conclusions can be extracted from the above exercise. First, the distance of each school to the closest city hall appears to be a weak instrument, as the effect derived from the first stage is too imprecise to be considered as statistically different from zero. Second, regarding the number of rival schools in concentric proximity areas, we have at least six excluded instruments that we can consider relevant since their corresponding F-statistics are above traditional critical values (Staiger and Stock, 1997). From these, we decided to choose the three most relevant, rivals $(3,6)$, rivals $(4,6)$, and rivals $(4,8)$ to conduct further endogeneity, tests and use them in the central estimation procedure to recover the structural parameters of the mean utility equation (2.7). 
Table 2.7: Instrument Selection - First Stage Regressions

\begin{tabular}{lccccc}
\hline \hline Instrument & Estimate & S.E. & Observations & R-squared & F-stat $(1,285)$ \\
& $(1)$ & $(2)$ & $(3)$ & $(4)$ & $(5)$ \\
\hline Distance to city hall & -0.305 & $(0.186)$ & 286 & 0.945 & 2.695 \\
rivals $(0,2)$ & 0.642 & $(0.422)$ & 286 & 0.945 & 2.318 \\
rivals $(2,4)$ & 0.196 & $(0.281)$ & 286 & 0.945 & 0.491 \\
rivals $(4,6)$ & $-1.231 * * *$ & $(0.135)$ & 286 & 0.958 & 83.52 \\
rivals $(0,3)$ & $0.843 * * *$ & $(0.278)$ & 286 & 0.948 & 9.227 \\
rivals $(3,6)$ & $-0.778 * * *$ & $(0.084)$ & 286 & 0.954 & 86.54 \\
rivals $(6,9)$ & $-0.651 * * *$ & $(0.079)$ & 286 & 0.955 & 67.45 \\
rivals $(0,4)$ & 0.230 & $(0.219)$ & 286 & 0.945 & 1.101 \\
rivals $(4,8)$ & $-0.533 * * *$ & $(0.059)$ & 286 & 0.956 & 82.49 \\
rivals $(8,12)$ & $-0.303 * * *$ & $(0.090)$ & 286 & 0.947 & 11.38 \\
rivals $(0,5)$ & 0.085 & $(0.149)$ & 286 & 0.945 & 0.331 \\
rivals $(5,10)$ & $-0.416 * * *$ & $(0.046)$ & 286 & 0.955 & 81.97 \\
rivals $(10,15)$ & -0.060 & $(0.078)$ & 286 & 0.945 & 0.583 \\
rivals $(0,6)$ & $-0.440 * * *$ & $(0.115)$ & 286 & 0.948 & 14.69 \\
rivals $(6,12)$ & $-0.303 * * *$ & $(0.052)$ & 286 & 0.950 & 33.47 \\
rivals $(12,18)$ & 0.013 & $(0.061)$ & 286 & 0.945 & 0.049 \\
\hline
\end{tabular}

Exogeneity: While a direct test of the exogeneity assumption is not available, it is possible to argue that each school's location in the artificially-build concentric rings is uncorrelated with mean preferences for track denomination. To further develop this idea, we implement the procedure followed by Altonji et al. (2005) to show that, conditional to non-track related school attributes, the instruments selected from the relevance analysis are uncorrelated with the academic track supply. This test works in a two step estimation process: First, we regress each instrument on school attributes unrelated to the track denomination, plus a set of fixed effects at the school board and municipal levels. Then, the resulting residuals are regressed on the set of dummy variables that indicate whether a particular alternative corresponds to a higher or a lower track. Not being able to reject the joint null hypothesis that the coefficients from the latter regressions are equal to zero provides evidence that the exclusion restriction for each instrument holds. Table 2.8 display our findings on this exogeneity test. As expected, none of the three instruments previously selected appear to be correlated with the track denomination. This fact suggest that, while school-track location might be endogenous, location in the artificially built concentric areas is plausible random. 
Table 2.8: Instrument Exogeneity

\begin{tabular}{lccc}
\hline \hline & $\begin{array}{c}\text { rivals }(3,6) \\
(2)\end{array}$ & $\begin{array}{c}\text { rivals }(4,6) \\
(1)\end{array}$ & $\begin{array}{c}\text { rivals }(4,8) \\
(3)\end{array}$ \\
\hline & & & \\
1[High Track] & -0.061 & -0.066 & -0.125 \\
& $(0.084)$ & $(0.059)$ & $(0.129)$ \\
1[Low Track] & 0.070 & 0.076 & 0.144 \\
& $(0.084)$ & $(0.064)$ & $(0.140)$ \\
& & & \\
Observations & 286 & 286 & 286 \\
R-squared & 0.004 & 0.009 & 0.007 \\
F-stat (2,284) & 0.615 & 1.309 & 0.993 \\
p-value & 0.541 & 0.272 & 0.372 \\
\hline
\end{tabular}

Notes: In each specification the dependent variable is the fitted residuals from regressing each instrument against a set of school board and municipality fixed effects, plus all school-track attributes with the exception of the academic track type. Standard errors are clustered at the school-track level and reported in parentheses. * p-value $<0.1 * * \mathrm{p}$-value $<$ $0.05 * * *$ p-value $<0.01$.

\subsubsection{Parental Willingness to Travel for School-Track Attributes}

Table 2.9 reports the reduced form (columns (1)-(3)), first stage (columns (4)-(6)), instrumental variables (IV) (columns (7)-(9)), and naive OLS (column (10)) results from estimating equation 2.7. In the structural, reduced, and OLS forms, the dependent variable is the mean utility level of each alternative that was recovered using the BLP algorithm. In the first stage specifications, the dependent variable is the average cycling distance (measured in kilometers) that pupils have to commute to attend education at a particular school-track. Given our central research questions we include other relevant school-track attributes as controls, but we abstain to interpret any other parameters than $\left(\gamma_{h}, \gamma_{l}, \beta^{m}\right)$.

Regarding valuations for track denominations, coefficients for the low and high track barely differ. The coefficient associated to the average cycling distance variable seems to be overestimated under OLS. However, this bias is on the order of $10 \%$. Regarding the instrumental variables requirements, while the reduced and first stage forms suggest that all instruments previously selected are statistically significant, in the structural form it is clear that rivals $(4,8)$ is the strongest instrument as it has associated the highest F-statistic. Hereafter, the results from this study will be obtained using this instrument alone. 


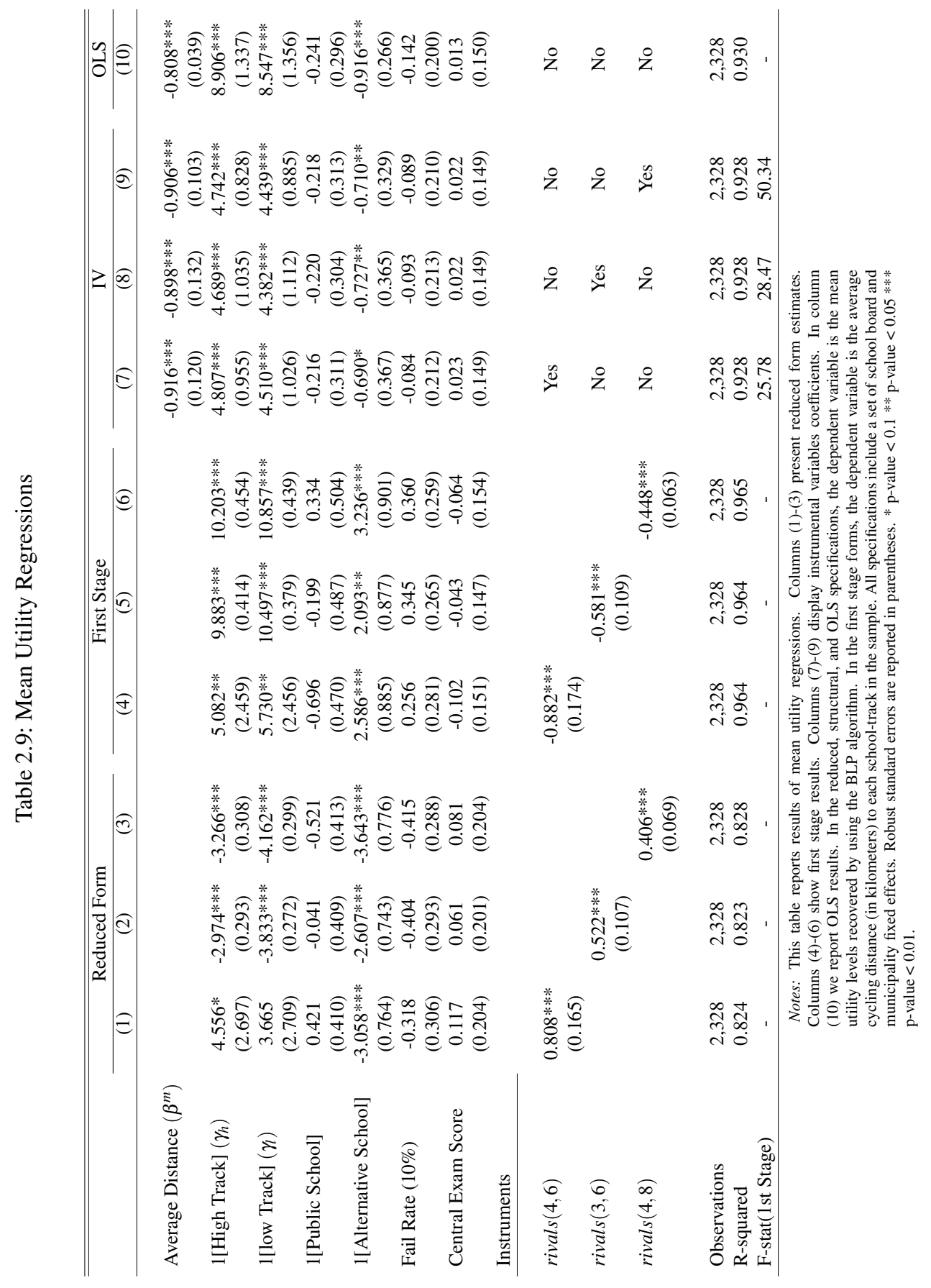


In Table 2.10, we provide an economic interpretation of our results by showing willingness to travel estimates for all non-vocational tracks. Column (1) and (2) report valuations that are recovered from an OLS hedonic travel model, either by using the average cycling distance, or the current cycling distance as a dependent variable, respectively. Column (3) presents the implied willingness to travel from the IV approach using mean utility levels as a dependent variable, and the number of rival schools located in a concentric ring between four and eight kilometers, rivals $(4,8)$, as an instrument. All specifications contain fixed effects at the school board and municipality levels. These coefficients measure the distance in kilometers that a pupil is willing to cycle in order to attend (or avoid) a school-track with a particular attribute. Our results suggest that parents hold positive preferences for non-vocational tracks. On average, parents are willing to let their child commute 5.2 (4.8) kilometers to attend the higher (lower) track, which supports the common idea that academically demanding tracks are (individually) valued much more in the market. Moreover, ignoring unobserved school-track features implies an overestimation of the reserve price (measured in kilometers) students will pay to receive education by roughly fifty percent.

Table 2.10: Willingness to Travel for School-Track Features

\begin{tabular}{lccc}
\hline \hline & Hedonic Model I (OLS) & Hedonic Model II (OLS) & BLP (IV) \\
\hline Dependent Variable & Average & Current & Mean \\
& Cycling Distance & Cycling Distance & Utility Values \\
& $(1)$ & $(2)$ & $(3)$ \\
\hline 1[High Track] & $9.514^{* * *}$ & $11.674^{* * *}$ & $5.233^{* * *}$ \\
& $(0.557)$ & $(0.819)$ & $(0.446)$ \\
1 [Low Track] & $10.088^{* * *}$ & $11.569^{* * *}$ & $4.898^{* * *}$ \\
& $(0.548)$ & $(0.822)$ & $(0.520)$ \\
1 [Public School] & 0.226 & $0.704^{*}$ & -0.241 \\
& $(0.521)$ & $(0.360)$ & $(0.343)$ \\
1[Alternative School] & $2.095^{* *}$ & 0.483 & $-0.784^{*}$ \\
& $(0.896)$ & $(0.437)$ & $(0.424)$ \\
Fail Rate (10\%) & $0.542^{*}$ & 0.347 & -0.098 \\
& $(0.284)$ & $(0.243)$ & $(0.236)$ \\
Central Exam Score & 0.095 & 0.126 & 0.025 \\
& $(0.172)$ & $(0.145)$ & $(0.164)$ \\
\hline Observations & 2,328 & 2,328 & 2,328 \\
\hline
\end{tabular}

Notes: This table report wilingness to travel estimates from OLS hedonic model regressions (Columns (1) and (2)) and IV regressions (Column (3)). The interpretation of the coefficients is the kilometers parents are willing to let their children cycle to attend a school-track with a particular attribute. Standard errors are clustered at the school-track level, computed using the delta method, and reported in parentheses. * p-value $<0.1 * *$ p-value $<0.05 * * *$ p-value $<0.01$.

\subsubsection{Heterogeneous Preferences for Track Placement}

Table 2.11 extends the previous findings by comparing willingness to travel for low and highly educated parents. Panels A and B display valuations for the higher and lower tracks, respectively. The parameter of interest is the interaction between the parental educational attainment and the dummy variable indicating 
the track denomination (third and sixth rows). Positive (negative) coefficients will suggest that highly educated parents value more (less) each alternative, relative to less educated parents.

Notably, while all parents value both tracks positively, the latter are willing to let their child cycle roughly 0.8 kilometers more in order to attend the higher track, relative to parents from lower educational backgrounds. This difference in mean preferences cannot be recovered by a simple OLS-hedonic travel regressions. This fact suggests that OLS estimates present a downward bias in the reserve price of commuting for highly educated parents, as well as in the difference in valuations among parents with diverse degrees of education. The fact that the interaction coefficient in Panel B is the negative of the one obtained for the higher track allows us to conclude that there is educational sorting. Children from highly educated families will cycle to avoid attending the lower track and can travel twice the distance if that guarantees to be enrolled in the higher track.

Table 2.11: WTT for Pre-University Tracks by Parental Educational Background

\begin{tabular}{|c|c|c|c|}
\hline & Hedonic Model I (OLS) & Hedonic Model II (OLS) & BLP (IV) \\
\hline Dependent Variable & $\begin{array}{c}\text { Average } \\
\text { Cycling Distance } \\
(1)\end{array}$ & $\begin{array}{c}\text { Current } \\
\text { Cycling Distance } \\
(2)\end{array}$ & $\begin{array}{c}\text { Mean } \\
\text { Utility Values } \\
\text { (3) }\end{array}$ \\
\hline \multicolumn{4}{|l|}{ Panel A: High Track Valuations } \\
\hline $1[$ High Track $]$ & $\begin{array}{c}6.775 * * * \\
(0.540)\end{array}$ & $\begin{array}{c}4.300 * * * \\
(0.697)\end{array}$ & $\begin{array}{c}4.230 * * * \\
(0.403)\end{array}$ \\
\hline 1[High Educated] & $\begin{array}{c}-0.093 \\
(0.421)\end{array}$ & $\begin{array}{c}0.118 \\
(0.243)\end{array}$ & $\begin{array}{c}0.957 * * * \\
(0.161)\end{array}$ \\
\hline $1[$ High Track $] \times 1[$ High Educated $]$ & $\begin{array}{c}0.192 \\
(0.487) \\
\end{array}$ & $\begin{array}{c}-0.156 \\
(0.320)\end{array}$ & $\begin{array}{c}0.763 * * * \\
(0.188)\end{array}$ \\
\hline \multicolumn{4}{|l|}{ Panel B: Low Track Valuations } \\
\hline $1[$ Low Track] & $\begin{array}{c}7.444 * * * \\
(0.539)\end{array}$ & $\begin{array}{c}4.125 * * * \\
(0.695)\end{array}$ & $\begin{array}{c}4.519 * * * \\
(0.430)\end{array}$ \\
\hline $1[$ High Educated] & $\begin{array}{c}0.099 \\
(0.246)\end{array}$ & $\begin{array}{l}-0.038 \\
(0.205)\end{array}$ & $\begin{array}{c}1.719 * * * \\
(0.177)\end{array}$ \\
\hline $1[$ Low Track $] \times 1[$ High Educated $]$ & $\begin{array}{l}-0.192 \\
(0.487)\end{array}$ & $\begin{array}{c}0.156 \\
(0.320)\end{array}$ & $\begin{array}{c}-0.763 * * * \\
(0.188)\end{array}$ \\
\hline Observations & 2,328 & 2,328 & 2,328 \\
\hline
\end{tabular}

Notes: This table report wilingness to travel estimates from OLS and IV regressions, by parental educational attainments. Panel A presents valuations for the high track. Panel B shows valuations for the lower track. Columns (1) and (2) present OLS estimates from hedonic regressions where the dependent variables are the average and current commuting distances, respectively. Column (3) displays IV estimates where the instrumental variable is the number of rival schools located in a concentric ring between $4 \mathrm{~km}$. and $8 \mathrm{~km}$ far from each school. The interpretation of the coefficients is the kilometers parents are willing to let their child cycle to attend a school-track with a particular attribute. Standard errors are clustered at the school-track level, computed using the delta method, and reported in parentheses. ${ }^{*}$ p-value $<0.1 * *$ p-value $<0.05 * * *$ p-value $<0.01$.

In order to support the previous finding we also calculated the elasticity distance-demand for all parents in our sample. This elasticity reflects the percentage points the enrollment in a particular track decreases when the average distance to commute increases by 10 meters (1\%). Figure 2.2 shows how this elasticity 
distributes for high and low-educated parents. Although no difference is spotted for elasticities regarding the low track, low-educated parents appear to be more sensitive to changes on average commuting costs regarding the high track. on average, we obtain elasticities of -4.46 and -3.43 for low and high-educated families, respectively. These large values reflect how, in sharp contrast with other studies in the literature of school choice, sensitivity to commuting costs is especially high in school systems where the mode of transportation is uniform, relatively easy to access and, from the supply side, schools cannot create legal barriers on enrollment other than minimum academic requirements to be fulfilled by students at the end of elementary school.

To assess the extent to which heterogeneity in preferences is sensitive to students' attributes, we report differences in mean willingness to travel between pupils from low-educated parents vs. high-educated (Table 2.12). Negative values indicate that, relative to parents with post-secondary education, parents from lower educational backgrounds are less inclined to let their child travel to attend a school-track far away from home. Our findings suggest that, for the high track, parents whose pupils excel at the CITO test have comparable preferences to those with higher educational attainments. By including primary school recommendations, it is clear that the heterogeneity is driven mostly by the advice pupils receive, rather than their achievements at the CITO test. Furthermore, contrary to other studies on school choice, neither primary school peer effects nor gender have a role explaining differences in preferences among parents. We conjecture that this partially reflects the fact that pupils from low-educated parents might receive more conservative recommendations than pupils from better household backgrounds.

\subsubsection{Welfare Considerations}

Using estimates from our model we can simulate a shutdown policy of all academic options concerning pre-university tracks to assess how much parents value the counterfactual system implied by the policy, relative to the original setting they based their choices from. To understand the relevance of this exercise, consider the situation where in a particular market the higher track is no longer available. For those students who originally chose a lower track, this policy intervention will have no effect. However, students that originally might have selected the high track will decide whether to travel longer distances and find a comparable alternative, or selecting a lower track available close home. As children with high educated parents are willing to travel longer distances, we might expect that the policy intervention has a welfare-decreasing effect that largely impact pupils from low educated backgrounds that could have attended the higher track otherwise. 
Figure 2.2: Elasticity of Enrollment respect to Cycling Distance

(a) Low Track

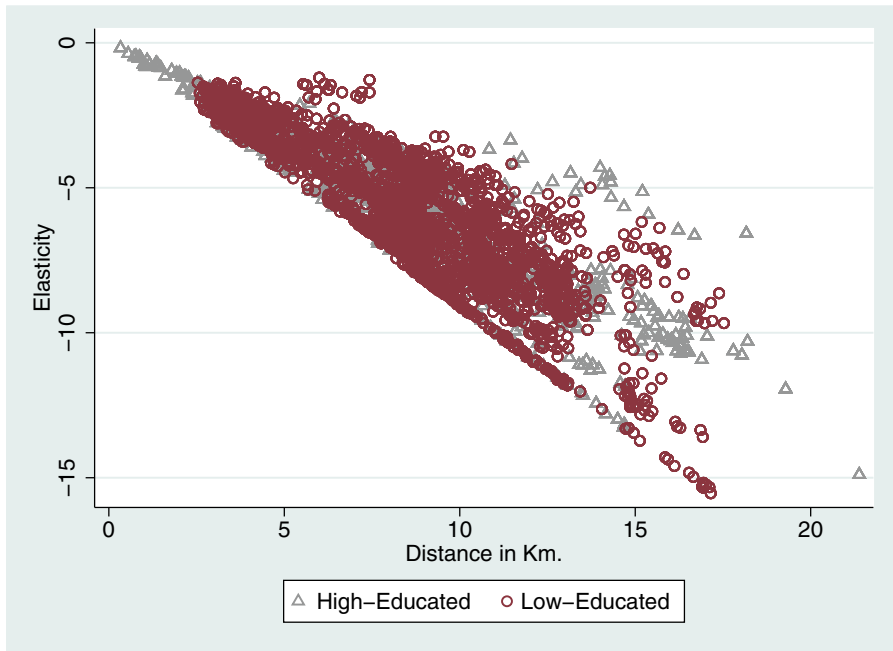

(b) High Track

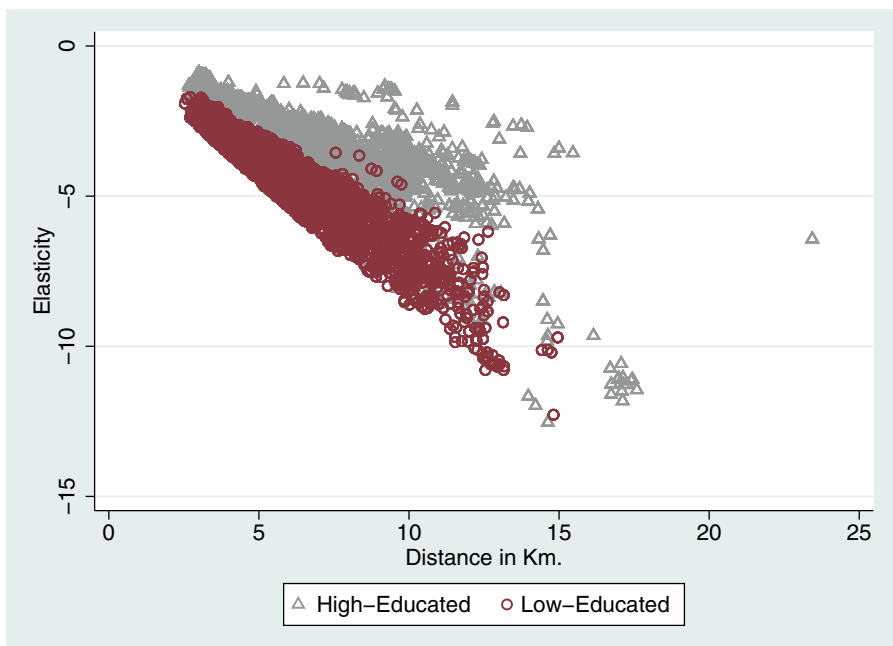

Notes: These figures represent the demand elasticity with respect the average distance pupils need to commute to attend the low track (a), and the high track (b). This elasticity reflects the percentage points decrease in the enrollment rate of a particular track when the average distance to cycle increases by 10 meters $(1 \%)$. 
Table 2.12: Differences in WTT for Pre-University Tracks by Students’ Features

\begin{tabular}{lcc}
\hline \hline low vs. high-educated & $\begin{array}{c}\text { Low Track } \\
(1)\end{array}$ & $\begin{array}{c}\text { High Track } \\
(2)\end{array}$ \\
\hline CITO Score $>P_{90}$ & 0.3007 & -0.1571 \\
& $(0.3715)$ & $(0.1887)$ \\
CITO Score $\left[P_{75}, P_{90}\right]$ & -0.2018 & -0.2511 \\
& $(0.1376)$ & $(0.1874)$ \\
CITO Score $\left[P_{50}, P_{75}\right)$ & -0.1170 & $-0.3596^{* *}$ \\
& $(0.0862)$ & $(0.1737)$ \\
1 [advice: high track] & $-0.3626^{* *}$ & $-1.4656^{* * *}$ \\
& $(0.1632)$ & $(0.2381)$ \\
$1[$ advice: mixed] & -0.2570 & $-1.1825^{* * *}$ \\
& $(0.1656)$ & $(0.2328)$ \\
1[advice: low track] & $-0.4677^{* * *}$ & $-1.4374 * * *$ \\
& $(0.1523)$ & $(0.2237)$ \\
1[Female] & $-0.3886^{* * *}$ & -0.1147 \\
& $(0.0968)$ & $(0.0733)$ \\
\#Peers primary school & 0.0067 & 0.0336 \\
& $(0.0211)$ & $(0.0226)$ \\
\hline Observations & 2328 & 2328 \\
\hline
\end{tabular}

Notes: This table report differences in the wilingness to travel from IV regressions, for pupils with low and higheducated parents. Column (1) presents results for the high track. Columns (2) presents result for the low track. The excluded instruments in all specifications are the distance (in $\mathrm{km}$.) from each school to the closest city-hall, and the number of rival schools located in a ring between $4 \mathrm{~km}$. and $8 \mathrm{~km}$ far from each school. The interpretation of the coefficients is the kilometers low-educated parents are willing to let their child cycle to attend a school-track with a particular attribute, relative to high-educated parents. Standard errors are clustered at the school-track level, computed using the delta method, and reported in parentheses. * p-value $<0.1 * *$ p-value $<0.05 * * *$ p-value $<0.01$.

We use a standard measure of compensated variation (CV), which consists in the amount of additional kilometers a student should commute that equalizes utility across both states of nature: the one implied by the shutdown policy, and the one implied by the status quo. To translate these costs in monetary terms we apply the following rule: we calculate the amount of euros that a student should be compensated using as a benchmark an average speed of $16 \mathrm{~km} / \mathrm{hour}$, and an hourly compensation of 2.7 Euros per hour implied by the minimum wage regulations in the Netherlands. Then, the number obtained is multiplied by two, assuming the student is compensated for the whole commuting costs of attending school (i.e. the round trip).

Hence, following Nevo (2000) and Train (2009), the compensated variation (in Km.) per student $i$ is given by:

$$
C V_{i}=\frac{\ln \left[\sum_{j=0}^{\breve{J_{t}}} \exp \left(\breve{V_{i j t}}\right)\right]-\ln \left[\sum_{j=0}^{J_{t}} \exp \left(V_{i j t}\right)\right]}{-\beta^{m}}
$$


where $\left(\check{V}_{i t}\right)$ denotes the utility perceived for alternative $j$ in market $t$ under the shutdown policy, and $\left(V_{i j t}\right)$ is the utility level enjoyed under the original choice set. Table 2.13 presents this set of results. Both tracks are socially valuable since their absence implies a positive CV for all students. On average, students attending the high track have to commute an additional kilometer to attend education if such option is no longer available. If society is willing to compensate students using as a benchmark the welfare loss of the worst-off student, our estimates imply that each student should be compensated by roughly 1 Euro per day attended at school. We find similar results for the low track, implying a social value of 0.76 euros per student/day at school. As observed, our policy experiment reflects that not only parents with better educational attainments value more pre-university options, but also that society place more value on those programs.

Table 2.13: Individual Compensated Valuation for the Absence of one Academic Track

\begin{tabular}{lccc}
\hline \hline & Mean & Max & Min \\
\hline No High Track & & & \\
Km & 0.9447 & 2.796 & 0.2113 \\
Euros & 0.3212 & 0.9505 & 0.0718 \\
\hline No Low Track & & & \\
Km & 0.7288 & 2.259 & 0.0367 \\
Euros & 0.2478 & 0.7684 & 0.0125 \\
\hline
\end{tabular}

Notes: This table report the compensated variation per student if a particular track is not longer available in the pupil's original choice set. This compensation is measured per day attended at school. In the computation was assummed a minimum hourly wage of 2.70 Euros, and a average speed of $16 \mathrm{~km} / \mathrm{hour}$.

\subsection{Concluding Remarks}

In this chapter, we have estimated a demand model to consistently recover parental preferences for academic options under an early tracking education system. The methodology implemented here allows us to identify potential educational sorting incentives mediated not only by previous academic performance, but by parental socio-economic background. Our results suggest that, conditional on students' performance, children from lower educated households tend to face small probabilities of enrollment into the tracks that have better economic prospects. Moreover, pupils with highly educated parents are willing to face larger costs (in terms to commuting) to attend academic offers that are more selective and exclusive, or to avoid programs deemed less attractive. We also present evidence on how recovering preferences is not a trivial task, by showing how OLS hedonic travel models, or traditional discrete choice demand models, neglect any educational sorting explained by non-academic determinants. Finally, our welfare analysis evidence that the educational sorting of pupils with highly educated parents is directed towards those options that society values the most. All these findings combined, show that inequalities on educational opportunities can arise, even in those cases where schooling systems are fairly designed, with almost no restrictions to choice in place. 
The findings from this study motivate interesting policy implications. First, it establishes the ground to design interventions aimed to reduce the existing enrollment gap between children of comparable ability but different socio-economic background. While student-based programs may offer short term benefits in terms of school enrollment and completion (e.g. Rodriguez-Planas, 2012), our research advocates for a more comprehensive approach that includes parents and schools alike. Given the moderate success of interventions aimed to provide information and create awareness about school quality (Hastings and Weinstein (2008)), an alternative is to apply such programs on the specific subset of households from lower educational backgrounds whose children's academic performance is at the top of the ability distribution. Second, schools should discourage the track misallocation, by giving more weight to objective performance measurements that are less likely to be precisely manipulated by parents with high socio-economic status. Finally, as our welfare analysis suggests, the education system should encourage (discourage) upward (downward) track mobility.

Our results are subject to the identification assumptions we have made. In particular, the source of endogeneity we have assumed is not individually driven. Only unobserved cofactors at the school-track level are relevant to explain the variation on preferences for commuting. While we decided to avoid any ad-hoc assumptions about how students' unobserved variables distribute, we cannot ignore the fact that our estimates are not robust to such source of unobserved heterogeneity. To our best, we consider this decision as optimal since there is not a clear transmission channel where this unobserved variation, if it exists, affects the substitution patterns reflected in the data. In addition, while recovering mean utility values, we can guarantee that these substitution patterns are identified for the particular set of interactions we included in the individual choice model. Designing and implementing an empirical strategy that accounts for both, observed and unobserved variation, and how these affect final schooling decisions, is an area of future research.

It is also important to remind that this is a demand-driven analysis. While unlikely, it is plausible that some schools engage in strategic behavior to discourage students from specific socio-economic backgrounds to pursue further studies into the higher track. In our model we assumed that this discriminatory behavior, if it exists, it is internalized by the household, modifying their willingness to travel for a particular school-track. We consider as a mandatory extension of this study the inclusion of the supply side of the educational relationship, to understand the incentives at the school level, that will in turn shape the design of policies aimed to promote social mobility through education. Overall, this study brings some light to understand the extent to which parental valuations of schooling attributes shape their children's future outcomes. Incentives to engage in suboptimal schooling decisions arise in a free school-choice system and they should determine the creation of policy instruments that improve intergenerational mobility and promote equity on the access to economic opportunities. 


\subsection{Appendix: Tables and Figures}

Table A.1.1: Aggregated Market Shares

\begin{tabular}{|c|c|c|c|c|}
\hline \multirow{3}{*}{ Municipality } & \multicolumn{2}{|c|}{ Low Educated Parents } & \multicolumn{2}{|c|}{ High Educated Parents } \\
\hline & Low & High & Low & High \\
\hline & Track & Track & Track & Track \\
\hline 1 & 0.223 & 0.233 & 0.190 & 0.517 \\
\hline 2 & 0.237 & 0.090 & 0.327 & 0.346 \\
\hline 3 & 0.081 & 0.189 & 0.154 & 0.577 \\
\hline 4 & 0.248 & 0.215 & 0.339 & 0.459 \\
\hline 5 & 0.253 & 0.253 & 0.167 & 0.667 \\
\hline 6 & 0.240 & 0.143 & 0.273 & 0.453 \\
\hline 7 & 0.267 & 0.184 & 0.368 & 0.355 \\
\hline 8 & 0.291 & 0.189 & 0.228 & 0.402 \\
\hline 9 & 0.313 & 0.250 & 0.071 & 0.786 \\
\hline 10 & 0.284 & 0.203 & 0.307 & 0.511 \\
\hline 11 & 0.210 & 0.250 & 0.293 & 0.488 \\
\hline 12 & 0.210 & 0.200 & 0.216 & 0.588 \\
\hline 13 & 0.190 & 0.167 & 0.290 & 0.290 \\
\hline 14 & 0.257 & 0.286 & 0.292 & 0.479 \\
\hline 15 & 0.212 & 0.192 & 0.176 & 0.588 \\
\hline 16 & 0.230 & 0.224 & 0.224 & 0.538 \\
\hline 17 & 0.283 & 0.260 & 0.275 & 0.391 \\
\hline 18 & 0.162 & 0.162 & 0.478 & 0.261 \\
\hline 19 & 0.235 & 0.235 & 0.379 & 0.362 \\
\hline 20 & 0.254 & 0.254 & 0.302 & 0.528 \\
\hline
\end{tabular}

Notes: In this table we report market shares of non-vocational tracks only. The market share of the outside option should be calculated as $1+$ sum of market shares for the high and low tracks. For instance, the market share of the outside option at the market composed by high educated families at municipality one is $1-(0.233+0.223)$. 


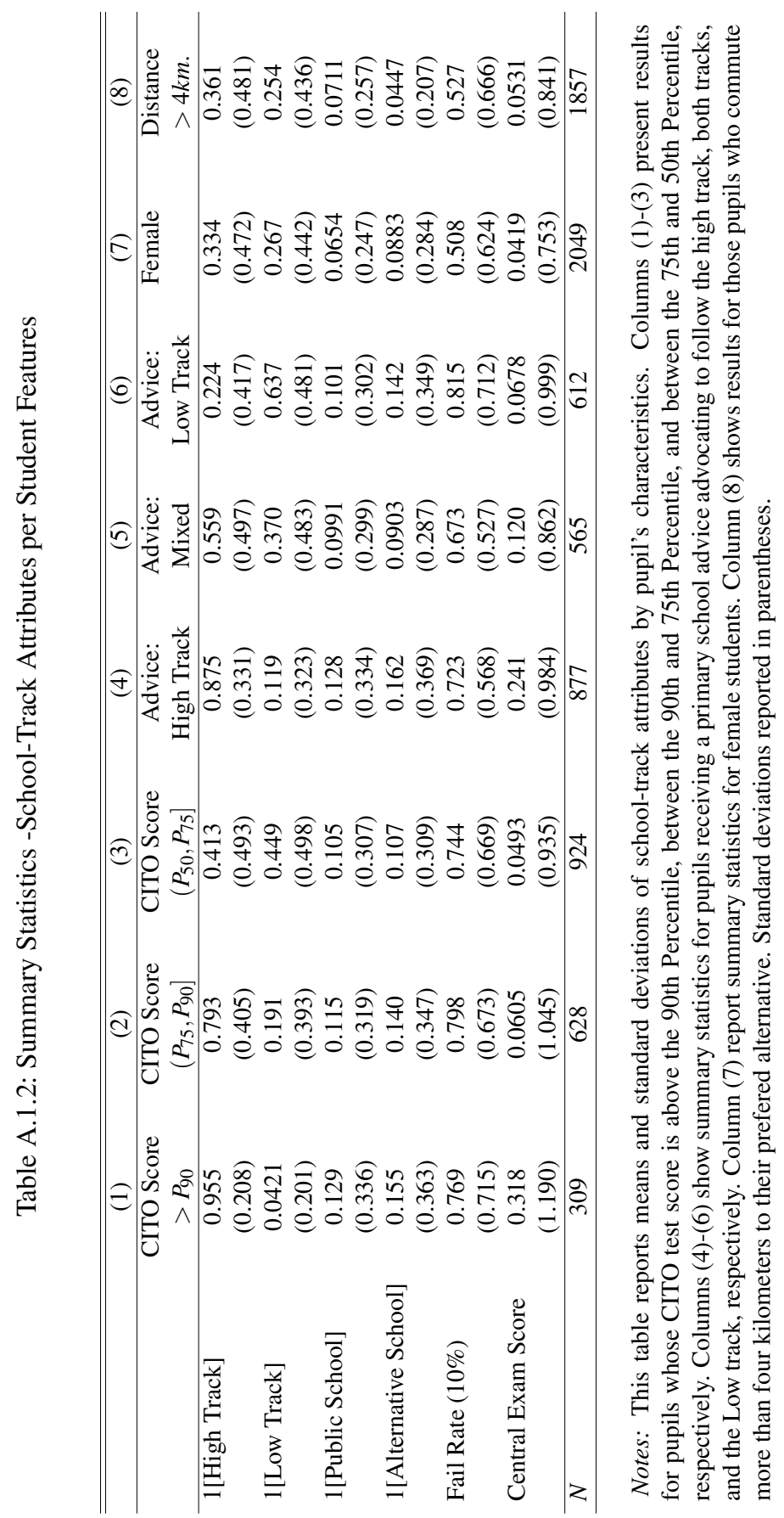





\section{Is Internally Forced Migration Affecting Educational Achievements in Hosting Communities? ${ }^{\dagger}$}

${ }^{\dagger}$ I am grateful to Lex Borghans, Alexander Dicks, Bart Golsteyn, Steffen Künn, Clotilde Mahé, Olivier Marie, and participants at the Learning and Work and the PhD Brown Bag seminars at Maastricht University for their comments and suggestions. 


\subsection{Introduction}

There is a wide consensus about the negative impacts of civil war on the economic well-being of adults and children (Blattman and Miguel, 2010). Regarding educational attainments, recent evidence suggests that human capital accumulation results are hampered by the reduction of expected returns to schooling, household reduced resources, destroyed infrastructure, and the long lasting impacts of physical and psychological violence inflicted to non-combatants (Shemyakina, 2011). While research has privileged the role of targeted violence and its main consequences as the relevant causal channels, very few contributions study the potentially negative effects for those communities not directly involved in the conflict. Focusing on forced migration outcomes, it is of paramount importance to understand their influence on educational attainments at arriving locations. Inevitably, original residents and the displaced population will interact and compete in several markets. Hence, migration flows will play a role in determining the future economic prospects for these groups.

This chapter provides empirical evidence on the causal link between forced migration and educational attainments at arrival municipalities in the context of the Colombian civil conflict. Because changes in forced migration flows are not necessarily random, we exploit the plausibly exogenous variation in internally displaced persons' (IDP) arrivals induced through random shifts in political support at highly competitive local elections. This study starts by developing a theoretical framework to formalize and understand the positive relationship between internally displaced reception and political loyalty, as data available on forced migration suggest that IDP inflows are significantly higher in electoral markets (municipalities) where the political support received by winning candidates is the largest. Secondly, by using a novel dataset on civil conflict outcomes and voting results for (province) Governors' elections, we empirically test and confirm the predictions we obtain from our theoretical model. Finally, we combine school-level administrative data from the mandatory high-school exit exam (SABER11) to estimate the causal effect of IDP inflows on schools' math and language test scores during the first two years of incumbency.

Our theoretical model begins by claiming that illegal armed groups are mostly concerned with establishing alliances with local political elites to maximize the extraction of rents. The extent to which they can induce voters to support their preferred candidates depends on whether intimidation, followed by targeted violence, is a cost-effective strategy to consolidate power. As the risk of intimidation faced by civilians is not uniformly distributed across electoral markets, different economic incentives influence them to i) grant their political loyalty without reserves or, ii) forcefully displace because of supporting an alternative candidate. As a result, the main prediction of our model is that IDP inflows are always higher in those areas where voters were politically loyal towards the incumbent candidate. Because illegal armed groups have less incentives to intimidate and exert violence at loyal municipalities, IDP rationally decide to leave those areas where their non-cooperative behavior is easily identified, to arrive and settle in politically loyal locations. 
We continue our study by estimating the causal effect of political loyalty on internally forced migration during the first two years of incumbency. In this setting, the margin of political loyalty is measured as the vote share spread between the winning candidate and the second most popular alternative. Thus, an electoral market is considered disloyal if it presents a strictly negative margin. Since variation in political support across municipalities is plausibly endogenous, we implement a regression-discontinuity (RD) design. Our analysis is focused at close elections where, because of increased competition, differences in vote shares between candidates are minimal and observed political loyalty is likely to be determined by chance. Our identification assumption relies on the fact that other attributes at the municipal level, that may influence future IDP inflows, do not discontinuously change because of shifts in political support. Furthermore, we provide evidence that there is no manipulation of the running variable across the margin's cutoff value of zero as candidates failed to precisely manipulate voting outcomes at local elections. These two reasons combined, allow us to exclusively attribute the impact on IDP inflows to variations in political loyalty at close elections.

We next quantify the impacts of internally forced migration on educational outcomes realized at the end of secondary education. By combining both municipal data on electoral outcomes and high-school exit exam results at the school level, we estimate a fuzzy RD model to identify the effects of IDP inflows on math and language test scores during the first two years after elections. As in any instrumental variables (IV) design, political loyalty needs to satisfy the relevance and exclusion requirements. The former implies that political loyalty should largely predict the changes in IDP inflows at arrival municipalities. The latter requirement states that internal displacement is the unique channel by which political loyalty can affect tests scores. This exclusion restriction implicitly assumes that candidates concerned with attracting voters' support presumably give the same relevance to better educational outcomes in their political agenda. From the voters' perspective, we expect their preferences for educational outcomes to be relatively similar at municipalities where elections are highly contested. Both assumptions imply that the observed differences in political support are driven neither by candidates drastically weighting educational policies above other policy objectives, nor voters abruptly modifying their preferences for educational outcomes at election years. We implement RD discontinuity tests for baseline covariates around the margin cutoff of zero to provide evidence that, to the best of our knowledge, the exclusion restriction holds.

Regarding the impacts of political loyalty on forced migration our estimations indicate a sizable increase in internally displaced arrivals on the order of thirteen IDP per 10,000 inhabitants, equivalent to a 0.48 standard deviations (SD) effect. We repeat our estimations by using the stock of IDP settled in each municipality as the main dependent variable, to find that politically loyal areas received 53 IDP more than comparable locations deemed disloyal, representing a 0.54 SD change in long-term IDP reception. In contrast, political loyalty seems to not influence IDP outflows, as all RD coefficients are statistically not different from zero. All these findings combined support the predictions from our theoretical model in the sense that political loyalty has a positive effect on IDP reception. 
We also test potential mechanisms by which there are more internally displaced arrivals in politically loyal communities. Regarding elections' characteristics, we obtain evidence suggesting "political sorting" as IDP reception seems to increase when the incumbent candidate belongs to a non-traditional party. Moreover, we observe IDP reception to be stronger in those election years where the Governor term was extended an additional year (from three to four years), amplifying the incentives to consolidate political support. In contrast, neither increased competition, measured by the number of candidates running for a seat, nor vertical integration between candidates running for the Mayor and Governor seats have a role in justifying the increased IDP reception at loyal areas. Considering civil conflict related violence as an alternative mechanism, we show that internally forced arrivals tend to be lower at those locations where victimization in the form of selective killings and massacres increased at election years. Contrarily, neither landmines victimization nor exposure to terrorist bombings appear to be relevant mechanisms explaining the observed contrasts in IDP arrival rates. Lastly, we examine whether variation in public finance's capacity among loyal municipalities explain the differences in IDP reception. In general, we show that a large fiscal autonomy is positively correlated with IDP arrivals since revenues transferred from the central government are negatively correlated. In addition, neither local revenues nor expenditures seem to be powerful predictors of forced migration inflows. In general, the enhanced political participation in the form of non-traditional parties contesting elections, a reduction in civil-conflict related violence, and an increased fiscal autonomy appear to be the factors that trigger displacement into politically loyal communities.

Focusing on the influence of IDP reception on test scores, our RD estimates suggest a causal effect of at least 3\% of a standard deviation per additional IDP arrival, in both academic subjects during the first two years of incumbency. These impacts are sizable as they represent an average effect of 0.4 SD. Examining these effects in the students' test performance distribution, all pupils are negatively affected by the increased IDP reception. Nonetheless, top performing students are harmed the most as they obtain significantly lower scores than students with comparable within-school performance at disloyal municipalities. These negative effects are predominantly evident in stem subjects, as math scores dropped on average by $0.3 \mathrm{SD}$.

We also explore how differences in schools' characteristics influence the decrease in tests scores we document. Two mechanisms are offered: First, we assess whether the different daily working spells schools operate influence the variation in test scores at loyal municipalities. Second, we test whether variation in pupils' gender composition at school induces changes in test scores across stem and non-stem subjects. Results from this exercise advocate for a full day working spell implementation, as schools operating in a half-day working spell (morning or afternoon) are largely exposed to the negative IDP reception effects. Regarding the gender composition of students, we show that schools with a more balanced gender distribution seem to be unaffected by the IDP influx, while schools with a large gender concentration are negatively affected. However, the drop in tests scores seems to be systematically larger for those schools with a large proportion of males, relative to schools with a higher female participation. 
This chapter is closely related to other contributions aimed to quantify the effect of migrant reception on educational outcomes of students at hosting communities. The literature on this subject is limited and it is established on the ground that variation in migrant composition across grades, schools, and/or countries is exogenous. Findings are also mixed, documenting negative impacts on school and residential segregation (Betts and Fairlie, 2003; Cascio and Lewis, 2012), matriculation rates (Gould et al., 2009), and test scores (Jensen and Rasmussen, 2011; Brunello and Rocco, 2013; Schneeweis, 2015). Other studies also present zero or even positive effects, partly explained when researchers control for negative selection of native students or suboptimal learning environments (Geay et al., 2013; Ohinata and Van Ours, 2013). A notable exception in this branch of the literature is the recent study by Figlio and Ozek (2017), which assesses the influence of a large refugee influx on natives' educational outcomes by exploiting the exogenous variation on forced migration attributed to the Haiti 2010 earthquake. In their paper, the authors find no effects on test scores, occurrence of disciplinary incidents, and school mobility. Our study shares their motivation of focusing on forced migration inflows as the main population shocks to analyze. Nevertheless, we differentiate our contribution from theirs by addressing common limitations of this body of literature, such as the existing language and cultural barriers between immigrants and natives. Our study focuses on internal displacement flows within a country that is linguistically and culturally homogeneous. Moreover, we depart from the use of classic instruments from the economics of migration literature (e.g. Card, 2001), proposing an alternative approach which relies on electoral outcomes as a tool to identify the effects of interest.

This study also contributes to a significant field of the literature that seeks to identify the microeconomic effects of violent conflicts on educational attainments (see for instance Alderman et al. 2006; Akresh and De Walque 2008; Swee 2009; Blattman and Annan 2010; Chamarbagwala and Morán 2011; De Groot and Goksel 2011; Justino et al. 2011; Leon 2012; Rodriguez and Sanchez 2012; Shemyakina 2011; Valente 2013; Kibris 2015; Akbulut-Yuksel 2014). While the magnitude and the persistence of these impacts might differ because of the characteristics of each conflict, the educational outcomes considered, the pre-war students' set of cognitive and non-cognitive skills, and other demographics such as age and gender, there is a wide consensus about the detrimental effects of violence on school enrollment, school attendance, and grade completion. However, there is a shortage of studies about the potential effect of civil conflict's collateral damage on educational attainments at those communities where violence is not directly inflicted. By considering IDP inflows as the civil conflict variable of interest, this research shares the motivation that lead other authors to account for negative health outcomes induced by refugees' reception (Montalvo and Reynal-Querol, 2007), and the impact of IDP inflows on labor market participation and wages at receiving locations (Calderón-Mejía and Ibáñez, 2016).

This chapter is organized as follows. Section 2 presents a brief overview of the Colombian civil conflict and the reasons why Governors' elections provide a good opportunity to estimate the effects of interest. Section 3 describes the theoretical model in detail. Section 4 describes our sources of information, final datasets, and main treatment and outcome variables. We continue in Section 5 by discussing the empirical strategy and identification assumptions we use in this study. Section 6 presents our results. Finally, Section 7 concludes. 


\subsection{Background Information}

\subsubsection{Internal Refugees in the Colombian Civil Conflict}

From the late 1950s, Colombia has experienced one of the most enduring, harmful internal conflicts around the globe. While the origin of this civil conflict is explained by the bipartisan earlier rivalry between the two traditional, liberal and conservative political parties, the modern Colombian conflict has its roots in struggles for land rights and ownership, political participation and exclusion, as well as the incentives of armed groups to consolidate illegal extraction of rents. The intensity of this conflict is currently fostered by the weak institutions susceptible to be regulatory-captured, the decentralization of local politics and public revenues that induce criminal alliances between public servants, local elites, and non-state armed groups, and the large profits obtained from illegal economic activities, drug trafficking being the most predominant.

While the Colombian state forces (Army and Police) and the two large left-wing guerrillas, the Colombian Revolutionary Armed Forces (FARC) and National Liberation Army (ELN), were the main actors of conflict, in the late 1980s several atomized extreme right-wing paramilitary groups emerged as a response from drug cartels and local elites, to self-defend against threats of extortion and kidnapping from insurgents. In addition, these non-state armed groups tried to influence regulation offering resistance to initiatives (from the central government or from civil organizations) aimed to increase political competition, implement redistributive agrarian reforms, sign extradition agreements with the U.S. government, and seek peace dialogues with left-wing guerrillas. In the year 1997, paramilitary groups formed a nationally coordinated coalition known as the United Self-Defense Groups of Colombia (AUC). From 1998 to 2002 paramilitaries expanded, enhancing their power and effectiveness in military operations, and becoming largely responsible for the escalation of violence, in the form of massacres and selective killings, against civilians. With the arrival of candidate Alvaro Uribe Velez as President in 2002, a defacto amnesty to members of the AUC coalition was offered. Consequently, the intensity of the internal conflict significantly declined, returning to pre-AUC formation levels (GMH, 2013).

Civilians have been, by far, the most affected by the civil conflict. More than 220.000 people have been killed between 1958 and 2012, with $81 \%$ being non-combatants (GMH, 2013). Regarding internal displacement, the intensification of the political violence and its expansion to the vast majority of Colombian municipalities implied that roughly 4.5 million of civilians, equivalent to $10 \%$ of the total population in 2009, have been forced to leave their homes and property to reach safety (Ibáñez and Vélez, 2008). The large majority of internal refugees are vulnerable population below the poverty line, women, with low educational attainments, and with large costs of integration into hosting communities in terms of labor market participation (Garay, 2008). While many households forcefully migrated as a response of being direct victims of selective killings, kidnapping, sexual abuse, and forced recruitment, the large majority moved from their original place of residence because of political intimidation, as well 
as to avoid the likelihood of being victimized in the future; a feature prominent in other civil conflicts worldwide (Moore and Shellman, 2004; Balcells, 2010; Steele, 2011). ${ }^{1}$

Figure 3.1 displays yearly average IDP flows per 10,000 inhabitants. Panel (a) presents the number of expelled IDP while Panel (b) shows the number of IDP arrivals. The dashed line represents the year (2002) that the AUC started contacts with the government to negotiate their legal situation, the same year in which IDP expulsions reach their peak of 187 civilians per 10,000 inhabitants. From that year onwards, there is a clear downward (upward) trend in the number of IDP expelled (received) per municipality, partly attributed to the dismantling of paramilitary forces that are considered to be one of the main push factors in origin areas. Another aspect to highlight from these trends is the lack of oneto-one correspondence between IDP inflows and outflows. This is partially explained by the victims' tendency to underreport their displacement status, and the fact that some households have been forcefully displaced more than once. While there may be some measurement error, we expect this measurement error to be equally distributed across municipalities with highly contested elections.

The variation in IDP flows is not unconditionally, randomly distributed across municipalities. To provide evidence of this, in Figure 3.2 we map the average number of civilians expelled and received during period 1993-2013. Panels (a) and (b) present the average of IDP during the first ten years. Panels (c) and (d) display the same maps but for period 2003-2013. As observed, two patterns emerge from mapping these displacement flows. First, while the number of IDP expelled has decreased, the number of IDP arrivals has almost doubled. Second, the variation on displacement rates is very localized, being the southern, the northwest, and the pacific regions the most affected by the largest forced migration movements. These facts suggest that, as our research advocates, it is necessary to implement an alternative empirical strategy, rather than exploiting variations in location and time, to identify the effects of interest.

\footnotetext{
${ }^{1}$ From an international perspective, in 2008 the Internal Displacement Monitoring Center estimated a total worldwide internal population displacement of 24.5 million people, with Colombia representing 14.3 percent of that total, and ranking second only to Sudan (Ibáñez, 2009).
} 
Figure 3.1: IDP flows by 10,000 Inhabitants

(a) IDP Expelled

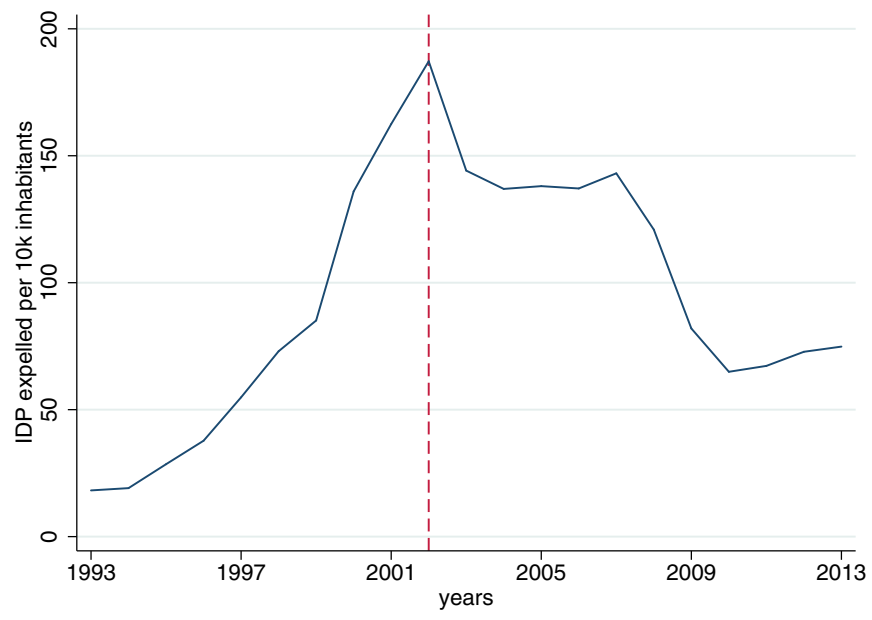

(b) IDP Received

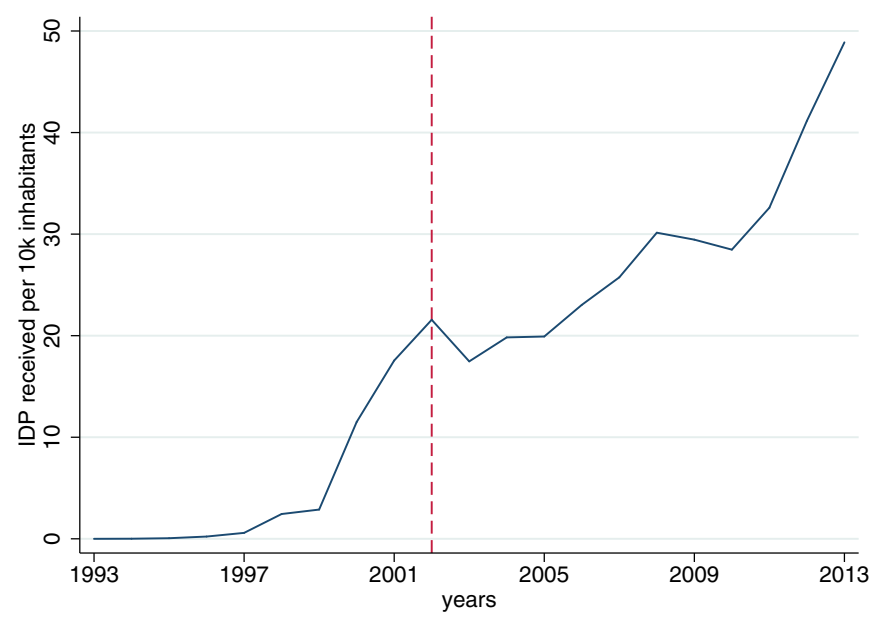

Source: Victims' Special Unit for Assistance and Reparation (RUV). Panel (a) shows IDP outflows per 10,000 inhabitants. Panel (b) displays IDP inflows. The red dashed line corresponds to year 2002, where the government in turn offered an amnesty to paramilitary groups conforming the AUC coalition. 
Figure 3.2: Internal Refugees Flows in Colombia (1993-2012)

(a) Civilians Expelled (1993-2002)

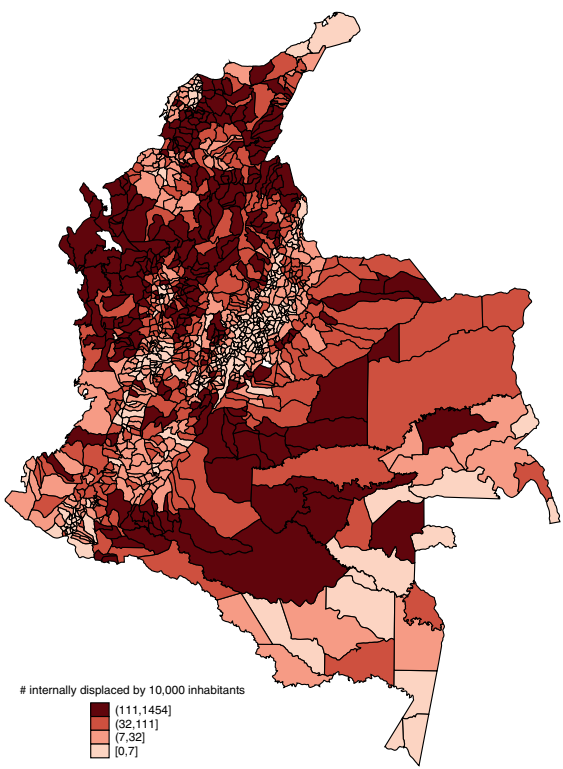

(c) Civilians Expelled (2003-2012)

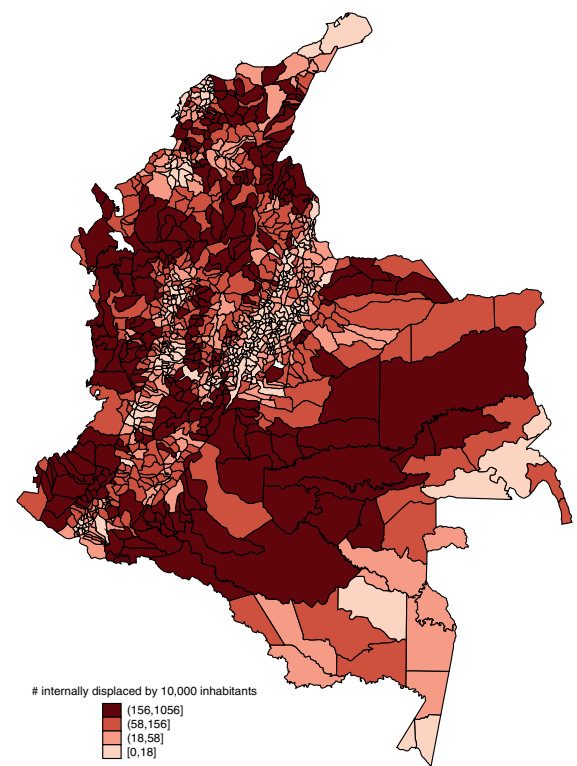

(b) Civilians Received (1993-2002)

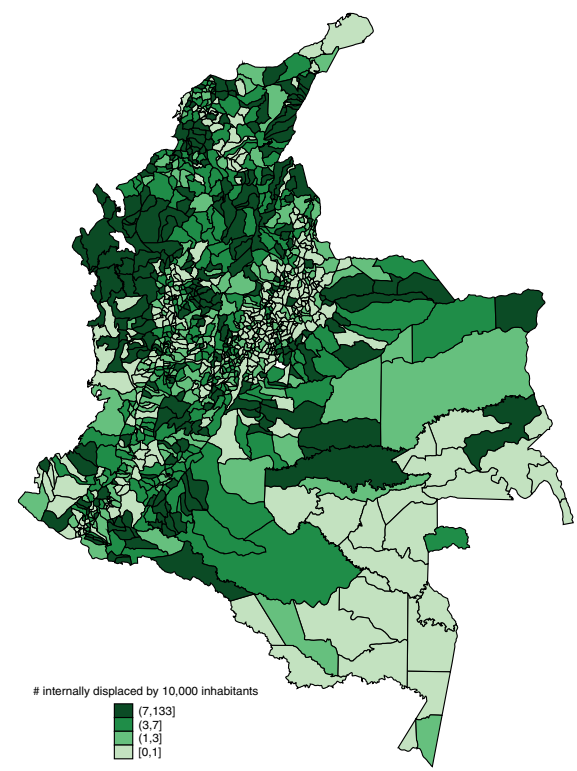

(d) Civilians Received (2003-2012)

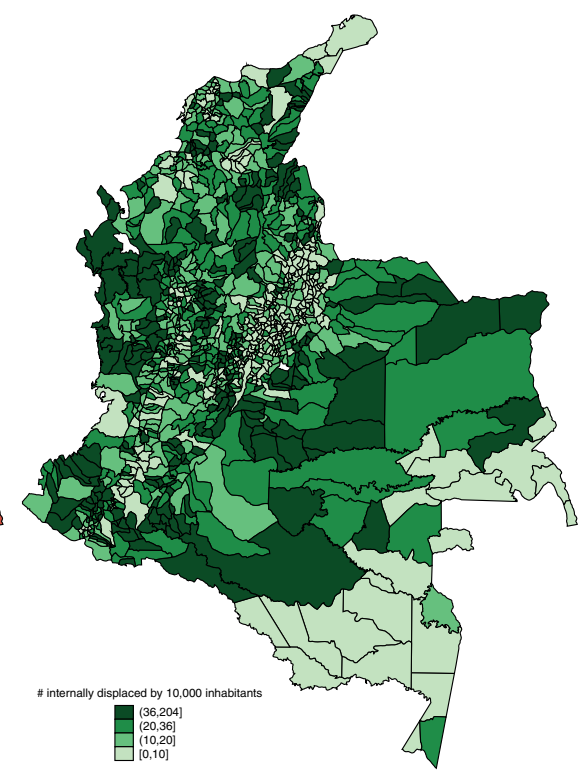

Notes: This figure displays the average IDP flows in a 10-year period. Panels (a) and (b) show average number of IDP expelled and received at each municipality during period 1993-2002, respectively. Panels (c) and (d) present the number of IDP expelled and received per municipality during period 2003-2012, respectively. White areas denote municipalities where no elections for Governor are held (e.g. Bogota D.C.) or municipalities which election data were not available. Source: Victims' Special Unit for Assistance and Reparation (RUV). 


\subsubsection{The Political System in Colombia}

The 1991 constitution formalizes the popular elections of municipal Mayors and province Governors who, under the previous constitution of 1886 , were appointed de-facto by the President. Until election year 2000 they served a three year term with no possibility of re-election. From 2003 onwards, the term was expanded to four years. Colombia is divided in 32 provinces (departments), containing roughly 1100 municipalities. Mayors and Governors are elected from a local constituency. Mayors win a seat as long as they obtain the majority vote at the municipality where they are contesting the election. Candidates for the Governor's seat are elected if they obtain the majority vote at the province level. Congressmen are also elected from a local constituency, with each candidate running in one out of 32 electoral provinces. In contrast, Senators are elected if they obtain at least $2 \%$ of the total votes countrywide.

There is evidence that voting results were manipulated by illegal armed groups. Non-state armed groups captured specific areas, influencing voters to grant their political support when the majority vote at the municipal level was required to win the incumbency, or when it was required to reach a minimum vote margin to obtain a seat in Congress. In contrast, we argue that manipulation was less precise in the case of Governors' elections. Influencing turnout in some municipalities is not enough to manipulate precisely electoral outcomes since incumbency is granted as long as the majority vote is obtained at the province level. Precise manipulation will imply that illegal armed groups controlled elections in all municipalities within a province; a result that might have triggered intervention of national authorities. Moreover, we focus our study on those municipalities where such manipulation, if existent, failed its primary objective as alternative and incumbent candidates received comparable political support. Later on, by examining the properties of the vote share's distribution between the winner and the second best candidate, we will provide empirical evidence encouraging the use of discontinuities in Governors' electoral outcomes as an instrumental variable.

\subsection{A Model of Political Loyalty and Internal Displacement}

At least two competing theories about the relationship between forced migration and political loyalty exist. The first theory suggests that illegal armed actors have a strong preference to govern compliant civilians within a territory. Provided that civil cooperation is highly malleable under the threat of violence, political loyalty and internally forced migration may not necessarily be correlated (Kalyvas, 2006). An alternative theory suggests that political loyalty is not easily modified. Once the political support of a community is clearly identified by past electoral outcomes, illegal armed groups have greater incentives to threaten civilians, forcing them to leave. This strategy is set as a dissuasive measure to punish defiant behavior, and to ensure higher levels of cooperation in the future. As a result, political loyalty should be positively correlated with internal displacement inflows, in a sense that civilians leave their (perceived disloyal) territories of origin, to more loyal areas where armed actors have less incentives to intimidate and enforce cooperation (Steele, 2011). 
In the context of the Colombian civil conflict, strong evidence supports the idea that during the paramilitary expansion, the AUC coalition not only made alliances with local political elites, but also implemented other strategies to affect elections at the local and national levels. Alliances with politicians took form in a series of meetings, where paramilitaries and prospective candidates signed secret agreements to foster future cooperation. In addition, many new political parties emerged as a response of the AUC to be represented in regions where their interests were at stake. Hence, the AUC coordinated actions focused on obtaining a large vote share for their preferred candidates and parties. These strategies mostly included: i) intimidating voters by forcing them to migrate from their municipalities of origin, ii) forcing voters to support the candidates sponsored by the AUC coalition, and iii) impairing other politicians to run elections against their preferred candidates, either by intimidation or by the use of targeted violence (Acemoglu et al., 2013). After successful criminal investigations to unveil these alliances between paramilitaries and politicians, almost one third of all legislators in 2012 were prosecuted (senate and congress), and at least sixteen former province Governors have been investigated because of allegedly supporting, by action or omission, criminal behavior from non-state armed groups. ${ }^{2}$

In order to account for these features of the Colombian civil conflict, in this section we propose a framework to formalize the relationship between political loyalty and internal displacement, modifying a theoretical framework initially proposed to explain the role of racial negative stereotypes and crime occurrence, as discussed in O'Flaherty and Sethi (2008). These authors build an economic model to explain the disparities of offense and victimization rates between different racial groups in the U.S. On the one hand, offenders inferring the victims' propensity to resist a robbery attempt will decide whether the crime should be executed, and to use violence if the victim's compliance needs to be enforced. On the other hand, potential victims should decide if resisting a criminal attempt is worthwhile, using the perpetrator's race as a way to infer the likelihood of a violent interaction after offering resistance.

We propose a modification of their model to explain differences in internally forced migration rates and political loyalty among municipalities with civilians and terrorists exhibiting heterogeneous preferences for intimidation and violence. The main prediction of our model is that communities considered disloyal will suffer more political intimidation and will be forced to move more often, with people fleeing to municipalities considered loyal as a strategy to avoid violent retaliation. Thus, IDP inflows will be higher in politically loyal areas. Moreover, this positive correlation remains robust, either when the probability of civil support is not uniformly distributed across municipalities, or when terrorists' incentives to implement intimidation and violence change across different electoral markets.

\footnotetext{
${ }^{2}$ Left-wing guerrillas did not influence elections by cooperating with local elites with the same intensity as paramilitary groups. Instead, their strategy to consolidate power involved massive attempts to boycott local elections using terrorist attacks and bombings (GMH, 2013).
} 


\subsubsection{Preliminaries}

Assume that a particular country is divided in two regions, labeled $A$ and $B$, populated by citizens and terrorists. We assume that both parties have incomplete information about the preferences and economic characteristics of the counterpart. Players are characterized by their types. Thus, each of the players' types is drawn from a set of types $\Theta=[\underline{\theta}, \bar{\theta}]$, such that $\theta$ summarizes all preferences for outcomes derived from political loyalty and intimidation. ${ }^{3}$ Let $\theta_{c}$ and $\theta_{t}$ denote the types for the citizen and the terrorist, respectively.

The interaction process between a citizen and a terrorist in each region can be described with a game of incomplete information as follows:

1. In the first stage the citizen decides to be loyal (cooperate) or disloyal (not cooperate) to a political party that, by assumption, has made an alliance with the terrorist in order to consolidate power. If the citizen cooperates, no further interaction is made and the terrorist extracts the largest rents possible, denoted by $X>0$, while the citizen obtains a payoff of zero.

2. Conditional on observing non-cooperation, the terrorist decides whether to intimidate the citizen or not. If there is no threat, the interaction ends, with the citizen and the terrorist receiving a payoff of $r\left(\theta_{c}\right)$ and zero, respectively.

3. If the terrorist decides to threaten the citizen, the latter should decide whether to leave or to stay. If the citizen migrates upon intimidation, the payoffs are $-z\left(\theta_{c}\right)$ for the citizen and $x\left(\theta_{t}\right)$ for the terrorist. If the citizen decides to stay, the terrorist will use targeted violence to punish previous non-compliance with probability one, so payoffs will be $-h\left(\theta_{c}\right)$ and $-w\left(\theta_{t}\right)$ for the citizen and the terrorist, respectively.

As the payoff structure above suggests, citizens favor a situation where non-cooperation is followed by no intimidation, and terrorist prefer full-compliance, followed by compliance upon intimidation, than using targeted violence as a last resort. Violent interaction is the least preferred option for both players.

While both parties have incomplete information about preferences for political loyalty and intimidation, it is commonly known how the types of both groups are distributed. Thus, let $G_{i}(\theta)$ and $F_{i}(\theta)$ for $i=\{A, B\}$ denote the cumulative distribution functions at region $i$, for citizens and terrorists, respectively. The respective density functions are denoted by lower case letters. We also assume that functional forms $r, z, x, h$ and $w$ are identical for both regions, continuous, and differentiable in $\theta$. These functions, along with the cumulative density functions aforementioned, define a Bayesian game in extensive form. We

\footnotetext{
${ }^{3}$ Each agent's type $\theta$ can be alternatively interpreted as a latent variable that is a function of wealth, education, socio-economic status, and other psychological variables that decrease (increase) the terrorist's (citizen's) willingness to intimidate (not cooperate). Thus, lower types can be considered as "worse" types.
} 
are now focused to understand the extent to which cooperation, intimidation, and forced migration rates change across regions $A$ and $B$.

\subsubsection{Equilibrium}

Using a backward induction analysis, we first describe the behavioral assumptions and deduce the optimal decision rule for terrorists within a particular region. Next, we perform the same analysis for citizens. Finally, we define the equilibrium.

\subsubsection{The Terrorist's Optimal Intimidation Rule}

To understand the optimal decision rule for terrorists, we first need to impose some behavioral assumptions:

Assumption 1 (intimidation and violence by the worst types):

$$
x(\underline{\theta})>w(\underline{\theta})>0 \text { and } w(\bar{\theta})>x(\bar{\theta})>0 .
$$

Assumption 2 (marginal decreasing returns for intimidation):

$$
\text { For all } \theta \in \Theta, w^{\prime}(\theta)>0>x^{\prime}(\theta) \text {. }
$$

Assumption 3 (full cooperation is always preferred):

$$
\text { For all } \theta \in \Theta, X>x(\theta) \text {. }
$$

Assumption 1 states that terrorists with the lowest (worst) type will strictly prefer to intimidate and exert violence, even if no civilian decides to leave. On the contrary, the better (higher) the terrorist's type, the larger the costs of threatening civilians, as subsequent violence is more costly. Therefore, the best types prefer not to coerce citizens if the latter prefer to stay. Assumption 2 specifies that the benefits (costs) of intimidation are marginally decreasing (increasing) in $\theta$. Assumptions 1-2 together imply that $x(\theta)>0$ and $w(\theta)>0$ for all $\theta \in \Theta$, so the benefits and costs of intimidation are always positive 
for all terrorists' types. Finally, Assumption 3 claims that initial cooperation is always preferred over intimidation followed by forced displacement.

Now consider a terrorist drawn from region $i$, facing a citizen from the same region with type $\theta$, who has a probability $\gamma_{i j}$ to forcefully migrate to region $j$ (with $i \neq j$ ) if a threat is received. Then, the terrorist will intimidate the civilian as long as the net benefits from such strategy are strictly positive:

$$
\gamma_{i j} x(\theta)-\left(1-\gamma_{i j}\right) w(\theta)>0
$$

An alternative interpretation of inequality (3.1) is the maximum intimidation threshold $\tilde{\theta}\left(\gamma_{i j}\right)$, where terrorists with types below it will intimidate, and terrorists above such threshold will do otherwise:

$$
\theta<\tilde{\theta}\left(\gamma_{i j}\right) \equiv \rho^{-1}\left(\gamma_{i j}\right)
$$

with $\rho(\theta) \equiv w(\theta) /(x(\theta)+w(\theta))$. Assumptions 1-2 together imply that $\rho(\theta)$ is increasing in $\theta$. Therefore, by the inverse function theorem, $\tilde{\theta}\left(\gamma_{i j}\right)$ is increasing in the probability of forced migration $\gamma_{i j}$. Then, the rate of intimidation for region $i$, as a function of the displacement rate $\gamma_{i j}$, is defined as follows:

$$
\mu_{i}\left(\gamma_{i j}\right)=F_{i}\left(\tilde{\theta}\left(\gamma_{i j}\right)\right)
$$

In general, the above condition states that the lower the propensity of citizens to displace, the lower the proportion of terrorists that will intimidate citizens from region $i$ if non-compliance is observed. Hence, if civilians suffering intimidation will forcefully migrate with certainty, all terrorists will decide to intimidate. On the contrary, if no civilian is willing to leave their region of residence upon being threatened, no terrorist will use intimidation in the first place. A natural implication of condition (3.2) is that intimidation is most likely to be implemented by terrorists with low types.

\subsubsection{The Citizen's Optimal Decision Rule}

We now state the behavioral assumptions for citizens facing the threat of intimidation:

Assumption 4 (high types are more likely to cooperate):

$$
r(\underline{\theta})>z(\underline{\theta})>h(\underline{\theta})>0 \text { and } h(\bar{\theta})>z(\bar{\theta})>r(\bar{\theta})>0 .
$$


Assumption 5 (marginally decreasing returns from defiant behavior by higher types):

For all $\theta \in \Theta, h^{\prime}(\theta)>z^{\prime}(\theta)>0>r^{\prime}(\theta)$.

Assumption 4 claims that citizens with the lowest types will mostly benefit from non-cooperation followed by the terrorists' lack of retaliation. However, in the case of intimidation, these types will suffer targeted violence as the costs of forced migration prohibit these citizens to leave and reach safety in another location. For citizens with the highest types, the benefits of supporting an alternative candidate cannot outweigh the potential costs of forced migration because of terrorist intimidation. Assumption 5 states that costs (benefits) from non-cooperation are monotonically increasing (decreasing) in $\theta$, implying that i) the benefits from defiant behavior decay rapidly the higher the citizen's type, ii) the costs of intimidation are greater the higher the citizen's type, and iii) the cost of retaliatory violence increase more rapidly than the costs of internal displacement. Assumptions 4-5 together imply that i) benefits/costs of non-cooperation for citizens are always positive, ii) citizens with lower types are more likely to support an alternative status quo than citizens with higher types, and iii) conditional to being intimidated by terrorists, citizens with higher types are more likely to forcefully migrate than citizens with lower types.

Now we consider the citizen's optimal decision to non-cooperate with the candidate that is, by construction, allied with terrorists. Suppose that a victim with type $\theta$ from region $i$ expects a probability $\mu_{i}$ to be intimidated if non-compliance is observed. Then, defiant behavior is optimal if its net benefits are strictly positive:

$$
\left(1-\mu_{i}\right) r(\theta)-\mu_{i} \min \{h(\theta), z(\theta)\}>0,
$$

with full cooperation preferred otherwise. Inequality (3.3) can also be interpreted as the threshold $\hat{\theta}\left(\mu_{i}\right)>\underline{\theta}$, where types below it will not cooperate, and citizens with types above it will comply:

$$
\theta<\hat{\theta}\left(\mu_{i}\right) \equiv \lambda^{-1}\left(\mu_{i}\right)
$$

Assumptions 4-5 together, and the fact that $r(\theta)$ is decreasing in $\theta$, imply that:

$$
\lambda(\theta) \equiv r(\theta) /[r(\theta)+\min \{h(\theta), z(\theta)\}]
$$

is decreasing in $\theta$ as well. This implies that the threshold $\hat{\theta}\left(\mu_{i}\right)$ is decreasing in the probability of intimidation $\mu_{i}$. As the probability of suffering intimidation increases, more citizens are willing to cooperate. 
Hence, the proportion $\pi_{i}$ of citizens at region $i$ that will support an alternative candidate is set up by the following expression:

$$
\pi_{i}\left(\mu_{i}\right)=G_{i}\left(\hat{\theta}\left(\mu_{i}\right)\right)
$$

Considering displacement decisions among those citizens who decide not to cooperate, a fraction $\gamma_{i j}$ will forcefully migrate to region $j$ because of suffering intimidation, and a fraction $1-\gamma_{i j}$ will remain and endure targeted violence. Let $\theta_{d} \in(\underline{\theta}, \bar{\theta})$ denote the interior (and unique solution because of Assumptions 4 and 5) to equation $h(\theta)=z(\theta)$. Then, the proportion of forced migrants from region $i$ to region $j$ is set by:

$$
\gamma_{i j}\left(\mu_{i}\right)=\max \left\{1-\frac{G_{i}\left(\theta_{d}\right)}{\pi_{i}\left(\mu_{i}\right)}, 0\right\}
$$

Thus, the fraction of citizens that will displace upon intimidation will be $1-\frac{G_{i}\left(\theta_{d}\right)}{G_{i}\left(\hat{\theta}\left(\mu_{i}\right)\right)}$ if $\theta_{d}<\hat{\theta}$ and 0 otherwise. A feature of this model is the propensity of "middle" types to displace. Namely, if $\theta_{d}<\hat{\theta}$, only citizens with types $\theta_{d}<\theta<\hat{\theta}$ will migrate, while citizens with types $\theta<\theta_{d}$ will remain and suffer targeted violence as a consequence of their defiant behavior. In contrast, if $\theta_{d}>\hat{\theta}$, all citizens who supported a different candidate will remain in region $i$. We will demonstrate next that displacement rates are always positive, and the equilibrium in this model is characterized by an interior solution.

\subsubsection{Equilibrium Definition}

We define an equilibrium as a set of probabilities $\left\{\pi_{i}^{*}, \mu_{i}^{*}, \gamma_{i j}^{*}\right\}$ that satisfy conditions (3.2), (3.4), and (3.5). Given Assumptions 1-5 together, it is possible to show that this equilibrium exists, and that it constitutes a unique, interior solution.

Proposition 1. Under Assumptions 1-5 together, for each pair $i j$ with $i, j=\{A, B\}$ and $i \neq j$, there exist a unique interior equilibrium $\left\{\pi_{i}^{*}, \mu_{i}^{*}, \gamma_{i j}^{*}\right\}$.

Proof: See Appendix.

Since $\gamma_{i j}^{*} \in(0,1)$, we can rewrite equilibrium conditions as:

$$
\Omega_{i}\left(\gamma_{i j}^{*}\right)=G_{i}\left(\theta_{d}\right)
$$


where $\Omega_{i}\left(\gamma_{i j}^{*}\right) \equiv\left(1-\gamma_{i j}^{*}\right)\left[G_{i}\left(\hat{\theta}\left(F_{i}\left(\hat{\theta}\left(\gamma_{i j}^{*}\right)\right)\right)\right)\right]$. In equilibrium, some types will cooperate and others not. from the pool of citizens with defiant behavior, a fraction of them will leave to avoid violent retaliation, and the other fraction will remain and suffer violence. In this sense, this model explains three different events: i) non-cooperation followed by non-intimidation, ii) non-cooperation followed by forced migration because of political intimidation, and iii) non-cooperation followed by violent retaliation from illegal armed groups.

\subsubsection{Explaining Differences in Internally Displaced Flows}

Proposition 1 shows that, for each region where terrorists and civilians interact, a unique equilibrium behavior is determined. On the citizens' side, the decision to support or not the political party allied with terrorists will depend on the likelihood of suffering intimidation if defiance is observed. Likewise, terrorists will intimidate, depending on how likely victims will opt to forcefully migrate as a response. How can we rationalize observed differences in IDP inflows between loyal and disloyal communities? To answer this question we examine two different cases where disparities in displacement rates can exist. Firstly, we analyze the case when, for a given citizen's propensity to cooperate, one region faces a higher risk of intimidation. Secondly, we will study the case where, given the same risk of suffering intimidation, the citizens' propensity to not-cooperate is significantly higher in one region than the other.

Regarding the first case, we assume that the distribution of types for citizens at both regions are the same, so for a given victim's type, the likelihood of non-cooperation does not differ geographically. Holding the terrorist's type constant, differences in political loyalty and forced migration rates should be explained then by the extent to which one region faces a larger risk of intimidation. Without loss of generality, lets assume that region $A$ is riskier (more likely to be intimidated if non-cooperation is observed) than region $B$. Namely, region $B$ dominates stochastically region $A$. These two features of the model can be summarized in the following assumption.

Assumption 6 (Differences in the Risk of Suffering Intimidation):

For all $\theta \in \Theta, G_{A}(\theta)=G_{B}(\theta)$ and $F_{A}(\theta)>F_{B}(\theta)$.

We can justify Assumption 6 claiming that in some areas it is easier for illegal armed groups to establish economies of scale in rent seeking, making intimidation (in expectation) more profitable. The next result establishes how rates of political loyalty, intimidation, and forced migration change, assuming that citizens in both regions are fairly similar, but terrorists have a larger propensity to intimidate citizens in region $A$ than in region $B$. 
Proposition 2. Suppose Assumptions 1-6 hold. Then, $\pi_{A} *<\pi_{B} *, \mu_{A}^{*}>\mu_{B}^{*}$, and $\gamma_{A B}^{*}<\gamma_{B A}^{*}$.

Proof: See Appendix.

Hence, political support rates are uniformly higher (lower) if intimidation rates are higher (lower). As a result, the IDP influx to the loyal region (in this case, region A) is higher than the one occurring in the opposite direction (region B). In general, under Assumptions 1-6 together, the model predicts a positive correlation between political loyalty, political intimidation, and IDP inflows. As citizens decrease their political support to the candidate allied with terrorists, more citizens will be induced to leave their place of residence and locate in areas where such political support is substantial and no further intimidation is required.

Considering the second case, we can assume terrorists share the same distribution of types in both regions. However, for the same risk of intimidation, citizens in one region may have a larger propensity to support an alternate political option. As in the first case, differences in displacement rates across regions are explained by how political support triggers political intimidation, everything else assumed constant. Assumption 7 summarizes these features, again assuming that region $A$ is the one presenting the lowest political support.

Assumption 7 (Heterogeneous Propensity to Support Incumbent Candidates):

For all $\theta \in \Theta, G_{A}(\theta)>G_{B}(\theta)$ and $F_{A}(\theta)=F_{B}(\theta)$.

The next result states that, under a larger propensity to engage in defiant behavior, civilians in these regions will be intimidated more often and, as a result, will leave toward municipalities with higher levels of political support and lower intimidation rates.

Proposition 3. Suppose Assumptions 1-5 and 7 hold. Then, $\pi_{A} *>\pi_{B} *, \mu_{A}^{*}>\mu_{B}^{*}$, and $\gamma_{A B}^{*}>\gamma_{B A}^{*}$.

Proof: See Appendix.

In general, Propositions (2) and (3) provide a clear prediction: Irrespective of the level of intimidation that civilians may suffer as political loyalty is revealed, civilians in perceived disloyal municipalities will flee towards receiving areas with higher levels of political support. Hence, comparative advantage differences in and demand for intimidation do not play any role in explaining the positive correlation between IDP inflows and political loyalty. The correlation between internally displaced arrivals and political loyalty to the incumbent candidate is positive whatsoever. 


\subsection{Data Overview}

In this section, we explain how the main sources of information are combined to produce two different datasets. The first dataset, contains data on electoral outcomes, forced displacement and civil conflict related indicators, as well as other relevant covariates at the municipal level for all elections years considered. The second dataset is an expanded version of the first, where we merge test scores available at the school level.

\subsubsection{Municipal Elections}

We collect information on Governor elections results publicly available from the Colombian Electoral Office (Registraduria, in Spanish). This dataset comprises information on candidates, their political affiliation, and the number of valid votes obtained to win incumbency in five different election years: 1994, 1997, 2000, 2003, and 2007. We discard invalid votes but we use both valid and white votes, as the latter reveal the voters' neutrality/dislike to all running candidates. ${ }^{4}$ We consider municipalities as electoral markets in order to calculate the margin of loyalty towards the winning candidate. This margin is measured as the difference between the vote share obtained by the incumbent Governor and the maximum vote share obtained by any of the remaining candidates. Specifically, if an election occurs in municipality $m$ with $N$ alternatives (all candidates plus the "vote white" option), and candidate $i$ wins the election, the margin of political loyalty is defined by the following expression:

$$
\operatorname{Margin}_{m}=S_{i}-\operatorname{Max}\left\{S_{1}, \ldots, S_{i-1}, S_{i+1}, \ldots, S_{N}\right\}
$$

where $S_{i}$ denotes the vote share obtained by candidate $i$, with $i=\{1, \ldots, N\}$. Thus, non-negative values imply that voters in a municipality are loyal to the incumbent candidate, and negative values otherwise. ${ }^{5}$ After recovering our running variable, we obtain a dataset of 5,393 observations, each cell containing information at the municipality-election year combination. We merge information on election's characteristics and outcomes at other elections held in the same year, to capture aspects of the electoral competition that may be correlated with local political support. These variables include whether the winning candidate is from a traditional political party (liberal and conservative), whether the elected Governor and the elected municipal Mayor belong to the same political party, whether the winning candidate was

\footnotetext{
${ }^{4} \mathrm{~A}$ white vote is an additional alternative voters have to express their indifference towards all running candidates in a particular election. In case the "white vote" option is the one obtaining the maximum vote share among all alternatives, elections should be repeated with a different list of candidates. A vote is invalid when the voter has marked two or more preferred alternatives in the same electoral card.

${ }^{5}$ We assume municipalities with a draw (i.e. a zero margin of political loyalty) to be politically loyal. In total we have eleven cases satisfying this condition.
} 
placed first in the electoral card, and the number of unsuccessful times the winning candidate ran for office in the past. ${ }^{6}$

\subsubsection{Data on Internally Forced Migration and Civil Conflict}

We also collect information on our treatment variables for the first two years of incumbency (one and two years after election). ${ }^{7}$ Data on forced migration are available for the period 1993-2012, and are obtained through the Victims' Special Assistance and Reparation Office (RUV). This government agency was created in January 2012 to consolidate a dataset of civil-conflict related victims, as well as to provide immediate assistance and support to this population. In particular, we use the number of IDP expelled and received per municipality-year, to then calculate displacement inflow and outflow rates. Also, we construct the cumulative stock of IDP, defined as the number of citizens received and expelled per municipality since 1993 until each year of our sample. All IDP flows and stocks are measured per ten thousand inhabitants.

In order to account for other civil-conflict related variables that might influence our outcomes of interest, we collect information on the number of victims from massacres, selective killings, landmines, and terrorist bombings perpetrated by illegal armed groups from the National Center for Historical Memory (GMH, in its Spanish acronym). This civil commission was created by the central government in 2011 to document and record the history of the Colombian civil conflict. Their data are a combination of reports from a network of neutral catholic priests, and many different NGOs focused on tracking violent episodes against civilians by all actors of conflict. We stick to their definition of a massacre episode, as an event where at least four civilians, in a total state of helplessness, are killed in the same place by a recognized (legal or illegal) armed group. Selective killings are classified as episodes of violence where up to three victims are murdered in the same time and place. In contrast, a landmine accident is defined as an event where a civilian is killed or injured because of the random encounter with a landmine device that, in principle, has been placed and/or activated by members of an illegal armed group. A terrorist bombing is defined as an attempt to use explosives in a public space, with a large potential to inflict harm to both combatants and civilians. For all these episodes, we calculate (log) victimization rates by ten thousand inhabitants. Finally, we include a set of dummy variables indicating the presence of illegal armed groups: paramilitary groups (AUC), and left-wing guerrillas (ELN and FARC) with information provided by the National Police.

\footnotetext{
${ }^{6}$ Regarding information on elections, we use the publicly available digitized dataset constructed by the Center of Economic Development at Universidad de los Andes (CEDE). For an introduction on the use of this data, as well as its availability, see Pachón and Sánchez (2014).

${ }^{7}$ Hereafter, we will use the terms "years of incumbency" and "years after election" interchangeably.
} 


\subsubsection{Other Covariates}

We include a large set of municipality's baseline characteristics. Regarding fiscal capacity and public finance conditions we collect data on total revenues (tax revenues and other non-taxable revenues), capital revenues, total transfers (royalties) from the central government, and total expenditures (maintenance expenditures and public payroll) from the National Planning Department Office (DNP). ${ }^{8}$ As socio-demographic indicators, we control for total population, proportion of rural population and 1993 gini index and proportion of literate population at 1993. We also account for a diverse set of geographic covariates, such as municipality's surface area, altitude, quality of soil, availability of water, and a set of dummy variables indicating the region where the municipality is located, as well as a set of dummy variables indicating the century each municipality was founded. Socio-demographic information is available from the National Bureau of Statistics (DANE), and geographic covariates were collected from the National Geographic Institute (IGAC). ${ }^{9}$

\subsubsection{Merging Electoral Outcomes with Test Scores}

We use publicly available data on school-level standardized outcomes per academic subject from the SABER11 test. This exam is administrated by the Colombian Inspectorate of Education (ICFES, in its Spanish acronym) to measure the quality of education offered by schools, and to provide an objective performance measure which signals students' competencies to pursue tertiary education. In addition, it serves as a mandatory requirement students need to fulfill in order to obtain the high school diploma. This exam evaluates five core academic components: math, language, biology, chemistry, physics, and history. We take into account only test scores on the math and language subjects since these are the outcomes that are weighted the most in the construction of the general test score per student, as well as to compare our findings with other papers in the literature that focus on similar cognitive measures. Using student level data from years 2000-2012 we collapse test scores at the school level, and we calculate average tests scores, as well as other moments (percentiles) to characterize the whole test scores' distribution per subject within each school. Then, we merge this information at the municipal level with the dataset on electoral outcomes aforementioned, focusing on educational outcomes at incumbency years in our sample. This process leads to obtain an expanded dataset of 18,232 observations, where each observation corresponds to a school-election year combination.

\footnotetext{
${ }^{8}$ All public finance variables are deflated using 2005 consumer price index (CPI) and transformed into logarithms.

${ }^{9}$ While the sources of these controls are stated in the text, the Center for Economic Development at Universidad de los Andes (CEDE) in its municipal panel dataset provides a digitized version of these variables. This dataset is publicly available in the following link: https://datoscede.uniandes.edu.co/es/ catalogo-de-microdata
} 


\subsection{Empirical Strategy}

\subsubsection{Econometric Methodology}

In order to estimate how internally forced migration affects educational outcomes in hosting communities we implement a non-parametric fuzzy RD design:

$$
\begin{aligned}
I D P_{m, t+h} & =\alpha_{1}+\gamma_{1} \text { Loyal }_{m, t}+f_{(2)}\left(\text { Margin }_{m, t}, \text { Loyal }_{m, t}\right)+\varepsilon_{m, t} \\
\operatorname{TEST}_{s, m, t+h} & =\alpha_{2}+\gamma_{2} \text { Loyal }_{m, t}+f_{(2)}\left(\text { Margin }_{m, t}, \text { Loyal }_{m, t}\right)+u_{m, t}
\end{aligned}
$$

where equations (3.7) and (3.8) correspond to the first stage, and reduced form specifications, respectively. $I D P_{m, t+h}$ denotes our measurements of internal displacement, both the number of IDP arrivals and expulsions in municipality $m, h$ years after election, as well as the number of IDP received and expelled from municipality $m$ since 1993 until year $t+h$. TEST $_{s, m, t+h}$ denotes our educational outcomes of interest per school $s$ (standardized math and language test scores). Loyal ${ }_{m, t}$ is an indicator variable which takes the value of one if the margin of political victory, denoted by $\operatorname{Margin}_{m, t}$, is non-negative and is zero otherwise. The function $f_{(k)}($.$) is a k t h$-order polynomial that incorporates non-linearities and interactions between our running variable $\operatorname{Margin}_{m, t}$ and the variable of interest Loyal $_{m, t}$. In this chapter, we decided to focus on a quadratic polynomial specification to account for some flexibility without compromising the consistency of our estimates, according to what is suggested in the recent RD literature (Gelman and Imbens, 2017). Finally, $\varepsilon_{m, t}$ and $u_{m, t}$ are robust standard errors clustered at the province-election year combination.

The exogenous source of variation (political loyalty) and the treatment intensity (internally displacement indicators) change at the municipal level, while educational outcomes are observed at the school level. This implies that the first stage regression is performed using information from all municipalities in election years. Next, after merging information on schools' tests scores, we can run reduced form regressions using the resulting expanded dataset. In practice, we also estimate the first stage and reduced form regressions with the expanded dataset to jointly calculate the structural effects of interest and their corresponding standard errors. Regarding first stage regressions alone, we use observations where the margin of political loyalty lays within a bandwidth of $5 \%$ and $10 \%$ of the vote share around the cutoff value of zero. For the joint estimation, we use observations using the optimal bandwidth selection algorithm proposed by Calonico et al. (2014), which also provides biased-corrected estimates and robust confidence intervals. ${ }^{10}$

\footnotetext{
${ }^{10}$ This algorithm has also the advantage to optimally select narrower bandwidth values at higher convergence rates than other methods available in the RD literature (Ichimura and Todd, 2007; Imbens and Kalyanaraman, 2012).
} 


\subsubsection{Identifying the Effect of Internally Forced Migration on Test Scores}

In this setting, the parameters of interest are $\gamma_{1}$ and $\gamma_{2}$. The first measures, in number of civilians per ten thousand inhabitants units, the variation in IDP reception (or expulsion) that can be attributed to political loyalty alone. The second parameter $\left(\gamma_{2}\right)$ measures, in standard deviation (SD) units, the changes in test scores that can be attributed to shifts in political loyalty. The structural effect of interest is the ratio between the reduced form coefficient $\gamma_{2}$ and the first stage coefficient $\gamma_{1}$. That is the IV-Wald effect $\rho=\gamma_{2} / \gamma_{1}$, which captures the SD increase in tests scores explained by one additional IDP received, per 10,000 inhabitants.

Identification of $\rho$ relies on the use of political loyalty as an instrument that, in order to be valid, needs to satisfy two requirements. First, the instrument should explain a large portion of the variation on forced migration. This assumption is tested by checking the statistical significance of political loyalty's effect on forced migration from the first stage equation (3.7). As implied by the theoretical framework suggested in this study, we expect $\gamma_{1}$ to be positive and statistically significant. That is, a large fraction of internally displaced will flee towards politically loyal municipalities where armed actors have less incentives to intimidate civilians. Likewise, we expect the first stage relationship to be zero or statistically insignificant when IDP expulsion related indicators are used as the main instrument.

The second requirement is that the instrument should not be correlated with latent cofactors that affect both forced migration and test scores. While this assumption, in an instrumental variables framework, cannot be tested, we successfully check whether baseline covariates evolve continuously around the cutoff value of zero. In this way, we can neglect any potential unobservables explaining changes in test scores. Moreover, there are other reasons to believe political loyalty variation satisfies the exclusion restriction. Provided that education, on average, is given the same weight in the political agenda of all candidates, it is not clear to which extent voters in comparable municipalities, with almost identical (most likely positive) preferences for educative policies, will be marginally disloyal to the incumbent Governor for any other reason than the randomness in voting outcomes at close elections.

It is also worth mentioning that the effects that can be identified using a fuzzy regression-discontinuity design are local in nature. This is due to the fact that the impact on forced migration is significantly larger at municipalities where elections for Governor were highly contested. Therefore, we expect that the negative effect on test scores will be meaningful at those municipalities where pupils from internally displaced households were able to continue their studies and take the high-school exit exam in the new hosting location. Therefore, the effect that our empirical approach identifies is the local average treatment effect (LATE) among those municipalities where IDP inflows change dramatically after marginal changes in political loyalty towards the winning candidate. 


\subsection{Results}

\subsubsection{Summary Statistics}

Figure 3.3 plots the discontinuous relationship between IDP arrivals and the vote share in favor of the incumbent candidate as a measure of political loyalty. A negative margin indicates an election where voters were disloyal to the elected Governor. Each dark point represents the average value of the outcome in vote spread bins of 1.5 percentage points. Panels (a) and (b) present IDP inflow rates, for the first and second years after election. Panels (c) and (d) show similar graphs for the stocks of IDP received per municipality. Dashed lines show 95\% confidence intervals and all flows and stocks are measured per ten thousand inhabitants. As observed, there is a marked increase in the number of IDP arriving in municipalities considered loyal. They receive, on average, four additional IDP relative to comparable municipalities supporting the second-best candidate. The non-overlapping nature of the confidence intervals before and after the discontinuity suggests that changes induced by political loyalty are clearly statistically significant for the first two years of incumbency.

We repeat the same plots using the number of IDP outflows and the stock of IDP expelled (Appendix Figure A.3.1). Loyal municipalities have ejected on average 10 more civilians per 10,000 inhabitants than disloyal municipalities since 1993. However, the relationship suggested by the plots seems weaker, with a certain degree of overlap in terms of the confidence intervals of the discontinuity effect around the cutoff. All these figures combined suggest that if there is any effect of internally forced migration on educational outcomes, it is mostly driven by displaced population settling at loyal municipalities.

Finally, Figure 3.4 reports discontinuity graphs on the effect of political loyalty on educational outcomes. Panels (a) and (b) report discontinuity plots for average math test scores at the municipal level one and two years after election, respectively. Panels (c) and (d) present the same figures for average language test scores. Overall, these plots suggest a sizable negative relationship between IDP inflows and educational outcomes, as the plots of the reduced form effects seem to drop as the margin of political loyalty increases.

We also report in Table 3.1 municipality-level summary statistics, classifying municipalities by their political loyalty. Columns (1)-(5) report information for the full sample of municipalities. Columns (6)(7) present results for those municipalities deemed loyal. Columns (8)-(9) present the same information for disloyal municipalities. Differences in covariates (means) between both types of municipalities are reported in Columns (10)-(11). Relative to disloyal municipalities, those with a positive vote margin have less candidates running for elections, but such candidates also tend to run several times before winning the seat. Moreover, the data suggest some sort of vertical integration, as it is more frequent that both the elected Mayor and Governor belong to the same political party. Regarding civil conflict variables, loyal municipalities appear to be less vulnerable to terrorist attacks (mostly perpetrated by guerrilla groups), but more likely to have the presence of paramilitary groups. Concerning state capacity, loyal 
municipalities are intensive in public spending, but their revenues are also larger, in relation to disloyal municipalities. In general, disloyal municipalities appear to show worse socio-demographic indicators while there are very few differences in their geographic characteristics relative to municipalities with larger political support.

\subsubsection{On The Validity of the RD Design}

Two conditions are required to validate the research design implemented in this chapter. First, it demands that all variables (except the treatment) evolve smoothly around the cutoff point. We test this assumption by running the RD model with a quadratic polynomial implied from our baseline specification for each control variable reported in Table 3.1. In particular, we focus our attention on close elections whose vote shares lie within bandwidth values of $5 \%$ and $10 \%$ around the cutoff point of zero. Appendix Table A.3.1 reports these estimates. Each cell presents an RD coefficient with its respective standard error. Results from our 38 regressions (per bandwidth value) support the idea that covariates evolve continuously around the cutoff since only one coefficient is significant at the $95 \%$ confidence level, a result that it is expected to happen by pure chance. ${ }^{11}$

The second validity test we perform is to check whether there is precise manipulation of the running variable close to the cutoff. In practice, it is hard to imagine a reason why voters at some municipalities want to appear marginally loyal to a particular candidate, as victory is revealed when the voting count at the province level is completed. ${ }^{12}$ Even if there are incentives to manipulate elections at one municipality, its marginally loyal status will depend on electoral outcomes at those municipalities that did not suffer any sort of manipulation. However, if a particular group of interest has the power to force electoral outcomes in one direction at a large subset of municipalities, we should expect a sharp bump in the vote distribution around the zero cutoff. Addressing this concern, Appendix Figure A.3.2 shows graphic evidence that there is no precise manipulation of our running variable (Panel (a)). A more formal test, as is common in the RD literature (McCrary, 2008), supports the validity of our design. Indeed, with a $\log$ difference in the height of the density function of 0.05 and a standard error of 0.08 , we cannot reject the null hypothesis of no discontinuity around the cutoff (Panel (b)). We also conduct an alternative test using a local-polynomial density estimation procedure in the spirit of Cattaneo et al. (2016), to obtain robust bias-corrected estimated heights of 0.82 and 0.07 , with p-values of 0.41 and 0.94 , for observations within 5\% and 10\% bandwidth values around the cutoff point, respectively (Panels (c) and (d)). These results provide further evidence that there is no precise manipulation of the running variable, supporting the RD design implemented in this research.

\footnotetext{
${ }^{11}$ Under the null hypothesis of zero effects, one out of 20 regressions will report a statistically significant coefficient at the $5 \%$ significance level.

${ }^{12}$ It is useful to remind that the Governor's seat is won by the candidate receiving the majority of votes at the province (state) level. This departs drastically from other voting mechanisms, such as those granting victory to the candidate who is successful in accumulating victories at many electoral colleges as possible (municipalities in this case).
} 


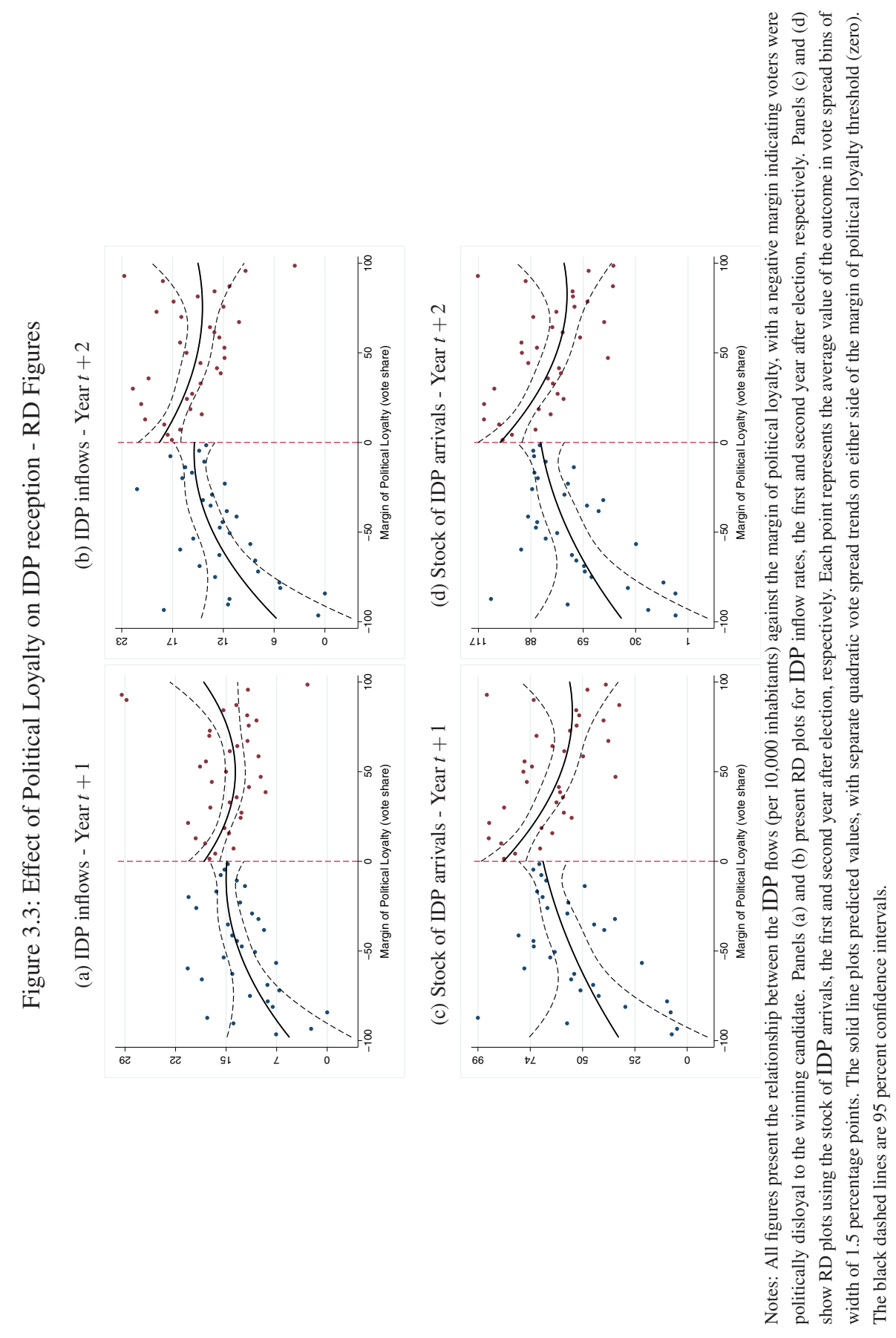




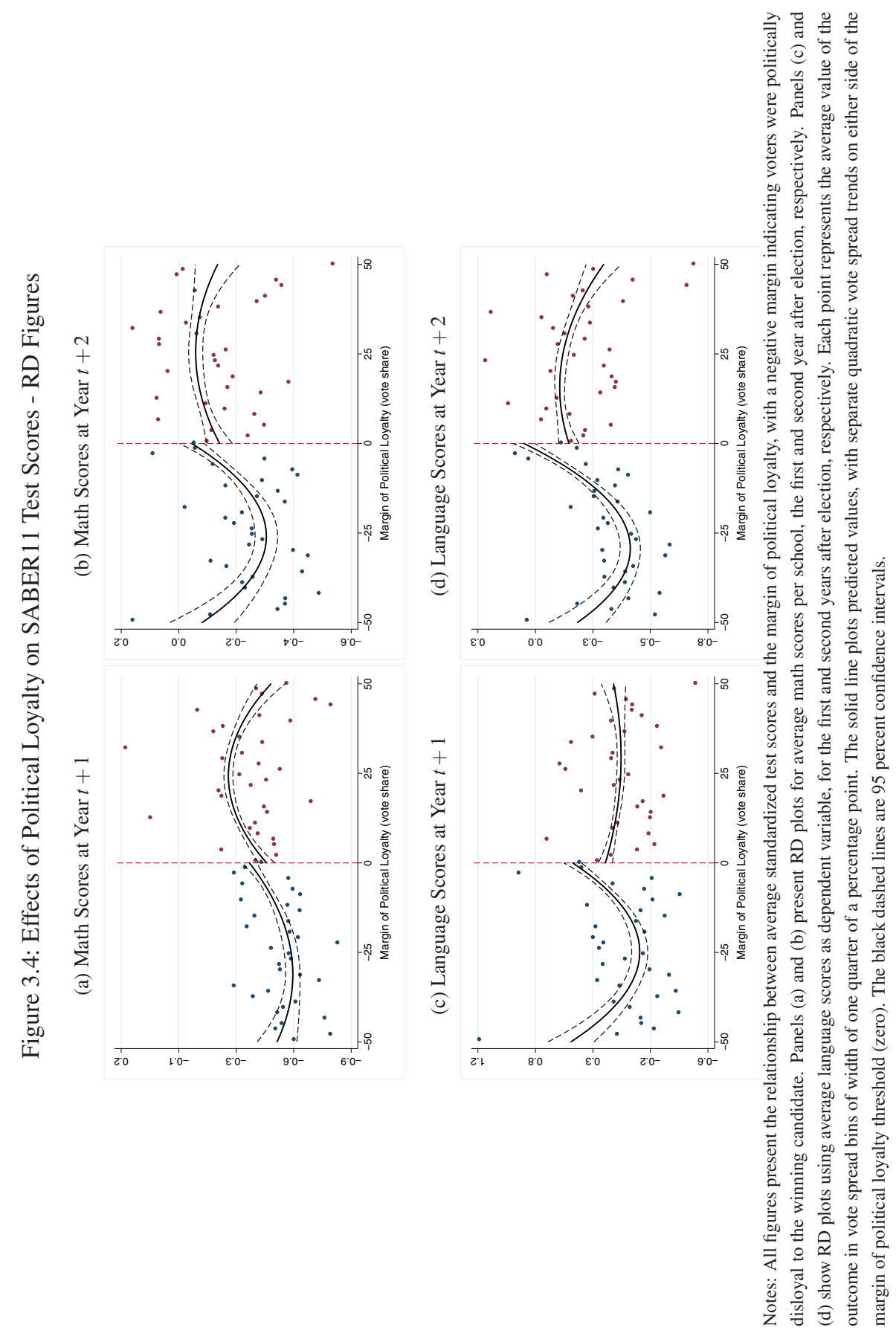




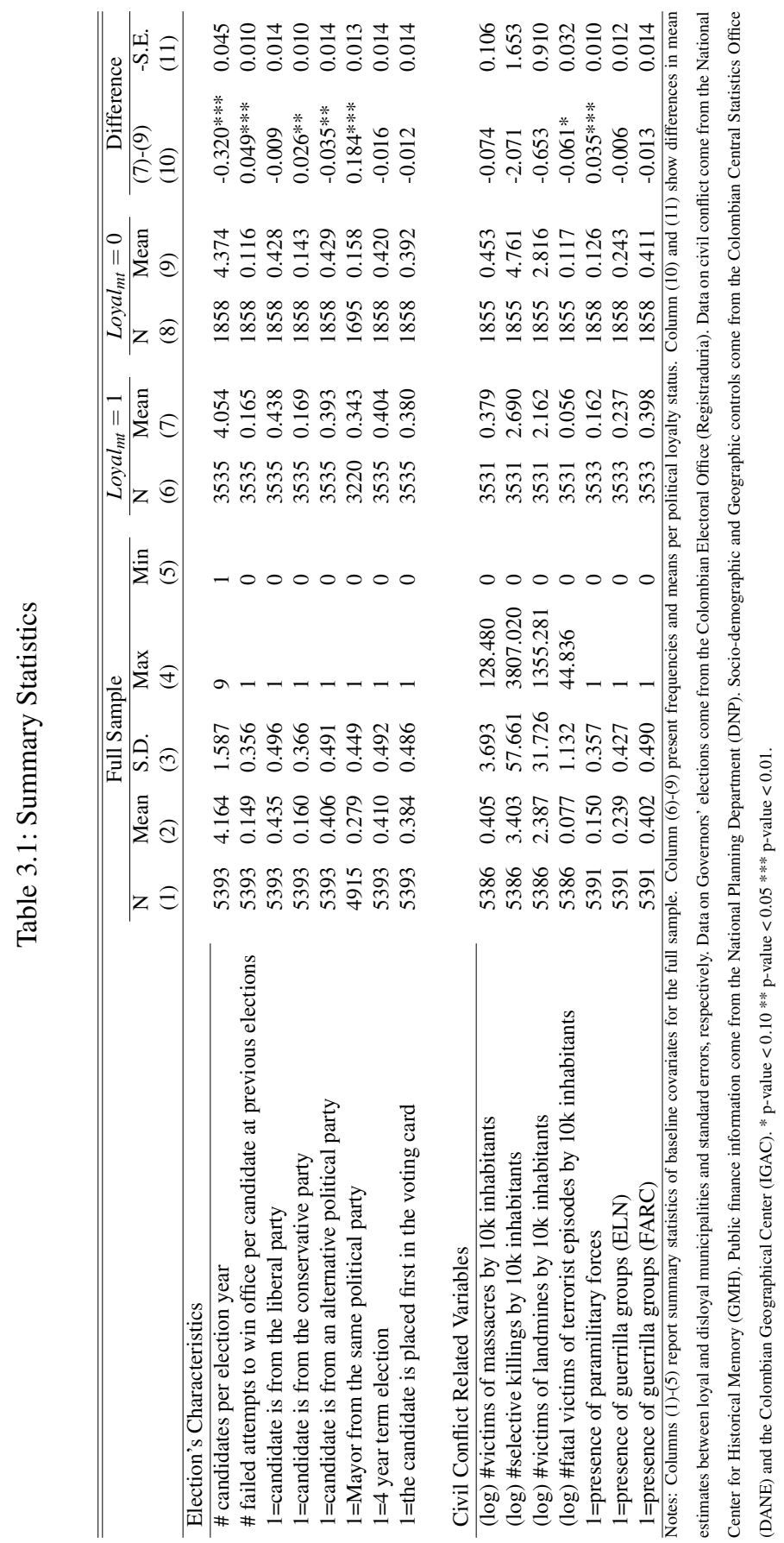




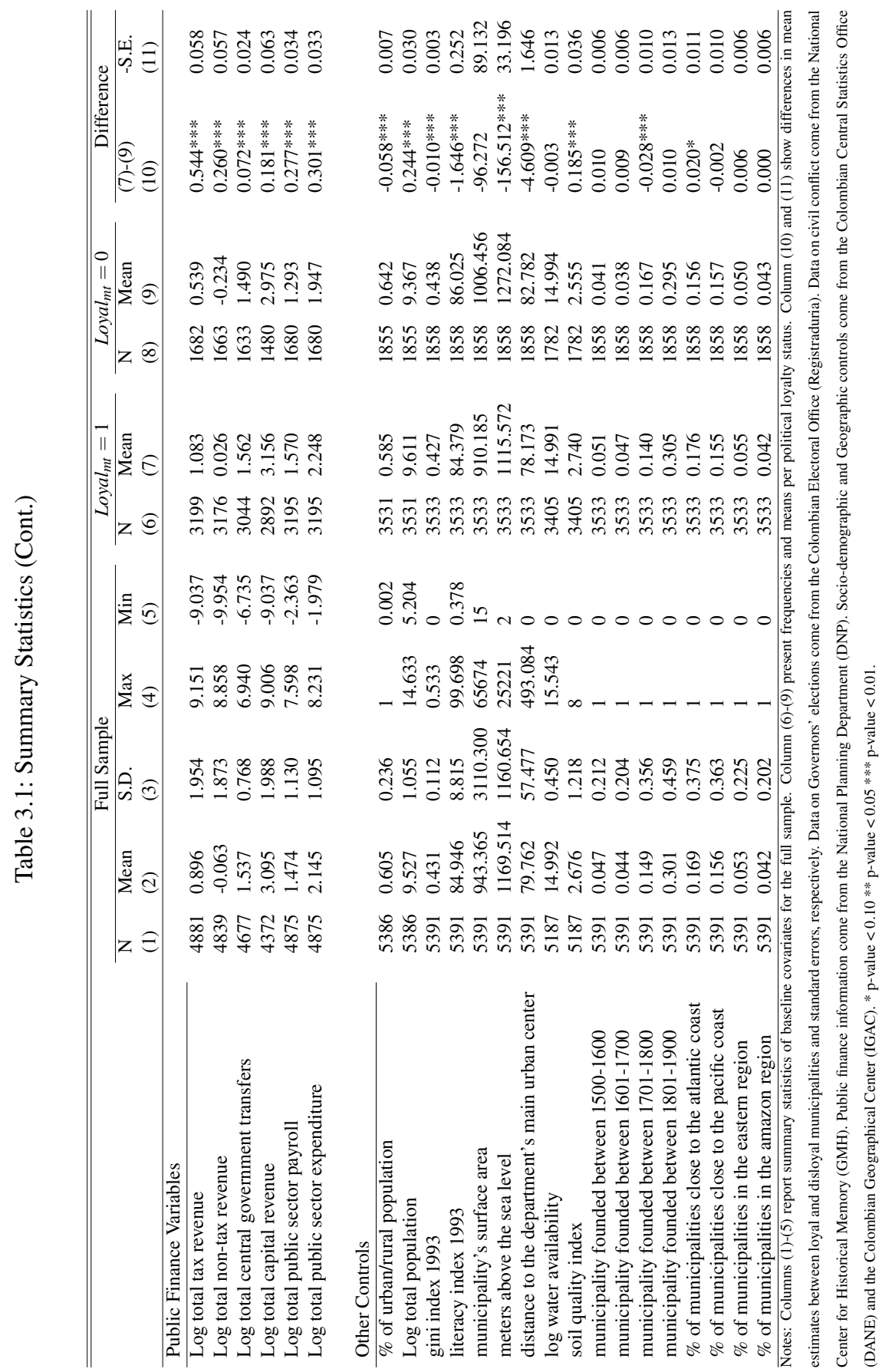




\subsubsection{The Effects of Political Loyalty on Internally Forced Migration}

Table 3.2 reports sharp Regression-Discontinuity (RD) estimates on the effects of political loyalty on internally forced migration into receiving municipalities. Columns (1)-(4) and columns (5)-(8) present the coefficients for the first and second year of incumbency, respectively. The dependent variables in these regressions are the number of IDP and the cumulative stock of IDP received in a particular municipality, per ten thousand inhabitants. We run these first stage regressions at the municipal level, using narrow bandwidths of five percent (Panel A) and ten percent (Panel B) of the margin of political loyalty around the cutoff point of zero. ${ }^{13}$ As described earlier, the margin of political loyalty is defined as the vote share difference between the incumbent candidate and the maximum vote share obtained among the remaining alternatives.

Comparing the size of the effects by the different bandwidths used, it is observed that the coefficients remain fairly robust across all specifications. Results for the first year after election appear to be nonsignificant at the five percent bandwidth, but as we double the bandwidth efficiency is improved without major sacrifices in consistency. Findings obtained for the second year after election are strongly significant, irrespective of the bandwidth value used.

Regarding effects on IDP inflows, coefficients displayed in columns (1)-(2) and columns (5)-(6) suggest that politically loyal communities receive on average between nine and thirteen more IDP than disloyal comparable municipalities. These are sizable impacts as they represent up to $0.48 \mathrm{SD}$ of the inflow rate for the first two years of mandate. Comparing RD estimates on IDP stocks, municipalities with a positive margin of political loyalty seem on average to receive between 53 (Column (4)) and 80 (Column (7)) IDP per ten thousand inhabitants the first and second years after election, respectively. These magnitudes are also economically meaningful as they represent up to a 0.54 SD impact on internally displaced migration.

To account for potential effects on forced expulsion from origin municipalities, we report in Appendix Table A.3.2 RD estimates for both the IDP outflows and cumulative stocks of IDP expelled per ten thousand inhabitants. While in absolute terms the coefficients obtained are higher in magnitude relative to the ones obtained for IDP reception outcomes, none of the estimates obtained are informative as they are not statistically different from zero using conventional significance levels. All results combined allow us to assert that there exist strong discontinuities in the reception of IDP alone, that can be causally attributed to random shifts in political support at local elections.

\footnotetext{
${ }^{13}$ We decided to use these bandwidth values to follow other literature using Colombian elections' results as a running variable (e.g. Galindo-Silva, 2015). Nonetheless, we use bandwidth values implied by non-parametric selection procedures when we estimate the structural effects of interest. See next section for details.
} 


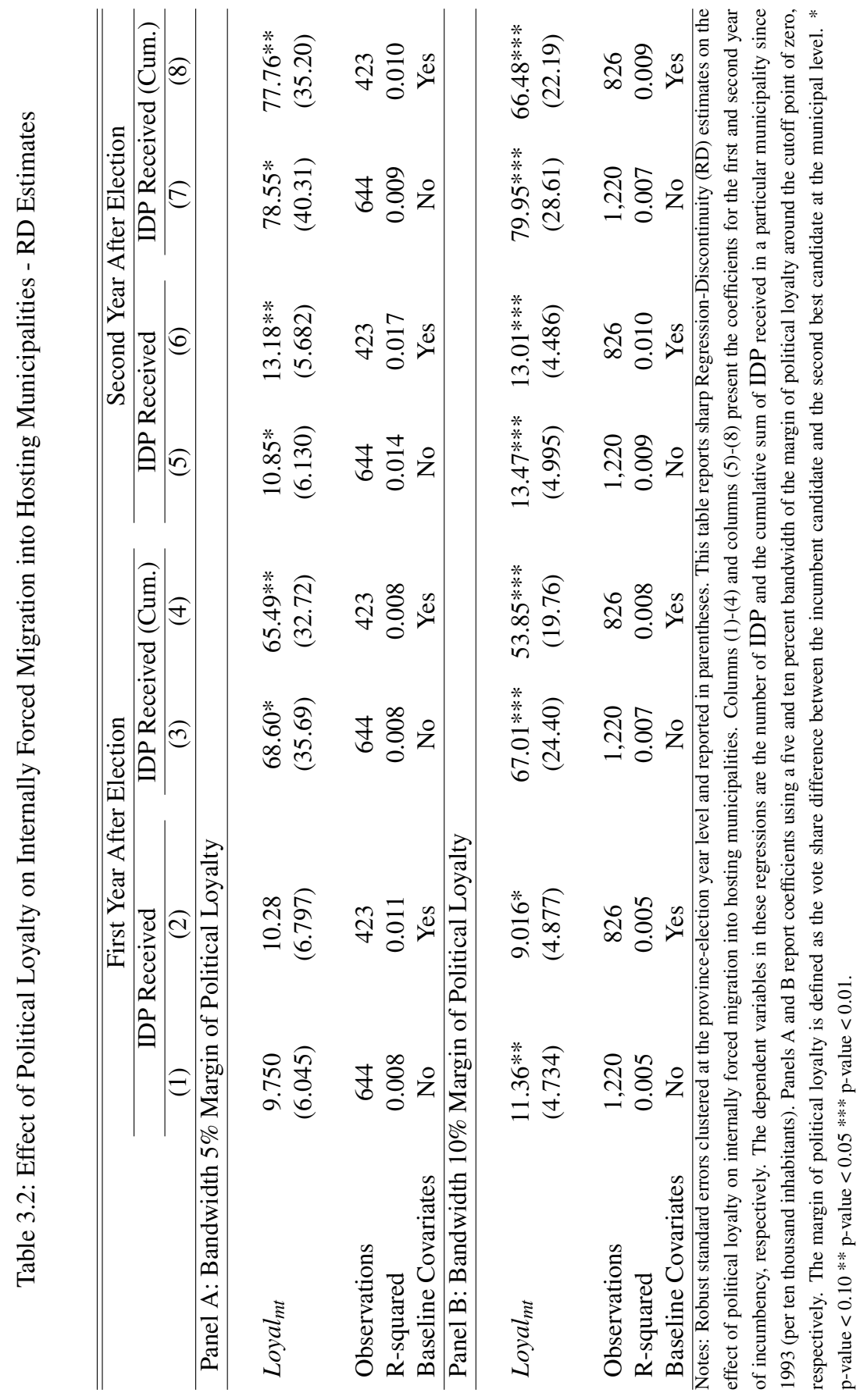




\subsubsection{Mechanisms}

In this section we suggest three mechanisms behind the sharp discontinuity in IDP reception at loyal municipalities. In particular, we examine whether election characteristics, civil conflict related violence, and central government fiscal capacity can serve as factors influencing the movement of displaced victims when political support to the incumbent Governor is revealed. To achieve this goal, we interact all baseline covariates under these three categories with our variable of interest Loyal $_{m, t}$, and with all variables included in the polynomial component $f_{(k)}($.$) of the first stage specification as of equation (7). In$ these estimations, the coefficient of interest is now the interaction of Loyal ${ }_{m, t}$ with each of the regressors considered.

Election Characteristics. Table 3.3 displays RD coefficients from interacting our political loyalty indicator with the different attributes of the Governors' elections in our sample. The first two columns report estimates where the dependent variable is the number of IDP received one and two years after election. Similar RD estimates are presented in the last two columns for the cumulative stock of IDP in hosting municipalities. Two elements appear to be good candidates in explaining the migration patterns obtained in our previous results. First, by analyzing the significance and sign of the effects when the party identity is controlled for, we obtain some evidence of political sorting as, on average, it is more likely that IDP migrate into loyal municipalities where the incumbent candidate does belong to a non-traditional political party. While this sorting is significant only at the $10 \%$ level, in the long-run this sorting pattern is fully revealed as municipalities where the incumbent candidate is from the conservative party received, since 1993, between 100 and 120 IDP less than equally loyal municipalities whose winning candidates belong to a different political party (Columns (3)-(4), third row). If we repeat this exercise, now focusing on whether the incumbent candidate was affiliated to a non-traditional party the impact is completely reversed (Columns (3)-(4), second row).

Secondly, it is clear that the increased reception of internally displaced was exacerbated after the political reform which extended the incumbency period one additional year, from the original term duration of three years. As coefficients in the last row suggest, elections from 2003 are positively associated with an increase in IDP received, relative to politically loyal municipalities in earlier election years. Our findings also rule out other mechanisms such as vertical integration between elected Mayors and Governors when they are from the same political party (fifth row). Moreover, increased political competition, measured as the number of running candidates per election, does not seem to be a major determinant of the variation in the influx of IDP into receiving communities. In general, political ideology and enhanced incentives appear to be the main leading explanations. 
Table 3.3: Mechanisms: Election Characteristics

\begin{tabular}{|c|c|c|c|c|}
\hline \multirow[b]{2}{*}{ Loyal $_{m t} \times$} & \multicolumn{2}{|c|}{ IDP Received } & \multicolumn{2}{|c|}{ IDP Received (Cum.) } \\
\hline & $\begin{array}{c}\text { First Year } \\
\text { After Election } \\
(1)\end{array}$ & $\begin{array}{l}\text { Second Year } \\
\text { After Election } \\
\text { (2) }\end{array}$ & $\begin{array}{c}\text { First Year } \\
\text { After Election } \\
(3)\end{array}$ & $\begin{array}{l}\text { Second Year } \\
\text { After Election } \\
\text { (4) }\end{array}$ \\
\hline \# candidates per election & $\begin{array}{c}1.740 \\
(2.603)\end{array}$ & $\begin{array}{c}2.101 \\
(2.394)\end{array}$ & $\begin{array}{c}3.547 \\
(11.368)\end{array}$ & $\begin{array}{c}5.777 \\
(13.103)\end{array}$ \\
\hline Observations & 1,220 & 1,220 & 1,220 & 1,220 \\
\hline R-squared & 0.023 & 0.035 & 0.022 & 0.026 \\
\hline 1=Liberal party & $\begin{array}{l}-7.002 \\
(9.057)\end{array}$ & $\begin{array}{l}-7.277 \\
(8.834)\end{array}$ & $\begin{array}{l}-70.230 * \\
(41.381)\end{array}$ & $\begin{array}{l}-77.192 \\
(48.579)\end{array}$ \\
\hline Observations & 1,220 & 1,220 & 1,220 & 1,220 \\
\hline R-squared & 0.019 & 0.040 & 0.036 & 0.040 \\
\hline $1=$ Conservative party & $\begin{array}{c}-17.159 * \\
(9.130)\end{array}$ & $\begin{array}{c}-22.702 * * \\
(8.872)\end{array}$ & $\begin{array}{c}-99.157 * * \\
(41.703)\end{array}$ & $\begin{array}{c}-120.793 * * \\
(49.287)\end{array}$ \\
\hline Observations & 1,220 & 1,220 & 1,220 & 1,220 \\
\hline R-squared & 0.016 & 0.024 & 0.014 & 0.017 \\
\hline $1=$ Alternative party & $\begin{array}{l}14.030 \\
(8.542)\end{array}$ & $\begin{array}{l}16.501 * \\
(8.714)\end{array}$ & $\begin{array}{c}109.519 * * * \\
(40.885)\end{array}$ & $\begin{array}{c}125.221 * * * \\
(47.623)\end{array}$ \\
\hline Observations & 1,220 & 1,220 & 1,220 & 1,220 \\
\hline R-squared & 0.038 & 0.072 & 0.057 & 0.064 \\
\hline $1=$ Mayor from the same political party & $\begin{array}{l}-11.930 \\
(11.829)\end{array}$ & $\begin{array}{c}0.065 \\
(12.665)\end{array}$ & $\begin{array}{l}-55.981 \\
(54.705)\end{array}$ & $\begin{array}{l}-53.691 \\
(65.704)\end{array}$ \\
\hline Observations & 1,118 & 1,118 & 1,118 & 1,118 \\
\hline R-squared & 0.014 & 0.028 & 0.030 & 0.031 \\
\hline $1=$ Placed first in the voting card & $\begin{array}{c}9.068 \\
(9.300)\end{array}$ & $\begin{array}{c}7.458 \\
(10.439)\end{array}$ & $\begin{array}{c}40.993 \\
(47.783)\end{array}$ & $\begin{array}{c}48.505 \\
(57.032)\end{array}$ \\
\hline Observations & 1,220 & 1,220 & 1,220 & 1,220 \\
\hline R-squared & 0.018 & 0.020 & 0.012 & 0.013 \\
\hline $1=$ four year period election & $\begin{array}{c}9.115 \\
(7.792)\end{array}$ & $\begin{array}{l}11.465 \\
(7.907)\end{array}$ & $\begin{array}{c}98.436 * * * \\
(32.711)\end{array}$ & $\begin{array}{c}109.205^{* * *} * \\
(38.429)\end{array}$ \\
\hline Observations & 1,220 & 1,220 & 1,220 & 1,220 \\
\hline R-squared & 0.110 & 0.113 & 0.228 & 0.226 \\
\hline
\end{tabular}


Civil Conflict Violence. How do incentives to migrate into politically loyal municipalities change when civil conflict related violence during elections increases? Table 3.4 intends to provide an answer to this question by reporting the RD estimates on the interaction of our political loyalty variable with indicators of violence perpetrated against civilians by illegal armed groups. As expected, almost all coefficients are negative in sign, suggesting that internally displaced civilians are less likely to migrate into politically loyal municipalities if a threat of victimization is present. Concerning IDP short run inflows, selective homicides seems to be the significant channel by which reception of civilians decreases (Columns (1)(2), second row). While this effect persist during first two years of incumbency, it is only significant at the $10 \%$ level.

In contrast, civilian targeted violence in the form of massacres emerges as a strong predictor of the decrease in the cumulative stock of IDP, presenting negative and strongly significant coefficients (Columns (3)-(4), first row). Surprisingly, the landmines victimization rate does not seem to be a relevant channel by which IDP inflows are affected as parameters are negative in sign but imprecisely estimated. We also obtain what appears to be a positive effect of terrorist bombings on IDP reception. Nonetheless, the resulting coefficient is only significant at the $10 \%$ level, and its statistical relevance disappears at the second year of incumbency. Overall, these results support the perception that political violence and IDP inflows are strongly, negatively correlated.

Public Finance. Table 3.5 presents RD coefficients where we interact municipalites' public finance indicators with their political loyalty status. We obtain no effects for almost all of our selected covariates with the notable exception of total revenues and transfers (Columns (1)-(2), fourth row). A potential explanation for the negative correlation obtained is the extent to which municipalities with a weaker local fiscal capacity are more dependent from central government's transfers to function. Hence, among loyal municipalities, those receiving fewer transfers are expected to be more independent in the provision of public goods funded from other sources of income such as local taxes or capital revenues. While the latter are not statistically significant, their corresponding coefficients exhibit a positive sign, suggesting that a stronger local fiscal capacity is, in general, positively correlated with internally displaced reception. 


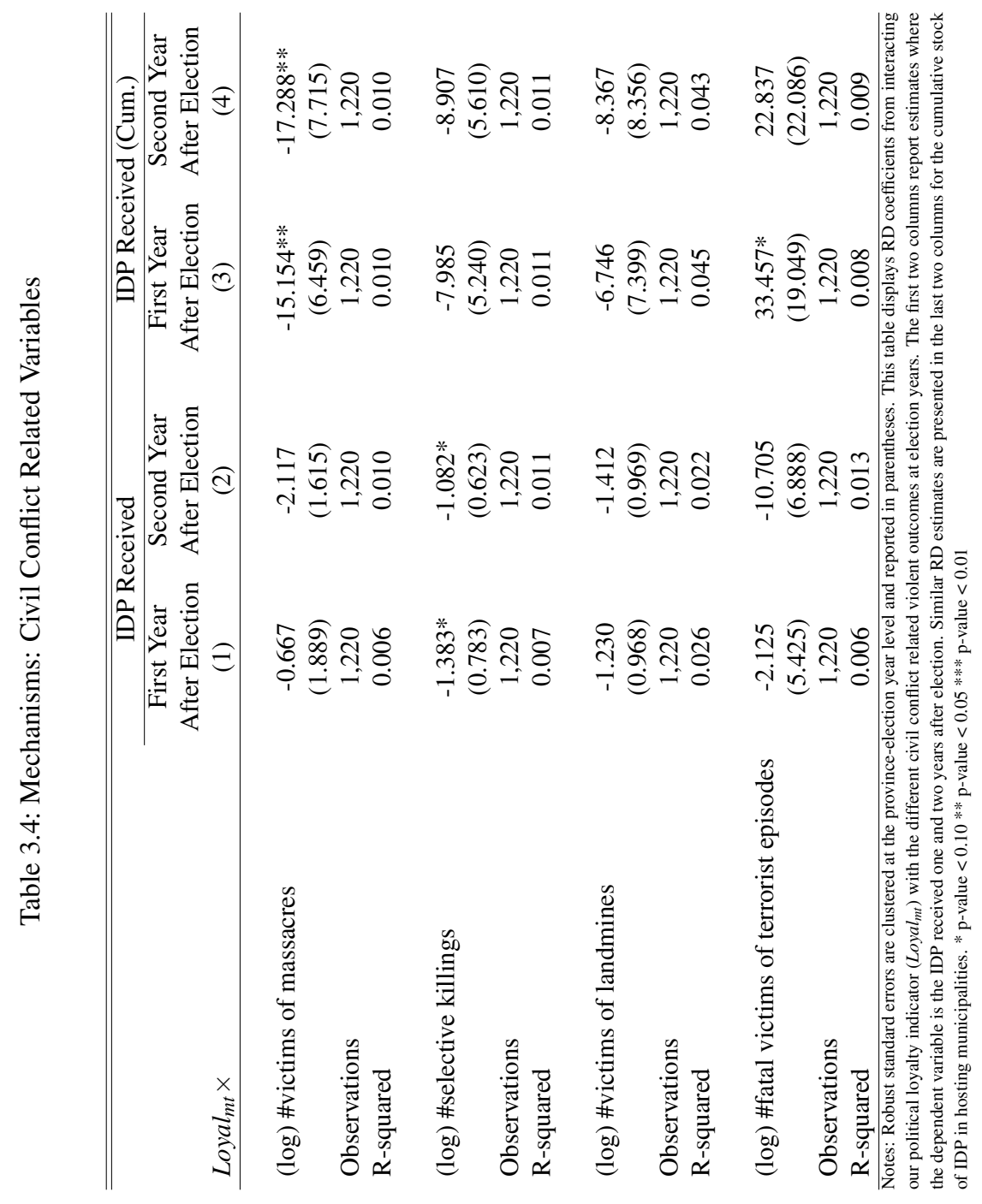


Table 3.5: Mechanisms: Public Finance Related Variables

\begin{tabular}{|c|c|c|c|c|}
\hline \multirow[b]{2}{*}{ Loyal $_{m t} \times$} & \multicolumn{2}{|c|}{ IDP Received } & \multicolumn{2}{|c|}{ IDP Received (Cum.) } \\
\hline & $\begin{array}{c}\text { First Year } \\
\text { After Election } \\
\text { (1) }\end{array}$ & $\begin{array}{l}\text { Second Year } \\
\text { After Election } \\
\text { (2) }\end{array}$ & $\begin{array}{c}\text { First Year } \\
\text { After Election } \\
\text { (3) }\end{array}$ & $\begin{array}{c}\text { Second Year } \\
\text { After Election } \\
\text { (4) }\end{array}$ \\
\hline Log total tax revenue & $\begin{array}{c}2.024 \\
(2.300)\end{array}$ & $\begin{array}{c}0.738 \\
(1.496)\end{array}$ & $\begin{array}{c}3.857 \\
(8.441)\end{array}$ & $\begin{array}{c}4.455 \\
(9.585)\end{array}$ \\
\hline Observations & 1,105 & 1,105 & 1,105 & 1,105 \\
\hline R-squared & 0.016 & 0.022 & 0.025 & 0.026 \\
\hline Log total non-tax revenue & $\begin{array}{c}2.407 \\
(3.241)\end{array}$ & $\begin{array}{c}1.642 \\
(2.956)\end{array}$ & $\begin{array}{l}-12.142 \\
(12.200)\end{array}$ & $\begin{array}{l}-10.428 \\
(14.254)\end{array}$ \\
\hline Observations & 1,095 & 1,095 & 1,095 & 1,095 \\
\hline R-squared & 0.008 & 0.014 & 0.012 & 0.013 \\
\hline Log total capital revenue & $\begin{array}{c}1.065 \\
(1.639)\end{array}$ & $\begin{array}{c}1.461 \\
(1.542)\end{array}$ & $\begin{array}{c}3.011 \\
(9.994)\end{array}$ & $\begin{array}{c}4.423 \\
(11.283)\end{array}$ \\
\hline Observations & 1,004 & 1,004 & 1,004 & 1,004 \\
\hline R-squared & 0.047 & 0.049 & 0.051 & 0.055 \\
\hline Log total central government transfers & $\begin{array}{l}-8.448^{*} \\
(4.601)\end{array}$ & $\begin{array}{c}-9.032 * * \\
(3.993)\end{array}$ & $\begin{array}{c}-36.432 \\
(26.191)\end{array}$ & $\begin{array}{c}-45.461 \\
(28.890)\end{array}$ \\
\hline Observations & 1,046 & 1,046 & 1,046 & 1,046 \\
\hline R-squared & 0.009 & 0.017 & 0.016 & 0.016 \\
\hline Log total public sector payroll & $\begin{array}{l}-2.771 \\
(2.933)\end{array}$ & $\begin{array}{l}-0.370 \\
(2.577)\end{array}$ & $\begin{array}{c}-9.152 \\
(16.706)\end{array}$ & $\begin{array}{c}-9.660 \\
(18.741)\end{array}$ \\
\hline Observations & 1,101 & 1,101 & 1,101 & 1,101 \\
\hline R-squared & 0.017 & 0.021 & 0.023 & 0.024 \\
\hline Log total public sector expenditure & $\begin{array}{l}-5.245^{*} \\
(2.991)\end{array}$ & $\begin{array}{l}-2.482 \\
(2.547)\end{array}$ & $\begin{array}{c}-26.088 \\
(16.900)\end{array}$ & $\begin{array}{c}-28.542 \\
(18.848)\end{array}$ \\
\hline Observations & 1,101 & 1,101 & 1,101 & 1,101 \\
\hline R-squared & 0.011 & 0.015 & 0.013 & 0.014 \\
\hline
\end{tabular}




\subsubsection{The Effects of IDP Reception on Educational Outcomes}

\subsubsection{Effects on Average Test Scores}

Table 3.6 documents the central results of this study. Panel A shows reduced form estimates from a sharp RD design, where the main outcomes of interest are schools' average standardized math and language test scores. Panel B displays fuzzy RD regressions (IV-Wald estimates), where the treatment variable is the influx rate, measured as the number of IDP received per ten thousand inhabitants. Finally, Panel C reports the first stage RD regressions, where the instrument implemented is a binary variable which indicates a municipality is politically loyal, Loyal ${ }_{m, t}$. Columns (1)-(2) and (3)-(4) present estimates on test scores and instrumental variables one and two years after elections. As mentioned earlier, instead of choosing an arbitrary bandwidth value, we opt to implement the algorithm suggested by Calonico, Cattaneo, and Titiunik (2014) that also provides biased-corrected estimates and robust confidence intervals. As in the previous section, robust standard errors are clustered at the province-election year combination. ${ }^{14}$

Intention to treat effects (ITT) reported in Panel A show that schools located in politically loyal municipalities suffered a drop in math scores on the order of 0.18 SD and 0.3 SD the first and second year of incumbency, respectively (Columns (1) and (3)). The drop in language scores is more dramatic, as in the first (second) year after election, scores fall by 0.6 (0.3) SD in municipalities supporting the winning candidate. Interestingly, it seems that there is some sort of "regression to the mean" effect for language scores, as the effects decrease after the second year of incumbency. In contrast, there is a monotone increasing loss in math scores as the political loyalty effect persists and increases during the first two years after elections.

Coefficients displayed in Panel B document the structural effects of interest. Regarding math scores, one additional IDP received in a loyal municipality implies a drop of $3 \%$ and $4 \%$ of a SD, during the first and second year after elections, respectively. The effect is larger for language scores, as the same increase in received IDP causes a decline up to $10 \%$ of a SD. These impacts are economically meaningful since they represent an average negative effect up to 0.4 SD and 0.6 SD on math and language scores, respectively. Moreover, examining coefficients from the first stage specification reported in Panel C, it is clear that political loyalty itself constitutes a strong instrument to predict the IDP inflows after election years. Coefficients are not only strongly significant, but the F-statistics associated to each specification is above the critical value of 10, allowing us to reject the null hypothesis of weak instruments in this design.

\footnotetext{
${ }^{14}$ Standard errors barely change if we cluster at the municipality level.
} 
Table 3.6: Effects of Internally Forced Migration Inflows on Average Test Scores

\begin{tabular}{|c|c|c|c|c|}
\hline & \multicolumn{2}{|c|}{ First Year After Election } & \multicolumn{2}{|c|}{ Second Year After Election } \\
\hline & (1) & (2) & (3) & (4) \\
\hline & Math & Language & Math & Language \\
\hline & Scores & Scores & Scores & Scores \\
\hline \multicolumn{5}{|c|}{ Panel A: Reduced Form Estimates } \\
\hline Loyal $_{m t}$ & $-0.179 * * *$ & $-0.593 * * *$ & $-0.298 * * *$ & $-0.308 * * *$ \\
\hline & $(0.025)$ & $(0.038)$ & $(0.023)$ & $(0.034)$ \\
\hline Observations & 8140 & 8140 & 7881 & 7881 \\
\hline Optimal Bandwidth (Vote Share) & 19.93 & 19.93 & 19.41 & 19.41 \\
\hline \multicolumn{5}{|c|}{ Panel B: IV-Wald Estimates } \\
\hline Loyal $_{m t}$ & $-0.030 * * *$ & $-0.099 * * *$ & $-0.037 * * *$ & $-0.038 * * *$ \\
\hline & $(0.009)$ & $(0.023)$ & $(0.007)$ & $(0.008)$ \\
\hline Observations & 8140 & 8140 & 7881 & 7881 \\
\hline Optimal Bandwidth (Vote Share) & 19.93 & 19.93 & 19.41 & 19.41 \\
\hline
\end{tabular}

Panel C: First Stage Estimates

$\begin{array}{lcc}\text { Loyal }_{m t} & 6.026 * * * & 7.571 * * * \\ & (1.437) & (1.403) \\ \text { Observations } & 9480 & 9349 \\ \text { Optimal Bandwidth (Vote Share) } & 19.93 & 19.41\end{array}$

Notes: Robust standard errors are clustered at the province-election year level and reported in parentheses. This table documents the effect of internally displaced reception on average standardized test scores. Panel A shows reduced form estimates from a sharp RD design, where the main outcomes of interest are school's math and language test scores. Panel B displays fuzzy RD regressions (IV-Wald estimates), where the treatment variables are the number of IDP received in a municipality per ten thousand inhabitants, one and two years after election. Panel $\mathrm{C}$ reports the first stage $\mathrm{RD}$ regressions, where the instrumental variable is whether in a particular election year voters were politically loyal to the winning candidate. Columns (1)-(2) and (3)-(4) present estimates on outcomes one and two years after elections. For all specifications we implement the optimal bandwidth selection algorithm suggested by Calonico, Cattaneo, and Titiunik (2014). * p-value $<0.10 * *$ p-value $<0.05 * * *$ p-value $<$ 0.01

\subsubsection{Effects Across the Test Scores' Distribution}

Are the negative effects aforementioned homogeneous across the students' population? To understand how internally displaced inflows affect the educational outcomes of pupils at the different segments of the ability distribution, we report IV-Wald and reduced form regressions, where the dependent variables are the different percentiles of the math and language test scores distributions. The intuition here is that, within each school, the same migration shock might influence the educational outcomes of students along the ability distribution differently. We abstain to report first stage results since, by construction, they are exactly the same as those reported in Table 3.6. 
Table 3.7 presents results on RD estimations for different percentiles of the math test scores per school. We observe a monotone decreasing drop in test scores the more we move towards the upper end of the distribution. Reduced form estimations from Panel A suggest, for instance, that students at the bottom $10 \%$ in loyal municipalities scored $7 \%$ of a SD less relative to comparable students at disloyal municipalities. Moreover, students at the Top $10 \%$ of the distribution obtained 0.14 SD less for the same migration shock. This implies that better students were affected twice as much as the lower achieving students. This pattern is also evident when we examine the effects for the second year after elections. Students at the bottom (top) $10 \%$ of the distribution scored $9 \%$ (20\%) of a SD less than students at the same percentile enrolled in schools located at disloyal municipalities. In general, these results highlight the fact that negative effects are prominent in the upper end of the students' ability distribution, and that they do not vanish after one period, ruling out possible "regression to the mean" event in the short-run. Concerning structural effects on math scores, there is a monotonic decreasing effect up to $2.5 \%$ of a SD for one additional IDP received the first two years after election (Panel B). Provided that loyal municipalities received on average twelve IDP per ten thousand inhabitants, this estimate implies a negative effect of about $0.35 \mathrm{SD}$ on math scores for students above the 90th percentile of the test scores distribution.

Table 3.8 repeats the above exercise using as dependent variables the different percentiles of the language test scores' distribution per school. Results in Panel A indicate that students in the bottom (top) $10 \%$ score 0.2 (0.3) SD less than comparable students in municipalities deemed disloyal. At the second year of incumbency ITT effects are more prominent, ranging from $8 \%$ to $18 \%$ of a SD for bottom $10 \%$ and top $10 \%$ students, respectively. Observing coefficients reported in Panel B, we can also conclude that students at the upper end of the distribution are the ones harmed the most by the internal displaced influx. Students attending education at loyal municipalities who belong to the 90 th percentile score $2 \%$ of a SD less because of receiving one additional IDP during the first two years of incumbency, implying an average impact of $0.3 \mathrm{SD}$. From these results, we can infer that all students at hosting communities, irrespective of their placement in the ability distribution, are unambiguously harmed by IDP reception. Top students are the most affected as their test scores, especially with respect to math, suffer a large drop. 


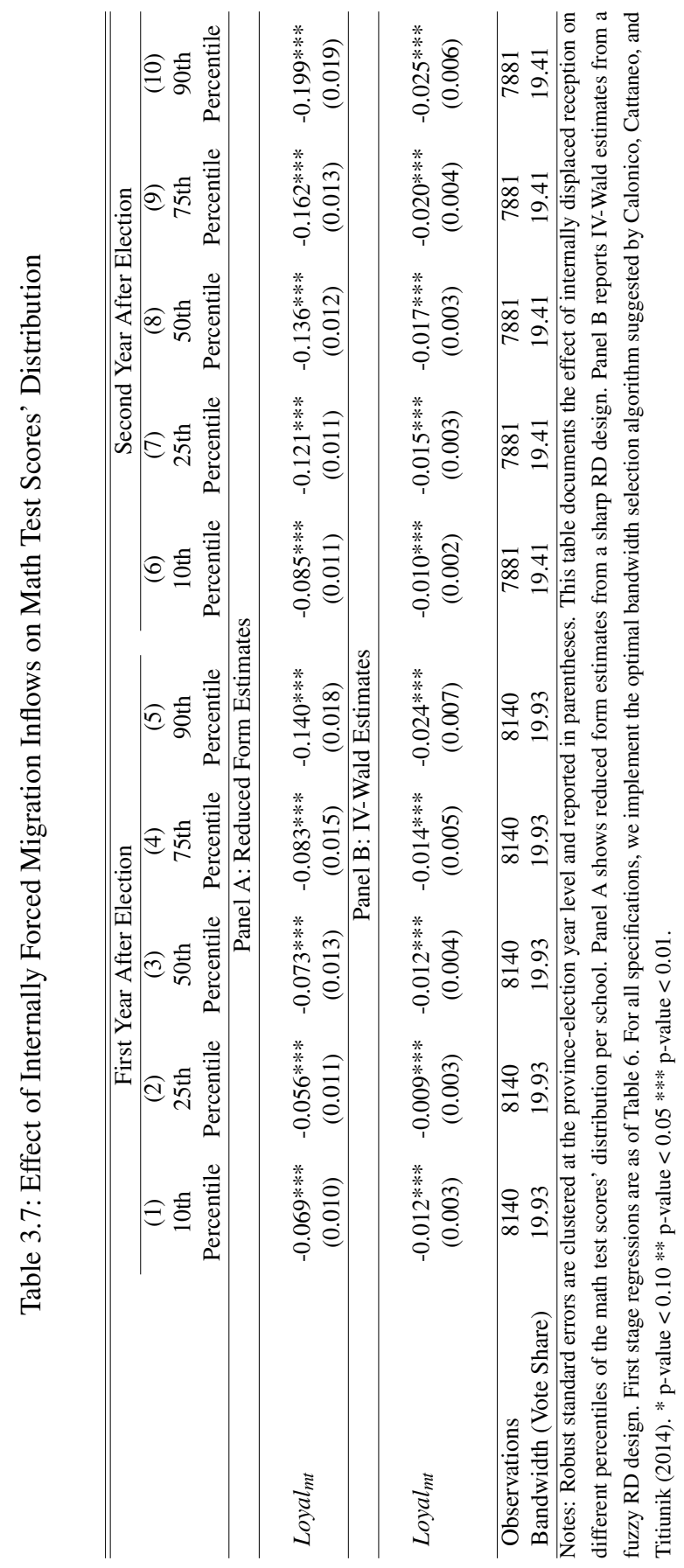




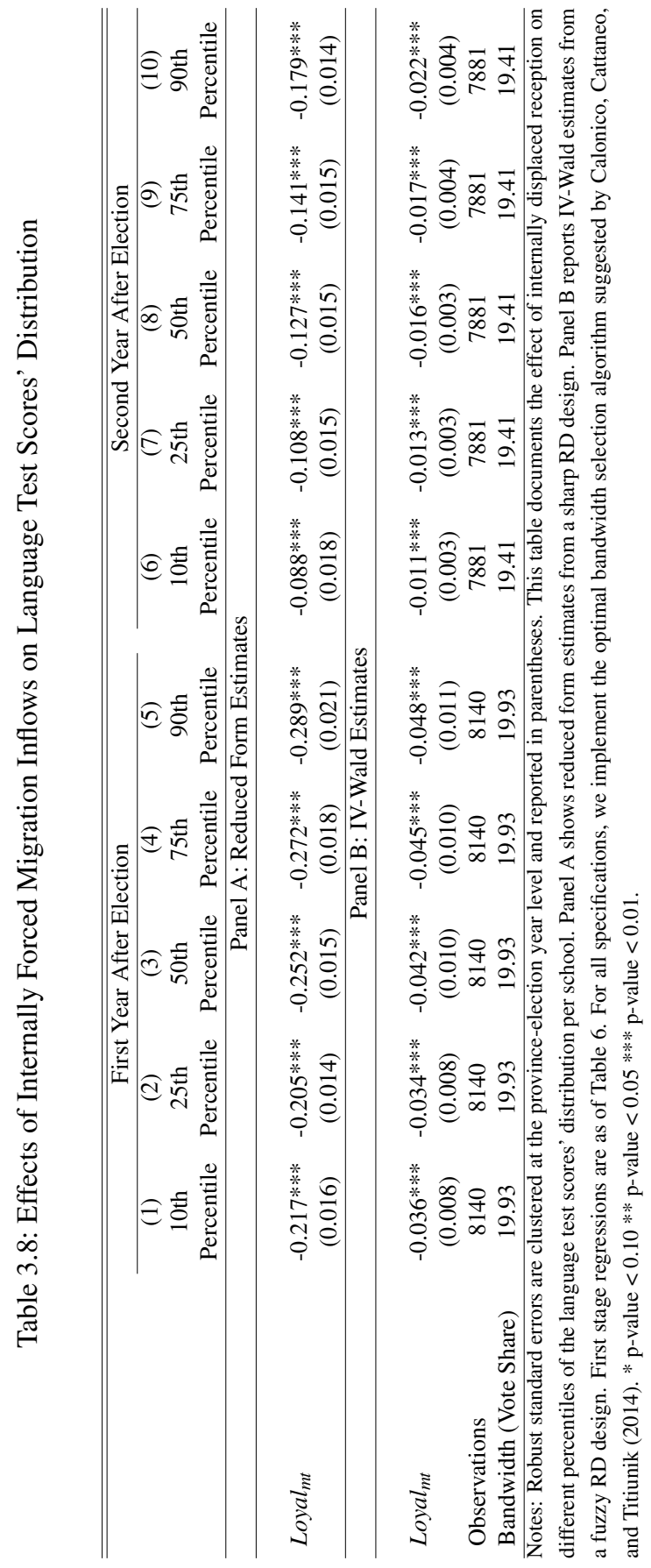




\subsubsection{Effects by Daily Working Schedules}

We explore an additional mechanism on the different daily working spells schools operate. Education is provided in four different schedules: Full day, a morning-exclusive spell from 7:00 to 12:30 hours, an afternoon-only schedule running from 13:00 to 17:30 hours, and a night-weekend schedule, which is rarely implemented. ${ }^{15}$ We expect the obtain significative differences in the effects of interest, relative to those schools operating under a full working day spell. Assuming the quality of education provided constant, a larger spell implies more time devoted to instruct and monitor the pupils' academic performance. In addition, we expect to observe different effects between schools running a morning-exclusive spell versus those implementing an afternoon-exclusive one. Students attending education in the morning might have more available time in the daylight to study and perform complementary activities that can be positively correlated with academic performance. If students in the morning-exclusive working spell are, relative to those studying in the afternoon, positively selected, we expect to detect significant negative effects in the former group rather than in the latter.

In Table 3.9 we provide evidence that, depending on the working spell students receive education, the negative effects documented can be more severe. We split the sample in four different groups, where each column represents a daily working schedule. Panels A and B report IV-Wald estimates from a fuzzy RD design where the dependent variables are average standardized math and language scores, respectively. We use the same optimal bandwidth value obtained from previous regressions as a way to compare our results with the ones obtained using our baseline specification.

Schools implementing a half-day working schedule are the most affected by the influx of internally forced migrants. Results displayed in Panel A suggest that math scores suffer a significant negative effect of $1.5 \%$ and $4 \%$ of a SD implied by an additional IDP per ten thousand inhabitants. We also obtain a significant negative impact of $9 \%$ of a SD on math scores for schools in the afternoon working spell. No significant effects for those schools focused on providing education exclusively to adult students are obtained.

A similar pattern is observed for language test scores. Coefficients reported in Panel B indicate a negative effect up to $4 \%$ of a SD in schools implementing a full day schedule. Interestingly, we observe a dramatic negative effect of $0.15 \mathrm{SD}$ for only-morning schools. However, this impact decreases to $3 \%$ of a SD the second year after elections. The negative effect obtained for schools implementing the afternoon working spell is also consistent for language scores, as we report a $10 \%$ of a SD drop explained by an increment of one additional IDP per ten thousand inhabitants. Overall, while all schools devoted to provide educational services to children are negatively affected by the internally displaced influx, it is clear that those implementing a morning schedule suffer the least, relative to schools working exclusively in the afternoon spell. Full day schools are the least affected as the extended workload mitigates the negative externalities on test scores attributed to the interaction between IDPs and original residents.

\footnotetext{
${ }^{15}$ The night-weekend schedule was designed to give working adults the opportunity to finish high-school.
} 


\subsubsection{Effects by Gender Composition at School}

We also examine whether differences in the gender composition at school explain the negative effects obtained. Assuming that female students hold a comparative advantage on stem subjects over male students, schools with a female-intensive gender composition may achieve better results in math. If male students perform better in non-stem subjects, the converse effect will hold.

Table 3.10 reports IV-Wald estimates of our baseline specification, splitting the sample on proportion of females at schools' quantiles. Negative effects on math scores are obtained for those schools with an extreme gender distribution of students (Panel A). Schools whose gender participation is less than 25\% report a $3 \%$ and $8 \%$ of a SD drop in test scores the first and second year after elections, respectively. In contrast, schools with a more "balanced" distribution of students do not present any significant effects to be considered (Columns (2) and (6)). As female participation increases, the effects become statistically significant. Schools in loyal municipalities with a female participation of $75 \%$ or more scored $3.5 \%$ of a SD less than schools in disloyal municipalities with a similar gender composition. Schools with more female students are less affected than those with a large proportion of male students. As the effects are higher during the second year of incumbency, it is safe to claim the effects reported to be relatively persistent in time.

We display results on language scores (Panel B). Effects decrease after the second year of incumbency. Schools with only up to $25 \%$ of male students report a drop of $10 \%$ of a SD in test scores during the first year of incumbency (Column (4)). The same effect decreases to 5\% of a SD during the second year (Column (7)). The decreasing effect in time is more moderate for those schools with a large participation of male students. Overall, these effects suggest that schools with a balanced gender composition are the least affected by the IDP influx. Moreover, the costs of IDP reception are significantly bigger for schools with a male-intensive gender composition, relative to schools with a more balanced distribution. 


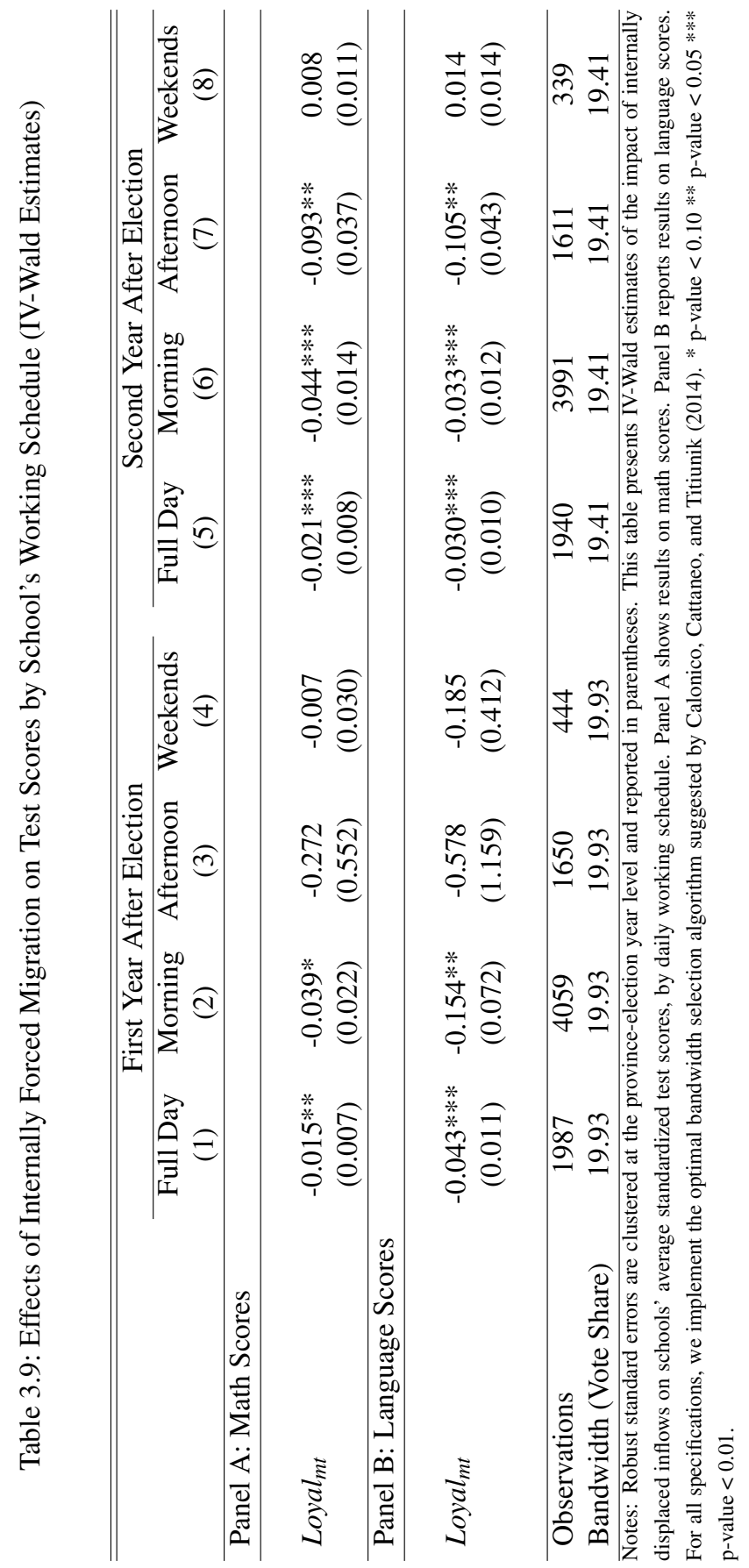




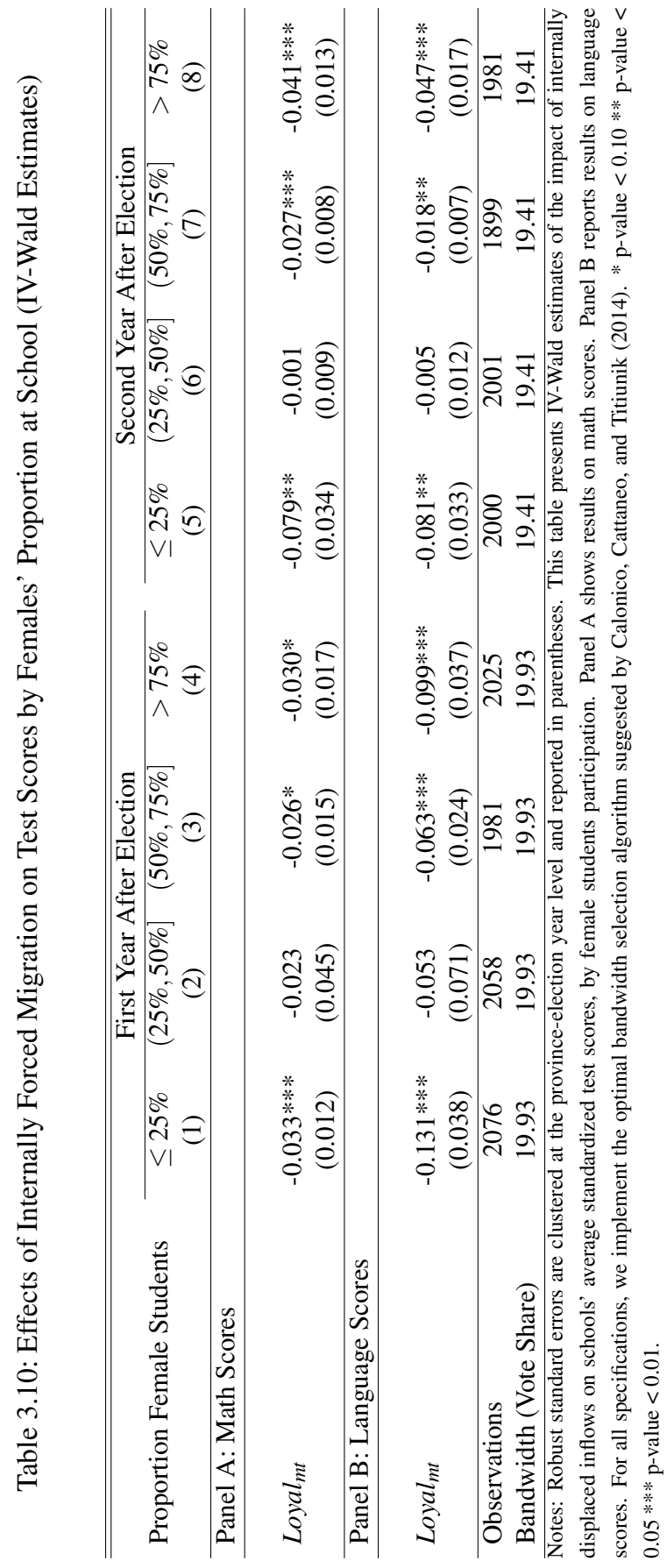




\subsection{Concluding Remarks}

Is internally forced migration affecting educational attainments of those living at hosting communities? In this chapter we address this question by estimating the causal effect of internal displaced inflows on math and language tests scores using a fuzzy RD design. We find a significantly negative impact, driven by shifts in political loyalty that induce massive amounts of civilians to be displaced into politically loyal municipalities. From a theoretical point of view, we offer an explanation on the extent to which political loyalty and IDP inflows are positively correlated. This stylized fact serves as the building block of our entire analysis, and motivates the empirical strategy we implement to identify the negative impact of civil-conflict related outcomes on educational achievements at secondary school.

We observe that communities with a large political participation, strong fiscal autonomy, and lower civilconflict related violence are more likely to receive a sharp IDP influx. At the school level, we find that schools with a comprehensive daily working spell and balanced students' gender distribution are the least affected by the IDP shock. However, we also show that IDP reception affects all students across the test performance's distribution, with top performers at loyal municipalities the ones suffering the highest drop in test scores, especially in stem subjects (math). We believe these findings are informative and provide evidence of the necessity to consider these specific elements into the educational policy design of the country.

From a public policy perspective our results support the idea that an intervention aimed to boost test scores at hosting communities should be powerful enough to counterweight the negative effects aforementioned. Since many of the effects documented in the economics of education literature are quite conservative, we claim that allocating resources to those programs in the shadow of the civil conflict might be an ineffective strategy to improve students' educational achievements. Rather than suggesting the elimination of complementary programs focused on improving educational outcomes, we argue in favor of a more comprehensive intervention targeted at displaced population in hosting municipalities to mitigate the negative impacts we find. We consider this issue as a promising area of further research. 


\subsection{Appendix: Mathematical Proofs}

Proof of Proposition 1: Because $\gamma_{i j}^{*}<1$ in all cases, we only need to prove that $\gamma_{i j}^{*}>0$ to show that $\gamma_{i j}^{*} \in(0,1)$. By way of contradiction, assume that $\gamma_{i j}^{*}=0$. Since $\tilde{\theta}\left(\gamma_{i j}\right)$ is increasing in $\gamma_{i j}$, this implies that $\mu_{i}^{*}=F_{i}(\tilde{\theta}(0))=0$. Moreover, because $\hat{\theta}\left(\mu_{i}\right)$ is decreasing in $\mu_{i}$, the probability of defiant behavior is equal to $\pi_{i}^{*}=G_{i}(\hat{\theta}(0))=1$. But this implies that $\gamma_{i j}^{*}=\max \left\{1-G_{i}\left(\theta_{d}\right), 0\right\}=1-G_{i}\left(\theta_{d}\right)>0$, which leads to a contradiction since we assumed that $\gamma_{i j}^{*}=0$. Hence,

$$
\gamma_{i j}^{*}=1-\frac{G_{i}\left(\theta_{d}\right)}{G_{i}\left(\hat{\theta}\left(\mu_{i}^{*}\right)\right)} \in(0,1) .
$$

Now, combining the above expression with conditions (3.2) and (3.4) we can express equilibrium as the value of $\gamma_{i j}^{*}$ such that the following expression (6) holds:

$$
\Omega_{i}\left(\gamma_{i j}^{*}\right)=G\left(\theta_{d}\right)
$$

with $\Omega_{i}\left(\gamma_{i j}^{*}\right) \equiv\left(1-\gamma_{i j}^{*}\right)\left[G_{i}\left(\hat{\theta}\left(F_{i}\left(\tilde{\theta}\left(\gamma_{i j}^{*}\right)\right)\right)\right)\right]$. Observe that $\Omega_{i}\left(\gamma_{i j}^{*}\right)$ is monotonically decreasing in $\gamma_{i j}^{*}$, with $\Omega_{i}(0)=1$ and $\Omega_{i}(1)=0$. Therefore, by the intermediate value theorem, there exists a unique $\gamma_{i j}^{*} \in(0,1)$ that satisfies the equilibrium condition $\Omega_{i}\left(\gamma_{i j}^{*}\right)=G\left(\theta_{d}\right)$. Uniqueness of both $\mu_{i}^{*}$ and $\pi_{i}^{*}$ follows directly as a result.

Proof of Proposition 2: We first prove that $\gamma_{A B}^{*}<\gamma_{B A}^{*}$. Assume $F_{A}(\theta)>F_{B}(\theta)$ for all $\theta \in \Theta$. This implies that $F_{A}\left(\tilde{\theta}\left(\gamma_{A B}^{*}\right)\right)>F_{B}\left(\tilde{\theta}\left(\gamma_{A B}^{*}\right)\right)$. Since $\hat{\theta}$ is decreasing in its argument, $\hat{\theta}\left(F_{A}\left(\tilde{\theta}\left(\gamma_{A B}^{*}\right)\right)\right)<\hat{\theta}\left(F_{B}\left(\tilde{\theta}\left(\gamma_{A B}^{*}\right)\right)\right)$ holds. Then, provided that $G($.$) is increasing in \theta$, the following lines hold as well:

$$
\begin{aligned}
G\left(\hat{\theta}\left(F_{B}\left(\tilde{\theta}\left(\gamma_{A B}^{*}\right)\right)\right)\right) & >G\left(\hat{\theta}\left(F_{A}\left(\tilde{\theta}\left(\gamma_{A B}^{*}\right)\right)\right)\right) \\
\left(1-\gamma_{A B}^{*}\right) G\left(\hat{\theta}\left(F_{B}\left(\tilde{\theta}\left(\gamma_{A B}^{*}\right)\right)\right)\right) & >\left(1-\gamma_{A B}^{*}\right) G\left(\hat{\theta}\left(F_{A}\left(\tilde{\theta}\left(\gamma_{A B}^{*}\right)\right)\right)\right)=\Omega_{A}\left(\gamma_{A B}^{*}\right) .
\end{aligned}
$$

Assuming Assumptions 1-6 hold together, in equilibrium $\Omega_{A}\left(\gamma_{A B}^{*}\right)=G\left(\theta_{d}\right)=\Omega_{B}\left(\gamma_{B A}^{*}\right)$. Therefore we obtain: 


$$
\begin{gathered}
\left(1-\gamma_{A B}^{*}\right) G\left(\hat{\theta}\left(F_{B}\left(\tilde{\theta}\left(\gamma_{A B}^{*}\right)\right)\right)\right)>\left(1-\gamma_{B A}^{*}\right) G\left(\hat{\theta}\left(F_{B}\left(\tilde{\theta}\left(\gamma_{B A}^{*}\right)\right)\right)\right) \\
\Longleftrightarrow \Omega_{B}\left(\gamma_{A B}^{*}\right)>\Omega_{B}\left(\gamma_{B A}^{*}\right) .
\end{gathered}
$$

we can observe that the function $\Omega_{i}($.$) , with i=\{A, B\}$, is a monotonically decreasing function in its argument. Likewise, this implies that $\gamma_{A B}^{*}<\gamma_{B A}^{*}$.

We continue this proof by showing that $\mu_{A}^{*}>\mu_{B}^{*}$. Assume, by a way of contradiction, that $\mu_{A}^{*} \leq \mu_{B}^{*}$. Because $\hat{\theta}$ is decreasing in $\mu$, then $\hat{\theta}\left(\mu_{A}^{*}\right) \geq \hat{\theta}\left(\mu_{B}^{*}\right)$, implying that $\gamma_{A B}^{*} \geq \gamma_{B A}^{*}$. As $\hat{\theta}$ is increasing in its argument, we obtain that $\tilde{\theta}\left(\gamma_{A B}^{*}\right) \geq \tilde{\theta}\left(\gamma_{B A}^{*}\right)$. By Assumption 6, this implies that:

$$
\mu_{A}^{*}=F_{A}\left(\tilde{\theta}\left(\gamma_{A B}^{*}\right)\right)>F_{B}\left(\tilde{\theta}\left(\gamma_{B A}^{*}\right)\right)=\mu_{B}^{*},
$$

which leads to a contradiction since we assumed that $\mu_{A}^{*} \leq \mu_{B}^{*}$. Hence, $\mu_{A}^{*}>\mu_{B}^{*}$. Finally, because $\hat{\theta}$ is decreasing in $\mu$, we obtain that $\pi_{A}^{*}=G\left(\hat{\theta}\left(\mu_{A}^{*}\right)\right)<G\left(\hat{\theta}\left(\mu_{B}^{*}\right)\right)=\pi_{B}^{*}$, proving our result.

Proof of Proposition 3: We start by proving that $\pi_{A}^{*}>\pi_{B}^{*}$. Assume, by a way of contradiction, that $\pi_{A}^{*} \leq \pi_{B}^{*}$. Then, provided that $G_{A}(\theta)>G_{B}(\theta)$ for all $\theta \in \Theta$, from condition (3.5) we obtain that $\gamma_{A B}^{*}<\gamma_{B A}^{*}$. As $\tilde{\theta}$ is monotonically increasing in $\gamma$, this implies that the following condition holds:

$$
\mu_{A}^{*}=F\left(\tilde{\theta}\left(\gamma_{A B}^{*}\right)\right)<F\left(\tilde{\theta}\left(\gamma_{B A}^{*}\right)\right)=\mu_{B}^{*} .
$$

Next, since $\hat{\theta}$ is decreasing in $\mu$, this implies that $\hat{\theta}\left(\mu_{A}^{*}\right)>\hat{\theta}\left(\mu_{B}^{*}\right)$, which also leads to obtain that:

$$
\pi_{A}^{*}=G_{A}\left(\hat{\theta}\left(\mu_{A}^{*}\right)\right)>G_{B}\left(\hat{\theta}\left(\mu_{B}^{*}\right)\right)=\pi_{B}^{*}
$$

However, this leads to a contradiction since we assumed that $\pi_{A}^{*} \leq \pi_{B}^{*}$. Hence, $\pi_{A}^{*}>\pi_{B}^{*}$.

We continue by proving that $\gamma_{A B}^{*}>\gamma_{B A}^{*}$. First, notice that Assumptions 1-5 imply that $G_{i}(\hat{\theta})>G_{i}\left(\theta_{d}\right)$ for $i=\{A, B\}$. Assume that $G_{A}(\theta)>G_{B}(\theta)$ and $F_{A}(\theta)=F_{B}(\theta)=F(\theta)$ for all $\theta \in \Theta$. Then, this implies that $G_{A}\left(\hat{\theta}\left(F\left(\tilde{\theta}\left(\gamma_{B A}^{*}\right)\right)\right)\right)>G_{B}\left(\hat{\theta}\left(F\left(\tilde{\theta}\left(\gamma_{B A}^{*}\right)\right)\right)\right)$. Thus, the following condition holds: 


$$
\Omega_{A}\left(\gamma_{B A}^{*}\right)=\Omega_{B}\left(\gamma_{B A}^{*}\right)\left[\frac{G_{A}\left(\hat{\theta}\left(F\left(\tilde{\theta}\left(\gamma_{B A}^{*}\right)\right)\right)\right)}{G_{B}\left(\hat{\theta}\left(F\left(\tilde{\theta}\left(\gamma_{B A}^{*}\right)\right)\right)\right)}\right]>\Omega_{B}\left(\gamma_{B A}^{*}\right)\left[\frac{G_{A}\left(\theta_{d}\right)}{G_{B}\left(\theta_{d}\right)}\right]=\Omega_{A}\left(\gamma_{A B}^{*}\right),
$$

with the last inequality holding from the fact that, in equilibrium, $\Omega_{B}\left(\gamma_{B A}^{*}\right)=G_{B}\left(\theta_{d}\right)$. As $\Omega_{i}($.$) is a$ monotonically decreasing function in $\gamma$. It follows that $\gamma_{A B}^{*}>\gamma_{B A}^{*}$. Observe that this result automatically implies that $\mu_{A}^{*}>\mu_{B}^{*}$. 


\subsection{Appendix: Tables and Figures}

Figure A.3.1: Effect of Political Loyalty on IDP Expulsion - RD Figures

(a) IDP Expelled - Year $t+1$

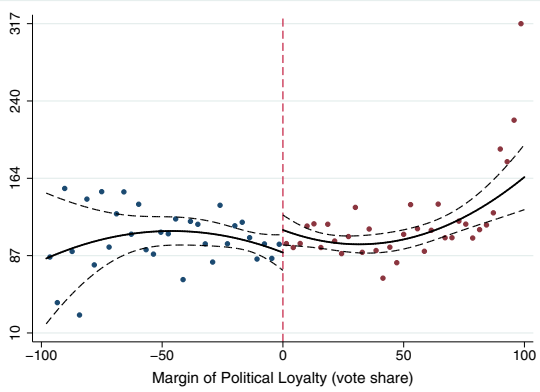

(c) IDP Expelled (Cum.) - Year $t+1$

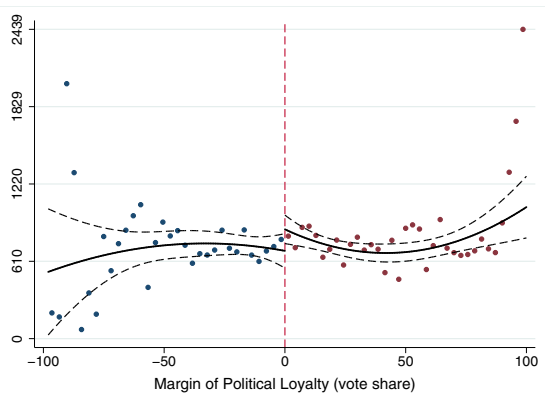

(b) IDP Expelled - Year $t+2$

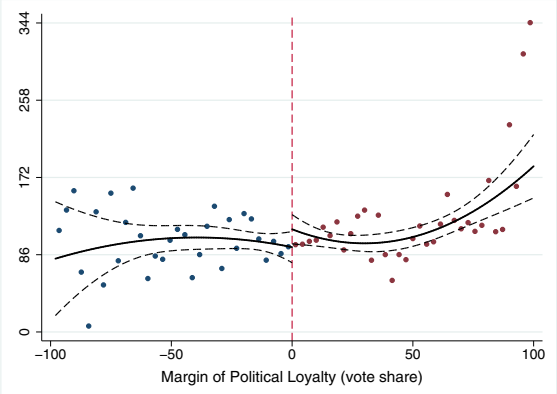

(d) IDP Expelled (Cum.) - Year $t+2$

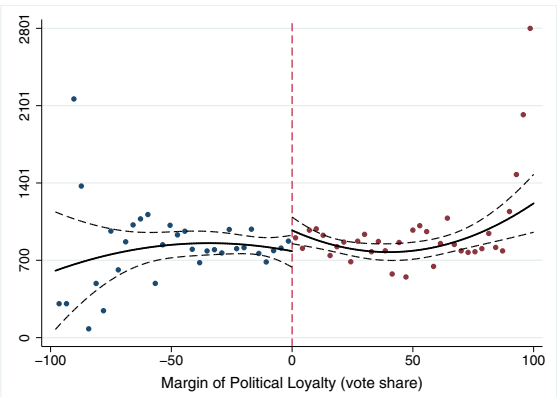

Notes: All figures present the relationship between the IDP flows (per 10,000 inhabitants) against the margin of political loyalty, with a negative margin indicating voters were politically disloyal to the winning candidate. Panels (a) and (b) present RD plots for IDP outflow rates, the first and second year after election, respectively. Panels (c) and (d) show RD plots using the stock of IDP expulsions, the first and second year after election, respectively. Each point represents the average value of the outcome in vote spread bins of width of 1.5 percentage points. The solid line plots predicted values, with separate quadratic vote spread trends on either side of the margin of political loyalty threshold (zero). The dashed lines are 95 percent confidence intervals. 
Figure A.3.2: Margin of Political Loyalty: Discontinuity Tests

(a) Histogram

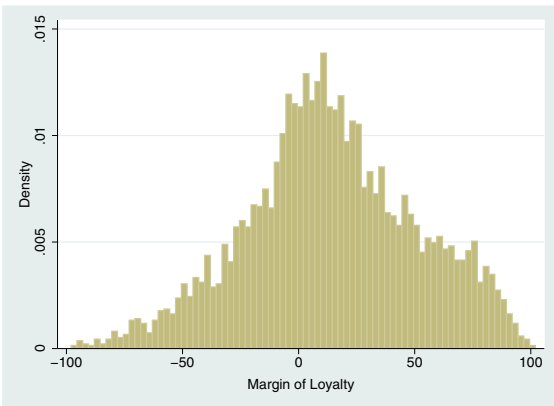

(c) CCT Density Test I

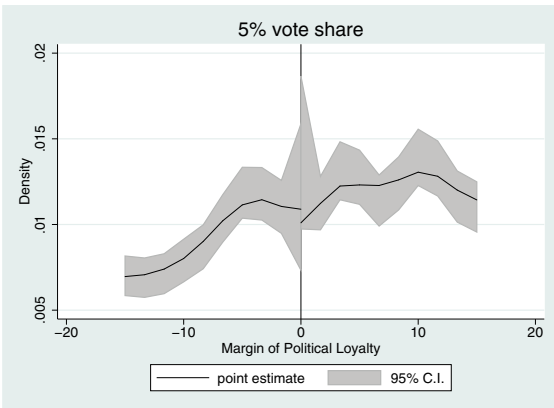

(b) McCrary (2008) Density Test

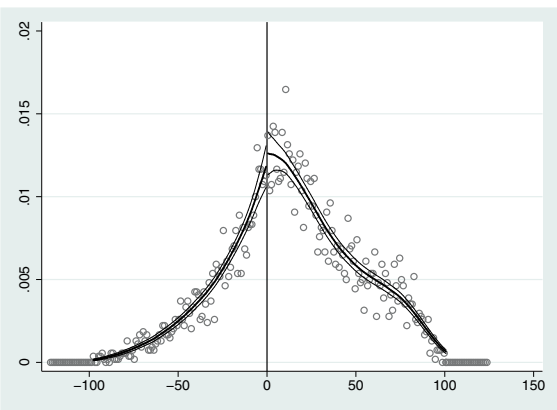

(d) CCT Density Test II

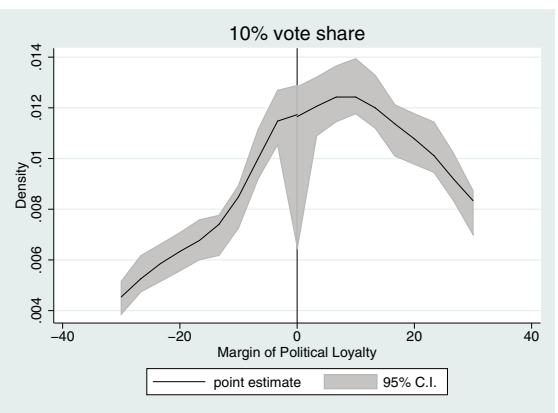

Panel (a) presents the density of the margin of political loyalty in Governor's elections (bin width=2\%). Panel (b) presents the finely-gridded histogram, smoothed using a local linear regression separately on each side of the margin of political loyalty's threshold (zero). The McCrary test reports a log difference (standard error) in the height of the density function of 0.05 (0.08) (McCrary, 2008). Panels (c) and (d) display discontinuity tests for a 5 $\%$ and $10 \%$ bandwidth using the local-polynomial density estimator suggested by Cattaneo et al. (2016). 


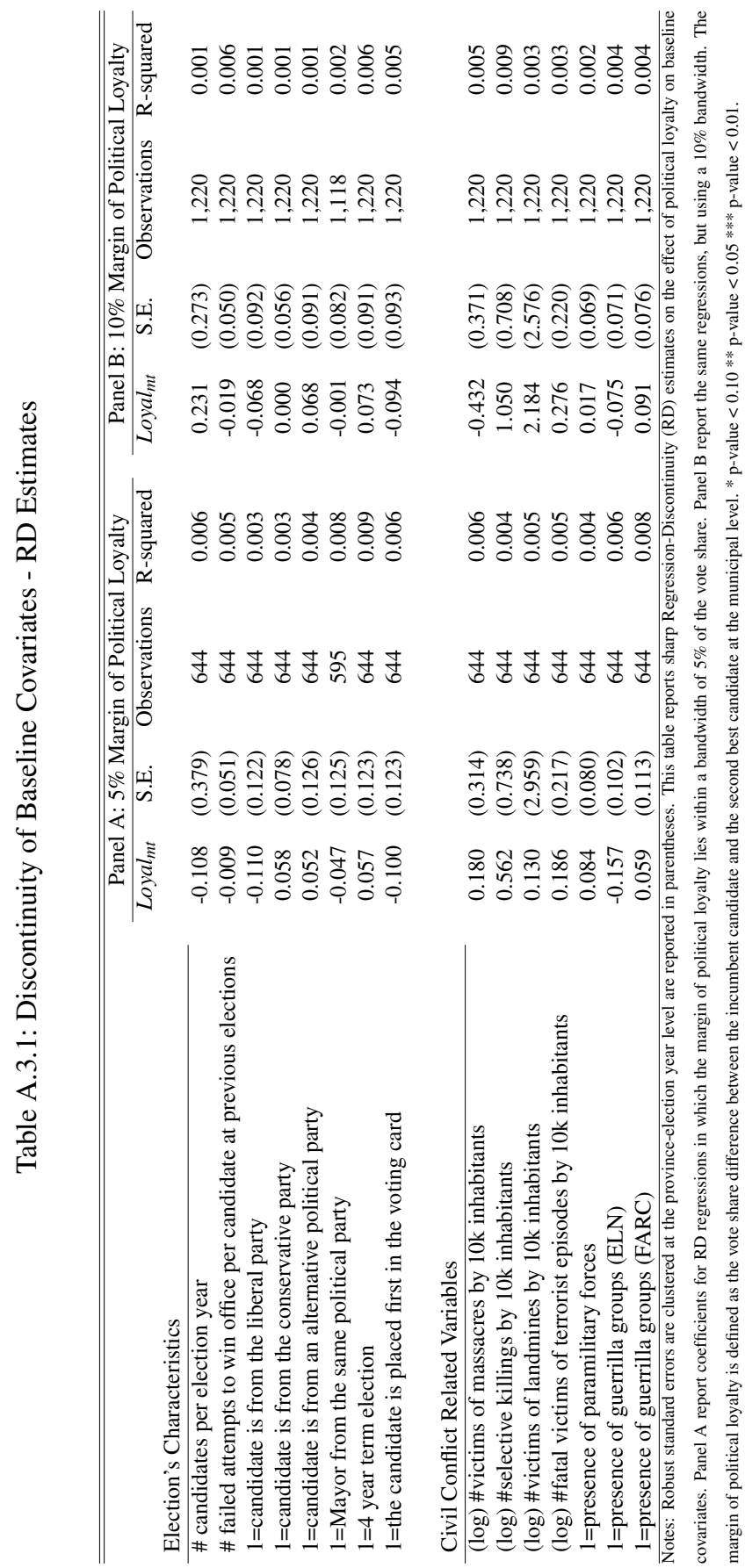




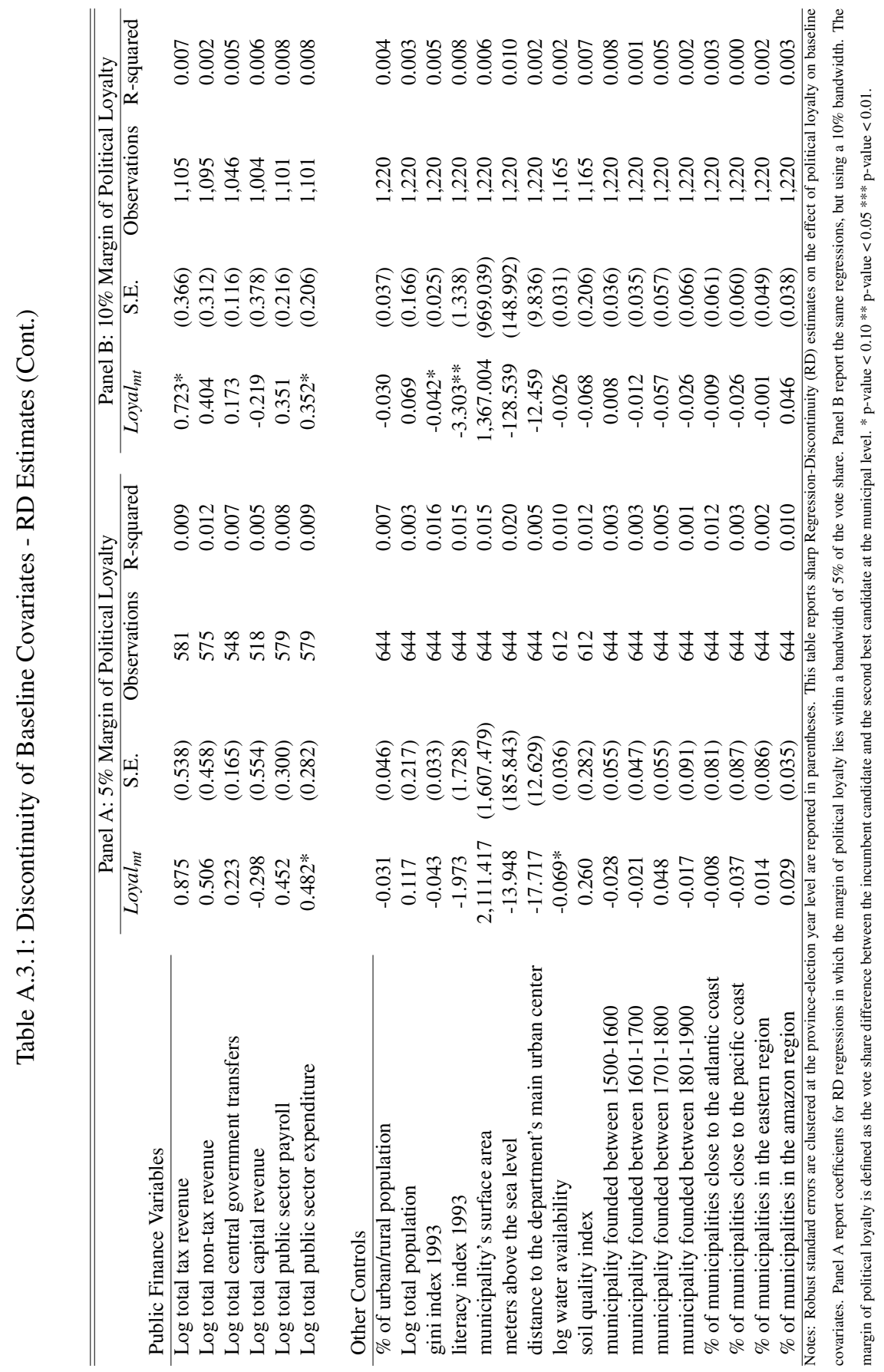


Table A.3.2: Effect of Political Loyalty on Internally Forced Migration from Origin Municipalities - RD Estimates

\begin{tabular}{|c|c|c|c|c|c|c|c|c|}
\hline & \multicolumn{4}{|c|}{$\begin{array}{l}\text { First Year After Election } \\
\end{array}$} & \multicolumn{4}{|c|}{ Second Year After Election } \\
\hline & \multicolumn{2}{|c|}{ IDP Expelled } & \multicolumn{2}{|c|}{ IDP Expelled (Cum.) } & \multicolumn{2}{|c|}{ IDP Expelled } & \multicolumn{2}{|c|}{ IDP Expelled (Cum.) } \\
\hline & (1) & $(2)$ & (3) & (4) & $(5)$ & $(6)$ & (7) & $(8)$ \\
\hline \multicolumn{9}{|c|}{ Panel A: Bandwidth 5\% Margin of Political Loyalty } \\
\hline Loyal $_{m t}$ & $\begin{array}{c}31.72 \\
(34.49)\end{array}$ & $\begin{array}{c}32.20 \\
(34.52)\end{array}$ & $\begin{array}{c}302.1 \\
(340.6)\end{array}$ & $\begin{array}{c}244.2 \\
(309.9)\end{array}$ & $\begin{array}{c}58.09 \\
(40.79)\end{array}$ & $\begin{array}{c}54.11 \\
(43.13)\end{array}$ & $\begin{array}{c}356.9 \\
(349.5)\end{array}$ & $\begin{array}{c}295.0 \\
(325.6)\end{array}$ \\
\hline Observations & 644 & 423 & 644 & 423 & 644 & 423 & 644 & 423 \\
\hline R-squared & 0.006 & 0.012 & 0.005 & 0.011 & 0.006 & 0.009 & 0.005 & 0.011 \\
\hline Baseline Covariates & No & Yes & No & Yes & No & Yes & No & Yes \\
\hline \multicolumn{9}{|c|}{ Panel B: Bandwidth 10\% Margin of Political Loyalty } \\
\hline Loyal $_{m t}$ & $\begin{array}{c}22.96 \\
(26.64)\end{array}$ & $\begin{array}{c}15.72 \\
(27.43)\end{array}$ & $\begin{array}{c}278.4 \\
(315.1)\end{array}$ & $\begin{array}{c}204.7 \\
(232.6)\end{array}$ & $\begin{array}{c}24.75 \\
(27.34)\end{array}$ & $\begin{array}{c}11.29 \\
(27.74)\end{array}$ & $\begin{array}{c}302.2 \\
(322.5)\end{array}$ & $\begin{array}{c}214.9 \\
(242.1)\end{array}$ \\
\hline Observations & 1,220 & 826 & 1,220 & 826 & 1,220 & 826 & 1,220 & 826 \\
\hline R-squared & 0.002 & 0.004 & 0.002 & 0.002 & 0.002 & 0.004 & 0.003 & 0.002 \\
\hline Baseline Covariates & No & Yes & No & Yes & No & Yes & No & Yes \\
\hline
\end{tabular}

Notes: Robust standard errors are clustered at the province-election year level and reported in parentheses. This table reports sharp Regression-Discontinuity (RD) estimates on the effect of political loyalty on internally forced migration from municipalities of origin. Columns (1)-(4) and columns (5)-(8) present the coefficients for the first and second year of incumbency, respectively. The dependent variables in these regressions are the number of IDP and the cumulative sum of IDP expelled from a particular municipality since 1993 (per ten thousand inhabitants). Panels A and B report coefficients using a five and ten percent bandwidth of the margin of political loyalty around the cutoff point of zero, respectively. The margin of political loyalty is defined as the vote share difference between the incumbent candidate and the second best candidate at the municipal level. * p-value $<0.10 * *$ p-value $<0.05$ $* * *$ p-value $<0.01$. 




\section{The Effect of Grade Retention on Secondary School Performance: Evidence from a Natural Experiment ${ }^{\ddagger}$}

\footnotetext{
${ }_{\ddagger}^{\ddagger}$ Joint work with Maria Ferreira Sequeda and Bart Golsteyn. This research is partly financed by a VIDI grant from the Netherlands Organization for Scientific Research (NWO). The authors are grateful to Lex Borghans, Giorgio Brunello, Andries de Grip, Caroline Hoxby, Olivier Marie, Annemarie Künn-Nelen, Steffen Künn and participants at the Maastricht University's Workshop in Economics, the 32nd conference of the European Society for Population Economics in Antwerp, and the 9th IWAEE workshop in Catanzaro for invaluable comments and suggestions. We also thank the Colombian Inspectorate of Education (ICFES), the National Bureau of Statistics (DANE) and the CEDE institute at Universidad de los Andes, Colombia, for sharing their datasets on the SABER11 test and the $\mathrm{C} 600$ census.
} 


\subsection{Introduction}

Retention in school is common and widespread, ${ }^{1}$ but its consequences for school performance are theoretically unclear and empirically understudied. Effects can be expected both for retained and nonretained students. For the retained, there may be positive effects as repeating a grade can help to acquire basic knowledge needed to perform well later on. But retention may instead also have negative effects on school performance if, for instance, self-esteem and motivation decrease as a result. For the non-retained, the relationship between retention and performance works via different mechanisms. One important positive effect for the non-retained at the upper end of the ability distribution may be that if weaker students in class are retained, the level of teaching adjusts accordingly, and better students can learn more. A positive effect of retention at the lower end of the ability distribution may be that the threat of being held back can stimulate children to work harder in school. ${ }^{2}$ But this threat may also have negative consequences, as there is a negative correlation between mental stress and academic performance. Taken together, empirical research on the effect of retention on school performance is needed as its expected effects are ambiguous from a theoretical point of view.

This chapter studies the causal effects of retention on school performance, both for students who are retained and for those who are not retained. Specifically, we analyze the effect of retention in 10th grade on performance in 11th grade, the last year in secondary school (nominal age: 16-17), using two administrative datasets from Colombia. The first, provided by the Inspectorate of Education, includes data for all students in Colombia on scores from a centralized exam in the last year of secondary education. The second dataset, from the National Bureau of Statistics, contains information on retention rates across all schools in Colombia. We are able to link the two datasets using unique school identifiers.

An important empirical challenge in studying the relationship between school performance and retention is that omitted variables may drive the relationship. For instance, high ability children may be less likely to be retained and may also obtain higher school grades. This implies that a naïve estimation of the effect of retention on grades may be negatively biased for retained students. In contrast, the impact can be positively biased for both non-retained pupils, and students at the margin of repeating a grade.

To overcome this problem, we exploit a policy change with respect to retention. From 2002 to 2009, schools were by law not allowed to retain more than 5 percent of their students. In 2010, this directive was abolished and since then, schools are free to decide how many children should repeat a grade. The abolishment of the law increased retention rates dramatically in some schools, while in others it had no effect. We analyze the effect of retention on school performance in a difference-in-differences setting in which treatment and control groups are defined by the above-median and below-median historical

\footnotetext{
${ }^{1}$ In the United States, around 10 percent of all students are retained between kindergarten and eighth grade. In Germany and France, respectively 9 and 18 percent of all students are retained in primary school (Fruehwirth et al., 2016).

${ }^{2}$ One may also argue that this threat leads to other effects. Belot and Vandenberghe (2014) exploit a law reform to find that an enhanced threat of grade retention does not lead to better medium-term outcomes.
} 
increase in retention attributed to the law change, respectively. This approach is for instance also used by Havnes and Mogstad (2011) and Bauernschuster et al. (2016) in a different context than ours. Placebo tests in which we impose that the change occurs in a different year than 2010 show that trends in math and language test scores are similar in control and treatment group before the law was repealed, indicating that we can use a difference-in-differences model to estimate the causal effects of increased retention on school performance.

Our results indicate that increased retention in schools has positive effects on the performance of retained students as they score higher on the language test. In contrast, we observe no significant effects on math scores. When analyzing the results across the distribution of language scores, we find that especially low performing retained students benefit from increased retention. These results suggest that by repeating a class, students at the lower end of the ability distribution get a more thorough understanding of the material which enables them to perform better later on. Distinguishing between low, middle and highly treated schools reveals the non-linearity of the effect of retention: in middle treated schools, i.e. schools that moderately increased retention, the improvement is more pronounced than in highly treated schools.

For marginally non-retained students, the effects of increased retention are negative on language scores, especially at the lower end of the test performance distribution. These results remain both qualitatively and quantitatively robust to the inclusion of potentially important control variables, clustering of standard errors at the school level, and when performing other robustness checks. Theoretically, there are several reasons for this negative effect. First, the positive selection effect for non-retained students may be dominated by a negative effect of sharing the classrooom with a larger share of lower performing peers. Second, it may be that students strategically substitute effort between stem and non-stem subjects as the probability of repeating a grade rises. Decreasing marginal productivity in both courses implies that math scores are not expected to increase as much as language scores decrease.

While the above explanations are plausible, we cannot explicitly test them as our sources of information do not contain data on motivation and/or individual effort across academic subjects. Instead, our analysis is focused on school-driven mechanisms that might explain the impacts we identify for retained and marginal students alike. We provide evidence that neither class size nor teachers' average educational achievements are relevant mechanisms which can explain our findings. In contrast, increasing participation of positively selected, inexperienced teachers in the classroom seems to be the amplifying force behind the benefits and costs of increased retention. Newly hired teachers are highly motivated but their effort may be directed on fulfilling the educational needs of good students, at the cost of neglecting the same needs for less able pupils.

Our analysis contributes to the literature in various disciplines that have studied the effects of retention on school performance. Several articles in School Psychology and Sociology of Education analyze the relationship between grade retention and later school performance, mostly reporting this relationship to be negative. McCoy and Reynolds (1999) report that retention has a negative relationship with reading 
achievement. Jimerson et al. (1997) find no evidence that retention is related to school performance. Jimerson (1999) follows students for 21 years in a longitudinal study to show that retained students have worse educational and employment outcomes in late adolescence. Silberglitt et al. (2006) find that retained students made less educational progress compared to a random group of other students. Stearns et al. (2007) report that students who repeat a grade prior to high school have a higher risk of dropping out of high school than students who are continuously promoted. An important caveat is that these articles report correlations and not causal estimates. Although correlations are informative, important confounders may bias such estimates. As previously explained, we expect a downward (upward) bias for retained (non-retained) students.

There is a small but growing literature that estimates the causal effect of grade retention on subsequent educational outcomes. ${ }^{3}$ The literature reveals that results are mixed, documenting positive as well as negative estimates. The results depend on the context and age of students. Firstly, some papers study the effects of retention at young ages. Koppensteiner (2014) examines the effect of automatic grade promotion on academic achievement (math scores) at primary school in Brazil. Applying a difference-indifferences approach that exploits variation over time and across schools in the grade promotion regime, the author finds a negative and significant effect of about seven percent of a standard deviation on math test scores. Fruehwirth et al. (2016) evaluate the effect of retention on achievement using data from children in kindergarten. Accounting for dynamic selection into retention, they find that children who are retained in kindergarten would have performed as much as 27 percent higher on math and reading tests in the next year if they had not been retained. Jacob and Lefgren (2004) instead find positive effects of retention at an early age. They assess the effects of retention in the Chicago Public School system using variation in retention generated by a test-based promotion policy, and find that retention has a modest but positive net impact on test scores for third grade students, while it increases academic achievement for low-achieving third graders. However, they also find that retention appears to have little or no effects for sixth-grade students.

Secondly, some studies have assessed the effects of retention on achievement in high school. A first set of papers reports negative effects. Jacob and Lefgren (2009) show that retention among younger students (sixth grade) does not affect the likelihood of high school completion, but retaining low-achieving eighth grade students in elementary school increases the probability that these students will drop out of high school. Manacorda (2012) studies the effects of retention in secondary junior high school (grades 7 to 9) in Uruguay on dropout rates and school attainment, exploiting a discontinuity established by a rule of automatic grade failure for pupils with more than three failed subjects at the end of the school year. The analysis reveals that retention increases school dropout and reduces school attainment. While analyses in secondary education focus mostly on dropout rates or completion of school, García-Pérez

\footnotetext{
${ }^{3}$ There may also be peer effects of retention. Hill (2014) investigates the extent to which course repeaters in high school mathematics courses exert negative externalities on their course-mates. Using individual and schoolspecific course fixed effects to control for ability and course selection, the study shows that increasing the share of repeaters in each course results in a moderate, significant increase in the probability of course failure for firsttime course-takers. Results suggest that the negative effect is only evident when the share of repeaters reaches a threshold of 5 to 10 percent of the total number of course-takers.
} 
et al. (2014) measure the effect of grade retention on Spanish students' PISA math scores at age 15, using the student's quarter of birth as an instrumental variable. They find that grade retention has a negative impact on educational outcomes. Those who are retained during primary education suffer more than those retained in secondary school.

Contrary to these findings, a second set of papers provides estimates of positive effects of retention in high school. Mahjoub (2017) finds large positive effects of retention on test scores: around 1.6 times the standard deviation of the achievement gain, using quarter of birth as an instrument. The average effect of the treatment on the treated (ATT) ranges between one and one-quarter of a standard deviation of the test scores. Grade repetition in junior high school is also shown to increase the probability of graduation by 2.5 percentage points. Eide and Showalter (2001) use an instrumental variable for retention based on exogenous variation across states in kindergarten entry dates to find tentative evidence that retention may benefit students by both lowering dropout rates and raising labor market earnings. They find these effects to be relevant for white students, but not for black students.

A common approach in these studies is that the benefits of retention are evaluated at the margin where retention was increased by the natural experiment. An important issue with this approach is that the estimated benefits may differ at other moments of the distribution of students. For low performing students, the benefits of repeating a class may be positive while for high performing students there are probably negative effects. Schools are aware of this and aim to retain students until the marginal student does not benefit from retention.

The main contribution of our study to this literature is that we analyze the non-linearity of the effect of retention on test scores at various moments of the ability distribution. We show that modest increases in retention lead to higher scores in language for the retained students, but when many students are retained, such gains decrease.

This analysis further contributes to the literature by studying the effects of retention on educational outcomes. Firstly, we separately analyze the effects of retention for retained and marginally non-retained students. As indicated earlier on, the expected effects of retention are different for these groups. To evaluate the costs or benefits of retention for society, it is important to take the effects for both groups into consideration. Second, we also test transmission mechanisms at the school level, highlighting the role of teachers' staff composition on determining the differentials in test scores we observe as an outcome of increased retention. Third, our empirical approach to elicit causal effects departs from most other papers in this literature. We exploit the effects of a law change, which enabled schools to retain more children. Finally, we provide evidence on the effect of retention for a developing economy using a large administrative dataset, fairly representative of the Colombian educational system.

Closest to our approach is the analysis developed by Koppensteiner (2014), who examines the effect of automatic grade promotion on academic achievement (math scores) in primary schools in Brazil using a difference-in-differences approach. Besides that we evaluate effects of retention separately for retained 
and non-retained students, and that we study the effects in secondary education and not in primary education, our study differs from his in the sense that we can show with placebo tests that the pre-treatment trends in school performance are common in treatment and control groups, i.e. the key underlying assumption of the difference-in-differences framework. Koppensteiner (2014) shows instead that school and student characteristics of treatment and control groups tend to be similar before the treatment occurred.

The setup of this chapter is as follows. Section 2 summarizes the Colombian context and the educational reform we exploit. Section 3 discusses the empirical strategy in detail. Section 4 describes the dataset and its main sources of information. Our central findings, additional robustness checks, and transmission mechanisms are presented in Section 5. Finally, Section 6 concludes.

\subsection{Institutional Background}

\subsubsection{The Colombian Educational System}

Colombia has an eleven-year system of elementary and secondary education, consisting of five years of primary school (1st to 5th grade), four years of lower secondary education (6th to 9th grade) and two years of upper secondary education (10th to 11 th grade). ${ }^{4}$ The required age of entry to 1 st grade is six years. Therefore, if children are not retained, they are expected to complete their secondary education at ages 16-17.

The educational system in Colombia is a comprehensive school system with no academic tracking at any grade. ${ }^{5}$ However, at the start of upper secondary education, schools differentiate in the provision of additional courses to complement the compulsory curriculum set by the Ministry of Education. These additional courses are organized in two specialization programs: one is more academic and the other more technical in nature. The academic program provides general education in arts, sciences and humanities, whereas the technical program provides vocational knowledge and practice in technology, craft industry, business, pedagogics, or agriculture.

Upon completion of the 11th grade of secondary school, all students, regardless of the chosen program, participate in a national standardized exam (“SABER11," in Spanish), an achievement and competency

\footnotetext{
${ }^{4}$ Elementary and secondary education in Colombia is offered in two school calendars: A calendar labeled "A" that runs from February until November, and a calendar "B" from September to June. Most schools (92\%) in the country operate in calendar A. Formal education is also offered by schools in three different class-schedules: a morning schedule, an afternoon schedule, and a full-day schedule. Students opt or are allocated by the school to attend either one of these. Most students in secondary education attend school either in the morning or the afternoon schedule $(78 \%)$.

${ }^{5}$ The Ministry of Education regulates all levels of education and national exams for both public and private schools.
} 
test that is administered every year by the National Institute for the Assessment of Education ("ICFES," in Spanish). ${ }^{6}$ This exam is a high-stakes evaluation, required not only for admission to tertiary education, but also to receive the high-school diploma. This test is also widely considered as the reference examination to evaluate the quality of secondary education across the country. In line with previous literature on grade retention, we focus on students' performance on the math and language parts of the test as the main outcome of our analyses.

\subsubsection{The Automatic Promotion Policy Rule (AUP)}

In 2002, by mandate of the Ministry of Education (Decree 230 of 2002), schools were each year permitted to retain up to a maximum of five percent of their students. This retention policy was implemented to reduce costs attributed to higher retention rates (i.e. low performance, low motivation, dropouts, etc.) without compromising the quality of education provided by the system (Martínez and Herrera, 2002). According to the policy mandate, a student should have been retained if at least one of the following three circumstances occurred: i) the student received an unsatisfactory performance evaluation in three or more academic subjects in the academic year, ii) the student received an unsatisfactory performance evaluation in math and language courses during the current and two previous grades, or iii) the student failed to attend at least $25 \%$ of all academic activities during the academic year. However, schools were required to adjust their evaluation standards to comply with the law, which forced them to promote at least $95 \%$ of all their students.

While the reform was considered moderately successful in terms of reducing school dropouts, the incentives to underperform at school as perceived by schools and teachers, led the Ministry of Education to eliminate the Automatic Promotion Policy rule. ${ }^{7}$ In February 2009, the 5\% retention restriction was replaced by the Ministry of Education through a new regulation mandate (Decree 1290 of 2009), allowing schools from 2010 onwards to retain as many students as they considered necessary, and thereby giving them more discretion in their evaluation and promotion procedures. We use the terms Automatic Promotion Policy (AUP) to indicate the period until 2009 and Free Retention Policy (FRP) from 2010 onwards. Overall, the abolition of the AUP regime increased students' retention rates across all grades of secondary education from 4.3 percent to 7.7 percent, on average, in all schools in the country.

\subsection{Empirical Strategy}

We evaluate the effects of retention in 10th grade on math and language performance in the secondary school exit exam conducted at 11th grade. The empirical challenge in studying this question is that omitted variables may drive the relationship. A naïve estimation using OLS may be negatively biased

\footnotetext{
${ }^{6}$ Hereafter, we will refer to this institute as the Inspectorate of Education.

${ }^{7}$ Ministry of Education, Press Release April 17, 2009.
} 
for retained students if the lower scores they obtain are not due to retention but to their lower ability. As students' ability increases, we might expect the benefits of grade retention to be decreasing and, for the upper end of the ability distribution, to negatively impact academic performance. Nonetheless, such counterproductive effects may be veiled by, for instance, the positive sorting of skilled students in subsequent grades as a byproduct of increased retention.

We exploit a policy change in Colombia that occurred in 2010 and implied that schools facing constraints in their retention requirements (AUP regime) were allowed to retain as many students as they considered appropriate (FRP regime). To identify the effect of grade retention on test scores, we implement a difference-in-differences framework which exploits the school-year variation on retention rates.

In particular, we classify schools in two groups: the treated group, consisting of schools that increase their retention rates after the law change, and the control group, composed by schools in which retention rates remained relatively constant. We classify schools into the treated or control categories using the difference between the schools' average retention rate at 10th grade between both policy regimes, the AUP regime (2007-2009) and the FRP regime (2010-2012). Sorting schools on this difference, we define the treated group as the pool of schools with an above-median increase in their retention rates, and the remaining schools are labeled the control group. ${ }^{8}$ Panel (a) in Figure 4.1 shows the retention rates for treated and control schools across years. In control schools, on average, such rates decreased slightly after the law change by approximately 1.4 percentage points. In contrast, treated schools increased retention rates by 7.6 percentage points, implying that the latter retained 9.0 percentage points more than control schools.

It is plausible that schools might have reacted differently to the same policy, suggesting that the grade retention effect is heterogeneous across schools with similar characteristics. We account for this by distinguishing quintiles of the difference in retention rates. Panel (b) in Figure 4.1 shows the retention rates across time for the four quintile groups in which schools raise retention during the FRP regime. First, we observe that retention rates among schools in the second quintile barely change. These schools can be considered as an alternative "control" group. Second, we observe three groups of schools (quintiles 3 to 5) that are affected differently by the policy change. Since retention rates in these groups increase on average by 2,6 , and 12 percentage points, we label these schools as low treated, medium treated, and highly treated, respectively. Furthermore, we observe schools in the first quintile as a group of defiant schools since they decrease retention rates by 4 percentage points. As we consider these schools not being fully comparable with the universe of compliant schools, we decided to exclude them only from this specific analysis. ${ }^{9}$ With exception of this latter group, all remaining schools retained students in the AUP regime as required, with an average retention rate of 3.6 percent.

\footnotetext{
${ }^{8}$ This treatment-control classification is increasingly implemented in the economics literature. Examples of this strategy are provided by Havnes and Mogstad (2011) and Bauernschuster et al. (2016). These authors analyze the effects of increased child care coverage on parental economic outcomes.

${ }^{9}$ Namely, we keep all observations in our estimations, but we refrain from interpreting effects for schools in the defiant group. This restriction in the our analyses is only relevant when we account for the heterogeneous effects of retention. In contrast, results involving treated and control schools classified by the use of the above-median increase in retention correspond to all schools in our sample.
} 
Figure 4.1: Retention Rates per Multiple Treatment Status

(a) Control vs. Treated Schools

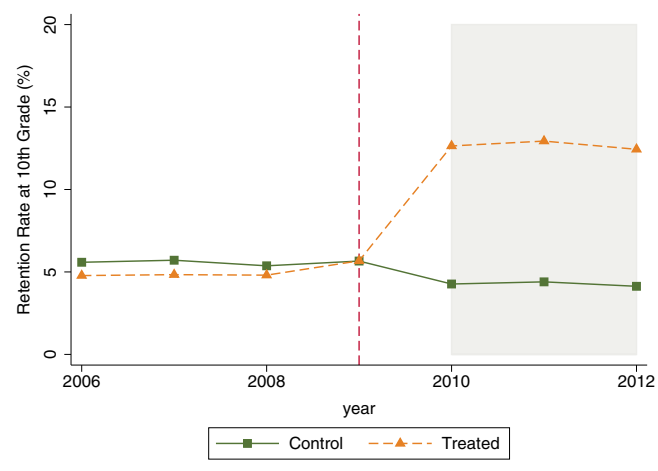

(b) Control vs Treated Schools - Heterogeneous Treatment Status

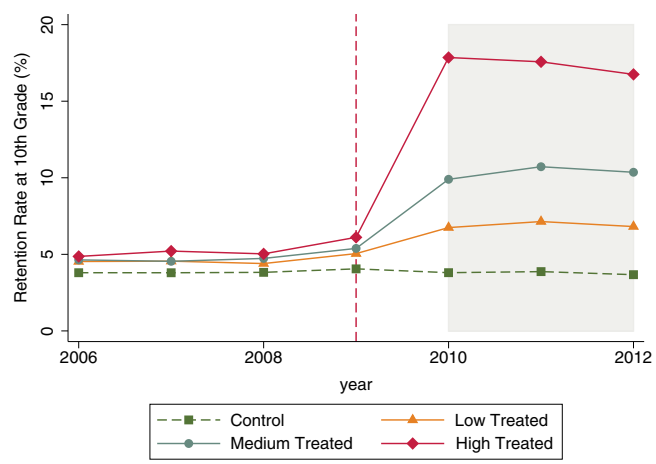

Notes: Panel (a) displays retention rates at 10th grade (in percentage points) for treated and control schools. Treatment schools are defined as those with above-median increase in their retention rates at 10th grade from the automatic promotion years to the free retention years. Control schools are defined as those with below-median increase. Panel (b) shows retention rates at 10th grade for control and treated schools, for the different treatment definitions explained in the main text: Highly Treated (HighTreated), Medium Treated (MediumTreated), and Low Treated (LowTreated). The dashed vertical line denotes year 2009 where schools were notified that the AUP regime will no longer hold. The gray area denotes the years where the FRP regime was in place.

The baseline difference-in-differences specification we implement is:

$$
Y_{s t}=\alpha_{s}+\delta_{t}+\sum_{h=1}^{2} \gamma_{h}\left[\text { Group }_{s} \times F R P_{t-h}\right]+\beta X_{s t}+\varepsilon_{s t}
$$

in which $Y_{s t}$ denotes standardized test scores for school $s$ in exam year $t . \alpha_{s}$ and $\delta_{t}$ are fixed effects by school and exam year, respectively. Group is a dummy variable that takes value 1 for schools in the treated group, and zero for schools in the control group. In our basic specification, treated schools 
$\left(\right.$ Treated $\left._{s}\right)$ are those with above median changes in retention rates and control schools with a belowmedian change in retention rates. In our more complete specification, we include three treatment dummies corresponding to low treated $\left(\right.$ Low_Treated $\left._{s}\right)$, medium treated (Medium_Treated $)$, and high treated schools $\left(\right.$ High_Treated $\left._{S}\right) . F R P_{t-h}$ is an indicator variable with value 1 if the FRP regime was in place $h$ years before exam year $t$, and zero otherwise. The interaction term Group $p_{s} \times F R P_{t-h}$ therefore measures the variation in tests scores that can be causally attributed to the shift in the retention policy from year $t-h$ onwards. For each regression, we run two specifications. First we run our regressions without covariates. Second, for each exam year we include covariates for the first two lags of school-specific attributes that change over time. In this way, we account for pre-FRP variation in characteristics among schools. This set of control variables is denoted in the equation as $X_{s t}$. Finally, $\varepsilon$ are standard errors clustered at the school level.

We aim to analyze the effects of increased retention separately for retained and non-retained students. However, it is worth explaining how we obtain these effects as we do not observe individual retention outcomes (see more on this in the data overview section). The cohort of students taking the exam in year $t$ is largely composed of two types of students: i) 10th grade students in year $t-1$ that were promoted to 11 th grade at year $t$, and ii) 10th grade students that were retained in year $t-2$, repeated and passed 10th grade in year $t-1$, and finally enrolled to 11 th grade in year $t$. Hence, our parameters of interest are $\gamma_{1}$ and $\gamma_{2}$.

The first parameter measures the effect of being exposed one year to the FRP policy in 10th grade on schools' tests scores in 11th grade the next year. The expected direction of this effect is ambiguous. On the one hand, the sign of $\gamma_{1}$ reveals whether non-retained students benefited from higher retention rates because of a positive sorting effect. In such a case we expect the effect to be positive. On the other hand, if we interpret this coefficient as the effect of increased retention on the marginal student (i.e. students that should have been retained but were promoted by a very small margin), we might expect the impact to have the opposite sign relative to the effect of retention on the retained students, For instance, if the latter effect is positive, marginal students are worse off when promoted to 11th grade because they will miss the chance to receive further training on the academic subjects they struggled with the most. The second parameter $\gamma_{2}$ measures the impact of FRP regime's exposure in the previous two consecutive years on schools' test scores. Assuming that students are retained in 10th grade only once, this impact can be mostly attributed to retained students. Because of our treatment-control classification, $\gamma_{1}$ and $\gamma_{2}$ are best interpreted as intention-to-treat effects (ITT). To obtain the average treatment effects on the treated (ATT), we will rescale these coefficients by the difference in retention rates between treated and control schools implied by the law change.

The main identification assumption in this setting is that the variation in retention rates is orthogonal to expected changes in test scores. This assumption is equivalent to claim that treatment and control schools would have shared similar trends in test scores if the retention policy had remained the same. We formulate an alternative specification to test this assumption: 


$$
\begin{aligned}
Y_{s t}= & \alpha_{s}+\delta_{t}+\sum_{k=2008}^{2010} \mu_{k}\left[\text { Treated }_{s} \times(\text { Year }=k)\right] \\
& +\sum_{k=2011}^{2013} \theta_{k}\left[\text { Treated }_{s} \times(\text { Year }=k)\right]+\beta X_{s t}+\varepsilon_{s t} .
\end{aligned}
$$

In equation (4.2), the null hypothesis of interest is that pre-FRP differences in trends between treated and control units are not significantly different from zero (i.e. $\mu_{2008}=\mu_{2009}=\mu_{2010}=0$ ). Namely, we control for the interaction between the treatment status and those exam years where test takers, by construction, were not exposed to increased retention rates because of the policy change. As we will elaborate further on, we are not able to reject such hypotheses at conventional significance levels.

In addition to the above specification, we also perform placebo tests to account for artificial policy changes that should not have any effect on test scores:

$$
Y_{s t}=\alpha_{s}+\delta_{t}+\sum_{h=1}^{2} \pi_{h}\left[\text { Group }_{s} \times \text { FakeFRP }_{k, t-h}\right]+\beta X_{s t}+\varepsilon_{s t}
$$

In equation (4.3), FakeFRP $P_{k, t-h}$ is an indicator variable that takes the value 1 if the FRP regime was in place during year $t-h$, assuming it (artificially) started either in $k=2008$ or $k=2007$. By not being able to reject the null hypothesis of non-significant effects (i.e. $\pi_{1}=\pi_{2}=0$ ), we are confirming that the changes in test scores can be attributed to the elimination of the AUP regime only.

\subsection{Data Overview}

Ideally, a suitable dataset to identify the causal effect of grade retention on school performance should meet two conditions: First, information on individual retention needs to be available. Second, variation on retention outcomes needs to be as good as random. For example, suppose that the Ministry of Education randomizes the obligation to retain no more than 5\% of students across all schools at an specific date. Then, if schools' attributes and outcomes have been followed through time, it is straightforward to adopt a difference-in-differences framework to recover the effect of such policy intervention. A variant of this experimental setting, in a panel data structure, would be that the compliance to the retention law in time changes randomly across schools with similar characteristics.

While our dataset does not fulfill the first requirement, this does not pose a threat to our study as we are able to recover school-level retention rates from administrative sources. As we use retention rates at 10th grade, the pool of test-takers in our sample consists of non-retained students and students who 
were retained in 10th grade only once. Controlling for the first two lags of our "FRP regime exposure" variable, we can differentiate the effect for each type of pupil. The second requirement is fulfilled since, conditional to the schools' treatment-control classification discussed before, variation in retention rates is attributed to the policy change alone.

\subsubsection{Sources of Information and Sample Selection}

The sample we use in this study is taken from two main sources. The first is a dataset from the Colombian Inspectorate of Education. The Inspectorate provides freely downloadable micro-level data on the centralized exam conducted among 2.7 million pupils in their last year of secondary education (11th grade). ${ }^{10}$ This exam, known as SABER11, is a standardized test that evaluates every year a range of seven school subjects. ${ }^{11}$ Test scores range from 0 to 100 in each subject and they are standardized by subject at the national level, so that each student's score is informative about his/her position relative to the national average in that subject. According to the Inspectorate of Education, the tests are comparable for the period 2000-2013.

We use available data from 2007 to 2013 that include math and language scores; student and school identifiers; some schools' attributes such as the academic calendar, daily class schedule, public or private status, specialization programs offered; and information on several individual characteristics such as age, gender, mother's education, and other socio-demographic indicators. We collapse these data at the school-year level, and focus only on our outcomes of interest (i.e. math and language test scores) at several moments of the distribution: mean, 10th percentile, 25th percentile, median, 75th percentile and 90th percentile of the schools' test scores. These scores are all standardized over the entire sample to interpret the effects in terms of standard deviations (SD) at the school level. While representative of the student body that is assessed at the last year of secondary school, this dataset does not collect information on pupil's retention at any stage of the education process.

To obtain retention rates at the school level we rely on the schools' official census, which the Ministry of Education releases each year for public use through the National Bureau of Statistics (DANE, in Spanish). Known as the C-600 census, this dataset contains information on academic indicators that all schools in the country are compelled to report on a yearly basis. We use information from this dataset on retention rates at 10th grade, as well as other school characteristics, such as the number of groups per grade, the number of students enrolled at 10th grade, the number of teachers with a professional degree, the number of teachers hired under the old and new pay scales regulated by the central government, and the number of non-academic staff (managerial, support, health) per school. We use this universal census information for the period 2005-2012. Using unique school identifiers, we are able to match $88.2 \%$ of all schools' test scores to the respective school retention data for the entire period 2007-2013. These

\footnotetext{
${ }^{10}$ This exam takes place every year in the month of September, three months prior to the official end of the school calendar A.

${ }^{11}$ These subjects are: Math, Language, Physics, Biology, Chemistry, History, and Philosophy.
} 
matched data correspond to $85.6 \%(\mathrm{~N}=2,363,997)$ of all students that took the exam during the same period.

Our unit of observation is a school-exam year combination. The estimation sample consists of first-time SABER 11 test takers ${ }^{12}$ from schools that i) offered education exclusively in Calendar A (February to November), ii) did not change this calendar during the period 2007-2013, iii) had no missing values on tests scores, retention rates, and schools' covariates, and iv) reported information on retention rates for at least 3 years, with at least one year before and after the retention law changed. The resulting dataset consist of an unbalanced panel of 6,248 schools, which in total across the 2007-2013 period contains 35,693 observations.

\subsubsection{Common Trends}

Figure 4.2 in panels (a) and (b) shows the average test scores across time for treated and control schools in math and language, respectively. On average, control schools performed better at both subjects during the AUP regime. For instance, students in control schools scored 0.1 of a standard deviation more in the math exam than students enrolled in treated schools. The same patterns are observed in language with students scoring around 0.12 of a standard deviation higher than students in treated schools. Appendix Figure A.4.1 shows the same results when we plot the residuals from a regression including exam-year and schools' fixed effects, as well as time-variant schools' attributes. Figure 4.3 reveals that such trends are also common when distinguishing the treatment groups for high, middle, and low treated schools. These results remain robust to the inclusion of school-specific covariates (Appendix Figure A.4.2).

The main conclusion from these graphs is that there is a common trend in test scores between treated and control schools. This allows us to use a difference-in-differences strategy. The difference-in-differences estimator will isolate time invariant confounding factors, leaving the remaining variation to be attributed to the effect of increasing retention in schools. In the results section, we will provide robust statistical evidence that the common trend assumption holds.

\subsubsection{Summary Statistics}

Table 4.1 reports summary statistics for the sample used to estimate our main results. We present information on schools' characteristics during the AUP regime. Columns (1) and (3) report the number of schools per treatment status, and columns (2) and (4) present the averages of each control variable for both treated and control groups, respectively. Columns (5) and (6) report differences in means and standard errors between treated and control schools.

\footnotetext{
${ }^{12}$ We leave out of the sample the top $1 \%$ and bottom $1 \%$ of students in terms of their age reported at the exam. This selection criterion excludes extreme outliers who reported ages below 12 or above 40 .
} 
Schools differ systematically in their attributes during the AUP regime. Considering socio-demographic attributes of students, control schools present a more favorable composition of students from highly educated households (measured as the proportion of mothers with tertiary education), and few students with poverty status. There is also a larger proportion of public schools in this group, relative to the treatment group. However, treated schools operate under shorter working spells relative to schools in the control group. Moreover, treated schools also seem to present some academic differentiation as they also provide other types of training (e.g. pedagogical, technical vocational training).

With regards to school-related characteristics, treated schools, on average, have more groups per grade and more qualified teachers employed at school. Regarding teachers' compensation and renewal of personnel, we observe that treated schools hire slightly more staff under the new pay scale than control schools, but the overall proportion of teachers under the new pay scale had increased during the last three years of the AUP regime for all schools. In contrast, control schools seem to employ more health professionals (e.g. dentists, physicians) than treated schools. Conversely, treated schools seem to hire more staff for managerial purposes than control schools.

While time-invariant differences between treated and control schools are controlled for by the inclusion of school-specific fixed effects, a potential concern for the identification strategy implemented in this research is that schools with different attributes might self-select into the treatment. To address this issue, we run OLS regressions where the dependent variable is the absolute change in retention rates between the AUP and FRP regime, as this change is used to classify schools into the different treatment and control categories. Controlling for all characteristics listed in Table 4.1, we focus our attention on the extent to which variation in such attributes explains the changes in retention rates that will imply a school to be classified as a treated unit. 
Figure 4.2: Test Scores by Treatment Status

(a) Math Scores

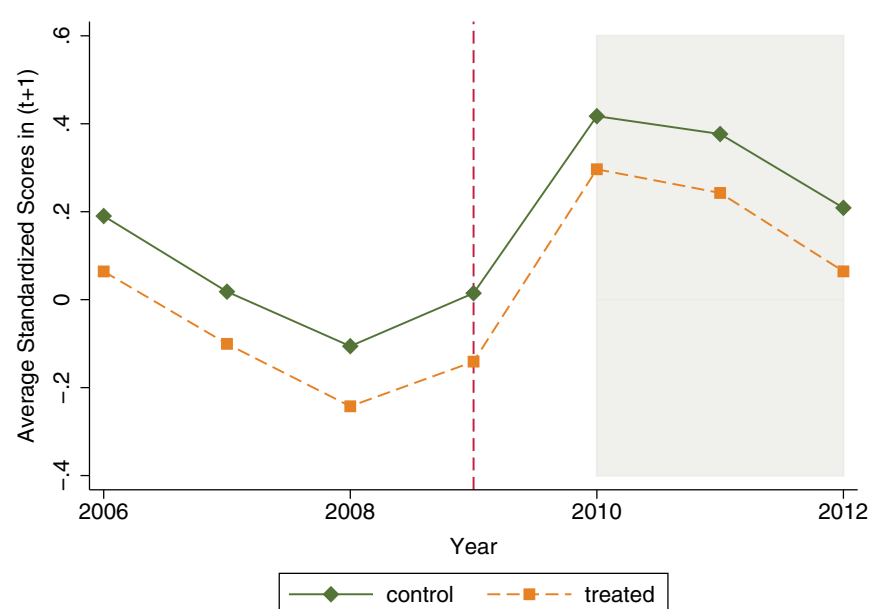

(b) Language Scores

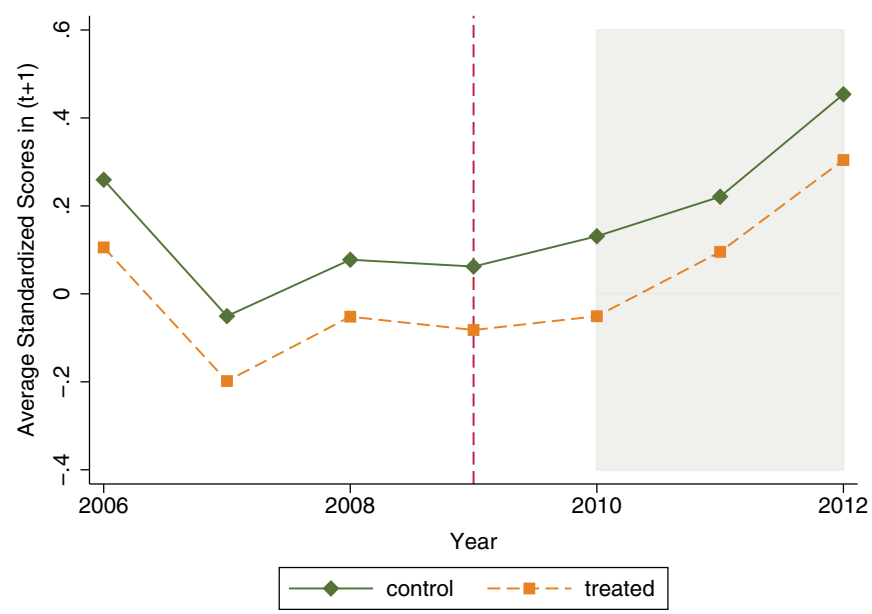

Notes: This figure displays average tests scores in year, for AUP and FRP years. Panel (a) presents common trends on average math scores between treated (dashed lines) and control (solid lines) schools. Panel (b) shows similar trends on average language test scores. 

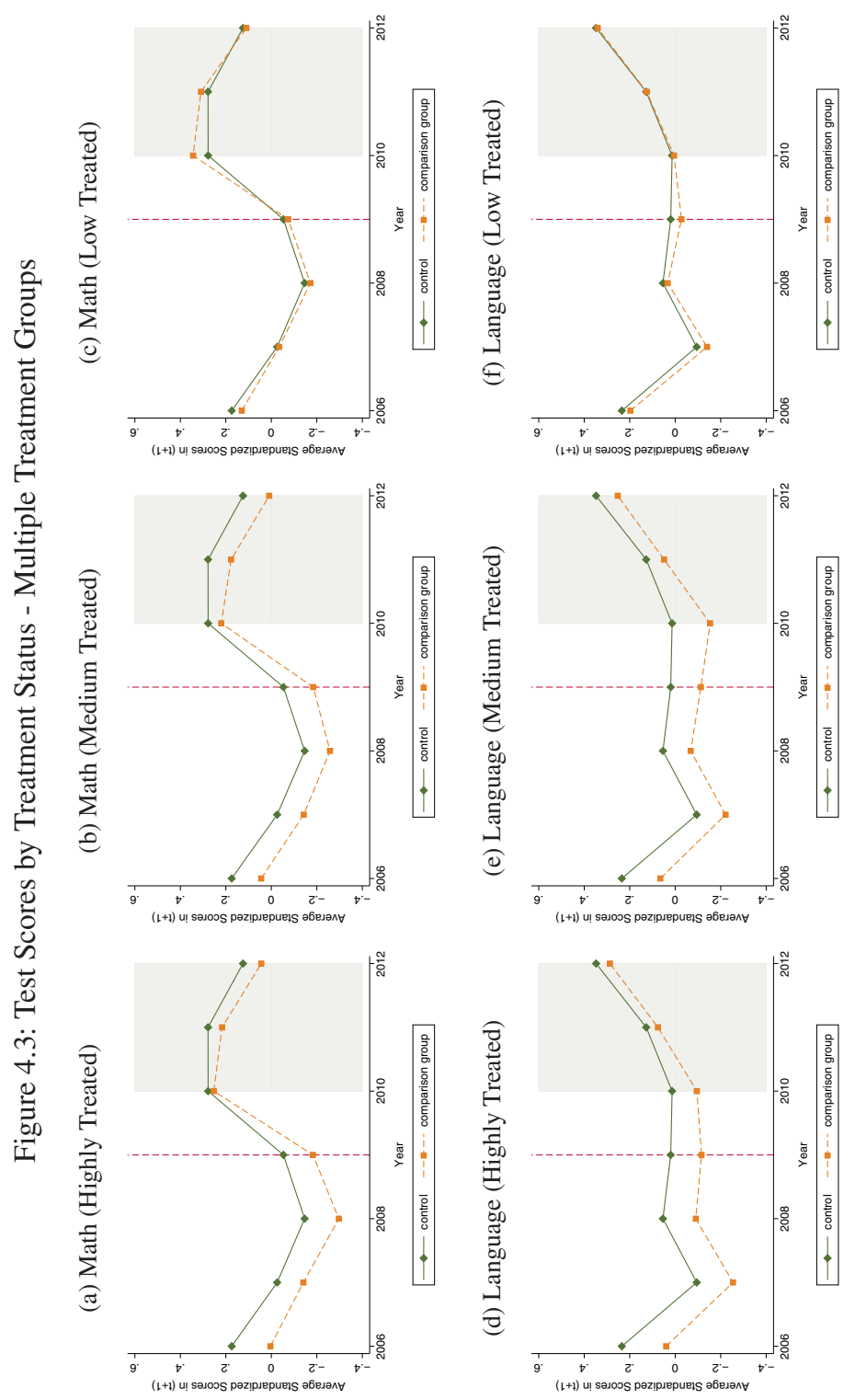

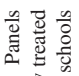

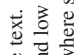

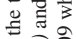

:

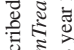

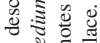

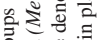

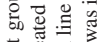

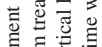

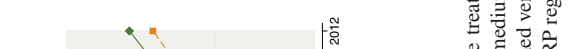

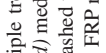

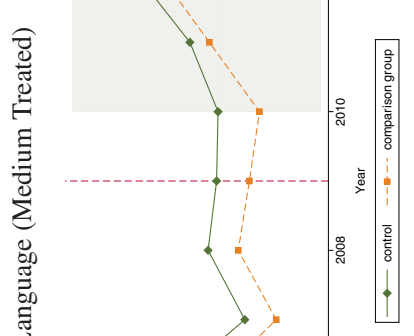

ปั

क है

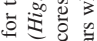

㐘芯芯

온형

可施

के 灵

ष氙

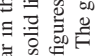

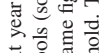

s

앵흘 흐

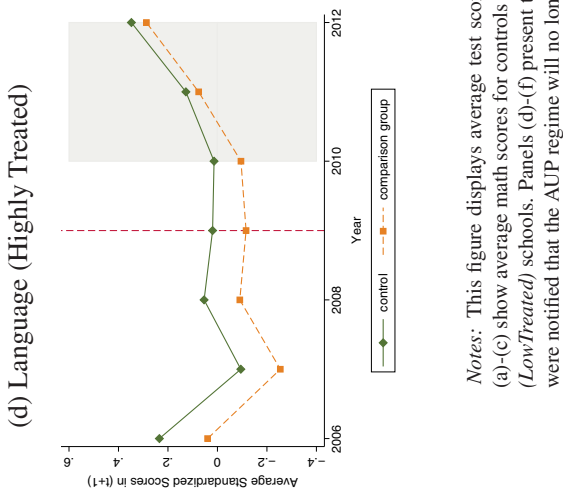




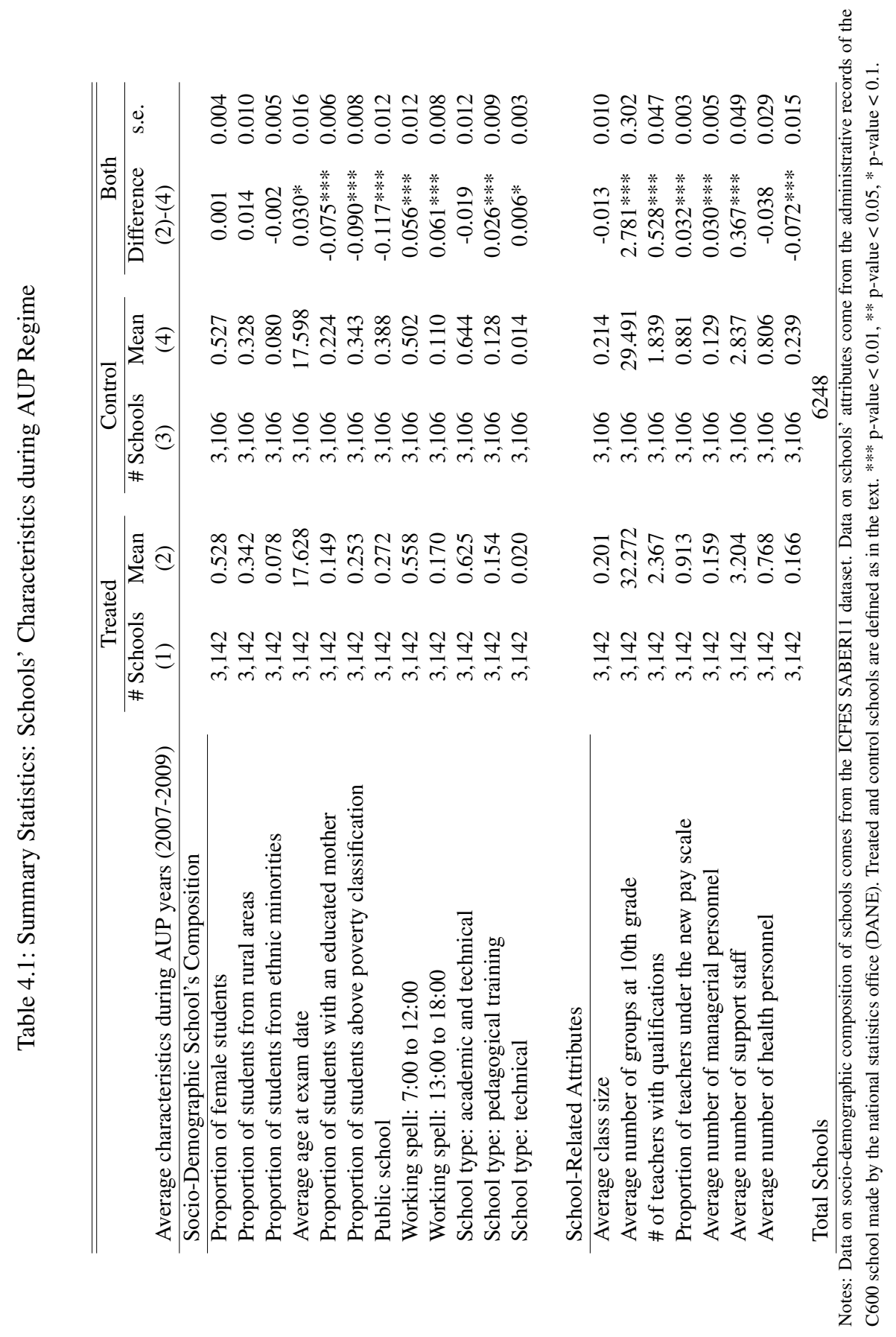


Table 4.2 reports these estimates. Each column reports the regression results using the different treatment groups aforementioned. Interestingly, some attributes are highly significant in explaining treatment status. Nonetheless, we observe that the marginal effects of these covariates are very close to zero. For instance, focusing on the proportion of female students per school, a 10 percentage point increase in this variable explains a decrease in the absolute retention change of about 0.001 percent (Column (1), first row). A notable exception is the positive selection into treatment by public schools, where changes in retention rates range from one to five percent ( 7 th row). However, this attribute is time invariant. Thus, between-school variation is perfectly controlled for with the inclusion of fixed effects per school. Morover, as the R-squared coefficient in all specifications suggests, all school attributes combined cannot explain more than $14 \%$ variation on the dependent variable. For our baseline specification without treatment heterogeneity, the R-squared coefficient indicates that all covariates considered can explain up to $6 \%$ variation on our treatment assignment variable (Column (1)). Similar conclusions can be obtained when we run these models using an ordered probit specification (Appendix Table A.4.1). Overall, these results ease the concerns about potential self-selection into higher retention rates as a function of school characteristics.

\subsection{Results}

\subsubsection{The Effect of the FRP Regime on Schools' Test Scores}

Table 4.3 presents our baseline estimates on the effects of higher retention due to the law change on average math and language standardized test scores. As implied by equation (4.1), in some specifications we include a set of time variant school-specific attributes to obtain the net impact of the FRP regime. All standard errors are clustered at the school level to ensure we account for potential serial correlation, as indicated in the difference-in-differences literature (Bertrand et al., 2004).

Our findings show that the increase in retention does not have a meaningful economic effect on average math school performance. In contrast, we obtain a positive and strongly significant effect on language scores of $6.5 \%$ of a SD for a consecutive 2-year prior exposure to the FRP regime, and an average negative effect of $5.5 \%$ of a SD (Columns (4)-(5), first row) for being exposed to higher retention rates one year before the exam is taken. As treated schools increased retention 9 percentage points more than control schools, this implies an increase in language scores of $7 \%$ of a SD for a 10 percentage point rise in retention rates at 10 th grade. 
Table 4.2: Selection Into Treatment Status - OLS Regressions

\begin{tabular}{|c|c|c|c|c|}
\hline $\begin{array}{l}\text { Dependent Variable: } \\
\text { Change in average retention from AUP to FRP }\end{array}$ & $\begin{array}{c}(1) \\
\text { Treated }_{s} \\
\text { Vs. Control }\end{array}$ & $\begin{array}{c}(2) \\
\text { HighTreated }_{s} \\
\text { Vs. Control }\end{array}$ & $\begin{array}{c}\text { (3) } \\
\text { MediumTreated }_{s} \\
\text { Vs. Control }\end{array}$ & $\begin{array}{c}(4) \\
\text { LowTreated }_{s} \\
\text { Vs. Control }\end{array}$ \\
\hline \multicolumn{5}{|l|}{ School's characteristics during AUP years (2007-2009) } \\
\hline Proportion of female students & $\begin{array}{c}-0.014 * * * \\
(0.004)\end{array}$ & $\begin{array}{l}-0.011 \\
(0.007)\end{array}$ & $\begin{array}{l}-0.000 \\
(0.003)\end{array}$ & $\begin{array}{c}0.000 \\
(0.002)\end{array}$ \\
\hline Proportion of students from rural areas & $\begin{array}{l}-0.003 \\
(0.003)\end{array}$ & $\begin{array}{c}-0.015 * * * \\
(0.005)\end{array}$ & $\begin{array}{l}-0.002 \\
(0.002)\end{array}$ & $\begin{array}{l}-0.001 \\
(0.001)\end{array}$ \\
\hline Proportion of students from ethnic minorities & $\begin{array}{l}-0.003 \\
(0.004)\end{array}$ & $\begin{array}{l}-0.006 \\
(0.008)\end{array}$ & $\begin{array}{l}-0.001 \\
(0.003)\end{array}$ & $\begin{array}{c}0.001 \\
(0.001)\end{array}$ \\
\hline Average students' age at exam & $\begin{array}{l}-0.002 \\
(0.002)\end{array}$ & $\begin{array}{l}-0.000 \\
(0.003)\end{array}$ & $\begin{array}{l}-0.001 \\
(0.001)\end{array}$ & $\begin{array}{l}-0.001^{*} \\
(0.001)\end{array}$ \\
\hline Proportion of students with an educated mother & $\begin{array}{c}-0.019 * * * \\
(0.005)\end{array}$ & $\begin{array}{c}-0.034 * * * \\
(0.009)\end{array}$ & $\begin{array}{c}-0.008 * * \\
(0.004)\end{array}$ & $\begin{array}{l}-0.003 * \\
(0.002)\end{array}$ \\
\hline Proportion of students above poverty classification & $\begin{array}{c}0.010^{* *} \\
(0.004)\end{array}$ & $\begin{array}{l}0.012 * \\
(0.007)\end{array}$ & $\begin{array}{l}-0.001 \\
(0.003)\end{array}$ & $\begin{array}{c}0.002 \\
(0.001)\end{array}$ \\
\hline Public school & $\begin{array}{c}0.026^{* * * *} \\
(0.003)\end{array}$ & $\begin{array}{c}0.049 * * * \\
(0.005)\end{array}$ & $\begin{array}{c}0.012 * * * \\
(0.002)\end{array}$ & $\begin{array}{c}0.005^{* * * *} \\
(0.001)\end{array}$ \\
\hline Working spell: $7: 00$ to $12: 00$ & $\begin{array}{l}-0.002 \\
(0.002)\end{array}$ & $\begin{array}{l}-0.001 \\
(0.003)\end{array}$ & $\begin{array}{c}0.001 \\
(0.001)\end{array}$ & $\begin{array}{c}0.000 \\
(0.001)\end{array}$ \\
\hline Working spell: $13: 00$ to $18: 00$ & $\begin{array}{c}0.004 \\
(0.003)\end{array}$ & $\begin{array}{c}0.001 \\
(0.005)\end{array}$ & $\begin{array}{c}0.000 \\
(0.002)\end{array}$ & $\begin{array}{c}0.001 \\
(0.001)\end{array}$ \\
\hline School type: academic and technical & $\begin{array}{l}-0.001 \\
(0.002)\end{array}$ & $\begin{array}{c}0.005 \\
(0.004)\end{array}$ & $\begin{array}{c}0.002 \\
(0.002)\end{array}$ & $\begin{array}{l}-0.000 \\
(0.001)\end{array}$ \\
\hline School type: pedagogical training & $\begin{array}{l}-0.006 \\
(0.005)\end{array}$ & $\begin{array}{l}-0.012 \\
(0.010)\end{array}$ & $\begin{array}{l}-0.003 \\
(0.005)\end{array}$ & $\begin{array}{c}0.001 \\
(0.002)\end{array}$ \\
\hline School type: technical & $\begin{array}{c}-0.009 * * * \\
(0.002)\end{array}$ & $\begin{array}{c}-0.013 * * * \\
(0.003)\end{array}$ & $\begin{array}{l}-0.001 \\
(0.001)\end{array}$ & $\begin{array}{l}-0.001 \\
(0.001)\end{array}$ \\
\hline Average class size & $\begin{array}{c}0.000^{* *} \\
(0.000)\end{array}$ & $\begin{array}{c}0.000 \\
(0.000)\end{array}$ & $\begin{array}{c}0.000 * * \\
(0.000)\end{array}$ & $\begin{array}{c}0.000 \\
(0.000)\end{array}$ \\
\hline Average number of groups at 10 th grade & $\begin{array}{c}0.003 * * * \\
(0.001)\end{array}$ & $\begin{array}{c}0.001 \\
(0.001)\end{array}$ & $\begin{array}{c}0.000 \\
(0.001)\end{array}$ & $\begin{array}{c}0.000 \\
(0.000)\end{array}$ \\
\hline Proportion of teachers with qualifications & $\begin{array}{c}0.003 \\
(0.006)\end{array}$ & $\begin{array}{c}0.000 \\
(0.011)\end{array}$ & $\begin{array}{c}0.005 \\
(0.005)\end{array}$ & $\begin{array}{l}-0.000 \\
(0.002)\end{array}$ \\
\hline Proportion of teachers under the new pay scale & $\begin{array}{c}0.005 \\
(0.005)\end{array}$ & $\begin{array}{l}-0.003 \\
(0.009)\end{array}$ & $\begin{array}{l}-0.003 \\
(0.004)\end{array}$ & $\begin{array}{c}0.001 \\
(0.002)\end{array}$ \\
\hline Average number of managerial personnel & $\begin{array}{c}0.000 \\
(0.001)\end{array}$ & $\begin{array}{c}0.002 \\
(0.001)\end{array}$ & $\begin{array}{c}0.001 * * \\
(0.000)\end{array}$ & $\begin{array}{l}0.000^{*} \\
(0.000)\end{array}$ \\
\hline Average number of support staff & $\begin{array}{l}-0.001 \\
(0.001)\end{array}$ & $\begin{array}{l}-0.000 \\
(0.001)\end{array}$ & $\begin{array}{l}-0.000 \\
(0.001)\end{array}$ & $\begin{array}{c}0.000 \\
(0.000)\end{array}$ \\
\hline Average number of health personnel & $\begin{array}{l}-0.001 \\
(0.001)\end{array}$ & $\begin{array}{l}-0.004 * \\
(0.002)\end{array}$ & $\begin{array}{l}-0.002 \\
(0.001)\end{array}$ & $\begin{array}{l}-0.000 \\
(0.000)\end{array}$ \\
\hline $\begin{array}{l}\text { Observations } \\
\text { R-squared }\end{array}$ & $\begin{array}{l}6,248 \\
0.064\end{array}$ & $\begin{array}{l}2,474 \\
0.140\end{array}$ & $\begin{array}{l}2,479 \\
0.088\end{array}$ & $\begin{array}{l}2,477 \\
0.046\end{array}$ \\
\hline
\end{tabular}

Notes: Robust standard errors reported in parentheses. This table report OLS regressions where the dependent variable is the absolute retention change from the AUP regime to the FRP regime. Column (1) presents results using all sample of treated and control schools according with the definition from the text. Columns (2)-(4) show estimates for comparable control schools vs. schools labeled highly, medium, and low treated. information on the socio-demographic composition of schools comes from the SABER11 (ICFES) dataset. Information about other school attributes comes from the DANE c600 Census. $* * *$ p-value $<0.01, * *$ p-value $<0.05, *$ p-value $<0.1$. 
A plausible explanation for the positive effect attributed to retained students is that repeating a grade allows them to get a more thorough understanding of the material. Conversely, there may be several reasons for the negative effect on the non-retained students. First, the positive selection effect may be dominated by the negative influence of being in a group with a large fraction of lower performing peers after retention rates increased. Secondly, it may be that students started to allocate strategically more time and effort to study stem subjects when retention rates increased. Decreasing marginal productivity in both subjects implies that math scores do not increase as much as language scores decrease. This latter effect might be particularly relevant for students at the margin of repeating a grade.

\subsubsection{Defining Retained and Non-Retained Students}

To provide further evidence on these effects, we decided to classify students among two retention categories. In the Colombian educational system, the nominal age of graduation is 17 years. Differences in age at the exam date can be explained mostly by having experienced grade retention before (not necessarily at 10th grade only). Hence, we label students as "non-retained" if at the date of the exam they are 17 years old or younger. In contrast, we label students as "potentially retained" if they are 18 years old or older. ${ }^{13}$ Then, we collapse the student and school datasets to create a unbalanced panel where the unit of observation is a school-exam year-retention status combination. ${ }^{14}$ Finally, we estimate the baseline specification for both samples separately.

Table 4.4 presents our findings from the above exercise. Regarding effects on math scores, increased retention rates do not have any strongly significant impact on math scores for either type of students (columns (1)-(4)). For language scores the conclusions differ. In particular, while outcomes for nonretained students are still unaffected, potentially retained students' scores are affected. Estimates in columns (5) and (6) imply that being exposed to higher retention rates under the FRP regime one year (two years) before the exam causes a reduction (increase) of 5\% (6\%) of a SD on language scores. In general, this evidence supports the notion that i) the effect captured by the two-year prior exposure can be fully attributed to retained students and measures the impact of increased retention on test scores and, ii) the one-year prior exposure coefficient accounts for the effect of increased retention on marginal students that should have been retained but managed to "survive" the higher retention rates corresponding to the FRP regime.

\footnotetext{
${ }^{13}$ In Colombia, individuals are legally considered as adults if they are 18 years old or older.

${ }^{14}$ This process leads to have two different datasets. A dataset from non-retained students comprising of 35,103 observations corresponding to 6,235 schools, and a second dataset with information on potentially retained students with 34,534 observations from 6,237 schools.
} 


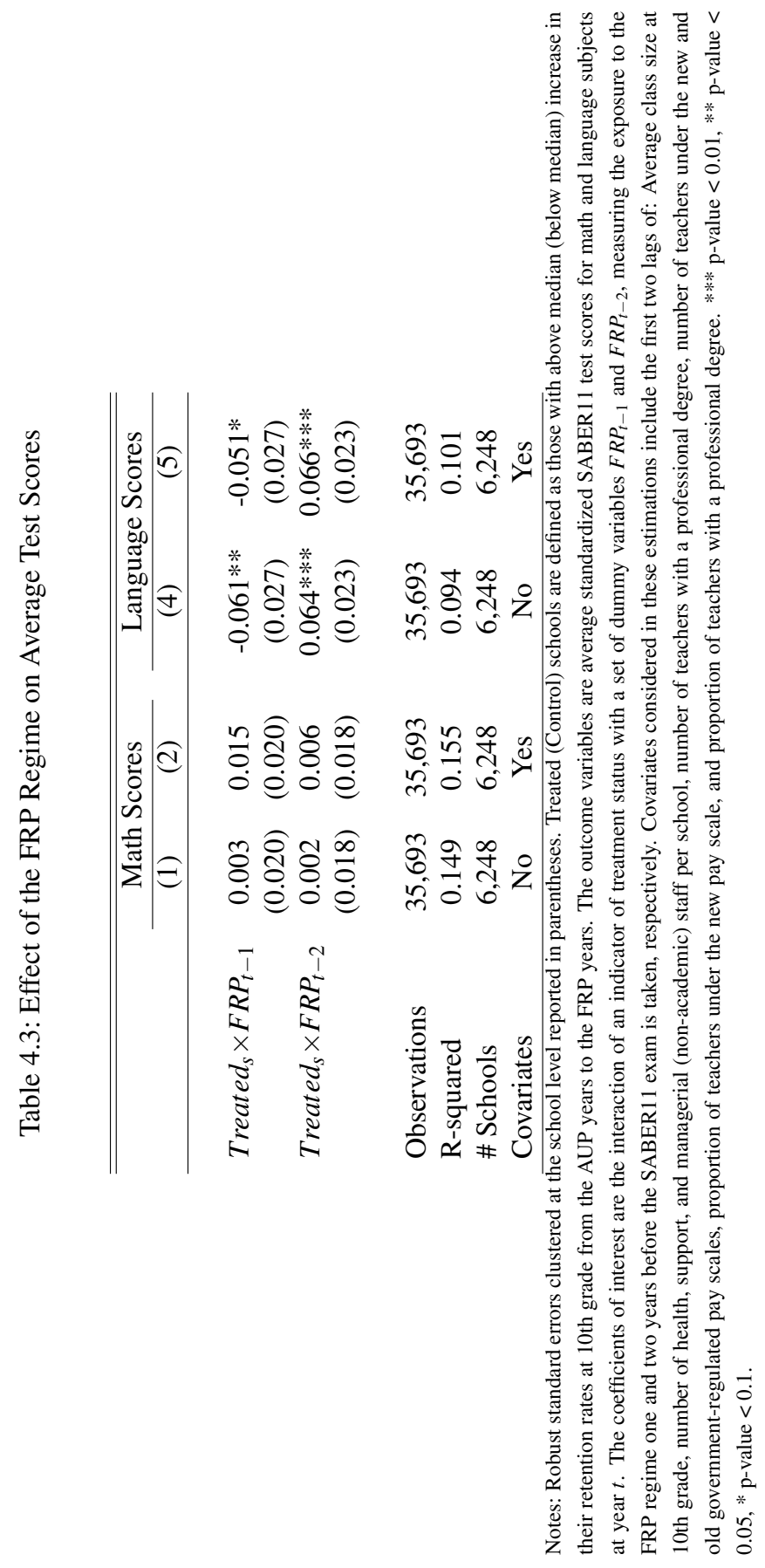




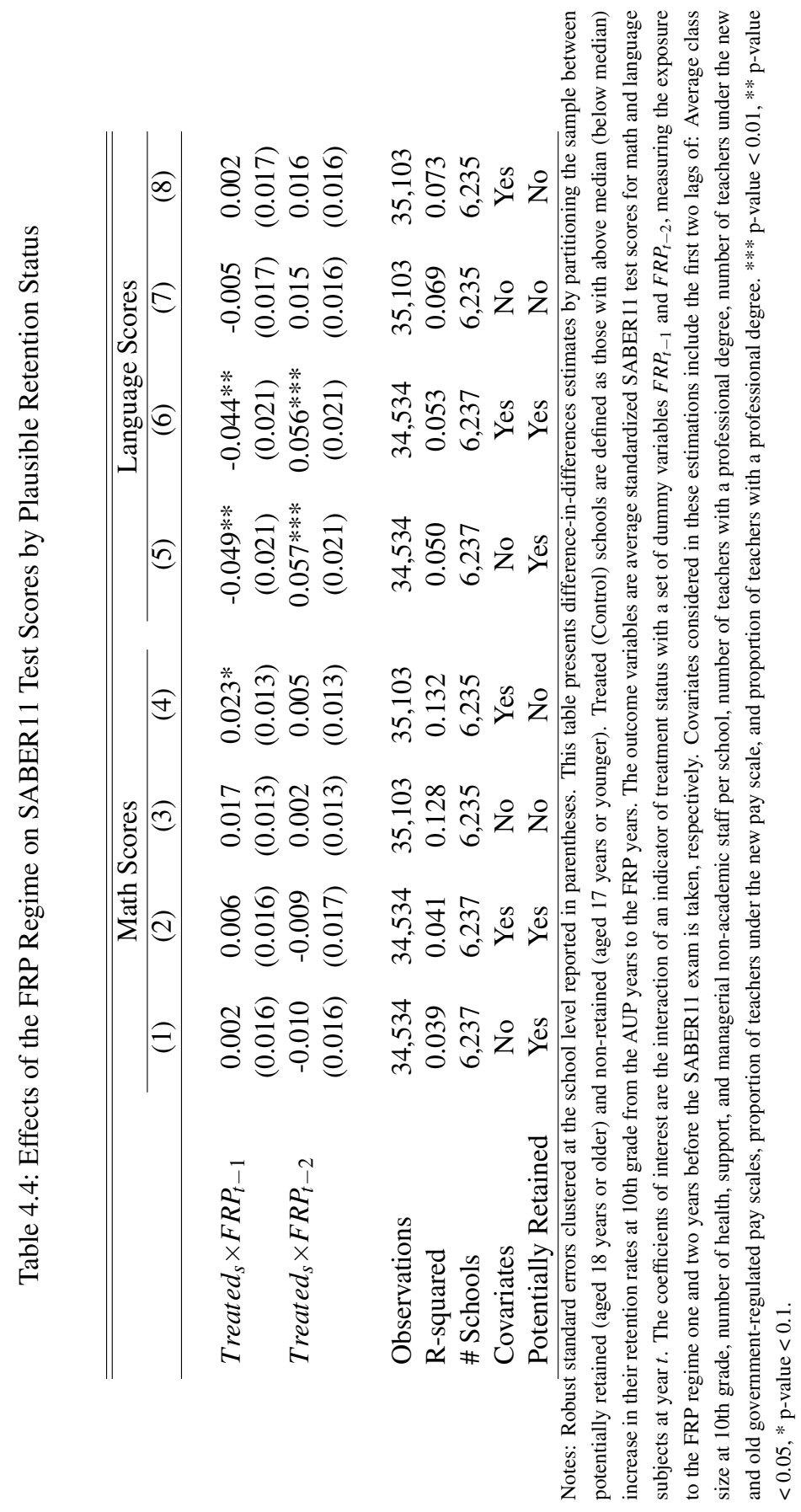




\subsubsection{On the Non-Linear Effects of Grade Retention}

Table 4.5 documents the effects using the baseline specification implied by equation (1) with three dummy variables for all treatment groups of interest, i.e., low, middle and highly treated schools. In line with our basic specification, results from columns (1)-(2) suggest no significant effects of being exposed to the FRP period in years $t-1$ and $t-2$ on average math scores at year $t$. In contrast, we obtain significant effects for average language test scores which vary depending on the school's treatment classification (columns (3)-(4)).

Coefficients displayed in the first, third, and fifth rows suggest that middle treated schools score $13 \%$ of a SD lower relative to control schools because of a 6 percentage point rise in retention. The effects for all other treatment groups, even those not statistically significant, suggest a non-linear quadratic pattern. As all coefficients displayed have a negative sign, we believe there are confounding factors that are positively correlated with the probability of repeating a grade. These factors are masking the true detrimental impact of increased retention on marginal students, especially of those enrolled in schools that retain at nearly optimal levels. By using the difference-in-differences estimator, we isolate the true effects from the bias attributed to such unobserved variation.

The increase in language scores of the retained students is significant both for the middle and highly treatment groups. Interestingly, the gains on test scores appear to be similar for these groups. Dividing these results by the percentage points jump in retention rates corresponding to each group reveals that the ATT coefficient of the highly treated group is smaller than that of the medium treated group. Considering that highly treated schools experienced a 12 percentage point increase in retention two years because of the FRP regime, our findings imply that a one percentage point rise in retention rates at 10th grade explains a $1.08 \%$ of a SD increase in test scores. The aforementioned impacts are larger for schools in the "medium treated" group. Namely, a 6 percentage points increase in retention rates at year $t-2$ implies a rise in test scores of about $13 \%$ of a SD in year $t$, so the effect is around $2.16 \%$ of a SD per one percentage point jump in retention. Hence, the same percentage point change in middle treated schools is two times as effective as it is in highly treated schools.

Our estimates suggest that retaining students is a strategy that exhibits decreasing marginal returns because there is a non-linear effect on language scores. At some point, higher retention is not expected to increase language performance. These students may, for instance, become demotivated because they must take the same classes again. For the marginal students, the results are only highly significant for the medium treatment group which also shows the non-linear nature of the effects obtained.

The main conclusion from these findings is that there is a non-linear effect of retention, as schools that actively retain students do not necessarily benefit more from such strategy, relative to other schools promoting more students. For the same percentage point increase in retention, middle treated schools obtain larger gains relative to schools that retain more students. 
Table 4.5: Effects of the FRP Regime on SABER11 Test Scores: Results by Multiple Treatment Categories

\begin{tabular}{|c|c|c|c|c|}
\hline & \multicolumn{2}{|c|}{ Math Scores } & \multicolumn{2}{|c|}{ Language Scores } \\
\hline & (1) & (2) & $(4)$ & (5) \\
\hline \multirow{2}{*}{ High_Treated $_{s} \times F R P_{t-1}$} & 0.037 & 0.053 & $-0.093 * *$ & $-0.081 *$ \\
\hline & $(0.033)$ & $(0.033)$ & $(0.043)$ & $(0.042)$ \\
\hline \multirow[t]{2}{*}{ High_Treated $_{s} \times F R P_{t-2}$} & -0.007 & -0.003 & $0.124 * * *$ & $0.127 * * *$ \\
\hline & $(0.030)$ & $(0.031)$ & $(0.037)$ & $(0.037)$ \\
\hline \multirow{2}{*}{ Medium_Treated $_{s} \times F R P_{t-1}$} & -0.015 & -0.003 & $-0.138 * * *$ & $-0.127 * * *$ \\
\hline & $(0.032)$ & $(0.032)$ & $(0.043)$ & $(0.043)$ \\
\hline \multirow{2}{*}{ Medium_Treated $_{s} \times F R P_{t-2}$} & -0.017 & -0.013 & $0.127 * * *$ & $0.128 * * *$ \\
\hline & $(0.030)$ & $(0.030)$ & $(0.037)$ & $(0.037)$ \\
\hline \multirow[t]{2}{*}{ Low_Treated $_{s} \times F R P_{t-1}$} & 0.020 & 0.027 & $-0.077^{*}$ & -0.072 \\
\hline & $(0.033)$ & $(0.032)$ & $(0.046)$ & $(0.045)$ \\
\hline \multirow[t]{2}{*}{ Low_Treated $_{s} \times F R P_{t-2}$} & -0.014 & -0.012 & 0.061 & 0.062 \\
\hline & $(0.030)$ & $(0.031)$ & $(0.039)$ & $(0.039)$ \\
\hline Observations & 35,693 & 35,693 & 35,693 & 35,693 \\
\hline R-squared & 0.149 & 0.156 & 0.095 & 0.102 \\
\hline \# Schools & 6,248 & 6,248 & 6,248 & 6,248 \\
\hline Covariates & No & Yes & No & Yes \\
\hline
\end{tabular}

Notes: Robust standard errors clustered at the school level reported in parentheses. Treated schools are defined as in the main text. The outcome variables are average standardized SABER11 test scores for math and language subjects at year $t$. The coefficients of interest are the interaction of an indicator of treatment status with a set of dummy variables $F R P_{t-1}$ and $F R P_{t-2}$, measuring the exposure to the FRP regime one and two years before the SABER11 exam is taken, respectively. Covariates considered in these estimations include the first two lags of: Average class size at 10th grade, number of health, support, and managerial non-academic staff per school, number of teachers with a professional degree, number of teachers under the new and old government-regulated pay scales, proportion of teachers under the new pay scale, and proportion of teachers with a professional degree. $* * *$ p-value $<0.01, * *$ p-value $<0.05, *$ p-value $<0.1$.

\subsubsection{Effects along the Test Scores' Distribution}

In Figure 4.4 we plot our difference-in-differences coefficients, this time considering test scores' percentiles by school as dependent variables, and using the above-median change in retention as the treatment classification criteria. In all these estimations we include school-specific covariates, although results barely change when the latter are excluded.

For math scores, we again obtain no effects for retained and marginal students across the entire test score distribution. On the contrary, results on language scores attributed to marginal pupils displayed in panel (c) show that the negative effect discussed earlier is strongest at the lower end of the distribution. For example, students performing at the 25th percentile in treated schools score up to $7 \%$ of a SD lower than 
comparable students at control schools. As average language scores for all students in the upper segment of the distribution were not affected by retention, these findings suggest that the negative effect of being exposed to higher retention is more severe towards lower performing but still non-retained students. We conjecture that this effect can be explained by the fact that students at the bottom of the ability distribution faced a higher threat of retention under the FRP regime, therefore compromising their test scores in the future.

Regarding language scores of retained students, the effect of higher retention is decreasing in students' test performance. Relative to students at the 10th percentile, students in treated schools scored $11 \%$ of a SD higher because of the FRP Regime. The effect is still significant but reduces in magnitude as performance increases. For instance, students in the 25 th percentile score $8 \%$ of a SD more than students with comparable performance at control schools. The FRP regime appears to have no effect for those students performing at the median or above. Overall, these findings suggest that pupils at the lower end of the distribution benefited more from being in schools with increased retention rates due to repeating their coursework. This may also indicate that the benefits of retention are not linear. That is, being retained can be highly beneficial for underperforming students.

We perform the same exercise for the specification in which we classify three treatment groups as already discussed. Table 4.6 presents the difference-in-differences coefficients for math and language scores. The table shows the results across the test scores' distributions distinguishing between low, medium and high treated schools. For math scores we obtain positive impacts at the upper end of the distribution that can be attributed to marginal students, although these effects are only significant at the $10 \%$ level. We do observe a significant negative effect for retained students on math scores of nine percent of a SD, suggesting that retained students' performance at the top of the distribution might be compromised as retention increases. In contrast, the positive effects on language scores for retained students, and the negative effects for the marginal students, are mostly relevant for middle treated schools. These results support our earlier finding that the retention effects on test scores are non-linear. 


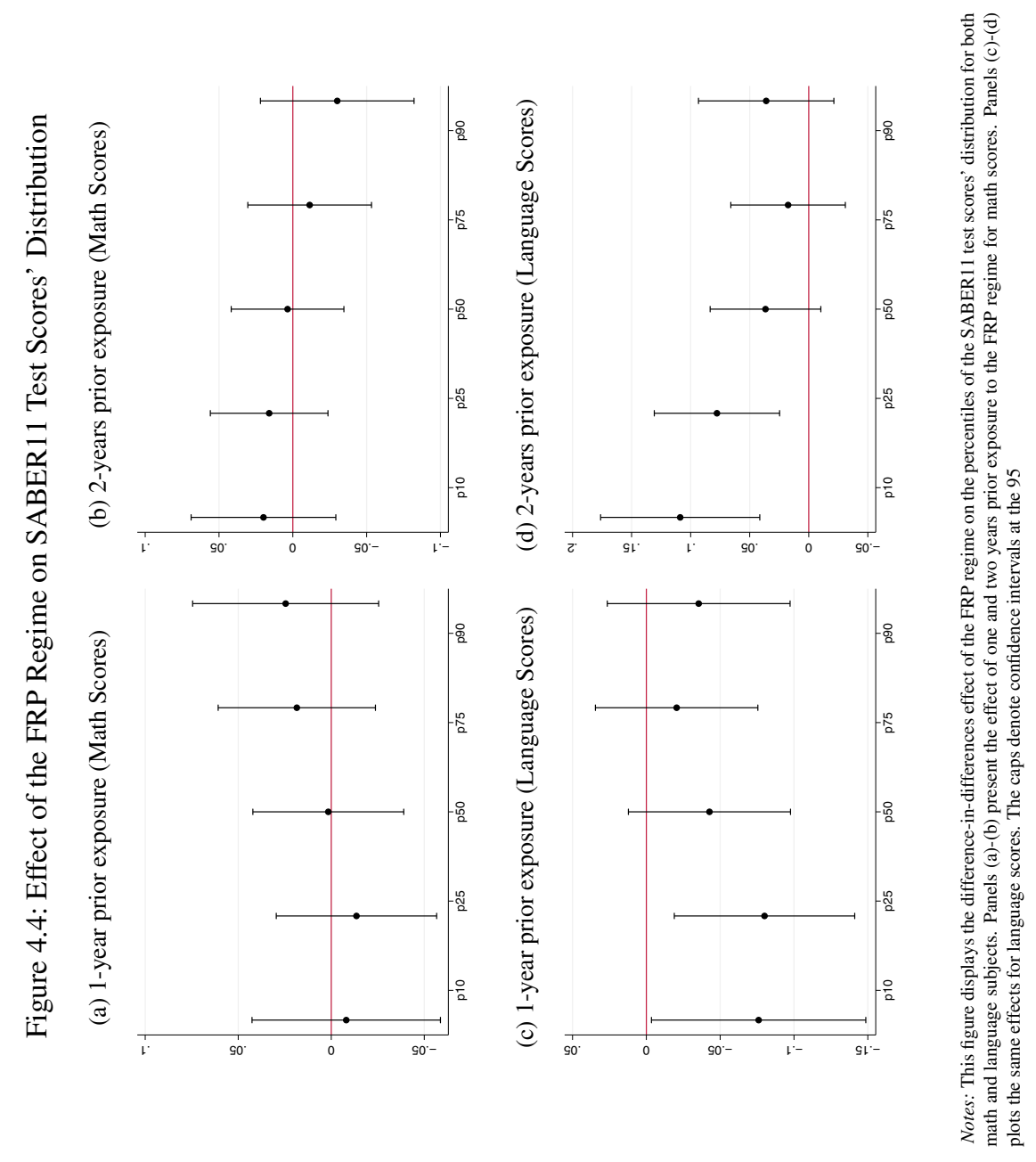




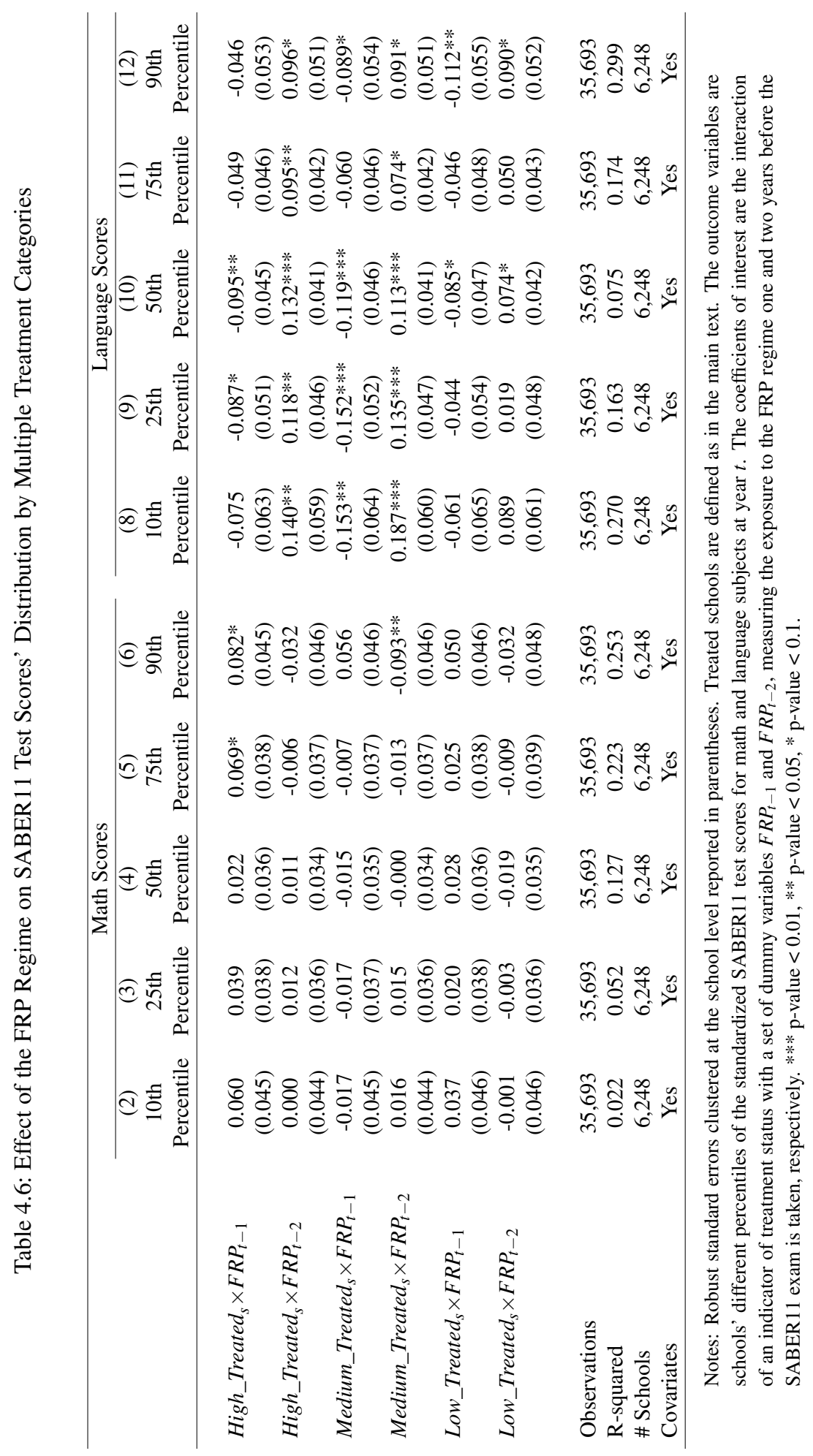


Several conclusions can be obtained from the estimates presented in this section. First, higher retention does not affect math scores, neither at the average nor at any below-median percentiles of the distribution. Second, higher retention positively (negatively) affects language scores for retained students (marginal students). Third, the fact that the results are stronger for middle treated schools suggests that the effect of retention is non-linear, as these schools obtain larger returns for the same percentage point increase in retention. Higher retention at some point no longer leads to higher scores for the retained students or lower scores for the students at the margin of repeating 10th grade. This also shows that our results are not driven by alternative reasons, such as selection. Finally, results obtained for both retained and marginal students are strongest at the lower end of the test score distribution. This indicates that low ability, retained students might benefit more from increased retention due to repeating classes or because the stigma of retention becomes of lower importance. Marginal students with similar ability score lower because they might face a higher threat of being retained, underperforming at the test later on.

\subsubsection{Testing the Common Trend Assumption}

Table 4.7 presents difference-in-differences estimates of the common trends in test scores between treated and control schools implied by equation (4.2), using exam year 2007 as a baseline. We report coefficients and robust standard errors clustered at the school level, and F-statistics of the joint test that the pre-FRP coefficients are not statistically different from zero. Observing results at column (1) it might appear that there are some meaningful differences in AUP trends on math scores. However, after including schoolspecific covariates the effect dissapears and we are not able to reject, neither individually nor globally, the null hyphothesis that the coefficients are different from zero. Regarding language scores, it is clear that no pre-existing trends are globally significant. These results combined allow us to conclude that we do not observe any prior trends that might affect test scores during the FRP period. Appendix Table A.4.2 reports the same analysis for higher, middle, and low treated schools, confirming that no AUP-specific trends play a role in determine tests scores during the FRP regime. 
Table 4.7: Common Trends Assumption Test

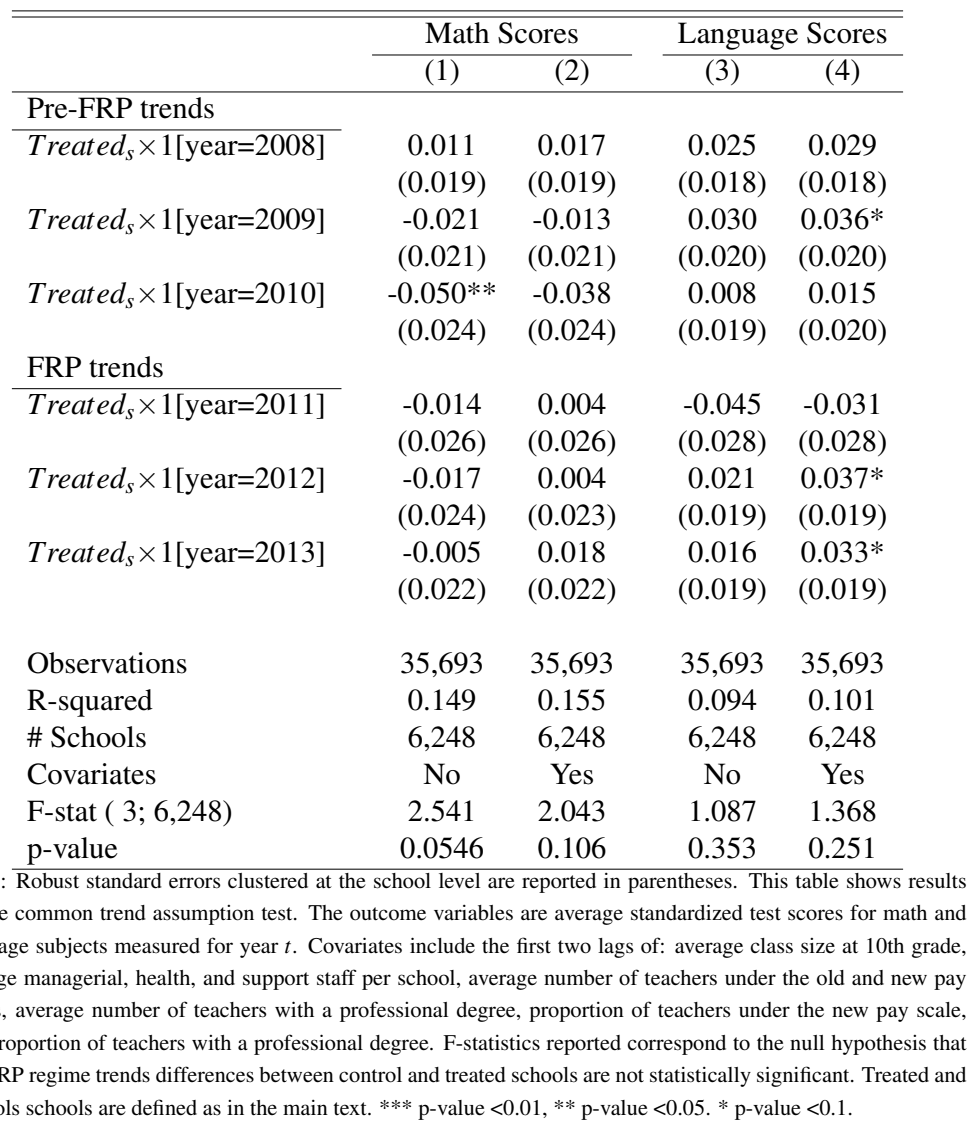

We also conduct placebo tests that simulate an artificial FRP regime starting before year 2010 (Table 4.8). Columns (1)-(4) and columns (5)-(8) present estimates using our full sample, but now assuming the FRP regime started in 2008 and 2007, respectively. For each specification, we report the F-statistics associated with a joint significance test of our coefficients of interest. Estimates obtained for both math and language scores are lower in magnitude and individually insignificant. We also observe that it is not possible to reject the joint null hypothesis that the coefficients are statistically different from zero. As an additional robustness check, we perform the same analysis using the alternative treatment groups already considered. We report these results in Appendix Table A.4.3. Once again, we do not find evidence indicating pre-FRP trends' effects on test scores. 
Table 4.8: Placebo Tests: FRP Regime Started Before Original Date

\begin{tabular}{|c|c|c|c|c|c|c|c|c|}
\hline & \multicolumn{2}{|c|}{ Math Scores } & \multicolumn{2}{|c|}{ Language Scores } & \multicolumn{2}{|c|}{ Math Scores } & \multicolumn{2}{|c|}{ Language Scores } \\
\hline & (1) & (2) & (3) & (4) & (5) & (6) & (7) & (8) \\
\hline \multirow{2}{*}{ Treated $_{s} \times$ FakeFRP $_{2008, t-1}$} & -0.026 & -0.021 & 0.018 & 0.021 & & & & \\
\hline & $(0.018)$ & $(0.018)$ & $(0.017)$ & $(0.017)$ & & & & \\
\hline \multirow[t]{2}{*}{ Treated $_{s} \times$ FakeF RP $_{2008, t-2}$} & -0.001 & 0.009 & -0.030 & -0.023 & & & & \\
\hline & $(0.017)$ & $(0.017)$ & $(0.019)$ & $(0.018)$ & & & & \\
\hline \multirow[t]{2}{*}{ Treated $_{s} \times{\text { FakeF } R P_{2007, t-1}}$} & & & & & 0.011 & 0.018 & 0.024 & 0.028 \\
\hline & & & & & $(0.019)$ & $(0.019)$ & $(0.018)$ & $(0.018)$ \\
\hline \multirow[t]{2}{*}{ Treated $_{s} \times$ FakeFRP $_{2007, t-1}$} & & & & & $-0.032 *$ & -0.022 & -0.018 & -0.011 \\
\hline & & & & & $(0.019)$ & $(0.018)$ & $(0.017)$ & $(0.016)$ \\
\hline Observations & 35,693 & 35,693 & 35,693 & 35,693 & 35,693 & 35,693 & 35,693 & 35,693 \\
\hline R-squared & 0.149 & 0.155 & 0.094 & 0.101 & 0.149 & 0.155 & 0.094 & 0.101 \\
\hline \# Schools & 6,248 & 6,248 & 6,248 & 6,248 & 6,248 & 6,248 & 6,248 & 6,248 \\
\hline Covariates & No & Yes & No & Yes & No & Yes & No & Yes \\
\hline F-stats $(2 ; 6,248)$ & 1.390 & 0.692 & 1.290 & 0.972 & 1.520 & 0.817 & 0.960 & 1.233 \\
\hline p-value & 0.249 & 0.500 & 0.275 & 0.378 & 0.219 & 0.442 & 0.383 & 0.291 \\
\hline
\end{tabular}

Notes: Robust standard errors clustered at the school level are reported in parentheses. Treated (Control) schools are defined as those with above median (below median) increase in their retention rates at 10th grade from the AUP years to the FRP years. The dependent variables are average standardized math and language SABER11's test scores. Columns (1)-(4) report results on the placebo test assuming the FRP regime started in 2008. Columns (5)-(8) show estimates on the placebo test assuming the FRP regime started in 2007. F-statistics reported correspond to the joint test of the null hypothesis that placebo effects are not different from zero. Covariates include the first two lags of: average class size at 10th grade, average managerial, health, and support staff per school, average number of teachers under the old and new pay scales, average number of teachers with a professional degree, proportion of teachers under the new pay scale, and proportion of teachers with a professional degree. $* * * \mathrm{p}$-value $<0.01, * * \mathrm{p}$-value $<0.05$. * $\mathrm{p}$-value $<0.1$.

\subsubsection{Additional Robustness Checks}

As indicated in the data section, there is attrition in our data for schools in which either retention rates or pre-FRP regime's characteristics are not completely observed throughout the period of interest. To analyze whether this attrition is selective, we report estimates in Appendix Table A.4.4 using only schools from the seven-years balanced panel. As expected, attrition increases dramatically, leaving only 3,281 schools left to consider in the estimation. However, we observe that the signs of our estimates do not change. If anything, the effects become more significant and slightly higher in magnitude, giving strong support to our baseline findings. In fact, given the magnitudes obtained from this robustness check, we can consider the coefficients provided in our baseline results as lower bound estimates of the true effect of the FRP regime on test scores.

Another concern in our empirical strategy is the timing between the announcement of the policy change and the time the new regime was officially in place. As discussed before, schools were informed in 2009 that from 2010 onwards they will be allowed to retain as many students as they prefer. It is plausible then that some schools reacted to this announcement by increasing retention rates in 2009. To check whether our results are robust to this behavior we repeat the estimations of our baseline specification, but 
excluding observations from exam year 2010. Appendix Table A.4.5 reports difference-in-differences coefficients from this exercise. All coefficients are virtually the same as the ones we obtain in our central findings, suggesting that schools' incentives to anticipate the policy change are not the main source of variation driving the effects we are documenting in this study.

\subsubsection{Potential Mechanisms}

In this section we explore propagation channels that may drive the effects we obtain. As implied by the FRP regime, treated schools significantly increased their retention rates, relative to schools in the control group. Are there any school characteristics that induce some institutions to retain more students? Are some school attributes amplifying the impacts of increased retention? To answer these questions, we assess the extent to which average class size at 10th grade, teachers' qualifications, and changes in the way teachers are remunerated play a role in disseminating the effects of grade retention.

There is a large consensus in the economics of education literature about the negative effects of large class sizes on students' academic performance (Angrist and Lavy, 1999; Fredriksson et al., 2012). Nonetheless, to our knowledge there is no discussion on whether grade retention and class size at school exhibit some complementarities. Assuming everything else constant, increased retention may have a positive impact on class size. We can also reverse the direction of the relationship. Schools with more students per group might have fewer incentives to retain students as classrooms with large class sizes are more difficult to manage. Hence, we might expect the positive (negative) effects of retention to be weaker (stronger) on retained (marginal) students as the number of pupils per group rises.

Regarding our second transmission channel, recent papers highlight the empirical challenges of identifying the effects of teacher quality in the classroom (Rivkin et al., 2005; Gerritsen et al., 2017). We may expect the benefits (costs) of retention to be amplified (reduced) as teachers' education improves. Nonetheless, since the accumulation of human capital across the life cycle becomes more specific than general, we might also expect teachers' education to exhibit marginal decreasing returns.

Finally, we exploit a regulation change in the way public school teachers are remunerated. From 2002 onwards, under Decree 1278, the remuneration, probation period, and screening process for newly hired teachers changed substantially. Under the new system, prospective teachers need to participate in a public entry contest which, after completion, will determine their starting rank and wage. In addition, teachers hired under this new scheme will be subject to a probation period up to 12 months, to then receive tenure that can be revoked if subsequent performance evaluations are not satisfactory. In contrast, teachers hired before June 2002 were subject to the old 1979's, more lenient regulation (Decree 2277). This innovation in the employment relationship of teachers created a mixture of academic staff paid with the old and new pay scales. As it is expected that newly hired teachers will replace those about to retire, the proportion of teachers under the new pay scale at school may be a key amplifying mechanism. Likewise, the direction of the effect is unclear. On the one hand, there is empirical evidence suggesting that teachers under 
the new regulation are positively selected, implying positive but moderate effects on school performance (Brutti and Sánchez, 2017). On the other hand, newly hired teachers may be inexperienced on identifying students with different educational needs. As career concerns are prevalent in their probation period, teachers might have incentives to focus their effort on students that are more likely to succeed. Thus, increasing participation of teachers under the new pay scale might have detrimental effects on students, especially those at the lower end of the ability distribution.

To test these mechanisms, we modify our baseline specification as follows:

$$
\begin{aligned}
Y_{s t} & =\alpha_{s}+\delta_{t}+\sum_{h=1}^{2} \gamma_{h}\left[\text { Treated }_{s} \times F R P_{t-h}\right]+\sum_{h=1}^{2} \beta_{h} \text { Attribut }_{t-h} \\
& +\sum_{h=1}^{2} \rho_{h}\left[\text { Treated }_{s} \times F R P_{t-h} \times \text { Attribut }_{t-h}\right]+\varepsilon_{s t},
\end{aligned}
$$

where the variable Attribute $_{t-h}$ denotes each mechanism we intend to test, one and two years before the exam takes place. The coefficients of interest in this specification are $\rho_{1}$ and $\rho_{2}$, which measure how each attribute in question propagates the effects of increased retention for marginal and retained students, respectively. We present our findings from this analysis in Table 4.9. Panel A reports the differencein-differences coefficients. Panels B, C, and D show estimates on the interaction of the differencein-differences effects with average school's class size at 10th grade, the proportion of teachers with a post-secondary education degree, and the proportion of teachers under the new, government regulated pay scale, respectively.

As observed in Columns (1)-(3) none of the mechanisms considered is masking the null effect of grade retention on math scores. We obtain a marginally significant effect of class size for retained students, but we claim that this can be ignored as it is only significant at the $10 \%$ level and very small in magnitude. In contrast, results for language scores indicate two propagation mechanisms worth to be discussed. First, we observe a negative effect of increased teachers' qualifications on test scores, as both coefficients of interest exhibit a negative sign. However, it seems that the effect in question is relevant (at the 10\% significance level) only for retained students. These findings support the idea that policy interventions aimed to foster the human capital acquisiton of teachers may not be as effective as other measures to extract the largest gains from grade retention.

Second, we observe the teachers' composition at treated schools to play a key role in propagating the effects of increased retention. In particular, a 10\% jump in the proportion of newly hired teachers implies a rise (drop) in language scores of 2.5\% (3.6\%) of a SD for retained (marginally non-retained) students. To present these effects in more detail, Figure 4.5 displays the marginal effects of a 10 percentage points increment in the proportion of teachers hired under the new pay scale, one and two years before the exam takes place (panels (a) and (b), respectively). It is clear that benefits and costs of increased retention for 
language scores are monotonically increasing. This fact suggests that retained students benefit more from a young academic workforce that is willing to invest time and effort in their education, while marginally non-retained students are harmed as inexperienced teachers may fail to target their educational needs.

Table 4.9: Effect of the FRP Regimen on SABER11 Test Scores: Mechanisms

\begin{tabular}{|c|c|c|c|c|c|c|}
\hline & \multicolumn{3}{|c|}{ Math Scores } & \multicolumn{3}{|c|}{ Language Scores } \\
\hline & (1) & $(2)$ & (3) & (4) & $(5)$ & (6) \\
\hline \multicolumn{7}{|l|}{ Panel A: Difference in Differences Effect } \\
\hline DID $_{s, t-1}=$ Treated $_{s} \times F R P_{t-1}$ & $\begin{array}{c}0.006 \\
(0.029)\end{array}$ & $\begin{array}{c}0.073 \\
(0.067)\end{array}$ & $\begin{array}{c}0.015 \\
(0.023)\end{array}$ & $\begin{array}{c}-0.079 * * \\
(0.036)\end{array}$ & $\begin{array}{c}0.063 \\
(0.078)\end{array}$ & $\begin{array}{c}0.036 \\
(0.031)\end{array}$ \\
\hline DID $_{s, t-2}=$ Treated $_{s} \times F R P_{t-2}$ & $\begin{array}{c}0.036 \\
(0.027)\end{array}$ & $\begin{array}{l}-0.006 \\
(0.058)\end{array}$ & $\begin{array}{c}0.002 \\
(0.021)\end{array}$ & $\begin{array}{l}0.051^{*} \\
(0.030)\end{array}$ & $\begin{array}{c}0.155 * * * \\
(0.056)\end{array}$ & $\begin{array}{c}0.017 \\
(0.025)\end{array}$ \\
\hline \multicolumn{7}{|l|}{ Panel B: Effects by Class Size } \\
\hline$D I D_{s, t-1} \times C l a s s \_S i z e_{s, t-1}$ & $\begin{array}{c}0.000 \\
(0.001)\end{array}$ & & & $\begin{array}{c}0.001 \\
(0.001)\end{array}$ & & \\
\hline$D I D_{s, t-2} \times C l a s s \_S i z e_{s, t-2}$ & $\begin{array}{r}-0.001 * \\
(0.001)\end{array}$ & & & $\begin{array}{c}0.000 \\
(0.000)\end{array}$ & & \\
\hline \multicolumn{7}{|l|}{ Panel C: Effects by Teacher's Qualifications } \\
\hline DID $_{s, t-1} \times$ Teachers_Qual ${ }_{s, t-1}$ & & $\begin{array}{l}-0.064 \\
(0.068)\end{array}$ & & & $\begin{array}{l}-0.125 \\
(0.077)\end{array}$ & \\
\hline$D I D_{s, t-2} \times$ Teachers_Qual $s_{s, t-2}$ & & $\begin{array}{c}0.015 \\
(0.058)\end{array}$ & & & $\begin{array}{l}-0.093^{*} \\
(0.054)\end{array}$ & \\
\hline \multicolumn{7}{|l|}{ Panel D: Effects by Teacher's Pay Scale } \\
\hline$D_{I D} D_{s-1} \times$ Teachers_Newpay $y_{s, t-1}$ & & & $\begin{array}{c}0.001 \\
(0.054)\end{array}$ & & & $\begin{array}{c}-0.365 * * * \\
(0.060)\end{array}$ \\
\hline$D I D_{s, t-2} \times$ Teachers_Newpay $y_{s, t-2}$ & & & $\begin{array}{c}0.015 \\
(0.047)\end{array}$ & & & $\begin{array}{c}0.249 * * * \\
(0.050)\end{array}$ \\
\hline Observations & 35,693 & 35,693 & 35,693 & 35,693 & 35,693 & 35,693 \\
\hline R-squared & 0.155 & 0.155 & 0.155 & 0.101 & 0.102 & 0.104 \\
\hline \# Schools & 6,248 & 6,248 & 6,248 & 6,248 & 6,248 & 6,248 \\
\hline
\end{tabular}

Notes: Robust standard errors clustered at the school level reported in parentheses. This table presents difference-in-differences estimates and their interactions with different school attributes. Treated (Control) schools are defined as those with above median (below median) increase in their retention rates at 10th grade from the AUP years to the FRP years. The outcome variables are average standardized SABER11 test scores for math and language subjects at year $t$. Class_Size measures the average number of students per group at 10th grade. Teachers_Qual accounts for the proportion of teachers with a post-secondary education degree per school. Teachers_Newpay measures the proportion of teachers per school under the new pay scale regulated by the central government. The new pay scale refers to the regulation change in the way newly-hired teachers are remunerated from 2002 onwards (Decree 1278). *** p-value $<0.01, * *$ p-value $<0.05, *$ p-value $<0.1$. 
Figure 4.5: Mechanisms: Variation in Teachers' Composition

(a) 1-year prior exposure

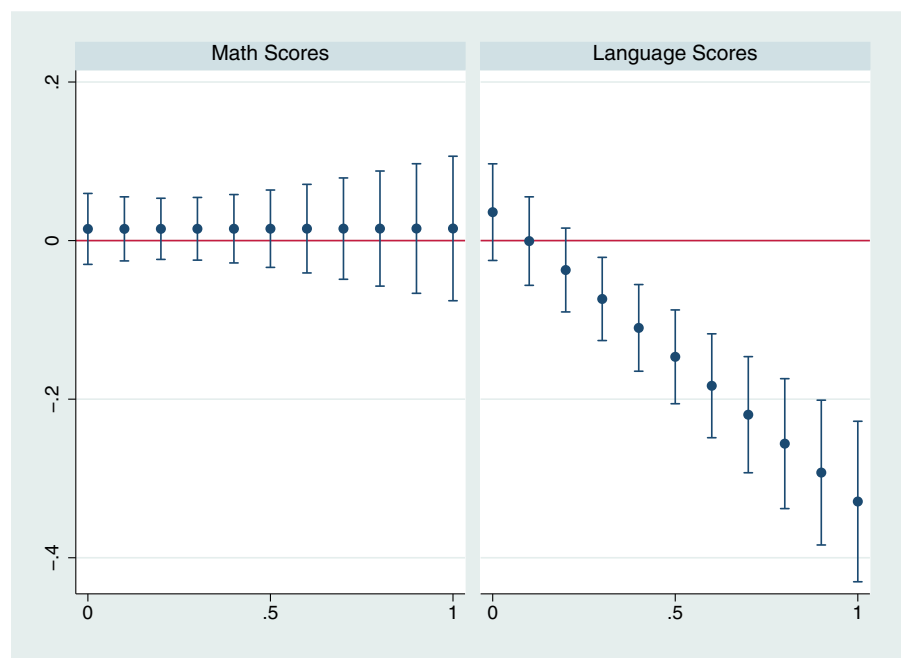

(b) 2-years prior exposure

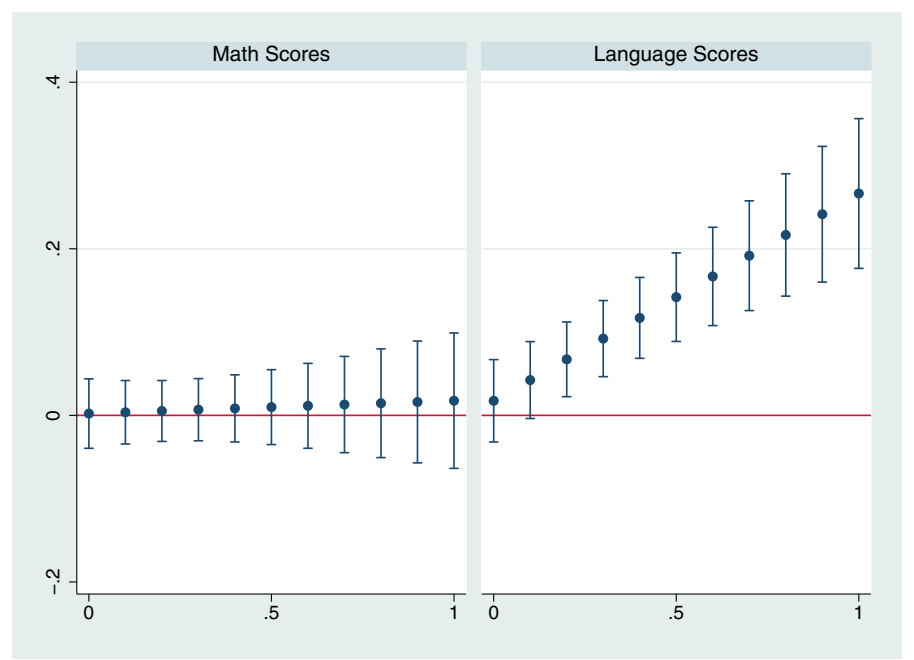

Notes: This figure plots the marginal effects from a difference-in-differences estimation, interacted with the proportion of teachers under the new pay scale. each cap denotes confidence intervals at the 95 


\subsection{Concluding Remarks}

This chapter analyzes the effect of retention in 10th grade on school performance at the end of highschool (grade 11th). We exploit a law change in Colombia with respect to retention. Until 2010, schools were allowed to retain a maximum of 5 percent of their total number of students. After the abolishment of the law in 2010, schools were free to retain as many students as they considered appropriate. This led to a large increase in retention, with considerable heterogeneity across schools. We use a difference-indifferences analysis to study the effect of retention on test performance. Placebo tests suggest that there are common trends in scores among schools that responded in various degrees to the law change.

Our estimates reveal that there are positive effects of more retention on language test performance for retained students. These effects are non-linear, as modest increases in retention have positive effects but larger increases in retention do not necessarily lead to better performance. In addition, our findings suggest that non-retained students at the lower end of the ability distribution perform worse in language tests. Potential explanations for this effect include the negative spillover impacts from formerly retained students, the strategic substitution of effort between stem and non-stem subjects in order to avoid grade retention, and the changes in teachers' workforce composition. We provide evidence of the latter channel, with career concerned, inexperienced teachers failing to identify students at the margin of being retained as the main transmission mechanism. In contrast, we do not find any effects on math scores that can be attributed either to retained or non-retained pupils.

This research shows the importance of analyzing effects of retention at different margins of the ability distribution. Although data restrictions do not allow to recover information on individual retention, we feel confident that the empirical strategy and data construction implemented in this study aids to solve this limitation by decomposing the effect of retention among different types of students. More research is needed to investigate whether the gains of retention we identify can be outweighed by other costs of retention, such as school dropouts, career choice regret, delayed (or sudden) labor market participation, forgone income, and the formation of undesirable personality traits, preferences and risk attitudes across the life cycle. 


\subsection{Appendix: Tables and Figures}

Figure A.4.1: Test Scores Residuals by Treatment Status

(a) Math Scores

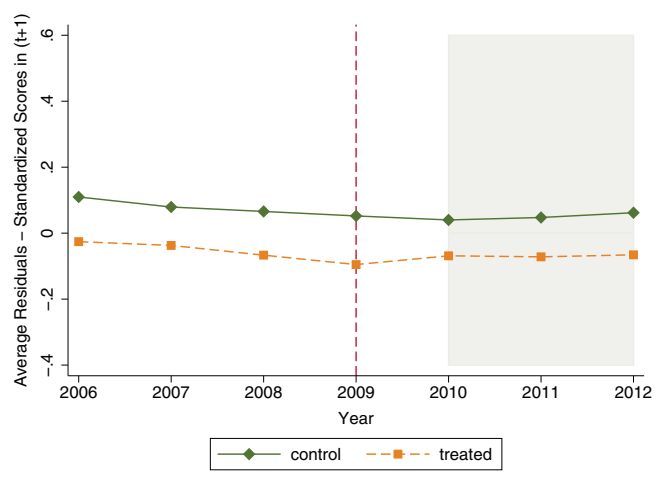

(b) Language Scores

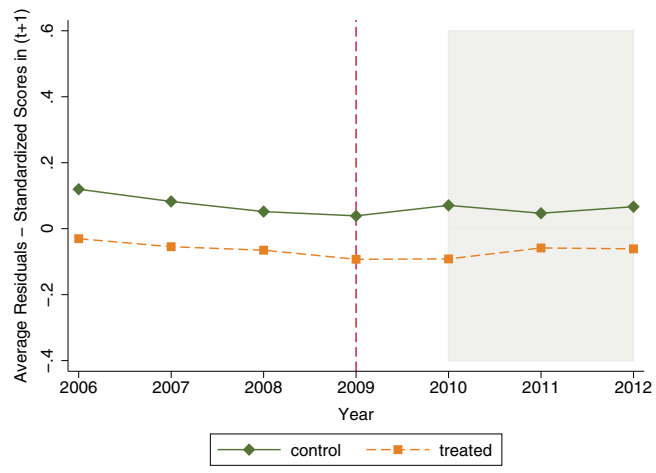

Notes: This figure displays average residuals from an OLS regression where the dependent variable is the average tests scores in year $t+1$ as a function of school and exam-year fixed effects, and a set of school specific covariates. Panel (a) presents common trends on math scores' average residuals between treated (dashed lines) and control (solid lines) schools. Panel (b) shows similar trends on language test scores' average residuals. Covariates considered in these estimations include the first two lags of: Average class size at 10th grade, number of health, support, and managerial non-academic staff per school, number of teachers with a professional degree, number of teachers under the new and old government-regulated pay scales, proportion of teachers under the new pay scale, and proportion of teachers with a professional degree. 


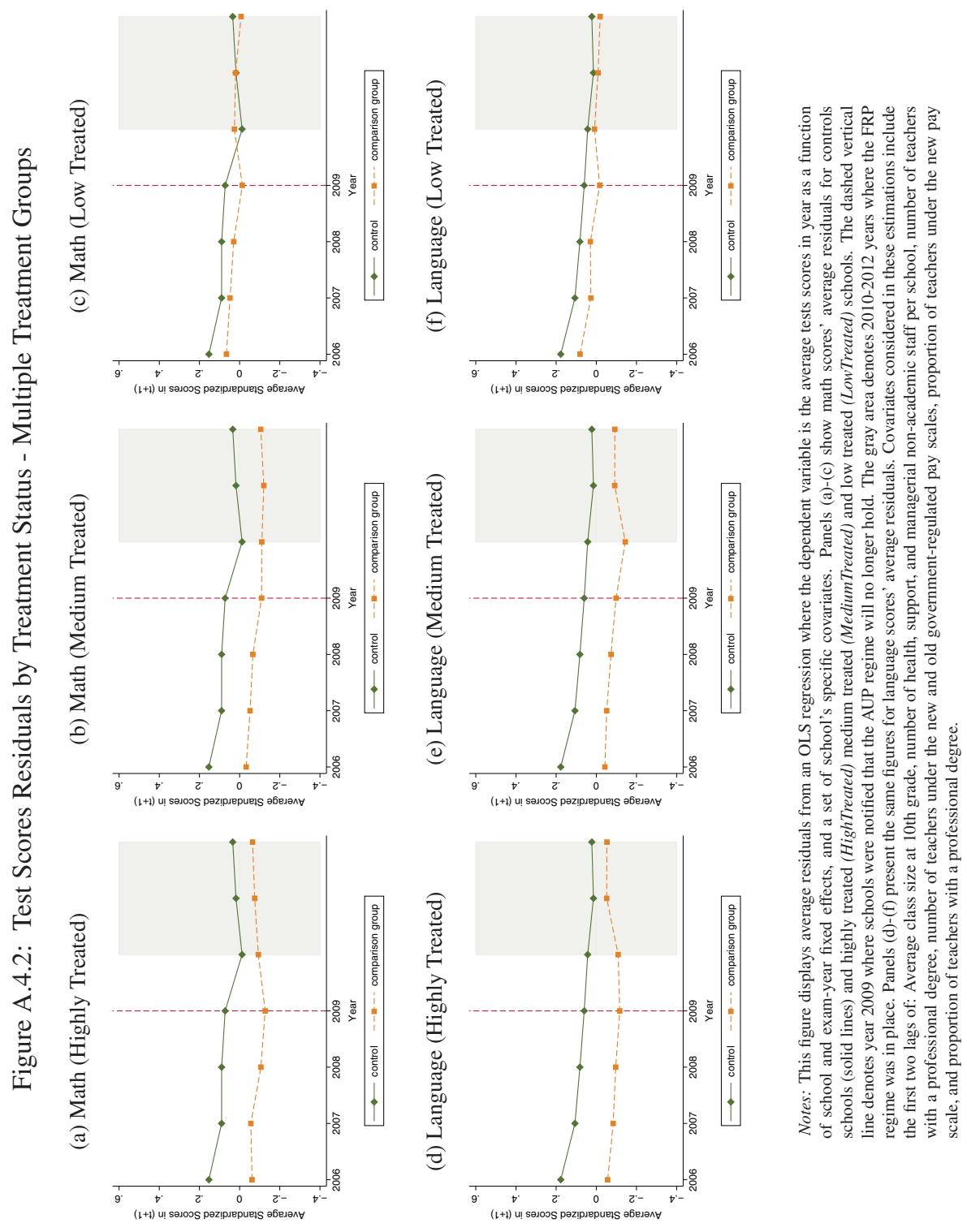


Table A.4.1: Selection Into Treatment Status - Ordered Probit Models

\begin{tabular}{|c|c|c|c|c|}
\hline Dependent Variable & $\begin{array}{c}(1) \\
\text { Treated }_{s}\end{array}$ & $\begin{array}{c}(2) \\
\text { HighTreated }_{s}\end{array}$ & $\begin{array}{c}\text { (3) } \\
\text { MediumTreated }_{s}\end{array}$ & $\begin{array}{c}(4) \\
\text { LowTreated }_{s}\end{array}$ \\
\hline \multicolumn{5}{|l|}{ School's characteristics during AUP years (2007-2009) } \\
\hline Proportion of female students & $\begin{array}{l}-0.073^{*} \\
(0.038)\end{array}$ & $\begin{array}{l}-0.066 \\
(0.059)\end{array}$ & $\begin{array}{c}0.065 \\
(0.058)\end{array}$ & $\begin{array}{c}0.089 \\
(0.056)\end{array}$ \\
\hline Proportion of students from rural areas & $\begin{array}{l}-0.031 \\
(0.021)\end{array}$ & $\begin{array}{c}-0.116 * * * \\
(0.032)\end{array}$ & $\begin{array}{l}-0.028 \\
(0.034)\end{array}$ & $\begin{array}{l}-0.026 \\
(0.036)\end{array}$ \\
\hline Proportion of students from ethnic minorities & $\begin{array}{l}-0.017 \\
(0.031)\end{array}$ & $\begin{array}{l}-0.058 \\
(0.047)\end{array}$ & $\begin{array}{l}-0.049 \\
(0.049)\end{array}$ & $\begin{array}{c}0.014 \\
(0.050)\end{array}$ \\
\hline Average students' age at exam & $\begin{array}{c}-0.036 * * * \\
(0.013)\end{array}$ & $\begin{array}{l}-0.022 \\
(0.020)\end{array}$ & $\begin{array}{l}-0.024 \\
(0.020)\end{array}$ & $\begin{array}{l}-0.035^{*} \\
(0.021)\end{array}$ \\
\hline Proportion of students with an educated mother & $\begin{array}{c}-0.192 * * * \\
(0.045)\end{array}$ & $\begin{array}{c}-0.297 * * * \\
(0.068)\end{array}$ & $\begin{array}{c}-0.145 * * \\
(0.067)\end{array}$ & $\begin{array}{c}-0.145^{* *} \\
(0.066)\end{array}$ \\
\hline Proportion of students above poverty classification & $\begin{array}{c}0.075 * * \\
(0.031)\end{array}$ & $\begin{array}{l}0.085^{*} \\
(0.047)\end{array}$ & $\begin{array}{l}-0.008 \\
(0.049)\end{array}$ & $\begin{array}{c}0.066 \\
(0.049)\end{array}$ \\
\hline Public school & $\begin{array}{c}0.216^{* * * *} \\
(0.025)\end{array}$ & $\begin{array}{c}0.345^{* * * *} \\
(0.036)\end{array}$ & $\begin{array}{c}0.195^{* * * *} \\
(0.038)\end{array}$ & $\begin{array}{c}0.160^{* * * *} \\
(0.039)\end{array}$ \\
\hline Working spell: $7: 00$ to $12: 00$ & $\begin{array}{l}-0.002 \\
(0.015)\end{array}$ & $\begin{array}{l}-0.017 \\
(0.023)\end{array}$ & $\begin{array}{c}0.008 \\
(0.024)\end{array}$ & $\begin{array}{l}-0.004 \\
(0.024)\end{array}$ \\
\hline Working spell: $13: 00$ to $18: 00$ & $\begin{array}{c}0.037 \\
(0.024)\end{array}$ & $\begin{array}{c}0.013 \\
(0.035)\end{array}$ & $\begin{array}{c}0.002 \\
(0.038)\end{array}$ & $\begin{array}{c}0.004 \\
(0.040)\end{array}$ \\
\hline School type: academic and technical & $\begin{array}{l}-0.010 \\
(0.019)\end{array}$ & $\begin{array}{c}0.030 \\
(0.028)\end{array}$ & $\begin{array}{c}0.030 \\
(0.031)\end{array}$ & $\begin{array}{c}0.019 \\
(0.032)\end{array}$ \\
\hline School type: pedagogical training & $\begin{array}{c}0.004 \\
(0.048)\end{array}$ & $\begin{array}{l}-0.039 \\
(0.074)\end{array}$ & $\begin{array}{l}-0.057 \\
(0.077)\end{array}$ & $\begin{array}{c}0.058 \\
(0.074)\end{array}$ \\
\hline School type: technical & $\begin{array}{c}-0.051^{* * *} \\
(0.016)\end{array}$ & $\begin{array}{c}-0.079^{* * * *} \\
(0.024)\end{array}$ & $\begin{array}{l}-0.018 \\
(0.025)\end{array}$ & $\begin{array}{l}-0.014 \\
(0.026)\end{array}$ \\
\hline Average class size & $\begin{array}{c}0.001 \\
(0.001)\end{array}$ & $\begin{array}{c}0.001 \\
(0.001)\end{array}$ & $\begin{array}{l}0.002 * * \\
(0.001)\end{array}$ & $\begin{array}{c}0.002 * * \\
(0.001)\end{array}$ \\
\hline Average number of groups at 10 th grade & $\begin{array}{c}0.019 * * * \\
(0.006)\end{array}$ & $\begin{array}{l}0.015^{* * *} \\
(0.008)\end{array}$ & $\begin{array}{c}0.006 \\
(0.009)\end{array}$ & $\begin{array}{l}-0.004 \\
(0.009)\end{array}$ \\
\hline Proportion of teachers with qualifications & $\begin{array}{c}0.064 \\
(0.051)\end{array}$ & $\begin{array}{c}0.027 \\
(0.075)\end{array}$ & $\begin{array}{c}0.080 \\
(0.080)\end{array}$ & $\begin{array}{l}-0.042 \\
(0.078)\end{array}$ \\
\hline Proportion of teachers under the new pay scale & $\begin{array}{c}0.039 \\
(0.037)\end{array}$ & $\begin{array}{l}-0.003 \\
(0.056)\end{array}$ & $\begin{array}{l}-0.041 \\
(0.059)\end{array}$ & $\begin{array}{c}0.045 \\
(0.060)\end{array}$ \\
\hline Average number of managerial personnel & $\begin{array}{c}0.005 \\
(0.005)\end{array}$ & $\begin{array}{l}0.010 \\
(0.008)\end{array}$ & $\begin{array}{c}0.020 * * \\
(0.008)\end{array}$ & $\begin{array}{c}0.022 * * * \\
(0.008)\end{array}$ \\
\hline Average number of support staff & $\begin{array}{l}-0.008 \\
(0.007)\end{array}$ & $\begin{array}{c}0.001 \\
(0.011)\end{array}$ & $\begin{array}{l}-0.004 \\
(0.013)\end{array}$ & $\begin{array}{c}0.012 \\
(0.013)\end{array}$ \\
\hline Average number of health personnel & $\begin{array}{l}-0.010 \\
(0.012)\end{array}$ & $\begin{array}{l}-0.036^{*} \\
(0.018)\end{array}$ & $\begin{array}{l}-0.023 \\
(0.019)\end{array}$ & $\begin{array}{l}-0.015 \\
(0.018)\end{array}$ \\
\hline Observations & 6,248 & 2,474 & 2,479 & 2,477 \\
\hline Pseudo R2 & 0.0552 & 0.135 & 0.0660 & 0.0362 \\
\hline Log-Likelihood & -4092 & -1483 & -1604 & -1654 \\
\hline
\end{tabular}

Notes: Robust standard errors reported in parentheses. This table report marginal effects from ordered probit regressions where the dependent variable is a binary outcome indicating that the school belongs to the treatment group. Column (1) presents results using all sample of treated and control schools according with the definition from the text. Columns (2)-(4) show estimates for comparable control schools vs. schools labeled highly, medium, and low treated. information on the socio-demographic composition of schools comes from the SABER11 (ICFES) dataset. Information about other school attributes comes from the DANE c600 Census. *** p-value $<0.01$, ** p-value $<0.05,{ }^{*}$ p-value $<0.1$. 
Table A.4.2: Common Trend Assumption Test by Multiple Treatment Categories

\begin{tabular}{|c|c|c|c|c|}
\hline & \multicolumn{2}{|c|}{ Math Scores } & \multicolumn{2}{|c|}{ Language Scores } \\
\hline & $(1)$ & $(2)$ & (3) & (4) \\
\hline \multirow{2}{*}{ HighTreated $_{s} \times 1[$ year $=2008]$} & 0.034 & 0.044 & 0.032 & 0.040 \\
\hline & $(0.030)$ & $(0.030)$ & $(0.030)$ & $(0.030)$ \\
\hline \multirow{2}{*}{ HighTreated $_{s} \times 1[$ year $=2009]$} & -0.021 & -0.008 & 0.046 & $0.057^{*}$ \\
\hline & $(0.033)$ & $(0.033)$ & $(0.031)$ & $(0.031)$ \\
\hline \multirow[t]{2}{*}{ HighTreated $_{s} \times 1[$ year $=2010]$} & -0.047 & -0.029 & 0.027 & 0.039 \\
\hline & $(0.037)$ & $(0.037)$ & $(0.031)$ & $(0.031)$ \\
\hline \multirow{2}{*}{ MediumTreated $_{s} \times 1[$ year $=2008]$} & 0.003 & 0.011 & 0.032 & 0.038 \\
\hline & $(0.032)$ & $(0.032)$ & $(0.031)$ & $(0.031)$ \\
\hline \multirow[t]{2}{*}{ MediumTreated $_{s} \times 1[$ year $=2009]$} & -0.028 & -0.018 & 0.029 & 0.038 \\
\hline & $(0.035)$ & $(0.035)$ & $(0.033)$ & $(0.033)$ \\
\hline \multirow[t]{2}{*}{ MediumTreated $_{s} \times 1[$ year $=2010]$} & $-0.080 * *$ & $-0.066^{*}$ & -0.002 & 0.008 \\
\hline & $(0.039)$ & $(0.039)$ & $(0.032)$ & $(0.032)$ \\
\hline \multirow[t]{2}{*}{ LowTreated $_{s} \times 1[$ year $=2008]$} & 0.000 & 0.006 & -0.025 & -0.021 \\
\hline & $(0.031)$ & $(0.031)$ & $(0.030)$ & $(0.031)$ \\
\hline \multirow{2}{*}{ LowTreated $_{s} \times 1[$ year $=2009]$} & -0.013 & -0.003 & 0.024 & 0.031 \\
\hline & $(0.035)$ & $(0.035)$ & $(0.032)$ & $(0.033)$ \\
\hline \multirow{2}{*}{ LowTreated $_{s} \times 1[$ year $=2010]$} & -0.047 & -0.035 & -0.012 & -0.002 \\
\hline & $(0.037)$ & $(0.037)$ & $(0.032)$ & $(0.033)$ \\
\hline Observations & 35,693 & 35,693 & 35,693 & 35,693 \\
\hline R-squared & 0.150 & 0.156 & 0.096 & 0.103 \\
\hline \# Schools & 6,248 & 6,248 & 6,248 & 6,248 \\
\hline Covariates & No & Yes & No & Yes \\
\hline F-stat $(9,6614)$ & 1.051 & 0.968 & 1.064 & 1.220 \\
\hline p-value & 0.397 & 0.464 & 0.386 & 0.277 \\
\hline
\end{tabular}

Notes: Robust standard errors clustered at the school level are reported in parentheses. This table shows results for the common trend assumption test. For matters of space, we only report the coefficients from the pre-FRP trends years. The outcome variables are average standardized test scores for math and language subjects measured for year $t$. Covariates include the first two lags of: average class size at 10th grade, average managerial, health, and support staff per school, average number of teachers under the old and new pay scales, average number of teachers with a professional degree, proportion of teachers under the new pay scale, and proportion of teachers with a professional degree. F-statistics reported correspond to the null hypothesis that pre-FRP regime trends differences between control and treated schools are not statistically significant. Treated and controls schools are defined as in the main text. $* * *$ p-value $<0.01$, ** p-value $<0.05$. * p-value $<0.1$. 
Table A.4.3: Placebo Test Using Multiple Treatment Groups: FRP Regime Started Before 2010

\begin{tabular}{|c|c|c|c|c|c|c|c|c|}
\hline & \multicolumn{2}{|c|}{ Math Scores } & \multicolumn{2}{|c|}{ Language Scores } & \multicolumn{2}{|c|}{ Math Scores } & \multicolumn{2}{|c|}{ Language Scores } \\
\hline & (1) & (2) & (3) & (4) & (5) & (6) & (7) & $(8)$ \\
\hline Panel A: FRP started in 2008 & & & & & & & & \\
\hline HighTreated $\times$ FakeFRP $2008, t-1$ & $\begin{array}{l}-0.037 \\
(0.028)\end{array}$ & $\begin{array}{l}-0.029 \\
(0.028)\end{array}$ & $\begin{array}{c}0.030 \\
(0.026)\end{array}$ & $\begin{array}{c}0.037 \\
(0.026)\end{array}$ & & & & \\
\hline HighTreated $\times$ FakeFRP $2008, t-2$ & $\begin{array}{c}0.025 \\
(0.028)\end{array}$ & $\begin{array}{c}0.038 \\
(0.028)\end{array}$ & $\begin{array}{l}-0.027 \\
(0.029)\end{array}$ & $\begin{array}{l}-0.018 \\
(0.028)\end{array}$ & & & & \\
\hline MediumTreated $\times$ FakeFRP $P_{2008, t-1}$ & $\begin{array}{l}-0.029 \\
(0.029)\end{array}$ & $\begin{array}{l}-0.023 \\
(0.029)\end{array}$ & $\begin{array}{c}0.013 \\
(0.027)\end{array}$ & $\begin{array}{l}0.018 \\
(0.027)\end{array}$ & & & & \\
\hline MediumTreated $\times$ FakeFRP $2008, t-2$ & $\begin{array}{l}-0.034 \\
(0.027)\end{array}$ & $\begin{array}{l}-0.024 \\
(0.027)\end{array}$ & $\begin{array}{c}-0.058^{* *} \\
(0.029)\end{array}$ & $\begin{array}{l}-0.051^{*} \\
(0.029)\end{array}$ & & & & \\
\hline LowTreated $\times$ FakeFRP $2008, t-1$ & $\begin{array}{l}-0.012 \\
(0.030)\end{array}$ & $\begin{array}{l}-0.006 \\
(0.030)\end{array}$ & $\begin{array}{c}0.036 \\
(0.027)\end{array}$ & $\begin{array}{c}0.041 \\
(0.027)\end{array}$ & & & & \\
\hline LowTreated $\times$ FakeFRP $2008, t-2$ & $\begin{array}{l}-0.004 \\
(0.028)\end{array}$ & $\begin{array}{c}0.001 \\
(0.028)\end{array}$ & $\begin{aligned}-0.056^{*} \\
(0.030)\end{aligned}$ & $\begin{array}{l}-0.053^{*} \\
(0.030)\end{array}$ & & & & \\
\hline Panel B: FRP started in 2007 & & & & & & & & \\
\hline HighTreated $\times$ FakeFRP $2007, t-1$ & & & & & $\begin{array}{c}0.035 \\
(0.030)\end{array}$ & $\begin{array}{c}0.046 \\
(0.030)\end{array}$ & $\begin{array}{c}0.031 \\
(0.030)\end{array}$ & $\begin{array}{c}0.040 \\
(0.030)\end{array}$ \\
\hline HighTreated $\times$ FakeFRP $P_{2007, t-2}$ & & & & & $\begin{array}{l}-0.035 \\
(0.030)\end{array}$ & $\begin{array}{l}-0.022 \\
(0.030)\end{array}$ & $\begin{array}{l}-0.007 \\
(0.027)\end{array}$ & $\begin{array}{c}0.002 \\
(0.026)\end{array}$ \\
\hline MediumTreated $\times$ FakeF $R P_{2007, t-1}$ & & & & & $\begin{array}{c}0.003 \\
(0.032)\end{array}$ & $\begin{array}{c}0.010 \\
(0.032)\end{array}$ & $\begin{array}{c}0.031 \\
(0.031)\end{array}$ & $\begin{array}{c}0.037 \\
(0.031)\end{array}$ \\
\hline MediumTreated $\times$ FakeF $R P_{2007, t-2}$ & & & & & $\begin{array}{l}-0.057^{*} \\
(0.030)\end{array}$ & $\begin{array}{l}-0.047 \\
(0.030)\end{array}$ & $\begin{aligned}-0.049 * \\
(0.027)\end{aligned}$ & $\begin{array}{l}-0.041 \\
(0.026)\end{array}$ \\
\hline LowTreated $\times$ FakeF $R P_{2007, t-1}$ & & & & & $\begin{array}{c}0.001 \\
(0.031)\end{array}$ & $\begin{array}{c}0.006 \\
(0.031)\end{array}$ & $\begin{array}{l}-0.026 \\
(0.030)\end{array}$ & $\begin{array}{l}-0.022 \\
(0.031)\end{array}$ \\
\hline LowTreated $\times$ FakeF $R P_{2007, t-2}$ & & & & & $\begin{array}{l}-0.016 \\
(0.031)\end{array}$ & $\begin{array}{c}-0.008 \\
(0.031)\end{array}$ & $\begin{array}{c}0.004 \\
(0.027)\end{array}$ & $\begin{array}{c}0.010 \\
(0.027)\end{array}$ \\
\hline Observations & 35,693 & 35,693 & 35,693 & 35,693 & 35,693 & 35,693 & 35,693 & 35,693 \\
\hline R-squared & 0.149 & 0.155 & 0.094 & 0.101 & 0.149 & 0.155 & 0.094 & 0.101 \\
\hline \# Schools & 6,248 & 6,248 & 6,248 & 6,248 & 6,248 & 6,248 & 6,248 & 6,248 \\
\hline Covariates & No & Yes & No & Yes & No & Yes & No & Yes \\
\hline F-stats $(6 ; 6,614)$ & 1.535 & 1.462 & 1.456 & 1.478 & 1.181 & 1.146 & 1.808 & 2.015 \\
\hline $\mathrm{p}$-value & 0.162 & 0.187 & 0.189 & 0.181 & 0.313 & 0.333 & 0.0934 & 0.0602 \\
\hline
\end{tabular}

Notes: Robust standard errors clustered at the school level are reported in parentheses. This table presents results on placebo tests for the baseline difference-in-differences specification, assuming the FRP started in year 2008 . Treated (Control) schools are defined as those with above median (below median) increase in their retention rates at 10th grade from the AUP years to the FRP years. The dependent variables are average standardized math and language SABER11's test scores. F-statistics reported correspond to the joint test of the null hypothesis that placebo effects are not different from zero. Covariates include the first two lags of: average class size at 10th grade, average managerial, health, and support staff per school, average number of teachers under the old and new pay scales, average number of teachers with a professional degree, proportion of teachers under the new pay scale, and proportion of teachers with a professional degree. ${ }^{* * *}$ p-value $<0.01$, ** p-value $<0.05$. ${ }^{*}$ p-value $<0.1$. 
Table A.4.4: Effect of the FRP Regime on Test Scores: Balanced Panel Estimations

\begin{tabular}{lccccc}
\hline \hline & \multicolumn{2}{c}{ Math Scores } & & \multicolumn{2}{c}{ Language Scores } \\
\cline { 2 - 3 } \cline { 5 - 6 } & $(1)$ & $(2)$ & & $(4)$ & $(5)$ \\
\hline Treated $_{s} \times F R P_{t-1}$ & -0.021 & -0.007 & & $-0.091^{* * *}$ & $-0.079^{* *}$ \\
& $(0.023)$ & $(0.022)$ & & $(0.032)$ & $(0.031)$ \\
Treated $_{s} \times F R P_{t-2}$ & 0.019 & 0.024 & & $0.076^{* * *}$ & $0.079 * * *$ \\
& $(0.021)$ & $(0.021)$ & & $(0.027)$ & $(0.027)$ \\
Observations & & & & & \\
R-squared & 22,967 & 22,967 & & 22,967 & 22,967 \\
\# Schools & 0.176 & 0.184 & & 0.117 & 0.126 \\
Covariates & 3,281 & 3,281 & & 3,281 & 3,281 \\
\hline
\end{tabular}

Notes: Robust standard errors clustered at the school level reported in parentheses. This table reports estimations only using schools from a balanced panel dataset of seven years. Treated (Control) schools are defined as those with above median (below median) increase in their retention rates at 10th grade from the AUP years to the FRP years. The outcome variables are average standardized SABER11 test scores for math and language subjects at year $t$. The coefficients of interest are the interaction of an indicator of treatment status with a set of dummy variables $F R P_{t-1}$ and $F R P_{t-2}$, measuring the exposure to the FRP regime one and two years before the SABER11 exam is taken, respectively. Covariates considered in these estimations include the first two lags of: Average class size at 10th grade, number of health, support, and managerial non-academic staff per school, number of teachers with a professional degree, number of teachers under the new and old government-regulated pay scales, proportion of teachers under the new pay scale, and proportion of teachers with a professional degree. *** p-value $<0.01, * *$ p-value $<0.05,{ }^{*}$ p-value $<0.1$. 
Table A.4.5: Effect of the FRP Regime on Test Scores: Excluding Anticipatory Effects

\begin{tabular}{lccccc}
\hline \hline & \multicolumn{2}{c}{ Math Scores } & & \multicolumn{2}{c}{ Language Scores } \\
\cline { 2 - 3 } \cline { 5 - 6 } & $(1)$ & $(2)$ & & $(4)$ & $(5)$ \\
\hline \multirow{2}{*}{ Treated $_{s} \times F R P_{t-1}$} & -0.012 & 0.002 & & $-0.068^{* *}$ & $-0.056^{* *}$ \\
& $(0.022)$ & $(0.022)$ & & $(0.028)$ & $(0.028)$ \\
Treated $_{s} \times F R P_{t-2}$ & 0.006 & 0.010 & & $0.066^{* * *}$ & $0.068^{* * *}$ \\
& $(0.019)$ & $(0.019)$ & & $(0.023)$ & $(0.023)$ \\
& & & & & \\
Observations & 30,576 & 30,576 & & 30,576 & 30,576 \\
R-squared & 0.158 & 0.166 & & 0.105 & 0.112 \\
\# Schools & 6,234 & 6,234 & & 6,234 & 6,234 \\
Covariates & No & Yes & & No & Yes \\
\hline
\end{tabular}

Notes: Robust standard errors clustered at the school level reported in parentheses. This table reports differencein-differences regressions excluding observations from exam year 2010. Treated (Control) schools are defined as those with above median (below median) increase in their retention rates at 10th grade from the AUP years to the FRP years. The outcome variables are average standardized SABER11 test scores for math and language subjects at year $t$. The coefficients of interest are the interaction of an indicator of treatment status with a set of dummy variables $F R P_{t-1}$ and $F R P_{t-2}$, measuring the exposure to the FRP regime one and two years before the SABER11 exam is taken, respectively. Covariates considered in these estimations include the first two lags of: Average class size at 10th grade, number of health, support, and managerial non-academic staff per school, number of teachers with a professional degree, number of teachers under the new and old government-regulated pay scales, proportion of teachers under the new pay scale, and proportion of teachers with a professional degree. *** p-value $<0.01, * *$ p-value $<0.05,{ }^{*}$ p-value $<0.1$. 




\section{Bibliography}

Acemoglu, D., Robinson, J., and Santos, R. (2013). The monopoly of violence: Evidence from Colombia. Journal of the European Economic Association, 11(1):5-44.

Akbulut-Yuksel, M. (2014). Children of war: The long-run effects of large-scale physical destruction and warfare on children. Journal of Human Resources, 49(3):634-662.

Akresh, R. and De Walque, D. (2008). Armed conflict and schooling: evidence from the 1994 Rwandan genocide. IZA Discussion Papers, 3516.

Alderman, H., Hoddinott, J., and Kinsey, B. (2006). Long term consequences of early childhood malnutrition. Oxford Economic Papers, 58(3):450-474.

Alderman, H., Orazem, P. F., and Paterno, E. M. (2001). School quality, school cost, and the public/private school choices of low-income households in pakistan. Journal of Human Resources, 36(2):304-326.

Altonji, J. G., Elder, T. E., and Taber, C. R. (2005). An evaluation of instrumental variable strategies for estimating the effects of catholic schooling. Journal of Human resources, 40(4):791-821.

Angrist, J. D. and Lavy, V. (1999). Using maimonides' rule to estimate the effect of class size on scholastic achievement. The Quarterly Journal of Economics, 114(2):533-575.

Balcells, L. (2010). Rivalry and revenge: Violence against civilians in conventional civil wars. International Studies Quarterly, 54(2):291-313.

Bauernschuster, S., Hener, T., and Rainer, H. (2016). Children of a (policy) revolution: The introduction of universal child care and its effect on fertility. Journal of the European Economic Association, 14(4):975-1005.

Bayer, P., Ferreira, F., and McMillan, R. (2007). A unified framework for measuring preferences for schools and neighborhoods. Journal of Political Economy, 115(4):588-638. 
Bayer, P. and McMillan, R. (2005). Choice and competition in local education markets. NBER Working Paper, 11802.

Belot, M. and Vandenberghe, V. (2014). Evaluating the "threat" effects of grade repetition: Exploiting the 2001 reform by the french-speaking community of Belgium. Education Economics, 22(1):73-89.

Berry, S., Levinsohn, J., and Pakes, A. (1995). Automobile prices in market equilibrium. Econometrica, 63(4):841-890.

Berry, S., Levinsohn, J., and Pakes, A. (2004). Differentiated products demand systems from a combination of micro and macro data: The new car market. Journal of Political Economy, 112(1):68-105.

Bertrand, M., Duflo, E., and Mullainathan, S. (2004). How much should we trust Differences-inDifferences estimates? The Quarterly Journal of Economics, 119(1):249-275.

Betts, J. and Fairlie, R. (2003). Does immigration induce native flight from public schools into private schools? Journal of Public Economics, 87(5):987-1012.

Black, S. (1999). Do better schools matter? parental valuation of elementary education. The Quarterly Journal of Economics, 114(2):577-599.

Blattman, C. and Annan, J. (2010). The consequences of child soldiering. Review of Economics and Statistics, 92(4):882-898.

Blattman, C. and Miguel, E. (2010). Civil war. Journal of Economic Literature, 48(1):3-57.

Borghans, L., Golsteyn, B., and Zolitz, U. (2015). Parental preferences for primary school characteristics. The BE Journal of Economic Analysis \& Policy, 15(1):85-117.

Brunello, G. and Rocco, L. (2013). The effect of immigration on the school performance of natives: cross country evidence using PISA test scores. Economics of Education Review, 32:234-246.

Brutti, Z. and Sánchez, F. (2017). Does better teacher selection lead to better students? evidence from a large scale reform in colombia. Documento de trabajo CEDE, (11).

Burgess, S. and Briggs, A. (2010). School assignment, school choice and social mobility. Economics of Education Review, 29(4):639-649.

Cabus, S. and Cornelisz, I. (2014). On competition, student sorting, and performance gains in local education markets: The dutch secondary sector. TIER-Maastricht University working paper. 
Calderón-Mejía, V. and Ibáñez, A. (2016). Labour market effects of migration-related supply shocks: evidence from internal refugees in Colombia. Journal of Economic Geography, 16(3):695-713.

Calonico, S., Cattaneo, M. D., and Titiunik, R. (2014). Robust nonparametric confidence intervals for regression-discontinuity designs. Econometrica, 82(6):2295-2326.

Card, D. (2001). Immigrant inflows, native outflows, and the local labor market impacts of higher immigration. Journal of Labor Economics, 19(1):22-64.

Carneiro, P., Das, J., and Reis, H. (2016). The value of private schools: Evidence from pakistan. IZA Discussion Paper, 9960.

Cascio, E. and Lewis, E. (2012). Cracks in the melting pot: immigration, school choice, and segregation. American Economic Journal: Economic Policy, 4(3):91-117.

Cattaneo, M., Jansson, M., and Ma, X. (2016). rddensity: manipulation testing based on density discontinuity. The Stata Journal, 2:1-18.

Chamarbagwala, R. and Morán, H. (2011). The human capital consequences of civil war: evidence from Guatemala. Journal of Development Economics, 94(1):41-61.

Chumacero, R., Gomez, D., and Paredes, R. (2011). I would walk 500 miles (if it paid): Vouchers and school choice in chile. Economics of Education Review, 30(5):1103-1114.

Cullen, J., Jacob, B., and Levitt, S. (2006). The effect of school choice on participants: Evidence from randomized lotteries. Econometrica, 74(5):1191-1230.

Davis, P. (2006). Spatial competition in retail markets: Movie theaters. The RAND Journal of Economics, 37(4):964-982.

De Groot, O. and Goksel, I. (2011). Conflict and education demand in the Basque region. Journal of Conflict Resolution, 55(4):652-677.

Eide, E. R. and Showalter, M. H. (2001). The effect of grade retention on educational and labor market outcomes. Economics of Education Review, 20(6):563-576.

Figlio, D. and Hart, C. (2014). Competitive effects of means-tested school vouchers. American Economic Journal: Applied Economics, 6(1):133-156.

Figlio, D. and Ozek, U. (2017). Unwelcome guests? the effects of refugees on the educational outcomes of incumbent students. National Bureau of Economic Research, W23661. 
Fredriksson, P., Öckert, B., and Oosterbeek, H. (2012). Long-term effects of class size. The Quarterly Journal of Economics, 128(1):249-285.

Fruehwirth, J. C., Navarro, S., and Takahashi, Y. (2016). How the timing of grade retention affects outcomes: Identification and estimation of time-varying treatment effects. Journal of Labor Economics, 34(4):979-1021.

Galindo-Silva, H. (2015). New parties and policy outcomes: Evidence from colombian local governments. Journal of Public Economics, 126:86-103.

Garay, L. (2008). Proceso nacional de verificación de los derechos de la poblacón desplazada. First Report to the Colombian Constitutional Court.

García-Pérez, J. I., Hidalgo-Hidalgo, M., and Robles-Zurita, J. A. (2014). Does grade retention affect students' achievement? some evidence from spain. Applied Economics, 46(12):1373-1392.

Geay, C., McNally, S., and Telhaj, S. (2013). Non-native speakers of English in the classroom: What are the effects on pupil performance? The Economic Journal, 123(570):281-307.

Gelman, A. and Imbens, G. (2017). Why high-order polynomials should not be used in regression discontinuity designs. Journal of Business \& Economic Statistics, doi:10.1080/07350015.2017.1366909.

Gerritsen, S., Plug, E., and Webbink, D. (2017). Teacher quality and student achievement: Evidence from a sample of dutch twins. Journal of Applied Econometrics, 32(3):643-660.

GMH (2013). Basta ya colombia: Memorias de guerra y dignidad. Technical report, Centro Nacional de Memoria Histórica.

Gould, E., Lavy, V., and Daniele Paserman, M. (2009). Does immigration affect the long-term educational outcomes of natives? quasi-experimental evidence. The Economic Journal, 119(540):12431269.

Hastings, J., Kane, T. J., and Staiger, D. (2009). Heterogeneous preferences and the efficacy of public school choice. NBER Working Paper, 2145.

Hastings, J. and Weinstein, J. (2008). Information, school choice, and academic achievement: Evidence from two experiments. The Quarterly Journal of Economics, 123(4):1373-1414.

Havnes, T. and Mogstad, M. (2011). Money for nothing? Universal child care and maternal employment. Journal of Public Economics, 95(11):1455-1465. 
Hill, A. J. (2014). The costs of failure: Negative externalities in high school course repetition. Economics of Education Review, 43:91-105.

Houde, J. F. (2012). Spatial differentiation and vertical mergers in retail markets for gasoline. The American Economic Review, 102(5):2147-2182.

Hoxby, C. M. (2003). School choice and school competition: Evidence from the united states. Swedish Economic Policy Review, 10:9-65.

Hsieh, C. and Urquiola, M. (2006). The effects of generalized school choice on achievement and stratification: Evidence from chile's voucher program. Journal of Public Economics, 90(8):1477-1503.

Ibáñez, A. and Vélez, C. (2008). Civil conflict and forced migration: The micro determinants and welfare losses of displacement in Colombia. World Development, 36(4):659-676.

Ibáñez, A. M. (2009). Forced displacement in colombia: Magnitude and causes. The Economics of Peace and Security Journal, 4(1).

Ichimura, H. and Todd, P. E. (2007). Implementing nonparametric and semiparametric estimators. Handbook of Econometrics, 6:5369-5468.

Imbens, G. and Kalyanaraman, K. (2012). Optimal bandwidth choice for the regression discontinuity estimator. The Review of Economic Studies, 79(3):933-959.

Jacob, B. A. and Lefgren, L. (2004). Remedial education and student achievement: A RegressionDiscontinuity analysis. The Review of Economics and Statistics, 86(1):226-244.

Jacob, B. A. and Lefgren, L. (2009). The effect of grade retention on high school completion. American Economic Journal: Applied Economics, 1(3):33-58.

Jensen, P. and Rasmussen, A. (2011). The effect of immigrant concentration in schools on native and immigrant children's reading and math skills. Economics of Education Review, 30(6):1503-1515.

Jimerson, S., Carlson, E., Rotert, M., Egeland, B., and Sroufe, L. A. (1997). A prospective, longitudinal study of the correlates and consequences of early grade retention. Journal of School Psychology, $35(1): 3-25$.

Jimerson, S. R. (1999). On the failure of failure: Examining the association between early grade retention and education and employment outcomes during late adolescence. Journal of School Psychology, 37(3):243-272. 
Justino, P., Leone, M., and Salardi, P. (2011). Education and conflict recovery: The case of Timor Leste. Households in Conflict Network Working Papers, 100.

Kalyvas, S. (2006). The logic of violence in civil war. Cambridge University Press.

Kibris, A. (2015). The conflict trap revisited: Civil conflict and educational achievement. Journal of Conflict Resolution, 59(4):645-670.

Koning, P. and Van der Wiel, K. (2013). Ranking the schools: How school-quality information affects school choice in the netherlands. Journal of the European Economic Association, 11(2):466-493.

Koppensteiner, M. F. (2014). Automatic grade promotion and student performance: Evidence from Brazil. Journal of Development Economics, 107:277-290.

Korthals, R. (2015). The pre-tracking effects on parental background. ROA Research Memorandum, 5.

Leon, G. (2012). Civil conflict and human capital accumulation. The long term effects of political violence in Peru. Journal of Human Resources, 47(4):991-1022.

Mahjoub, M.-B. (2017). The treatment effect of grade repetitions. Education Economics, 25(4):418-432.

Manacorda, M. (2012). The cost of grade retention. Review of Economics and Statistics, 94(2):596-606.

Manski, C. F. (1992). Educational choice (vouchers) and social mobility. Economics of Education Review, 11(4):351-369.

Martínez, G. and Herrera, B. (2002). Finalidades y alcances del decreto 230 del 11 de febrero de 2002. Ministerio de Educación Nacional. Bogotá, pages 89-90.

McCoy, A. R. and Reynolds, A. J. (1999). Grade retention and school performance:: An extended investigation. Journal of School Psychology, 37(3):273-298.

McCrary, J. (2008). Manipulation of the running variable in the regression discontinuity design: A density test. Journal of Econometrics, 142(2):698-714.

McFadden, D. (1974). The measurement of urban travel demand. Journal of public economics, 3(4):303328.

McMillan, R. (2005). Competition, incentives, and public school productivity. Journal of Public Economics, 89(5):1133-1154. 
Montalvo, J. and Reynal-Querol, M. (2007). Fighting against malaria: Prevent wars while waiting for the miraculous vaccine. Review of Economics and Statistics, 89(1):165-177.

Moore, W. and Shellman, S. (2004). Fear of persecution: forced migration, 1952-1995. Journal of Conflict Resolution, 48(5):723-745.

Nevo, A. (2000). A practitioner's guide to estimation of random-coefficients logit models of demand. Journal of Economics and Management Strategy, 9(4):513-548.

Noailly, J., Vujić, S., and Aouragh, A. (2012). The effects of competition on the quality of primary schools in the Netherlands. Environment and Planning A, 44(9):2153-2170.

O'Flaherty, B. and Sethi, R. (2008). Racial stereotypes and robbery. Journal of Economic Behavior \& Organization, 68(3):511-524.

Ohinata, A. and Van Ours, J. (2013). How immigrant children affect the academic achievement of native Dutch children. The Economic Journal, 123(570):308-331.

Ozimek, A. and Miles, D. (2011). Stata utilities for geocoding and generating travel time and travel distance information. Stata Journal, 11(1):106.

Pachón, M. and Sánchez, F. (2014). Base de datos sobre resultados electorales 1958-2011. CedeUniversidad de los Andes, (012058).

Rincke, J. (2006). Competition in the public school sector: Evidence on strategic interaction among us school districts. Journal of Urban Economics, 59(3):352-369.

Rivkin, S. G., Hanushek, E. A., and Kain, J. F. (2005). Teachers, schools, and academic achievement. Econometrica, 73(2):417-458.

Rodriguez, C. and Sanchez, F. (2012). Armed conflict exposure, human capital investments and child labor: evidence from Colombia. Defence and Peace Economics, 23(2):161-184.

Rodriguez-Planas, N. (2012). Longer-term impacts of mentoring, educational services, and learning incentives: Evidence from a randomized trial in the united states. American Economic Journal: Applied Economics, 4(4):121-39.

Ruijs, N. and Oosterbeek, H. (2014). School choice in amsterdam: Which schools are chosen when school choice is free? TIER Working Paper. 
Schneeweis, N. (2015). Immigrant concentration in schools: Consequences for native and migrant students. Labour Economics, 35:63-76.

Shemyakina, O. (2011). The effect of armed conflict on accumulation of schooling: results from Tajikistan. Journal of Development Economics, 95(2):186-200.

Silberglitt, B., Appleton, J. J., Burns, M. K., and Jimerson, S. R. (2006). Examining the effects of grade retention on student reading performance: A longitudinal study. Journal of School Psychology, 44(4):255-270.

Staiger, D. and Stock, J. H. (1997). Instrumental variables regression with weak instruments. Econometrica, 65(3):557.

Stearns, E., Moller, S., Blau, J., and Potochnick, S. (2007). Staying back and dropping out: The relationship between grade retention and school dropout. Sociology of Education, 80(3):210-240.

Steele, A. (2011). Electing displacement: Political cleansing in Apartadó, Colombia. Journal of Conflict Resolution, 55(3):423-445.

Swee, E. (2009). On war and schooling attainment: The case of Bosnia and Herzegovina. Households in Conflict Network Working Papers, (57).

Train, K. (2009). Discrete choice models with simulation. Cambridge university Press.

Valente, C. (2013). Education and civil conflict in Nepal. World Bank Economic Review, 28(2).

Van Goeverden, C. and De Boer, E. (2013). School travel behaviour in the netherlands and flanders. Transport Policy, 26:73-84. 




\section{Addendum on Valorization}

This addendum on valorization is added in accordance with article 23.5 of the 'Regulation governing the attainment of doctoral degrees at Maastricht University' decreed by the 2013 resolution of the Board of Deans.

These Essays on Economics of Education and School Choice explore several interventions, intended and unintended, that have shaped the educational achievements of students at secondary education in both developed and developing countries. Given the increasing interest of students, parents, governments, donors, and further shareholders on implementing educational policies whose effects are backed up by causal empirical evidence, this thesis provides different examples of such trend. Notably, the identification of causal effects on economics of education turns out to be necessary, as many preconceptions about what works or not in the task of improving the schooling outcomes of children can be challenged.

By showing how parental heterogeneous preferences for academic attributes in a free school choice system determine their children's schooling outcomes and subsequent economic prospects, Chapter 2 informs educational interventions that might modify the tastes and values of underrepresented families in a context of early tracking, large academic differentiation, and a government-based funding system offering public and private alternatives to pursue education. Chapter 2 provides evidence on the positive (negative) educational sorting of pupils from high (low) educated backgrounds on the academic option that grants the right to pursue further university studies. Conceiving education as a vehicle to foster social and intergenerational mobility, it can be inferred from Chapter 2 that the combination of i) informational interventions focused on reducing the "awareness gap" between parents from different socio-economic status (SES) and, ii) school-level interventions aimed to base admission procedures on objective performance measurements alone, can be plausible strategies that can be used to reduce the enrollment gap observed between children with different socio-economic backgrounds but comparable cognitive ability.

Using administrative data sources on political competition, educational outcomes of children in secondary school, and civil conflict related indicators for a developing country, Chapter 3 provides causal evidence on the negative effect of internally forced migration on cognitive tests scores at hosting areas. This study is ingrained in the economics of education literature that is focused on identifying educational 
interventions aimed to foster students' academic performance. Considering that in this literature, detected effects are rather conservative, in many cases not surpassing $10 \%$ of a standard deviation impact, a key policy implication of this chapter is that any program implemented in the shadow of an internally displaced crisis will have its effectiveness compromised. Hence, designing policy programs focused on reducing the negative spillover effect from internally displaced civilians seems to be the natural recommendation. Chapter 3 provides evidence that can be generalized to contexts where internally displaced people (IDPs) compete in educational and labor markets with original residents, since no further language, cultural, and legal barriers are constraining market participation.

The debate about the effectiveness of grade retention, as a policy tool designed to attend the educational needs of underachieving students has gained increased popularity. This is partially due to the fact that its effects are ambiguous and highly depend on the segment of the ability distribution the retention policy threshold is set. In addition, the probability that a student faces grade retention is correlated with unobserved aspects of the educational relationship, such as ability and motivation. Chapter 4 makes use of a natural experiment in a developing country to assess the impact of increased retention rates at the school level on final results of the high-school exit exam. This Chapter shows that retention netbenefits (mostly in language) are non-linear in nature, affecting negatively students at the margin of being retained. At the school level, the returns of retaining more students are marginally decreasing, implying that schools which are retaining a large fraction of their students might be doing it inefficiently. These results inform the policy design, especially in contexts where educational regulators intend to restrict schools' discretion to promote or retain students without proper cost-benefit analysis in terms of the student's forgone earnings in the labor market versus the potential benefits as a better educational progress has been made while being retained.

These Essays have offered original insights by questioning and refining existing thinking in the field of Economics of Education. Some have been published as working papers, and analytical chapters are currently being reshaped to be submitted to peer-reviewed journals. They also have been presented in numerous internal and external conferences; fruitful opportunities to disseminate results and receive comments and suggestions. Examples of these conferences are: The Lisbon Research Workshop on Statistics, Econometrics and Economics of Education (Lisbon, 2016), the Maastricht Workshop on Economics of Education (Maastricht, 2018), The European Society of Population Economics (Glasgow 2017, Antwerp 2018), The International Workshop of Applied Economics of Education (IWAEE, Catanzaro 2018), and The European Economics Association Conference (Cologne 2018). 




\section{About the Author}

Sergio Parra-Cely was born on March 9, 1982, in Bogota, Colombia. He obtained his Bachelor's degree in Economics from Universidad Nacional de Colombia. After obtaining a Master's degree in Political Economy from the same university, he worked in the Economics Department at Pontificia Universidad Javeriana as a junior lecturer and research assistant. After this professional experience, Sergio traveled to France and obtained a Research Master's degree in Economic Theory and Econometrics from the Toulouse School of Economics - Université Toulouse I Capitole. Before joining Maastricht University as a Ph.D. candidate, He worked as a research intern in the Poverty Alleviation Program at TNP2K in Jakarta, Indonesia. Currently, Sergio is an assistant professor of economics at Universidad San Francisco de Quito, Ecuador. 
